Luana de Freitas Nascimento

\title{
Dosimetria usando Luminescência Opticamente Estimulada: aplicações, propriedades físicas e caracterização de materiais dosimétricos.
}

São Carlos - SP

Agosto/2007 


\section{Dosimetria usando Luminescência Opticamente Estimulada: aplicações, propriedades físicas e caracterização de materiais dosimétricos.}

Dissertação apresentada à Banca Examinadora no Departamento de Física do Instituto de Física de São Carlos da Universidade de São Paulo para a obtenção do título de Mestre em Física Aplicada.

Orientadora:

Profa. Dra. Maria Cristina Terrile

MESTRADO EM FÍSICA APLICADA

INSTITUTO DE FÍSICA DE SÃO CARLOS

UNIVERSIDADE DE SÃO PAULO

São Carlos - SP

Agosto/2007 
Aos meus pais amados, Adilson e Maria Regina; meus estimados irmãos, Aretha, Adilson e Julia; meu querido Luis Enrique e especialmente a Deus. 


\section{Agradecimentos}

Quero agradecer, em primeiro lugar, à minha orientadora Dra. Maria Cristina Terrile pela confiança, amizade e incentivo em minha carreira.

Agradeço de forma especial a Dra. Yvone Maria Mascarenhas Hornos (Sapra/Landauer - São Carlos) pela oportunidade de trabalhar com dosimetria e pelos incentivos constantes no aperfeiçoamento de minha formação como pesquisadora e como pessoa.

Várias pessoas contribuiram para a realização desse trabalho e merecem todo reconhecimento. Meus sinceros agradecimentos a: José Fernando de Lima (Grupo de Biofísica Molecular "Sérgio Mascarenhas" - IFSC), pelo suporte no uso do equipamento de EPR; ao Dr. Claudio Magon (Grupo de Ressonância Magnética - IFSC) e ao Dr. Octaciro Rangel Nascimento (Grupo de Biofísica Molecular "Sérgio Mascarenhas" - IFSC), pelas discussões sobre EPR; ao Elderson Cássio Domenecucci (Grupo de Crescimentos de Cristais - IFSC), por cortar minhas amostras; ao Edgar Aparecido Sanches (Grupo de Cristalografia de Proteinas - IFSC), pela ajuda em entender o processo de recuperação do Óxido de Alumínio e pela amizade; ao Nibio José Manjerona (Grupo de Polímeros "Prof. Bernhard Gross" - IFSC), pelas irradiações e por sempre se mostrar solicito; ao Dr. Eduardo Gardenali Yukihara (Radiation Dosimetry Laboratory - Oklahoma State University), por concretizar minha primeira experiência academica fora do Brasil me recebendo em seu laboratório, pela amizade e pelas discussões sobre OSL; a Dra Maria de Fátima Magon (Sapra/Landuaer - São Carlos), pela presteza, atenção a carinho nas muitas horas de duvidas teóricas e experimentais; ao Dr. Carlos Alberto Tronbella (Sapra/Landuaer - São Carlos), pela ajuda essencial nos testes de desempenho de detectores OSL, pelas irradiações e pela simpatia. 
Não menos importante agradeço ao meu companheiro Luis Enrique Correa da Rocha pelas constantes correções em meus textos, pela ajuda indispensavel quando tudo parecia nebuloso e perdido, por cobrar minha atenção e empenho, por ter sempre boas ideias e pelo carinho e respeito que sempre mostrou nesses anos de estrada academica e pessoal.

Agradeço ao meu grande amigo Roberto Vinicius Martins, por sempre ter ficado ao meu lado, por me compreender e sempre me apoiar, à minha querida amiga Cindy Petree por me acolher e ser uma mãe enquanto estive morando em Stillwater e ao meu tio Luiz Antonio Roveran pela amizade e ajuda essencial em momentos criticos que vivi.

Agradeço aos meus pais por sempre terem incentivado minha formação cultural, permitindo que eu me dedicasse exclusivamente ao que sempre gostei. Agradeço pelo apoio em minhas decisões, pela orientação e amor sem limites. Por terem me proporcionado uma infância pouco usual e muito interessante e por terem sempre acreditado mais no meu potencial do que nos diagnosticos dos médicos.

Agradeço à CNPQ (Comissão Nacional de Pesquisa e Desenvolvimento) pela bolsa que financiou esse projeto; à Landauer (Chicago - EUA) pelas amostras, pelos aparelhos de leitura OSL e pelo convite a conhecer seu laboratório em Glenwood (Chicago - EUA); à Oklahoma State University (Stillwater - EUA) pela ajuda financeira dada para a visita cientifica feita ao laboratório de dosimetria radiológica.

Finalmente agradeço a Deus, meu amigo fiel que me capacitou para que chegasse até aqui e a quem dou toda a glória pelas conquistas de minha vida. 


\section{RESUMO}

Dosimetria usando Luminescência Opticamente Estimulada (OSL) é uma área em constante crescimento dentro da ciência e com excelentes perspectivas comerciais. O Óxido de Alumínio crescido na presença de uma atmosfera rica em Carbono $\left(\mathrm{Al}_{2} \mathrm{O}_{3}: \mathrm{C}\right)$ tem fornecido bons resultados como detector luminescente. Esse material apresenta alta sensibilidade à radiação ionizante e boa resposta à estímulos ópticos. Estima-se que cerca de dois milhões de pessoas façam uso de dosímetros com detectores de $\mathrm{Al}_{2} \mathrm{O}_{3}: \mathrm{C}$ em rotinas de dosimetria individual externa, que por apresentar varias vantagens experimentais acredita-se substituirá as outras duas técnicas dosimétricas mais adotadas: dosimetria fotográfica e termoluminescente. A certificação de uma técnica de dosimetria para uso comercial exige uma série de estudos. Neste trabalho apresentamos contribuições que complementam o entendimento e adoção da técnica de OSL em dosimetria pessoal. Nossa primeira contribuição consiste numa serie de testes de desempenho mostrando a eficácia da técnica para justificar nossa proposta de certificação de dosimetria individual externa usando OSL no Brasil. No intuito de relacionar centros paramagnéticos e o processo de luminescência, apresentamos resultados de espectros de EPR em detectores OSL. Detectamos e classificamos sinais de EPR relacionados a impurezas nas amostras, porem, sinais dos centros luminescentes não foram detectados. Finalmente, apresentamos um estudo preliminar sobre a resposta de luminescência do $\mathrm{Al}_{2} \mathrm{O}_{3}: \mathrm{C}$ quando exposto a diferentes comprimentos de onda de radiação UV. A inexistência de dosimetria de nêutrons por técnicas de OSL motivou o estudo de vários óxidos dopados com Térbio como possíveis candidatos a material dosimétrico. Alguns resultados preliminares do espectro de EPR desses óxidos quando irradiados em campo beta de ${ }^{90} \mathrm{Sr} /{ }^{90} \mathrm{Y}$ e da resposta de luminescência em função da luz de excitação para análise dos tipos de armadilhas criadas pela presença do $\mathrm{Tb}^{+3}$ são apresentados.

Palavras Chave: Luminescência Opticamente Estimulada, Dosimetria, Física das Radiações. 


\section{ABSTRACT}

Dosimetry using Optically Stimulated Luminescence (OSL) is an expanding scientific research area which also shows excellent commercial potential. Aluminum oxide grown in an atmosphere in the presence of Carbon, $\mathrm{Al}_{2} \mathrm{O}_{3}: \mathrm{C}$, presented excellent results as a luminescent detector. This material has high sensitivity when exposed to ionizing radiation and good responses to optical stimulation. Over two million people use dosimeters with $\mathrm{Al}_{2} \mathrm{O}_{3}: \mathrm{C}$ detectors in personal dosimetry procedures. The experimental advantages of using OSL are believed to replace the two other usual techniques: photographic and thermoluminescent dosimetry. To validate the commercial use of a dosimetry technique it is necessary to evaluate a number of studies. In this work we present results which increase our understanding of OSL dosimetry. First we present a number of behavior tests to show the efficiency of the technique for the purpose of justifying the use of OSL in personal dosimetry in Brazil. In an attempt to correlate paramagnetic centers and the luminescence process we present EPR results in OSL detectors. We could detect and classify impurities centers in our samples; however we could not find conclusive results about paramagnetic centers generated by exposition to ionizing radiation. We present a preliminary study about the luminescence behavior from $\mathrm{Al}_{2} \mathrm{O}_{3}: \mathrm{C}$ when exposed to different UV wavelengths. The nonexistence of a neutron dosimetry using OSL suggested a study of three types of oxides doped with Terbium which are strong candidates as OSL detectors due to their sensitivity to-neutron expositions. We present preliminary results of EPR spectroscopy from these oxides when exposed in a $\beta$ field of ${ }^{90} \mathrm{Sr} /{ }^{90} \mathrm{Y}$ and the luminescent response when the excitation light is used to analyze traps generated by the presence of $\mathrm{Tb}^{+3}$.

Key Words: Optically Stimulatted Luminescence, Dosimetry, Radiation Physics. 


\section{Sumário}

Resumo

Abstract 7

Lista de Figuras

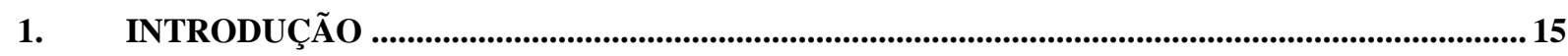

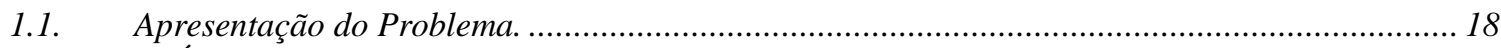

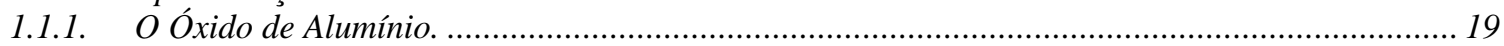

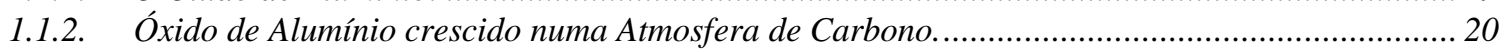

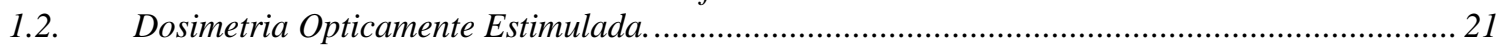

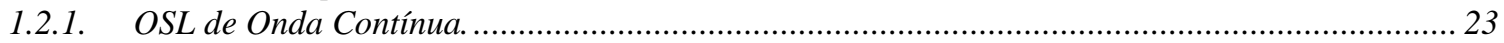

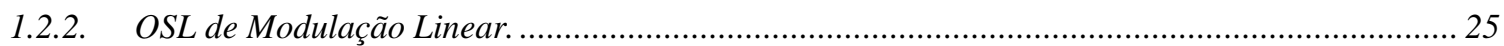

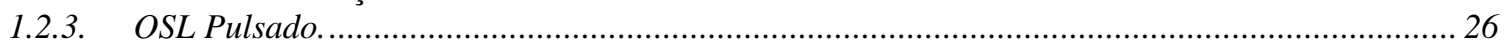

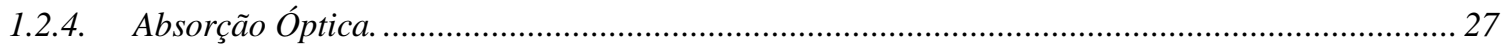

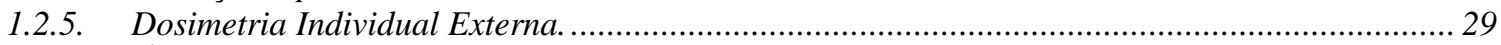

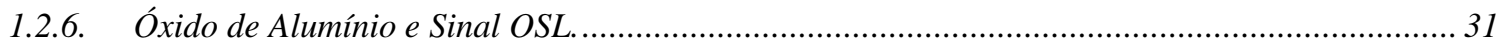

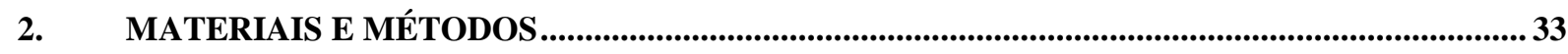

2.1. Monocristais Usados para Aquisição de Espectros de EPR....................................................... 33

2.2. Amostras em Pó Usadas para Aquisição de Espectros de EPR, de Excitação e de Emissão......... 33

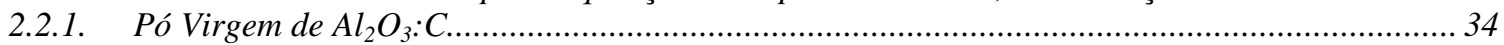

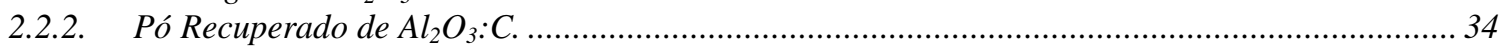

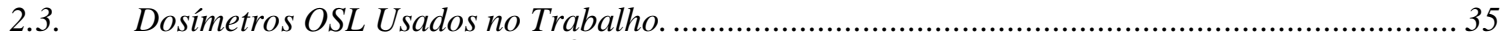

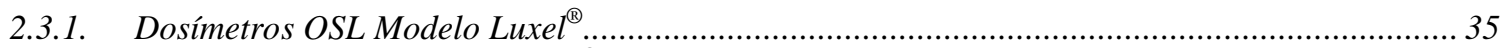

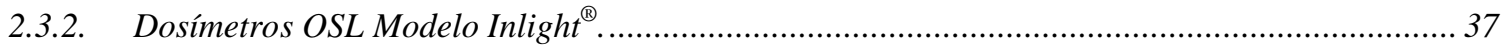

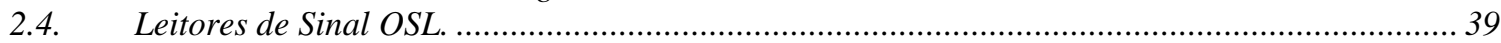

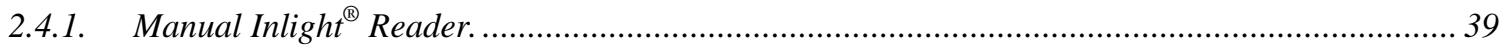

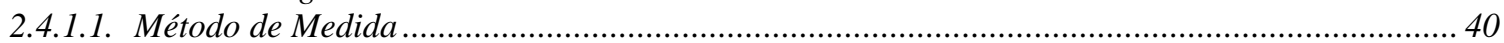

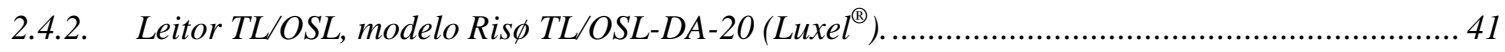

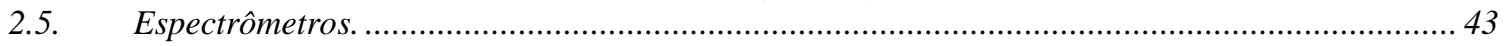

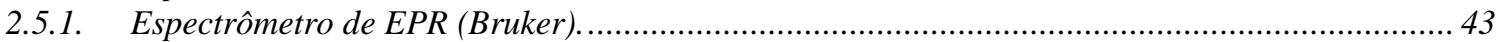

2.5.2. Espectroscopia Óptica: FluoroLog-3.......................................................................... 48

3. RESULTADOS I: MODELO DE CERTIFICAÇÃO DE DOSIMETRIA INDIVIDUAL

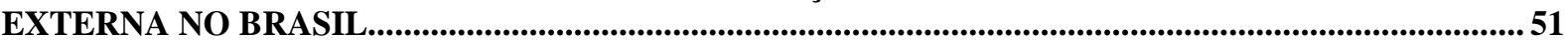

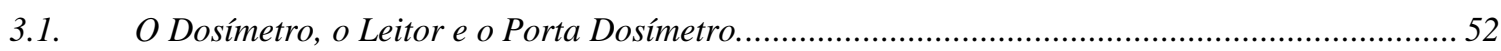

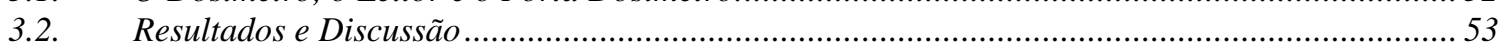

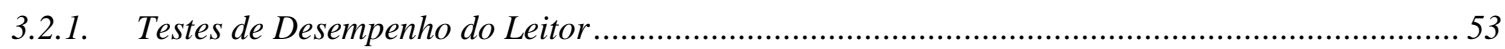

3.2.2. Teste de Desempenho do Porta Dosímetro. ............................................................................... 58

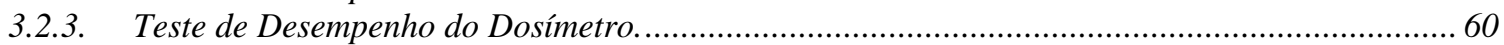

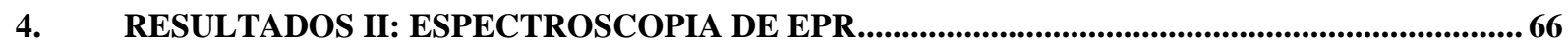

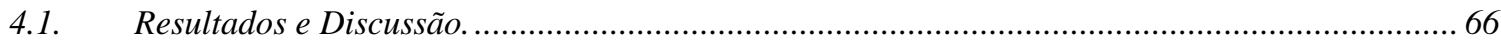

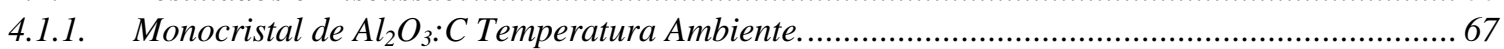

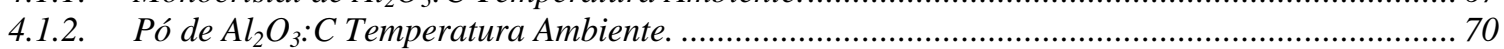

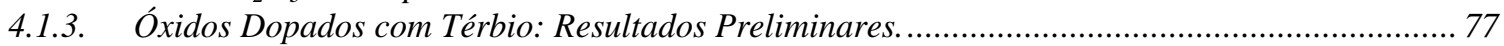

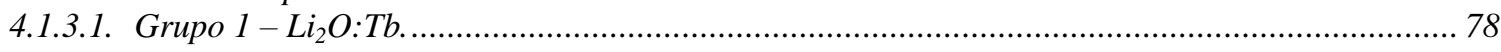

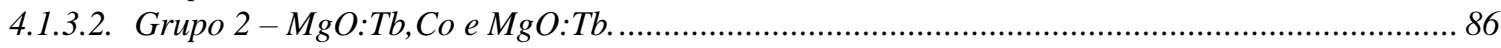




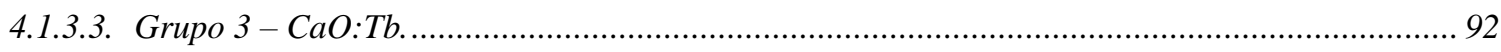

5. RESULTADOS III: SENSIBILIDADE DO $\mathrm{Al}_{2} \mathrm{O}_{3}: \mathrm{C}$ A UV ................................................96

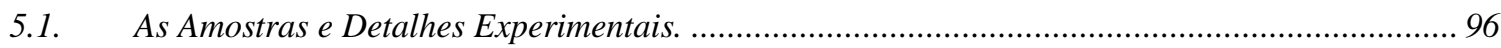

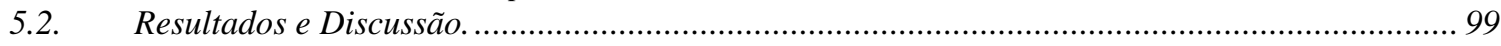

6. RESULTADOS IV: ESPECTRO DE EMISSÃO E EXCITAÇÃO EM ÓXIDOS DOPADOS COM

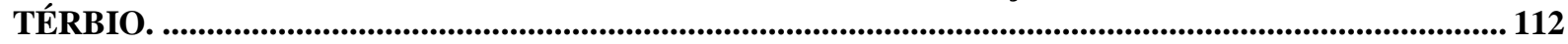

6.1. As Amostras e Detalhes Experimentais. .......................................................................... 112

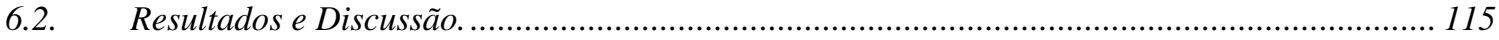

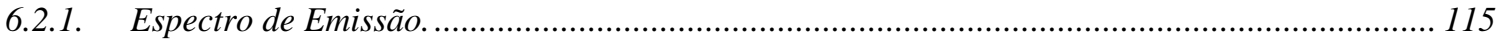

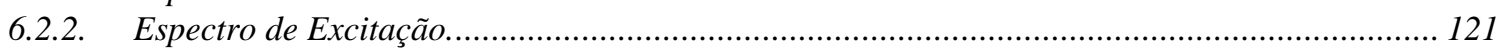

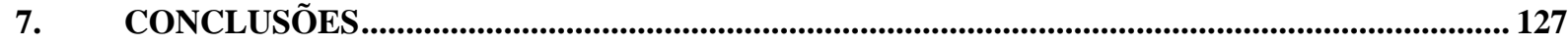

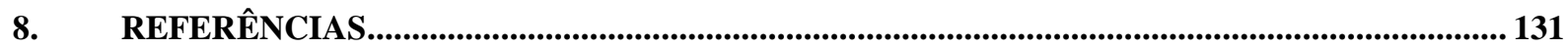

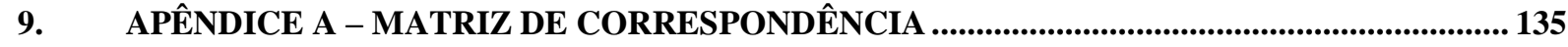

10. APÊNDICE B - MODELO ESTATÍSTICO PARA AVALIAÇÃO DOS TESTES PARA OSL. . 139 


\section{Lista de Figuras}

Figura 1.1. Óxido de Alumínio.

Figura 1.2. a) estrutura cristalina do Óxido de Alumínio; b) defeito pontual criado pelo crescimento em baixa atmosfera na presença de carbono. 21

Figura 1.3. a) Resposta OSL de onda continua para $\mathrm{Al}_{2} \mathrm{O}_{3}: \mathrm{C}$ e, b) estimulo OSL de Onda Continua (CW OSL).

Figura 1.4. a) Resposta OSL de modulação linear para Safira e, b) estimulo OSL de Modulação Linear (LM

$O S L)$. 26

Figura 1.5. a) Resposta OSL de estimulo pulsado para $\mathrm{Al}_{2} \mathrm{O}_{3}: \mathrm{C}$ e, b) estimulo $\mathrm{OSL}$ pulsado (POSL). 27

Figura 1.6. Esquema com absorções ópticas possíveis. 28

Figura 1.7. Esquema criação de pares buraco-elétron e geração de sinal OSL. 29

Figura 1.8. a) Sinal $\mathrm{TL}$ do $\mathrm{Al}_{2} \mathrm{O}_{3}: \mathrm{C}$ e b) Sinal $\mathrm{CW}$-OSL do $\mathrm{Al}_{2} \mathrm{O}_{3}: \mathrm{C}$. 31

Figura 1.9. a) Sinal OSL para diferentes doses de irradiação com $\beta$ e b) para exposição com diferentes fontes de radiação $(\beta, \mathrm{He}$, $\mathrm{C}$. Si e Fe). 32

Figura 2.1. Dosímetro Luxel ${ }^{\circledR}$ a) Fita com o detector OSL, b) estrutura com as quatro janelas e c) Badge. 37

Figura 2.2. Dosímetro Inlight ${ }^{\circledR}$ com a) Fita com o detector OSL (1) e janelas (2), b) protetor com informações do usuário (badge). 38

Figura 2.3. Esquema simplificado com o processo de leitura do leitor Manual Inlight ${ }^{\circledR}$. 40

Figura 2.4. a) Diagrama esquemático do grupo combinado de LEDs azuis e o laser IR para medidas de OSL e b) esquema visto de cima do prato com amostra para mostrar disposição das fontes. 42

Figura 2.5. Diagrama de níveis de energia para o spin de um elétron livre em função de um campo magnético aplicado $B$. 45

Figura 2.6. Esquema geral de um espectrômetro de EPR Bruker ELEXSYS E580 FT/CW. 46

Figura 2.7. Diagrama da ponte de microondas. 46

Figura 2.8. Esquema óptico do FluoroLog ${ }^{\circledR}-3$. 50

Figura 3.1. Contagem de fundo de fotomultiplicadora por leitura. 54

Figura 3.2. Medidas das três leituras, normalizadas pelas medidas da Leitura 1. 56 
Figura 3.3. Medias dos três grupos: condições normais, 35 oC e 20 oC.

Figura 3.4. Distribuição de medidas normalizadas pelas medidas sem exposição à luz.

Figura 3.5. Distribuição de medidas e limites. 60

Figura 3.6. Histograma com distribuição de medidas para teste de Reprodutibilidade. 63

Figura 3.7. Média por medida para teste de Releitura. 65

Figura 4.1. Orientações do cristal de $\mathrm{Al}_{2} \mathrm{O}_{3}: \mathrm{C}$. 68

Figura 4.2. Espectro de EPR para monocristal de $\mathrm{Al}_{2} \mathrm{O}_{3}$ : C no plano $\perp$ a $\vec{b}$. 68

Figura 4.3. Variação angular dos sinais de $\mathrm{Cr}^{3+}$ para uma varredura de $8000 \mathrm{G}$ no plano $\perp$ a $\vec{c}$. 69

Figura 4.4. Variação angular dos sinais de $\mathrm{Cr}^{3+}$ para uma varredura de $8000 \mathrm{G}$ no plano $\perp a \vec{b}$. 69

Figura 4.5. Espectro de EPR em banda X, temperatura ambiente e CW para amostras não irradiadas de pó recuperado da $\mathrm{Al}_{2} \mathrm{O}_{3}: \mathrm{C}$. 71

Figura 4.6. Espectro de EPR em banda X, temperatura ambiente e CW para Amostra 1 irradiada e não irradiadas de pó recuperado. 72

Figura 4.7. Espectro de EPR em banda X, temperatura ambiente e CW para Amostra 2 irradiada e não irradiadas de pó recuperado. 73

Figura 4.8. Espectro de EPR para as nove amostras de pó virgem de $\mathrm{Al}_{2} \mathrm{O}_{3}$ : $\mathrm{C}$ em banda $\mathrm{X}$, temperatura ambiente e CW. 75

Figura 4.9. Estrutura do Óxido de Lítio. 78

Figura 4.10. Espectro de EPR e medidos em banda X, temperatura ambiente e CW para Li $20: T b\left(G 1 \_2\right)$ não irradiado, irradiado com 50 Gy e 200 Gy. 79

Figura 4.11. Espectro de EPR e medidos em banda X, temperatura ambiente e CW para Li 2 O:Tb (G1_4) não irradiado, irradiado com 50 Gy e 200 Gy. 79

Figura 4.12. Espectro de EPR e medidos em banda X, temperatura ambiente e CW para Li2O:Tb (G1_8) não irradiado, irradiado com 50 Gy e 200 Gy.

Figura 4.13. Espectro para G1_2 e G1_4 irradiados com 200 Gy com linha desenhada em vermelho para sinal largo. 81

Figura 4.14. Espectro para G1_2, G1_4e G1_8 irradiados com 200 Gy e medidos em banda X, temperatura ambiente e $C W$. 82 
Figura 4.15. Espectro de EPR de centro F em monocristal de $\mathrm{Li}_{2} \mathrm{O}$ irradiado com 4.5 x 1021 nêutrons térmicos por $m^{2} \cdot[32]$ 82

Figura 4.16. Transições possíveis para $\mathrm{Tb}^{4+}$. 84

Figura 4.17. Impurezas classificadas nas amostras G1_2 e G1_4. 85

Figura 4.18. Estrutura do Óxido de Magnésio. 86

Figura 4.19. Espectro de EPR medidos em banda X, temperatura ambiente e CW para MgO:Tb,Co (G2_12) não irradiado, irradiado com 50 Gy e 200 Gy. 87

Figura 4.20. Espectro de EPR medidos em banda X, temperatura ambiente e CW para MgO:Tb,Co (G2_12) não irradiado, irradiado com 50 Gy e 200 Gy. 87

Figura 4.21. Espectro de EPR medidos em banda X, temperatura ambiente e CW para MgO:Tb (G2_16) não irradiado, irradiado com 50 Gy e 200 Gy. 88

Figura 4.22. Espectro de EPR medidos em banda X, temperatura ambiente e CW para MgO:Tb (G2_18) não irradiado, irradiado com 50 Gy e 200 Gy. 88

Figura 4.23. Espectro de EPR medidos em banda X, temperatura ambiente e CW de centro F em MgO. [39] 89

Figura 4.24. Linhas do $\mathrm{Cr}^{3+}$ em monocristal de $\mathrm{MgO}$. [42] 90

Figura 4.25. a) Linhas do $\mathrm{Cr}^{3+}$ em pó de $\mathrm{MgO}$. [42]. b) Estrutura do $\mathrm{Cr}^{3+}$ em simetria cúbica no $\mathrm{MgO}$. 91

Figura 4.26. Estrutura do Óxido de Cálcio. 92

Figura 4.27. Espectro de EPR medidos em banda X, temperatura ambiente e CW para CaO:Tb (G3_22) não irradiado, irradiado com 50 Gy e 200 Gy. 93

Figura 4.28. Espectro de EPR medidos em banda X, temperatura ambiente e CW para CaO:Tb (G3_24) não irradiado, irradiado com 50 Gy e 200 Gy. 93

Figura 4.29. Sinais do $\mathrm{Fe}^{+}$e $\mathrm{Fe}^{3+}$ em $\mathrm{CaO}\left(\mathrm{G} 2 \_22\right)$. 94

Figura 5.1. a) Fita Luxel de Al2O3:C e b) amostra no Ris $\phi$ para medida. 99

Figura 5.2. Intensidade da lâmpada de Xe por comprimento de onda. 100

Figura 5.3. a) sinal OSL da Amostra 2 exposta a $325 \mathrm{~nm}$ de UV para diferentes tempos e b) sinal OSL da amostra 2 irradiada com $\beta$ por três segundos. 101

Figura 5.4. Sinal integrado OSL por numero de fótons, para exposição de $350 \mathrm{~nm}$. 102

Figura 5.5. a) sinal OSL da Amostra 2 exposta a $325 \mathrm{~nm}$ de UV para diferentes tempos e b) sinal OSL da amostra 2 irradiada com $\beta$ por três segundos. 
Figura 5.6. Sinal integrado OSL por numero de fótons, para exposição de $325 \mathrm{~nm}$.

Figura 5.7. a) sinal OSL da Amostra 3 exposta a $300 \mathrm{~nm}$ de UV para diferentes tempos e b) sinal OSL da amostra 3 irradiada com $\beta$ por três segundos. 104

Figura 5.8. Sinal integrado OSL por numero de fótons, para exposição de $300 \mathrm{~nm}$. 105

Figura 5.9. a) sinal OSL da Amostra 4 exposta a $275 \mathrm{~nm}$ de UV para diferentes tempos e b) sinal OSL da amostra 4 irradiada com $\beta$ por três segundos. 105

Figura 5.10. Sinal integrado OSL por número de fótons, para exposição de $275 \mathrm{~nm}$. 106

Figura 5.11. a) sinal OSL da Amostra 5 exposta a $250 \mathrm{~nm}$ de UV para diferentes tempos e b) sinal OSL da amostra 5 irradiada com $\beta$ por três segundos.

Figura 5.12. Sinal integrado OSL por número de fótons, para exposição de $250 \mathrm{~nm}$. 107

Figura 5.13. a) sinal OSL da Amostra 6 exposta a $225 \mathrm{~nm}$ de UV para diferentes tempos e b) sinal OSL da amostra 6 irradiada com $\beta$ por três segundos. 108

Figura 5.14. Sinal integrado OSL por número de fótons, para exposição de $225 \mathrm{~nm}$. 109

Figura 5.15. a) sinal OSL da Amostra 7 exposta a $210 \mathrm{~nm}$ de UV para diferentes tempos e b) sinal OSL da amostra 7 irradiada com $\beta$ por três segundos. 109

Figura 5.16. Sinal integrado OSL por número de fótons, para exposição de $210 \mathrm{~nm}$. 110

Figura 5.17. Sinal OSL da Amostra 8 irradiada com $\square$ por três segundos. 111

Figura 6.1. a) balança analítica e b) amostra em pó disposta em copo de alumínio. 113

Figura 6.2. a) FluoroLog® em funcionamento b) amostra em pó disposta em copo de alumínio em pedaço de madeira com referência numérica. 114

Figura 6.3. Transmitância por comprimento de onda para filtro passa alta de $455 \mathrm{~nm}$. 114

Figura 6.4. Transmitância por comprimento de onda para filtro passa alta de $515 \mathrm{~nm}$. 115

Figura 6.5. Espectro de emissão para $\mathrm{Li}_{2} \mathrm{O}: \mathrm{Tb}\left(\mathrm{G1} \_2\right)$ irradiado, com excitação de $525 \mathrm{~nm}$. 116

Figura 6.6. Espectro de emissão para $\mathrm{Li}_{2} \mathrm{O}: \mathrm{Tb}\left(\mathrm{G1}{ }_{-} 4\right)$ irradiado, com excitação de $525 \mathrm{~nm}$. 116

Figura 6.7. Espectro de emissão para $\mathrm{Li}_{2} \mathrm{O}: \mathrm{Tb}\left(\mathrm{G1} \_\right.$8) irradiado, com excitação de $525 \mathrm{~nm}$. 117

Figura 6.8. Espectro de emissão para MgO:Tb (G2_12) irradiado, com excitação de $525 \mathrm{~nm}$. 117

Figura 6.9. Espectro de emissão para MgO:Tb (G2_14) irradiado, com excitação de $525 \mathrm{~nm}$. 118

Figura 6.10. Espectro de emissão para MgO:Tb (G2_16) irradiado, com excitação de $525 \mathrm{~nm}$. 118 
Figura 6.11. Espectro de emissão para MgO:Tb (G2_18) irradiado, com excitação de $525 \mathrm{~nm}$.

Figura 6.12. Espectro de emissão para CaO:Tb (G3_22) irradiado, com excitação de $525 \mathrm{~nm}$.

Figura 6.13. Espectro de emissão para CaO:Tb (G3_24) irradiado, com excitação de 525 nm. 120

Figura 6.14. a) Transições entre níveis de energia do Tb (diferença entre linhas não esta corretamente representada) e b) picos identificados no espectro de emissão da amostra $\mathrm{MgO}: \mathrm{Tb}\left(G 2 \_14\right)$, mas que se observa em todas as outras amostras, com exceção de Li2 $\mathrm{O}: T b$ na amostra $G 1_{-} 8$.

Figura 6.15. a) Espectro de excitação para $\mathrm{Li}_{2} \mathrm{O}: \mathrm{Tb}$ (G1_2) irradiado e não irradiado com emissão de $380 \mathrm{~nm}$ e b) $415 \mathrm{~nm}$. 122

Figura 6.16. a) Espectro de excitação para $\mathrm{Li}_{2} \mathrm{O}: \mathrm{Tb}\left(\mathrm{G1}{ }_{-} 4\right)$ irradiado e não irradiado com emissão de $380 \mathrm{~nm}$ e b) $415 \mathrm{~nm}$. 123

Figura 6.17. a) Espectro de excitação para $\mathrm{Li}_{2} \mathrm{O}: \mathrm{Tb}\left(\mathrm{G1} \_\right.$8) irradiado e não irradiado com emissão de $380 \mathrm{~nm}$ e b) $415 \mathrm{~nm}$. 123

Figura 6.18. a) Espectro de excitação para $\mathrm{MgO}: \mathrm{Tb}(\mathrm{G2}$ _12) irradiado e não irradiado com emissão de $380 \mathrm{~nm}$ e b) $415 \mathrm{~nm}$. 123

Figura 6.19. a) Espectro de excitação para $\mathrm{MgO}: \mathrm{Tb}\left(\mathrm{G} 2 \_14\right)$ irradiado e não irradiado com emissão de $380 \mathrm{~nm}$ e b) $415 \mathrm{~nm}$. 124

Figura 6.20. a) Espectro de excitação para $\mathrm{MgO}: \mathrm{Tb}\left(\mathrm{G2} \_16\right)$ irradiado e não irradiado com emissão de $380 \mathrm{~nm}$ e b) $415 \mathrm{~nm}$. 124

Figura 6.21. a) Espectro de excitação para MgO:Tb (G2_18) irradiado e não irradiado com emissão de 380 nm e b) $415 \mathrm{~nm}$. 124

Figura 6.22. a) Espectro de excitação para CaO:Tb (G3_22) irradiado e não irradiado com emissão de $380 \mathrm{~nm}$ e b) $415 \mathrm{~nm}$. 125

Figura 6.23. a) Espectro de excitação para CaO:Tb (G3_24) irradiado e não irradiado com emissão de 380 nm e b) $415 \mathrm{~nm}$. 


\section{INTRODUÇÃO}

Luminescência Opticamente Estimulada (Optically Stimulated Luminescence, OSL) é atualmente uma das principais técnicas em uso em dosimetria das radiações. Sua aplicação se estende desde a física médica até métodos de datação (em geologia e arqueologia), passando por dosimetria espacial, retrodosimetria e dosimetria individual externa [1].

Para o desenvolvimento de um modelo dosimétrico usando OSL é necessário a realização de uma série de estudos. A primeira etapa consiste em propor materiais que possam ser usados como detectores OSL, estes devem ser sensíveis à radiação ionizante e apresentar resposta a estímulos ópticos. Nessa fase faz-se a caracterização do material usando técnicas espectroscópicas e cristalográficas observando a resposta e comportamento do material para diferentes tipos de exposições (raios-X, $\alpha, \beta, \gamma$ e nêutrons) com faixas de doses diferentes. Depois de conhecida a resposta luminescente do material quando exposto à radiação, um algoritmo para o cálculo de dose é desenvolvido. Esse algoritmo deve considerar o tipo de estímulo (no caso óptico), o comportamento da resposta do material, o comprimento de onda do estímulo, o tipo de amostra, as condições climáticas e qualquer outro fator que influencie o espectro de emissão OSL. Finalmente para que seja possível o uso desse material para dosimetria comercial uma série de testes de desempenho devem ser realizados usando o novo detector e o aparato óptico desenvolvido para fazer as leituras de luminescência e cálculo de dose. Nesta fase, normas são seguidas para averiguação do comportamento do modelo segundo padrões estabelecidos pelos órgãos de controle governamental de proteção radiológica. Caso esses padrões sejam satisfatoriamente respondidos, estabelece-se assim, um modelo de dosimetria OSL. 
O presente trabalho contribui com resultados para varias fases do desenvolvimento de um modelo OSL para dosimetria. Essas contribuições são resultantes da parceria entre o Instituto de Física de São Carlos, da Universidade de São Paulo (IFSC USP), onde foram feitos estudos usando ressonância paramagnética eletrônica em um detector $\mathrm{OSL}\left(\mathrm{Al}_{2} \mathrm{O}_{3}: \mathrm{C}\right)$; a empresa Sapra Landauer Serviço de Assessoria e Proteção Radiológica de São Carlos, onde foi desenvolvida a proposta de certificação para o uso de OSL em dosimetria individual externa no Brasil; e o Laboratório de Dosimetria das Radiações (LDR) do departamento de Física da Universidade Estadual de Oklahoma (Stillwater, EUA) onde, em visita científica no período de Fevereiro a Abril de 2007, foram feitas medidas preliminares no estudo do comportamento de um detector OSL $\left(\mathrm{Al}_{2} \mathrm{O}_{3}: \mathrm{C}\right)$ para exposições a diferentes comprimentos de onda de ultravioleta e aquisição de espectros de EPR, de emissão e de excitação para amostras de óxidos com potencial para uso como detectores OSL.

No Capítulo 1 introduzimos o fenômeno da luminescência opticamente estimulada em linhas gerais, destacando as possíveis aplicações da técnica em dosimetria individual externa e as motivações para o estudo de $\mathrm{OSL}$ em $\mathrm{Al}_{2} \mathrm{O}_{3}: \mathrm{C}$ apresentando uma breve descrição do material e de seus bons resultados para dosimetria OSL.

No Capítulo 2 descrevemos as amostras e descrevemos os equipamentos utilizadas em cada estudo de forma esquemática e geral.

No Capítulo 3 justificamos nossa proposta de certificação de dosimetria individual externa no Brasil usando OSL apresentando os resultados de testes de desempenho para um leitor, um porta dosímetro e um detector OSL. Esses testes fazem parte dos testes de desempenho e de tipo apresentados no Apêndice A e são discutidos usando o método estatístico descrito no Apêndice B. 
O Capítulo 4 é dedicado aos resultados obtidos por espectroscopia de EPR para a caracterização dos centros luminescentes envolvidos no processo OSL no $\mathrm{Al}_{2} \mathrm{O}_{3}: \mathrm{C}$ e nos óxidos com potencial para detectores OSL. Apresentamos os espectros adquiridos para nossas amostras e, embora não tenhamos obtido resultados conclusivos que correlacionem nossos resultados aos centros luminescentes, apresentamos a caracterização das linhas dos espectros e algumas discussões sobre resultados encontrados.

No Capítulo 5 fornecemos informações sobre a resposta do sinal OSL do detector $\mathrm{Al}_{2} \mathrm{O}_{3}: \mathrm{C}$ quando exposto a diferentes comprimentos de onda de ultravioleta. A comparação entre o decaimento OSL entre amostras expostas a diferentes comprimentos de onda de UV e das mesmas amostras expostas a radiação $\beta$ abre espaço para trabalhos que permitam estudar o processo de recombinação de diferentes centros luminescentes em $\mathrm{Al}_{2} \mathrm{O}_{3}: \mathrm{C}$, bem como a criação de um modelo reprodutível para dosimetria em $\mathrm{Al}_{2} \mathrm{O}_{3}: \mathrm{C}$ para UV.

No Capítulo 6 apresentamos os espectros de emissão de excitação para os óxidos com potencial para detectores OSL. Esse estudo é o passo inicial no desenvolvimento de um modelo de dosimetria OSL para esses óxidos, especialmente para determinar com que comprimento de onda os materiais devem ser expostos para a leitura do sinal OSL e saber qual é a resposta dos materiais a esses estímulos luminosos.

Finalmente, no Capítulo 7, apresentamos as conclusões finais sobre os estudos feitos, mostrando as técnicas aprendidas, conhecimento adquirido e resultados obtidos. 


\subsection{Apresentação do Problema.}

A sugestão do uso de luminescência opticamente estimulada como técnica dosimétrica foi feita por Antonov-Romanovskii em 1956 e desde então tem sido amplamente estudada e aplicada em todas as áreas da dosimetria [2].

No item a seguir (1.1.1.) são apresentadas algumas propriedades físico-químicas do material usualmente adotado como detector OSL - o Óxido de Alumínio. Esse material é extensivamente usado em laboratórios que fornecem serviços de monitoração individual externa, estima-se que cerca de dois milhões de pessoas no mundo usem dosímetros OSL com detectores de Óxido de Alumínio crescido a baixa pressão na presença de Carbono, o que aumenta sua sensibilidade à radiação e resposta OSL. A boa resposta OSL é atribuída ao grande número de centros $\mathrm{F}$ e $\mathrm{F}^{+}$criados durante o processo de crescimento (defeitos pontuais). $\mathrm{O}$ centro do tipo $\mathrm{F}^{+}$possui um elétron desemparelhado sendo assim um centro paramagnético.

No item 1.2 apresentamos uma visão geral de dosimetria usando luminescência opticamente estimulada, com ênfase em dosimetria individual externa. Países como os Estados Unidos da América, Inglaterra, França e Japão possuem uma larga fração de dosimetria individual externa realizada com dosímetros OSL. Para que um serviço de monitoração individual externa seja certificado pela Comissão Nacional de Energia Nuclear (CNEN) é necessário que um plano de controle de qualidade de laboratório (SMIE) e um conjunto de medidas de caracterização do conjunto dosimétrico seja aprovado pelo comitê de certificação. No Brasil a regulamentação para a certificação do SMIE está disponível apenas para dosimetria 
fotográfica e termoluminescente. Sendo assim apresentamos uma proposta de certificação acompanhada de testes de desempenho para dosimetria individual externa usando OSL.

Como nossa proposta de certificação de dosimetria individual externa adota OSL usando como detector o $\mathrm{Al}_{2} \mathrm{O}_{3}: \mathrm{C}$, no Item 1.2.6. fazemos uma relação entre o material e esta propriedade.

Essa relação é importante para que possamos apresentar os resultados referentes à eficiência do $\mathrm{Al}_{2} \mathrm{O}_{3}: \mathrm{C}$ como detector OSL para luz ultravioleta e para discutirmos os resultados preliminares de espectroscopia óptica e de EPR de óxidos dopados com Térbio (materiais com potencial para aplicação em dosimetria OSL, especialmente dosimetria de nêutrons).

No Capítulo 2, apresentamos com mais detalhes os materiais, técnicas e aparelhos usados em nossas medidas. Passando então para a apresentação dos resultados e discussão, nos Capítulos 3,4 e 5.

\subsubsection{O Óxido de Alumínio.}

O Oxido de Alumínio (Figura 1.1) é um composto químico formado por átomos de Alumínio e de Oxigênio com a fórmula química $\mathrm{Al}_{2} \mathrm{O}_{3}$ (Figura 1.2. a.). Também é conhecido como Curundum em comunidades cientificas envolvidas com mineração, cerâmicas e ciência dos materiais.

Este material é um bom isolante térmico e elétrico sendo mais comumente utilizado na forma cristalina, chamado Curundum ou $\alpha$-alumina. Safiras e rubis são qualidades de gemas do Curundum com diferentes traços de impurezas em sua estrutura cristalina, que causam as diferentes cores. 
No estado sólido, $\mathrm{Al}_{2} \mathrm{O}_{3}$ apresenta densidade de $3,97 \mathrm{~g} / \mathrm{cm}^{3}$, solubilidade em água é nula; ponto de fusão de $2054{ }^{\circ} \mathrm{C}$; ponto de ebulição de aproximadamente $3000{ }^{\circ} \mathrm{C}$ e condutividade térmica de $18 \mathrm{~W} / \mathrm{mK}$.

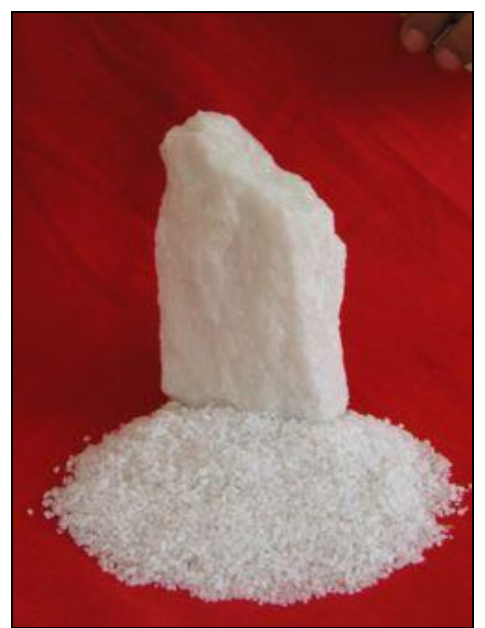

Figura 1.1. Óxido de Alumínio.

\subsection{2. Óxido de Alumínio crescido numa Atmosfera de Carbono.}

O material mais usado como dosímetro OSL é o Óxido de Alumínio crescido em baixa pressão na atmosfera de Carbono. Nesse processo, átomos de Alumínio são substituídos por átomos de Carbono e Oxigênios são retirados da estrutura, criando defeitos pontuais, como mostrado na estrutura da Figura 1.2. b.

Cristais de Curundum de alta pureza são crescidos segundo o método de Czochralski [3] derretidos a $2000{ }^{\circ} \mathrm{C}$ e recristalizados numa baixa pressão na atmosfera de Carbono. Segundo a literatura os defeitos pontuais criados nas vacâncias de oxigênio nesse processo são centros $\mathrm{Fe} \mathrm{F}^{+}[4]$, que são armadilhas de elétrons (Figura 1.2). 

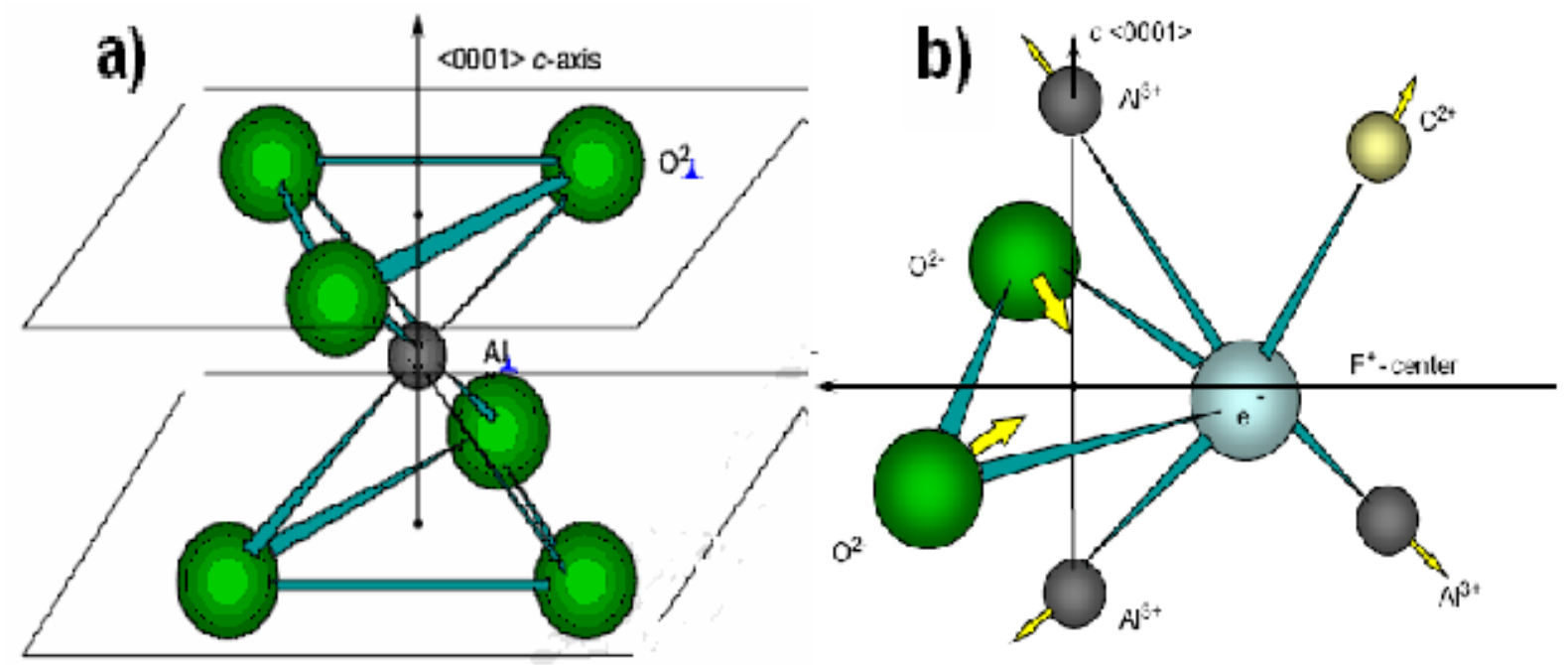

Figura 1.2. a) estrutura cristalina do Óxido de Alumínio; b) defeito pontual criado pelo crescimento em baixa pressão na presença de carbono.

A estrutura cristalina do Curundum é Hexagonal Close-Packet (HCP) (Figura 1.2. a.), os íons $\mathrm{Al}^{3+}$ ocupam sítios octaédricos distorcidos (Figura 1.2. b.) e as vacâncias de oxigênios (centros $\mathrm{F}, \mathrm{F}^{+}$) ocupam um sitio de simetria $\mathrm{C}_{2}$, ou seja, exido de torção de ordem 2. [4]. Os átomos de Carbono ocupam os mesmos sítios que os Alumínios.

\subsection{Dosimetria Opticamente Estimulada.}

Luminescência Opticamente Estimulada (OSL) é o sinal luminescente emitido por um isolante ou semicondutor (previamente irradiado) quando exposto à luz. A intensidade OSL é uma função da dose de radiação absorvida pela amostra, desta maneira a resposta luminescente pode ser usada como base de um método de dosimetria. O processo começa com a radiação causando ionização no material, com excitação dos elétrons da camada de valência e a conseqüente criação de par elétron/buraco. Defeitos pré-existentes no material armadilham os elétrons livres e os buracos em estados metaestáveis. Ao expor o material à 
luz, esses elétrons e buracos armadilhados se recombinam e emitem sinal luminescente; que é o sinal OSL proporcional à dose recebida pela amostra.

Numa descrição matemática do problema tem-se que a concentração total de estados metaestáveis no sistema no tempo t é representado por $\mu(\mathrm{t})$, de maneira que:

$$
\mu(t)=\int_{\gamma_{1} \gamma_{2}} \ldots \int_{\gamma_{m}} n\left(\gamma_{1}, \gamma_{2}, \ldots \gamma_{m}, t\right) d \gamma_{1} d \gamma_{2} . . d \gamma_{m} \quad \text { Equação (1.1) }
$$

$\mathrm{Na}$ Equação (1.1), $\mathrm{n}\left(\gamma_{1}, \gamma_{2}, . . \gamma_{\mathrm{m}}, \mathrm{t}\right)$ é a concentração de estados ocupados de 1 ao sítio m, descritos pelos parâmetros de estado $\gamma_{1}, \gamma_{2}, . . \gamma_{\mathrm{m}}$, e em geral $\mathrm{n}(\gamma, \mathrm{t})=\mathrm{N}(\gamma) \mathrm{f}(\gamma, \mathrm{t})$, sendo $\mathrm{N}(\gamma)$ a concentração de estados possíveis, e $\mathrm{f}(\gamma)$ a ocupância do estado ( $\mathrm{f}=1$ quando esta cheio e $\mathrm{f}=$ 0 quando esta vazio). Ambas f e $\mathrm{N}$ são funções dependentes do tempo.

Os parâmetros de estado ditam a estabilidade do estado metaestável sob condições de temperatura e intensidade de iluminação, ou seja, eles determinam a probabilidade por unidade de tempo do estado voltar à condição de equilíbrio.

Em medidas de luminescência opticamente estimulada a intensidade da luminescência é monitorada durante o retorno do sistema ao equilíbrio. A intensidade da luminescência, I(t), é proporcional ao decaimento dos estados metaestáveis, da seguinte maneira:

$$
I(t)=\left|\frac{d \mu(t)}{d t}\right|
$$

A luminescência estimulada é dependente do tempo através da dependência funcional de $\left|\frac{d \mu(t)}{d t}\right| \operatorname{com} \mathrm{n}\left(\gamma_{1}, \gamma_{2}, . . \gamma_{\mathrm{m}}, \mathrm{t}\right)$. Para desenvolver $\mathrm{I}(\mathrm{t})$ precisamos de uma relação entre $\left|\frac{d \mu(t)}{d t}\right| \mathrm{e}$ $\mathrm{n}\left(\gamma_{1}, \gamma_{2}, . . \gamma_{\mathrm{m}}, \mathrm{t}\right)$

Uma proposta é uma relação da forma: 


$$
\frac{d \mu(t)}{d t}=-\mu^{l}(t) P(t) \quad \text { Equação (1.3) }
$$

onde $\mathrm{P}(\mathrm{t})$ a probabilidade por unidade de tempo do decaimento de estados metaestáveis $\mu(\mathrm{t})$. Usando uma função de primeira ordem $(l=1)$ reescrevemos $I(t)$ da forma (sendo $\mathrm{P}\left(\gamma_{1}, \gamma_{2}, \ldots \gamma_{m}, t\right)$ a probabilidade para cada metaestado):

$$
I(t)=\left|\frac{d \mu(t)}{d t}\right|=\int_{\gamma_{1}} \int_{\gamma_{2}} \ldots \int_{\gamma_{m}} n\left(\gamma_{1}, \gamma_{2}, \ldots \gamma_{m}, t\right) P\left(\gamma_{1}, \gamma_{2}, \ldots \gamma_{m}, t\right) d \gamma_{1} d \gamma_{2} \ldots d \gamma_{m}
$$

A probabilidade depende do tempo e sua forma depende do método de estímulo, ou seja, estimulo óptico ou térmico do estado metaestável para a volta ao equilíbrio. Nosso interesse nesse estudo são os estímulos ópticos, então para estimulo ópticos tem-se que:

$$
p\left(E_{0}\right)=\phi \sigma\left(E_{0}\right)
$$

Na Equação (1.5), $\phi$ é a intensidade de estimulo óptico, $\sigma\left(E_{0}\right)$ é a seção de choque de fotoionização para a interação do estado metaestável com o fóton incidente, e $\mathrm{E}_{0}$ é o limiar de energia de estimulação óptica necessária para liberação da carga e retorno ao equilíbrio. Neste caso, $\mathrm{m}=1$ e $\gamma_{1}=\mathrm{E}_{0} \cdot[1,5]$

\subsubsection{OSL de Onda Contínua.}

Na representação da Equação (1.5), a temperatura, o comprimento de onda $\lambda$ e $\phi$ são valores fixos independentes do tempo. Quando as armadilhas estão sendo esvaziadas usando um comprimento de onda fixo e uma intensidade de iluminação estacionária $\phi$, a luminescência 
medida é conhecida como OSL de onda contínua (CW-OSL), cujo estimulo é conforme ilustrado na Figura 1.3.b.

Para estimulo do sinal OSL pode ser usado laser ou LED com comprimento de onda conhecido. A luminescência emitida pela amostra é monitorada continuamente enquanto o feixe de estimulo estiver ligado. Filtros são usados para discriminar entre a luz de excitação do sinal de luminescência. O sinal OSL é monitorado desde o instante em que a fonte é ligada e apresenta, comumente, um decaimento exponencial até que todas as armadilhas sejam esvaziadas. O sinal integrado da emissão (ou seja, a área embaixo da curva menos o sinal de fundo) é medido e usado para determinar a dose de radiação absorvida.

Em muitos casos, a curva OSL é exatamente uma exponencial (como no caso de medidas em $\mathrm{Al}_{2} \mathrm{O}_{3}: \mathrm{C}$, exemplo de emissão na Figura 1.3. a.), ou pode ser a soma de várias exponenciais. Em outros casos o sinal observado cresce inicialmente, para depois decair (como acontece para o Quartzo) [6]. Essa variedade de curvas sugere a multiplicidade de possíveis caminhos de recombinação e produção do sinal OSL. É conhecido que o comportamento do decaimento OSL de onda contínua depende da amostra, da dose absorvida, do comprimento de onda de estimulo, da intensidade de estimulo e da temperatura. 


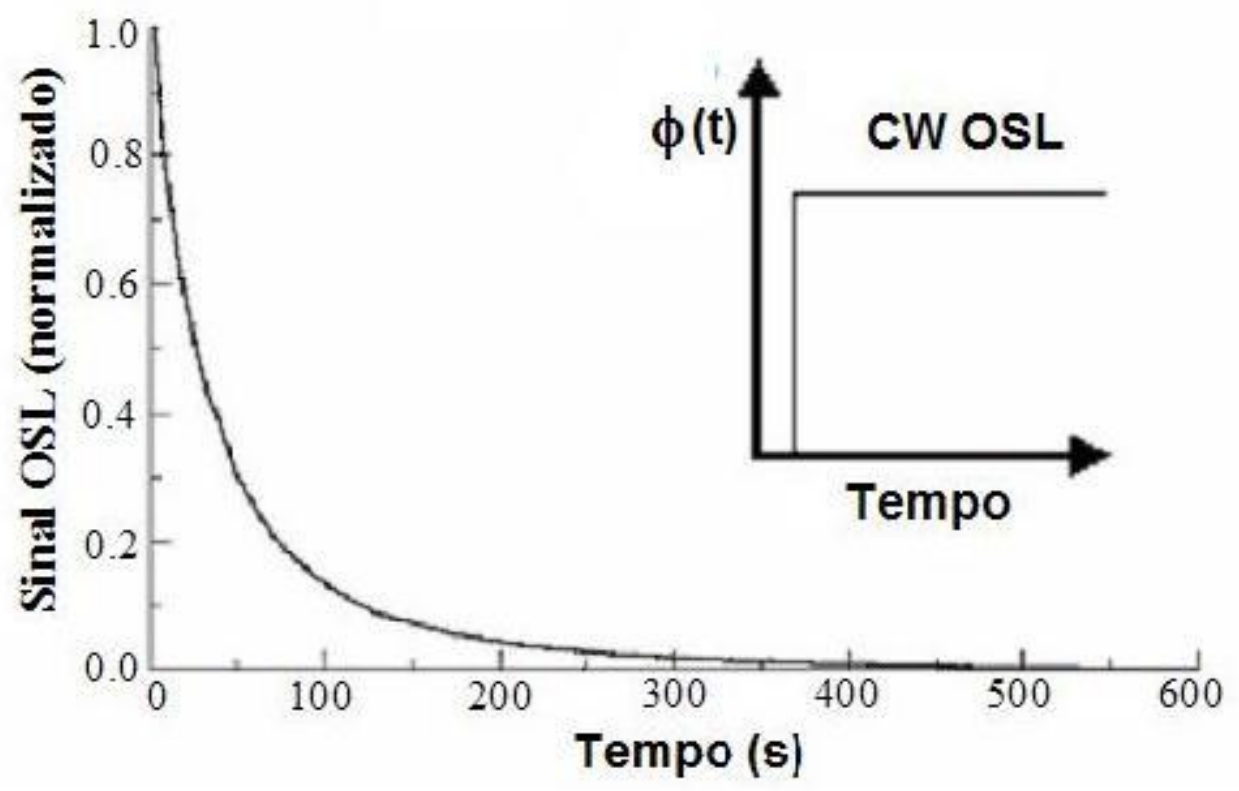

Figura 1.3. a) Resposta OSL de onda continua para $\mathrm{Al}_{2} \mathrm{O}_{3}: \mathrm{C}$ e, b) estimulo OSL de Onda Continua (CW OSL).

\subsubsection{OSL de Modulação Linear.}

Quando ocorre um crescimento linear na intensidade de estimulo óptico, a um comprimento de onda constante, tem-se que:

$$
\phi(t)=\phi_{0}+\beta_{\phi} t \quad \text { Equação (1.6), }
$$

sendo $\beta_{\phi}=d \phi / d t$.

OSL medido dessa maneira é chamado de OSL de modulação linear (ML-OSL). Estimulo e resposta de estimulo OSL de modulação linear são mostrados nas Figura 1.4.a e b. 


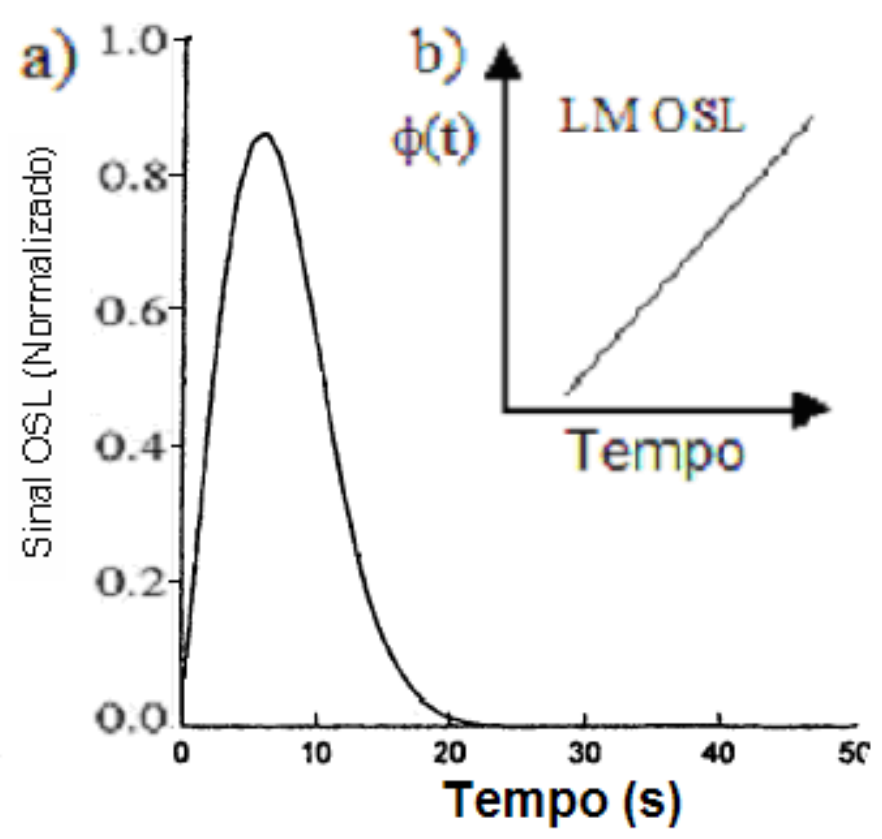

Figura 1.4. a) Resposta OSL de modulação linear para Safira e, b) estimulo OSL de Modulação Linear (LM OSL).

\subsubsection{OSL Pulsado.}

O estimulo OSL pode ser pulsado, de maneira que $\phi(\mathrm{t})=\phi_{0}$ para $\mathrm{t}_{0} \leq \mathrm{t}<\left(\mathrm{t}_{0}+\Delta \mathrm{t}\right)$ e $\phi(\mathrm{t})=0$ para $\left(\mathrm{t}_{0}+\Delta \mathrm{t}\right) \leq \mathrm{t}<\left(\mathrm{t}_{0}+\tau\right)$ sendo $\Delta \mathrm{t}$ a duração do pulso e $\tau$ o período. A esse tipo de estimulo se dá o nome de OSL pulsado (POSL), com exemplo de estimulo na Figura 1.5. b.

Nesse modo de excitação, a emissão OSL é medida apenas entre os pulsos (e não durante os pulsos). Dessa maneira a discriminação dos sinais, de excitação e de emissão, é feita por resolução temporal e não por resolução de comprimento de onda. Quando comparado a CWOSL e LM-OSL, POSL necessita de menos filtros ópticos. Exemplo de resposta OSL pulsado para $\mathrm{Al}_{2} \mathrm{O}_{3}: \mathrm{C}$ é mostrado na Figura 1.5. a. 


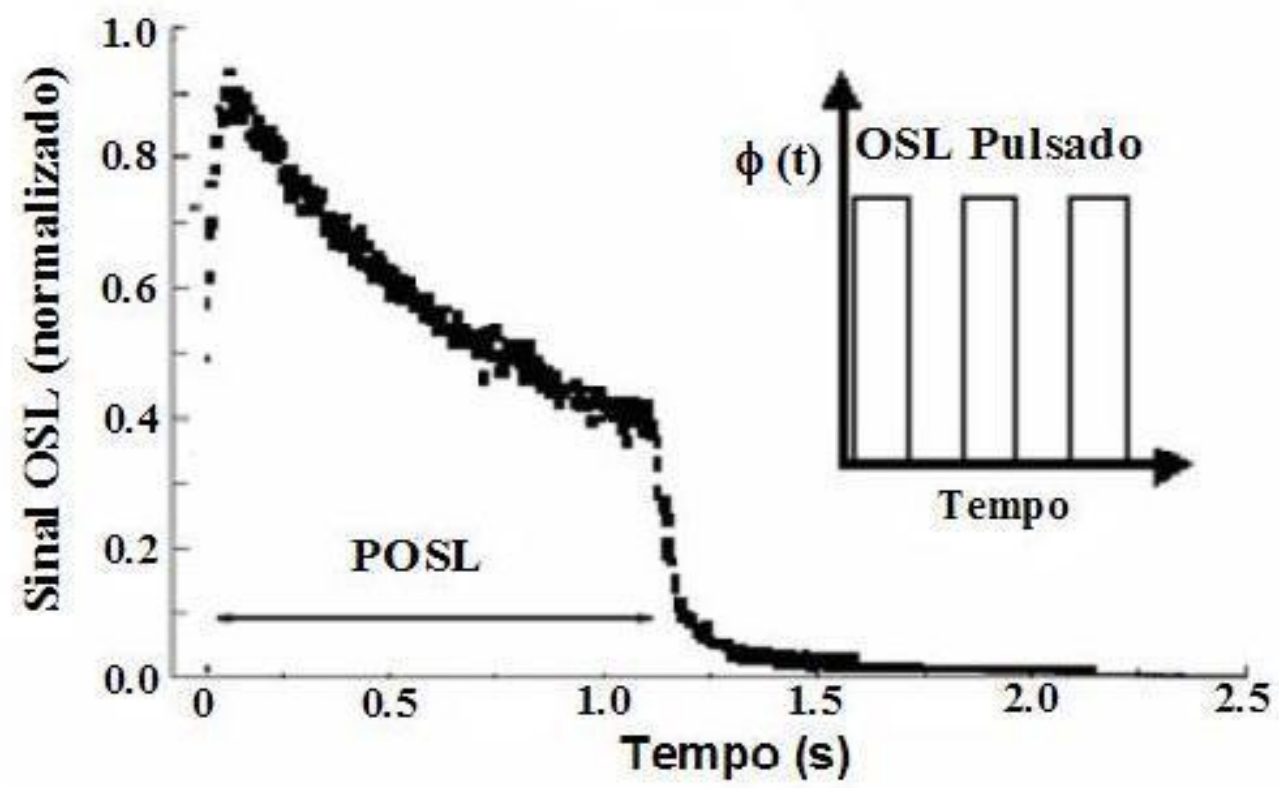

Figura 1.5. a) Resposta OSL de estimulo pulsado para $\mathrm{Al}_{2} \mathrm{O}_{3}$ : C e, b) estimulo OSL pulsado (POSL).

Existem outros estímulos possíveis, os citados acima são os mais comumente usados. Nesse trabalho usamos leitores de sinal luminescente que usam OSL pulsado (Inlight Reader, descrito no Capítulo 2, item 5) e de onda contínua (Risø, descrito no capítulo 2, item 6).

\subsubsection{Absorção Óptica.}

A absorção de luz incidente com intensidade $\mathrm{I}_{0}(\lambda)$ e comprimento de luz $\lambda$ como função da distancia x em um sólido é descrito pela lei de Lambert-Beer:

$$
I(\lambda, x)=I_{0}(\lambda) \exp [-\alpha(\lambda) x] \quad \text { Equação (1.7), }
$$

onde $\alpha(\lambda)$ é o coeficiente de absorção e $\mathrm{I}(\lambda, \mathrm{x})$ é a intensidade na posição x. O valor de $\alpha$ depende do processo de absorção óptica que ocorre para $\lambda$. Um esquema com as transições ópticas possíveis e que são importantes para dosimetria é mostrado na Figura 1.6. 


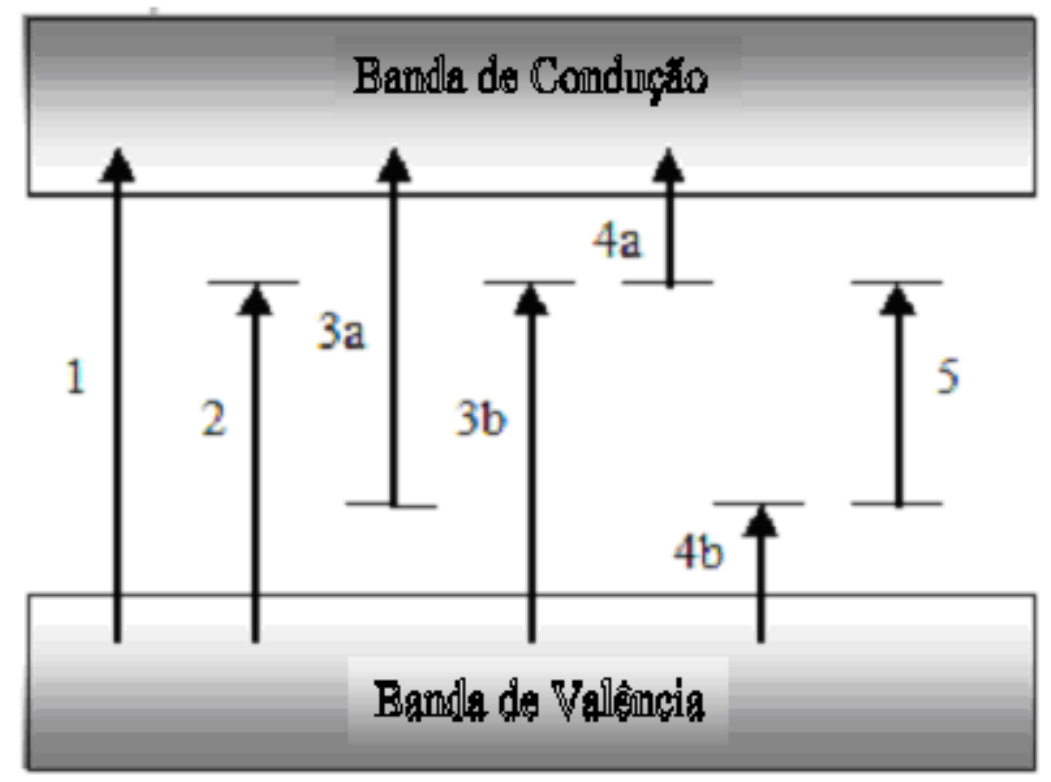

Figura 1.6. Esquema com absorções ópticas possíveis.

Transições de banda a banda (tipo 1) não são importantes para isolantes (com gap grande) que podem ser usados para dosimetria (ex: $\left.\mathrm{Al}_{2} \mathrm{O}_{3}, \mathrm{SiO}_{2}\right)$, mas são importantes para semicondutores com gap raso (ex: ZnSe). Excitação de formação (transição 2) pode levar a localização de carga e conseqüentemente a sinal TL ou OSL, mas esse tipo de transição geralmente ocorre em ultravioleta, que não é relevante para dosimetria das radiações ionizantes. As transições do tipo 3a e 3b são de ionização de defeitos e incluem, por exemplo, ionização dos centros $\mathrm{F}$ no $\mathrm{Al}_{2} \mathrm{O}_{3}: \mathrm{C}$ onde a absorção de um fóton de aproximadamente $6,5 \mathrm{eV}$ induz uma transição de elétron do estado fundamental ao estado $2 \mathrm{P}$ excitado do centro $\mathrm{F}$, uma vez que o estado 2P é acessível a banda de condução pode ocorrer ionização, levando ao armadilhamento e, subseqüentemente, a TL ou OSL [4].

Transições do tipo 4a e 4b dão origem ao sinal OSL. Após o material ser exposto a radiação ionizante, elétrons passam da banda de valência para a banda de condução e ao decaírem uma fração é armadilhada por defeitos do cristal (criação de pares elétron-buraco). O estimulo óptico dessas cargas armadilhadas por absorção de luz faz com que os elétrons voltem à banda 
de condução, decaiam e recombinem com os buracos armadilhados emitindo um sinal OSL. Transições desse tipo também levam a feitos de fototransferência e branqueamento óptico de sinais OSL ou TL. Em ambos os casos o sinal luminescente subseqüente (OSL, TL ou fototransferência) é uma função da dose inicial de radiação absorvida, do comprimento de onda, da intensidade e da duração do estimulo óptico. Um esquema mais detalhado do processo é mostrado na Figura 1.7.

Transições intrabanda (do tipo 5) são importantes em alguns processos envolvendo dosimetria opticamente estimulada em materiais naturais.
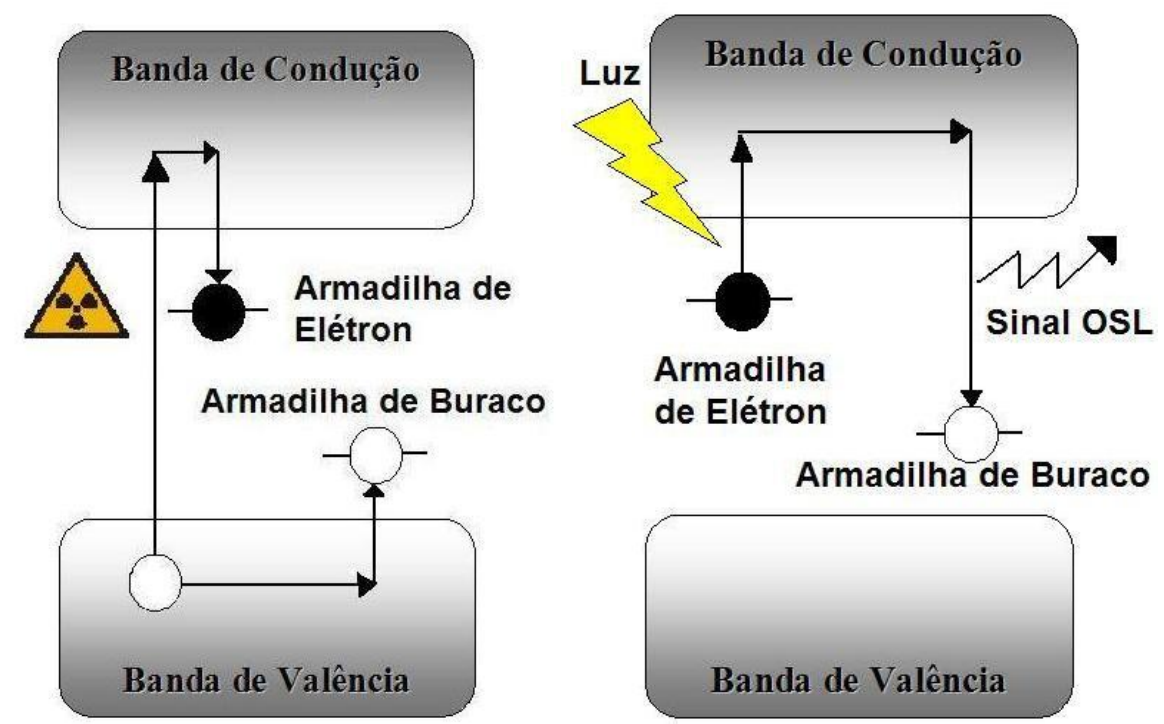

Figura 1.7. Esquema de criação de pares buraco-elétron e geração de sinal OSL.

\subsubsection{Dosimetria Individual Externa.}

Dosimetria radiológica permite o calculo de dose absorvida pela matéria ou tecido como resultado de exposição à radiação ionizante.

Dose absorvida (D) na unidade SI é medida em grays (Gy) e a grandeza é expressa por $\mathrm{D}=\mathrm{dE} / \mathrm{dm}$, onde $\mathrm{dE}$ é o valor esperado da energia depositada pela radiação em um volume 
elementar de matéria de massa dm, ou seja, um gray é a absorção de um Joule de energia por um quilograma de massa. [7].

Dosimetria individual é a área dentro da dosimetria que monitora a dose recebida por pessoas expostas a radiação ionizante. Nos últimos anos estabeleceu-se que esse monitoramento deveria apresentar as doses expostas pelas pessoas considerando-se a qualidade da irradiação. Essas doses são calculadas usando-se dose equivalente.

A Dose Equivalente $(\mathrm{HT})$ é a grandeza expressa por HT $=$ DTwR, onde DT é a dose absorvida média no órgão ou tecido humano e wR é o fator de ponderação da radiação. Para Raios-X, por exemplo, $w \mathrm{R}=1$, de maneira que dose equivalente é numericamente igual a dose absorvida. A unidade SI de dose equivalente é denominado Sievert (Sv).

Dose Profunda é a dose equivalente absorvida por tecido humano em uma profundidade equivalente a $1000 \mathrm{mg} / \mathrm{cm}^{2}$ (1,0 $\mathrm{cm}$ abaixo da pele superficial), nesse caso o interesse é em radiação de alta penetração, tais como: raios $\gamma, \beta$ de alta energia e Raios-X (com energia > 15 $\mathrm{keV})$.

Dose Rasa é a dose equivalente absorvida pela pele a uma profundidade de 5 a $10 \mathrm{mg} / \mathrm{cm}^{2}$; neste caso o interesse é em radiação de baixa penetração, tais como: $\beta$ de baixa energia e raios-X (com energia $<15 \mathrm{keV})$.

Dose de Cristalino é a dose equivalente absorvida pela lente do olho a uma profundidade de 3 $\mathrm{mm}$. 


\subsection{6. Óxido de Alumínio e Sinal OSL.}

Como já dito anteriormente, Óxido de Alumínio crescido em uma baixa pressão na presença de uma atmosfera de Carbono $\left(\mathrm{Al}_{2} \mathrm{O}_{3}: \mathrm{C}\right)$ aumenta o número de defeitos pontuais (centros $\mathrm{F}$, $\mathrm{F}^{+}$). Nos cristais usados nesse trabalho, o número de átomos de carbono no cristal varia de 20 a 100 ppm (por análise de absorção atômica, resultados não publicados) e defeitos pontuais estão presentes na ordem de 5000 ppm [1]. Esses cristais dopados com Carbono apresentam alta sensibilidade termoluminescente e luminescência opticamente estimulada (sinal normalizado nas Figuras 1.8.a, para termoluminescência e 1.8.b, para sinal opticamente estimulado).
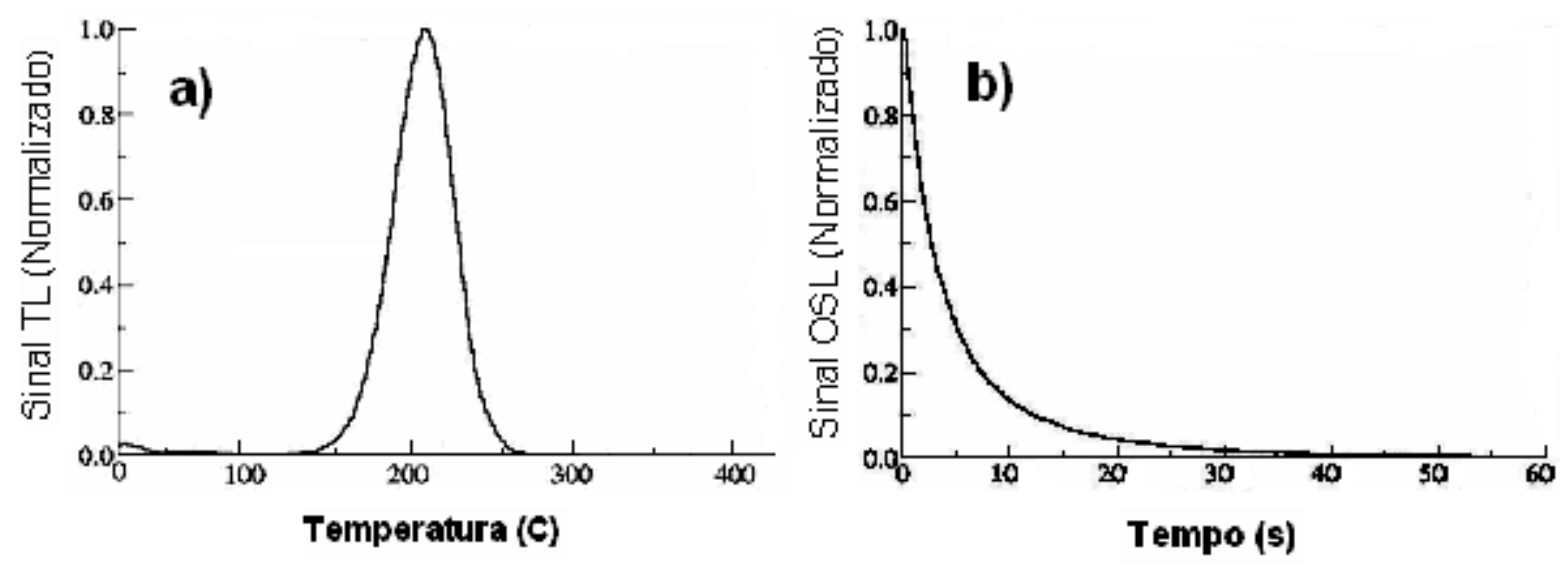

Figura 1.8. a) Sinal $\mathrm{TL}$ do $\mathrm{Al}_{2} \mathrm{O}_{3}: \mathrm{C}$ e b) Sinal CW-OSL do $\mathrm{Al}_{2} \mathrm{O}_{3}$ :C.

Existem muitos estudos que avaliam a sensibilidade do $\mathrm{Al}_{2} \mathrm{O}_{3}: \mathrm{C}$ para diferentes tipos de radiação $[8,9]$. $\mathrm{O} \mathrm{Al}_{2} \mathrm{O}_{3}: \mathrm{C}$ tem sensibilidade a exposições $\beta$ que vai desde $10 \mu \mathrm{Gy}$ até $100 \mathrm{~Gy}$ $[10,11]$. Suas respostas em dosimetria individual externa, datação e dosimetria espacial para Raios-X, $\beta, \gamma, \alpha$ e partículas pesadas, já são bastante conhecidas [12]. Alguns exemplos são mostrados no gráfico da Figura 1.9. a e b para estimulo com onda contínua (CW OSL). 
Não existem modelos de dosimetria OSL usando $\mathrm{Al}_{2} \mathrm{O}_{3}: \mathrm{C}$ como detector para exposições a nêutrons e ultravioleta. No caso de nêutrons o maior problema é devido a maneira como os nêutrons interagem com o material. No caso de UV estudos para o desenvolvimento de um modelo já estão sendo feitos. Já se conhece a resposta do material a UV para sinal termoluminescente e parte dos estudos preliminares de resposta OSL do material a exposição à UV são apresentados nesse trabalho, mostrando a resposta após exposição com diferentes comprimentos de onda.

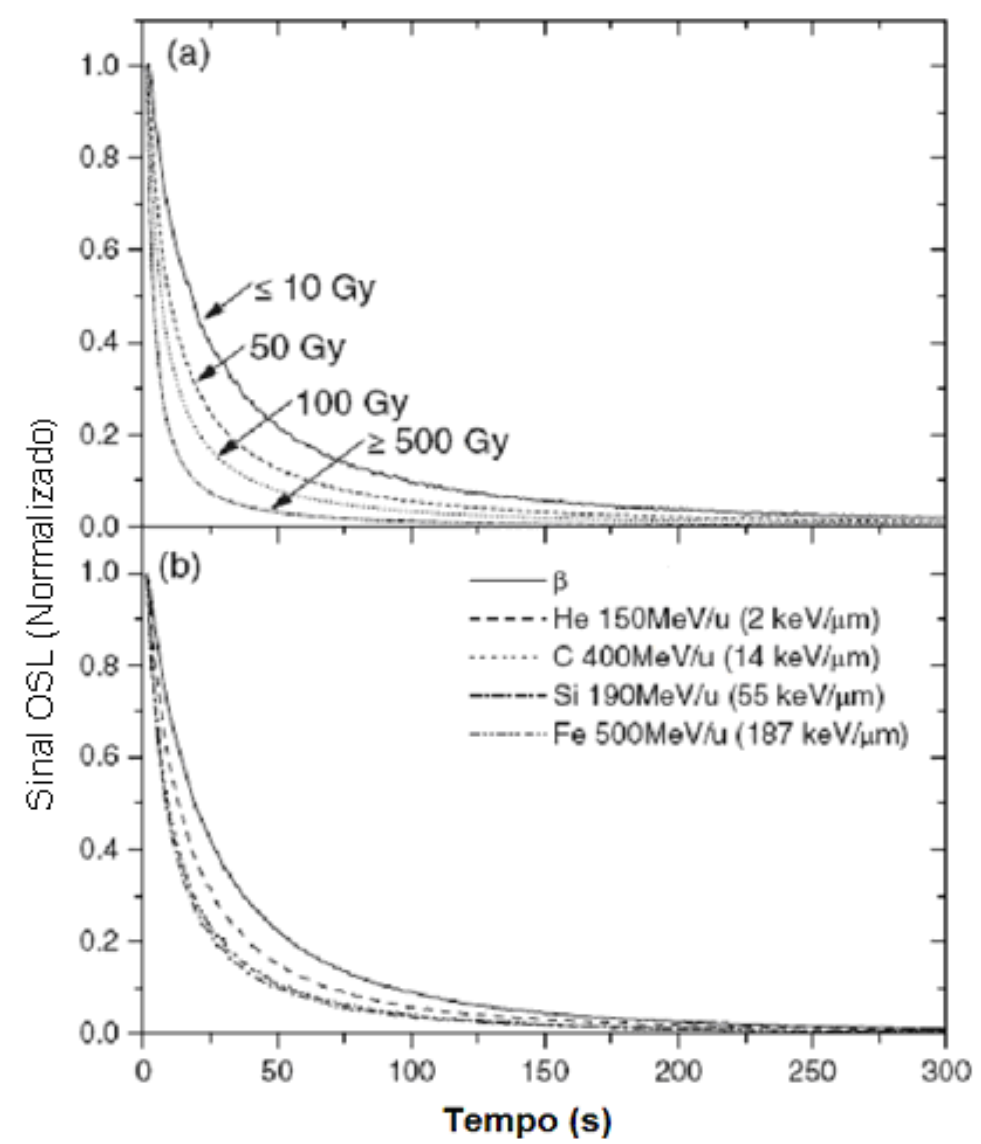

Figura 1.9. a) Sinal OSL para diferentes doses de irradiação $\operatorname{com} \beta$, e b) para exposição com diferentes fontes de radiação $(\beta, \mathrm{He}, \mathrm{C}, \mathrm{Si}$ e $\mathrm{Fe})$. 


\section{MATERIAIS E MÉTODOS}

\subsection{Monocristais Usados para Aquisição de Espectros de EPR.}

Os monocristais de $\mathrm{Al}_{2} \mathrm{O}_{3}: \mathrm{C}$ foram enviados pela Divisão de Crescimento de Cristais da Landauer Inc. (Landauer Crystal Growth Division, Stillwater, EUA).

Esses monocristais possuem forma cilíndrica com $3 \mathrm{~mm}$ de altura e $8 \mathrm{~mm}$ de diâmetro e impurezas de $\mathrm{Ca}, \mathrm{Cr}, \mathrm{Ti}, \mathrm{Ni}, \mathrm{Si}, \mathrm{Cu}, \mathrm{Mg}$ e $\mathrm{Fe}$ em p.p.m. Para este trabalho não foi feito nenhum tratamento químico e as amostras dos cristais foram cortadas pelo grupo de Crescimento de Cristais do Instituto de Física de São Carlos (USP) de maneira que ficassem quadrados de 5 x $5 \mathrm{~mm}$, mantendo os $3 \mathrm{~mm}$ de espessura.

\subsection{Amostras em Pó Usadas para Aquisição de Espectros de EPR, de Excitação e de Emissão.}

Amostras de pós de $\mathrm{Al}_{2} \mathrm{O}_{3}: \mathrm{C}$ foram utilizadas na aquisição de espectros de EPR. As amostras de pó de $\mathrm{MgO}: \mathrm{Tb}$, MgO:Tb,Co, $\mathrm{CaO}: \mathrm{Tb}$ e $\mathrm{Li}_{2} \mathrm{O}: \mathrm{Tb}$ foram utilizadas para aquisição de espectros de EPR, de emissão e de excitação.

As amostras de $\mathrm{MgO}: \mathrm{Tb}, \mathrm{MgO}: \mathrm{Tb}, \mathrm{Co}, \mathrm{CaO}: \mathrm{Tb}$ e de $\mathrm{Li}_{2} \mathrm{O}: \mathrm{Tb}$ foram preparadas no Instituto de Ciências Nucleares Vinca (Belgrado/Sérvia). Todas as amostras possuem concentrações acima de $0,2 \%$ em massa de Tb. As amostras foram separadas em grupos para esse trabalho e foram codificadas como mostrado na Tabela 2.1. As amostras de cada Grupo diferem-se pela concentração de dopante (Tb), segundo especificações dadas pelo fabricante. 


$\begin{array}{ccc}\text { Grupo 1 } & \text { Grupo 2 } & \text { Grupo 3 } \\ \text { G1_2- Li2O:Tb } & \text { G2_12- MgO:Tb,Co } & \text { G3_22- CaO:Tb } \\ \text { G1_4 - Li2O:Tb } & \text { G2_14- MgO:Tb,Co } & \text { G3_24- CaO:Tb } \\ \text { G1_8 - Li2O:Tb } & \text { G2_16- MgO:Tb } & - \\ - & \text { G2_18- MgO:Tb } & -\end{array}$

Tabela 2.1. Separação das amostras de óxidos por grupo.

Para esse trabalho foram usados dois tipos de pós de $\mathrm{Al}_{2} \mathrm{O}_{3}: \mathrm{C}$ : produzidos através de monocristais virgens e outro através da recuperação do material de dosímetros OSL já usados. Uma breve descrição de cada tipo de pó é dada a seguir.

\subsubsection{Pó Virgem de $\mathrm{Al}_{2} \mathrm{O}_{3}: \mathrm{C}$.}

$\mathrm{O}$ pó virgem de $\mathrm{Al}_{2} \mathrm{O}_{3}: \mathrm{C}$ usado nesse trabalho foi obtido a partir de cristais de $\mathrm{Al}_{2} \mathrm{O}_{3}: \mathrm{C}$ crescidos da maneira como já foi descrito no item 1.1.1. O tamanho de partícula deste pó é da ordem de $50 \mu \mathrm{m}$, segundo especificação dada pelo fabricante.

\subsubsection{Pó Recuperado de $\mathrm{Al}_{2} \mathrm{O}_{3}: \mathrm{C}$.}

A recuperação do pó de $\mathrm{Al}_{2} \mathrm{O}_{3}: \mathrm{C}$ foi feita nas dependências da empresa Sapra S/A (São Carlos). Sensores OSL do tipo Luxel ${ }^{\circledR}$ (descritos a seguir, no item 2.3) são submetidos a um processo de recuperação que consiste em duas calcinações.

Na primeira calcinação é feita a decomposição do componente polimérico dos sensores. $\mathrm{Na}$ segunda etapa do processo, chamada de "segunda calcinação" o material resultante do primeiro processo é inserido num forno tipo mufla, com temperatura controlada em torno de 
$700{ }^{\circ} \mathrm{C}$, para a eliminação completa da parte orgânica e posterior recuperação do material cerâmico [13].

O resultado final consiste em um pó fino, branco, com as mesmas características físicoquímicas do pó virgem. Esse material é usado para confecção de novos sensores OSL para uso em dosimetria individual externa.

\subsection{Dosímetros OSL Usados no Trabalho.}

Dois modelos de dosímetros OSL foram usados no trabalho. Um deles, Inlight ${ }^{\circledR}$, foi usado nos testes de desempenho para a certificação de OSL no Brasil e o outro, Luxel ${ }^{\circledR}$, teve o detector usado no estudo das mudanças de sensibilidade do material $\mathrm{Al}_{2} \mathrm{O}_{3}: \mathrm{C}$ a exposições com ultravioleta.

A descrição de cada um segue abaixo.

\subsubsection{Dosímetros OSL Modelo Luxel ${ }^{\circledR}$.}

O dosímetro do tipo Luxel ${ }^{\circledR}$ é mostrado na Figura 2.1. a-c. Este é um dosímetro destinado a dosimetria individual externa. A estrutura interna do dosímetro é o detector (Figura 2.1. a.) e consiste em uma fita de $\mathrm{Al}_{2} \mathrm{O}_{3}: \mathrm{C}$ em pó depositado em um filme de poliéster e coberto por outra camada de proteção de poliéster. O tamanho da área ativa do detector é de 16,5 x 18,5 mm e o tamanho da partícula de pó $\mathrm{Al}_{2} \mathrm{O}_{3}: \mathrm{C}$ varia entre 20 e $90 \mu \mathrm{m}$ (como especificado pelo fabricante). 
O detector é acondicionado em um porta amostra que contém quatro aberturas, ou janelas (Figura 2.1. b), sendo elas: uma janela totalmente aberta, uma janela com um filtro $250 \mu \mathrm{m}$ de $\mathrm{Cu}$, uma janela com um filtro de $500 \mu \mathrm{m}$ de $\mathrm{Sn}$ e uma janela contendo uma rede de $\mathrm{Cu}$ de $500 \mu \mathrm{m}$ com buracos de $1 \mathrm{~mm}$ de diâmetro. O conjunto (detector recoberto por estrutura com as janelas) é colocado dentro de uma proteção denominada monitor ou badge (Figura 2.1. c.) que é feita de maneira a impedir que o detector seja exposto à luz (o que causaria perda do sinal OSL) e para proteção física do conjunto.

Quando um dosímetro Luxel é lido é retirada essa proteção e luz incide em três das janelas simultaneamente (a janela aberta, a de $\mathrm{Cu}$ e a de $\mathrm{Sn}$ ). O sinal obtido para essas janelas é usado para calcular a Dose Profunda $(\mathrm{Hp}(10))$, Dose Rasa $(\mathrm{Hp}(0,07))$ e Dose de Cristalino $(\mathrm{Hp}(0,3))$, usando uma fórmula da forma:

$$
\mathrm{D}=\mathrm{A} . \mathrm{I}_{\mathrm{ja}}+\mathrm{B} \cdot \mathrm{I}_{\mathrm{Cu}}+\mathrm{C} . \mathrm{I}_{\mathrm{Sn}} \quad \text { Equação }(2.1)
$$

Sendo $\mathrm{I}_{\mathrm{ja}}$ a intensidade luminescente para janela aberta, $\mathrm{I}_{\mathrm{Cu}}$ a intensidade luminescente para janela de $\mathrm{Cu}$ e $\mathrm{I}_{\mathrm{sn}}$ a intensidade luminescente para janela de $\mathrm{Sn}$. As constantes A, B e C são coeficientes específicos de cada filtro e são usados pelo algoritmo de cálculo de dose (valores não fornecidos pelo fabricante).

A quarta janela, contendo a grade de cobre, é usada para medidas de distribuição espacial da dose o que não será discutido nesse trabalho. 
a)

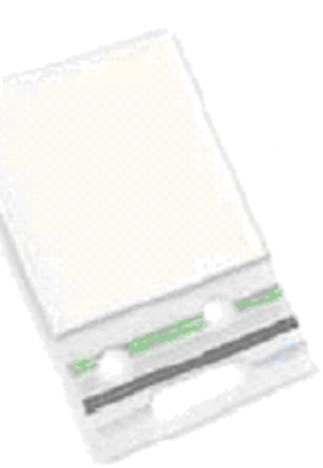

b)

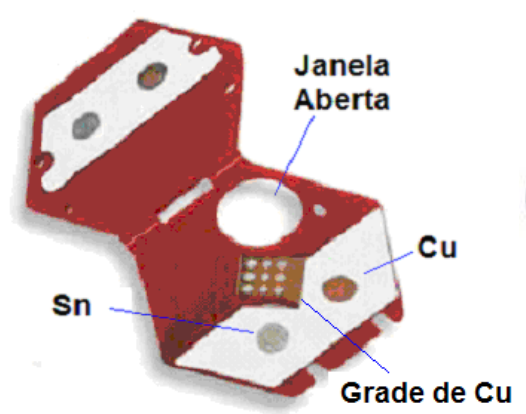

c)

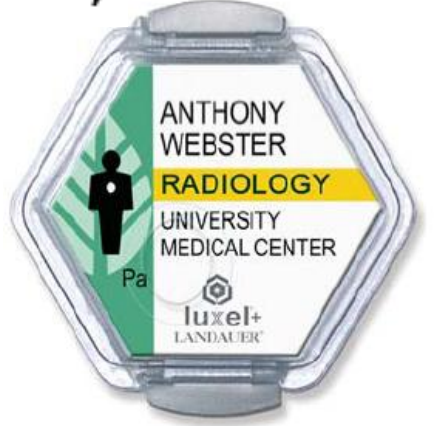

Figura 2.1. Dosímetro Luxel ${ }^{\circledR}$ a) Fita com o detector OSL, b) estrutura com as quatro janelas e c) Badge.

Dosímetros Luxel são lidos usando uma fonte de Laser. Esse tipo de leitura, devido a potência do Laser, limpa todo o sinal OSL dos detectores.

\subsubsection{Dosímetros OSL Modelo Inlight ${ }^{\circledR}$.}

O dosímetro Inlight ${ }^{\circledR}$ é também um produto para dosimetria individual externa, contudo, nesse caso o processo de leitura usa OSL contínuo (CW-OSL) que é estimulado por LEDs verdes. Neste dosímetro, o detector consiste em uma camada de $\mathrm{Al}_{2} \mathrm{O}_{3}: \mathrm{C}$ em pó depositado em um filme de poliéster (Figura 2.2. a. 1), colocado dentro de uma estrutura com quatro janelas (Figura 2.2 a. 2), sendo elas: janela completamente aberta, janela com filtro $250 \mu \mathrm{m}$ de $\mathrm{Pb}$, uma janela com um filtro de $500 \mu \mathrm{m}$ de $\mathrm{Al}$ e uma janela de plástico. O conjunto (detector recoberto por tampa com as janelas) é colocado dentro de uma proteção denominada monitor ou badge (Figura 2.2. b.) que é feita de maneira a impedir que o detector seja exposto à luz (o que causaria perda do sinal OSL) e para proteção física do conjunto.

A leitura OSL de dosímetros Inlight ${ }^{\circledR}$ segue uma rotina um pouco diferente da rotina dos dosímetros Luxel $^{\circledR}$. Por serem lidos usando LEDs há possibilidade de releitura do sinal, já que a potência dos LEDs é baixa e a quantidade do sinal lido pode ser feita de maneira que apenas 
uma pequena fração dos centros luminescentes sejam excitados e se recombinem. Dessa forma um laboratório pode fazer medidas de OSL em dosímetros Inlight durante, por exemplo, um ano, sem limpeza do sinal total, de modo que ao final desse período existam dados sobre dose parcial e dose total acumulada.

A sensibilidade de dosímetros Inlight ${ }^{\circledR}$ vai até 10 Gy para exposição por fótons com energia maior que $5 \mathrm{keV}$ e por elétrons com energia maior que $150 \mathrm{keV}$, não sendo sensível para exposição a nêutrons.

Os dosímetros Inlight ${ }^{\circledR}$ também possuem 4 janelas (Figura 2.2. a. 2), só que a quarta não é para medida de distribuição espacial de dose, e sim para cálculo de dose devido a exposição $\beta$ de baixa energia $(\mathrm{Hp}(0,07))$ como, por exemplo, a exposição de ${ }^{147} \mathrm{Pm},{ }^{206} \mathrm{Ti}$ e ${ }^{90} \mathrm{Sr} /{ }^{90} \mathrm{Y}$. Para tanto a quarta janela é feita de plástico (Mylar) e os grãos do pó de $\mathrm{Al}_{2} \mathrm{O}_{3}: \mathrm{C}$ possuem tamanhos entre 20 e $25 \mu \mathrm{m}$.

Quando um dosímetro Inlight ${ }^{\circledR}$ é lido, é retirado o badge e luz incide nas quatro janelas simultaneamente (a janela aberta, a de $\mathrm{Pb}$, a de $\mathrm{Al}$ e a de plástico). O sinal obtido para essas janelas é usado para calcular a Dose Profunda $(\mathrm{Hp}(10))$, Dose Rasa $(\mathrm{Hp}(0,07))$, Dose de Cristalino $(\mathrm{Hp}(0,3))$ e $\beta$.

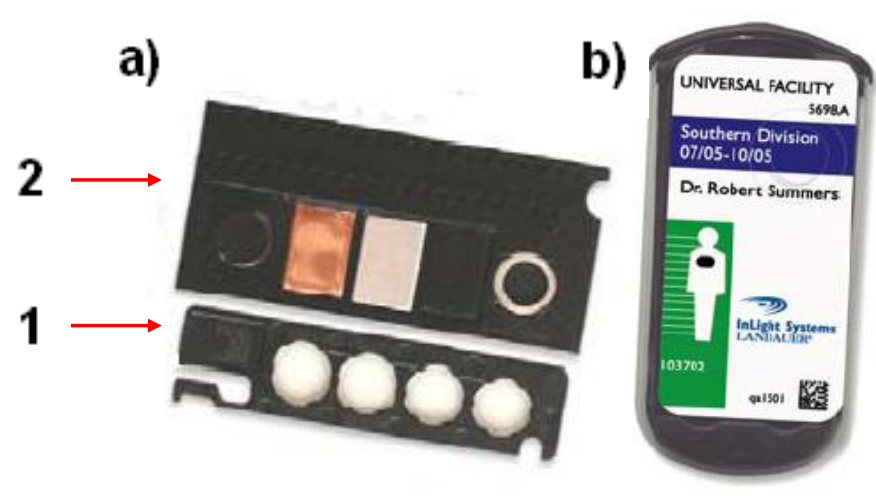

Figura 2.2. Dosímetro Inlight ${ }^{\circledR}$ com a) Fita com o detector OSL (1) e janelas (2), b) protetor com informações do usuário (badge). 


\subsection{Leitores de Sinal OSL.}

Nesse trabalho foram usados dois tipos diferentes de leitores de sinal OSL: leitor de OSL pulsado (Manual Inlight Reader) e de onda continua (Risø TL/OSL-DA-20). Esses leitores são descritos a seguir.

\subsubsection{Manual Inlight ${ }^{\circledR}$ Reader.}

A empresa Landauer Inc. oferece uma série de produtos e serviços para dosimetria individual externa. Uma das maiores linhas está nos dosímetros e leitores de OSL usando como material dosimétrico o $\mathrm{Al}_{2} \mathrm{O}_{3}: \mathrm{C}$.

O leitor OSL Inlight ${ }^{\circledR}$ só lê dosímetros Inlight ${ }^{\circledR}$. Neste processo são utilizados 36 LEDs para estimular o material dosimétrico e uma fotomultiplicadora para receber o sinal luminescente. O leitor possui um dispositivo para abrir os dosímetros e ler cada janela separadamente, e um software para calcular as doses equivalentes. Um esquema simplificado do aparelho é mostrado na Figura 2.3. Nele temos a fonte de luz, que fornece luz verde para a amostra. Antes de chegar à amostra, a luz passa por um dispositivo óptico que foca a luz incidente na amostra e filtra a luz espalhada para que não chegue à fotomultiplicadora. O sinal luminescente da amostra passa por um filtro de detecção que limpa o sinal que chegará a fotomultiplicadora.

Maiores detalhes sobre o dispositivo óptico, filtros e fotomultiplicadora não são fornecidos pelo fabricante. 


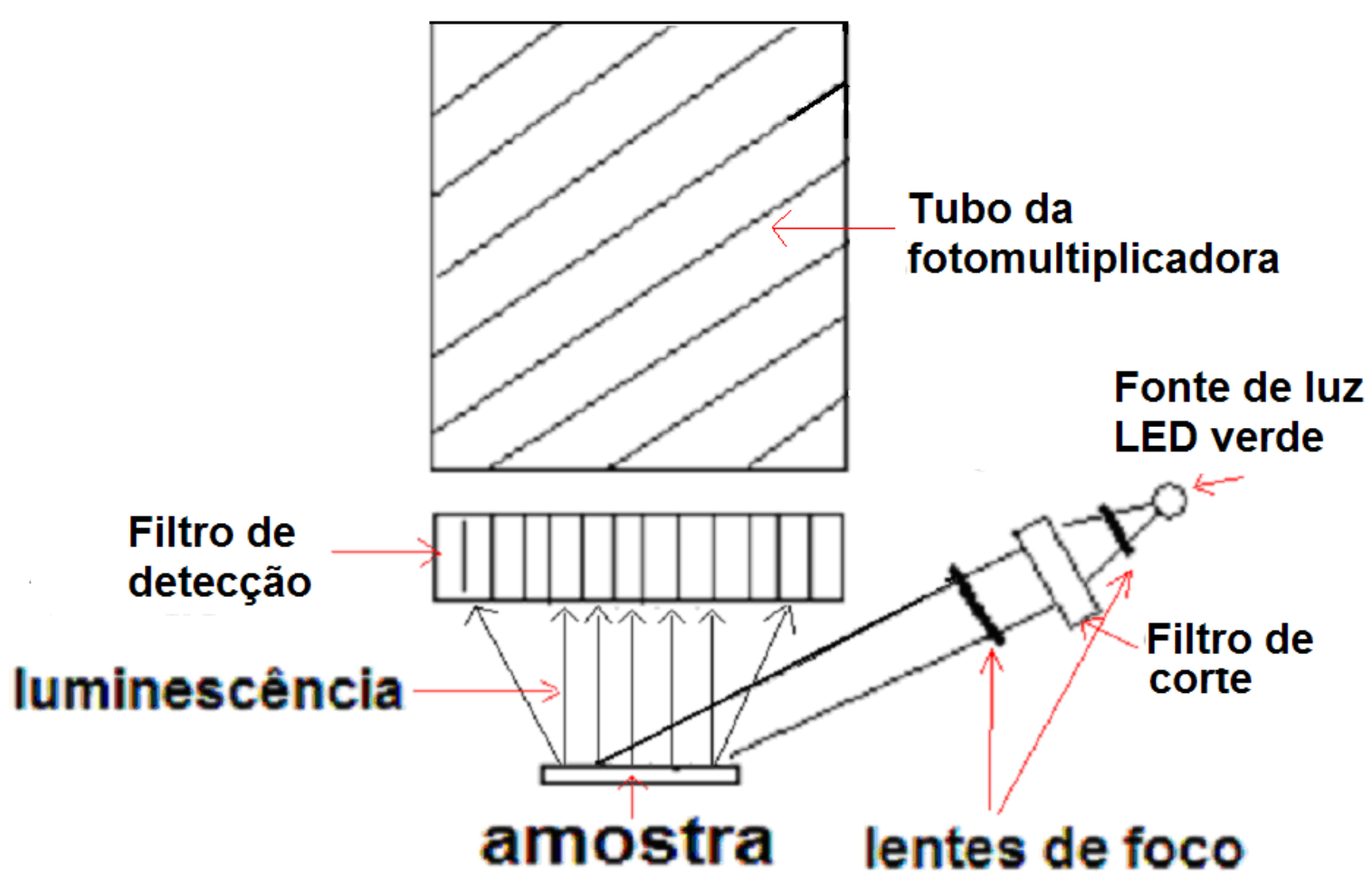

Figura 2.3. Esquema simplificado com o processo de leitura do leitor Manual Inlight ${ }^{\circledR}$.

\subsubsection{Método de Medida}

O dosímetro é colocado manualmente dentro da gaveta do aparelho. Fecha-se a gaveta e o aparelho lê o código de barras e o código 2-D do dosímetro para associar a dose com detector e slide (essa informação é usada para registrar os dados, relacionando-os com o usuário), o Leitor abre o dosímetro, para poder ler cada janela separadamente. Essa leitura é feita incidindo luz verde dos LEDs na amostra. O sinal luminescente é recebido pela fotomultiplicadora (passando antes por um sistema óptico para filtrar sinal dos LEDs) que vai converter a informação de maneira que o programa do aparelho possa usar o algoritmo para calcular as doses, tipo de radiação e a existência de radiação $\beta$. 


\subsubsection{Leitor TL/OSL, modelo Risø TL/OSL-DA-20 $\left(\right.$ Luxel $\left.^{\circledR}\right)$.}

O leitor de TL/OSL, modelo Ris $\varnothing$ TL/OSL-DA-20, é usado em estudos de luminescência como retro dosimetria [14], datação [15], dosimetria individual externa, etc. Os leitores são bastante flexíveis e podem ser programados para fazer uma ou uma série de medidas, irradiações e aquecimentos.

Ele possui uma gaveta para 48 amostras, unidades para leitura com estimulo no comprimento de onda de azul e infravermelho. Aquecimento linear para medidas de TL de até $700{ }^{\circ} \mathrm{C}$. Grupos de estimulo com 42 LEDs azuis Nichia $(470 \mathrm{~nm})$ com potencia de $50 \mathrm{~mW} / \mathrm{cm}^{2}$ e laser de infravermelho $(830 \mathrm{~nm})$ com potencia de $300 \mathrm{~mW} / \mathrm{cm}^{2}$ para medidas OSL. Uma fonte de radiação $\beta{ }^{90} \mathrm{Sr} /{ }^{90} \mathrm{Y}$ com capacidade de aproximadamente $0,1 \mathrm{~Gy} / \mathrm{s}$. Um esquema da unidade de medida OSL no aparelho é mostrado na Figura 2.4. 


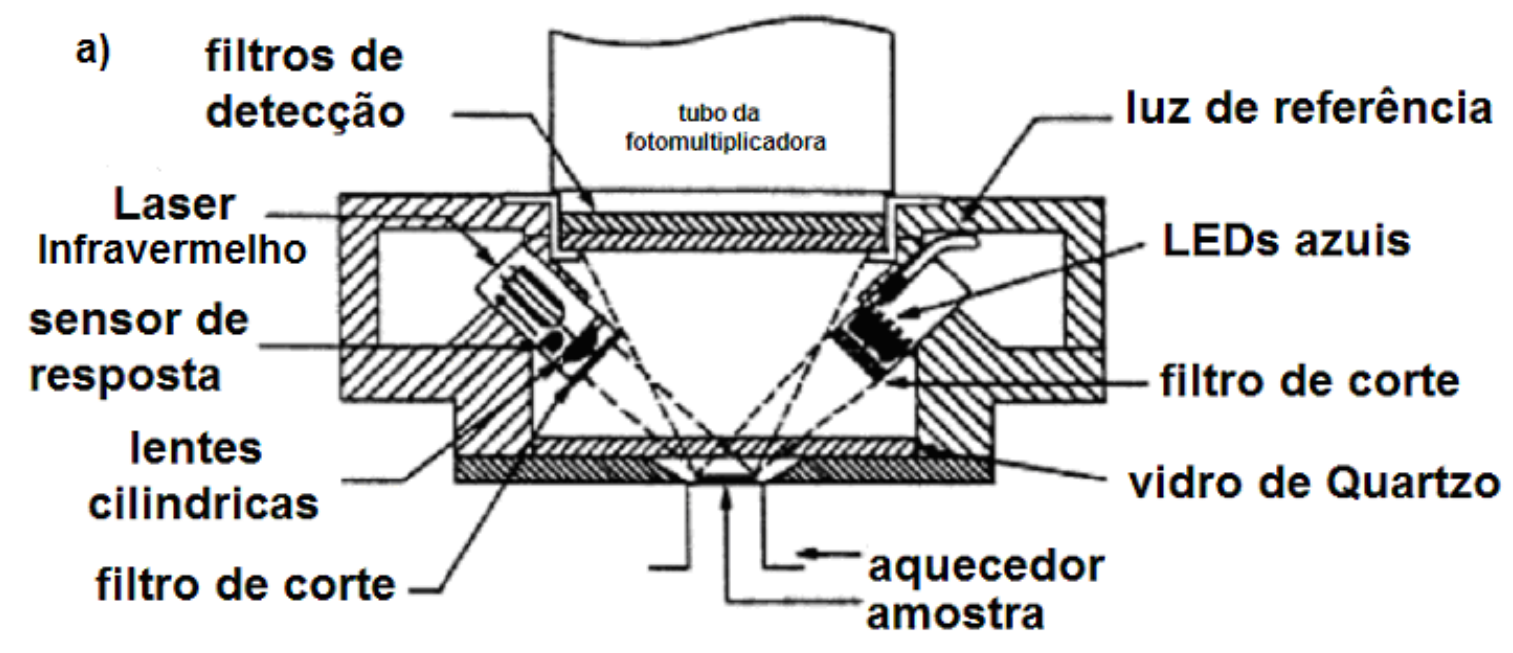

b) Laser

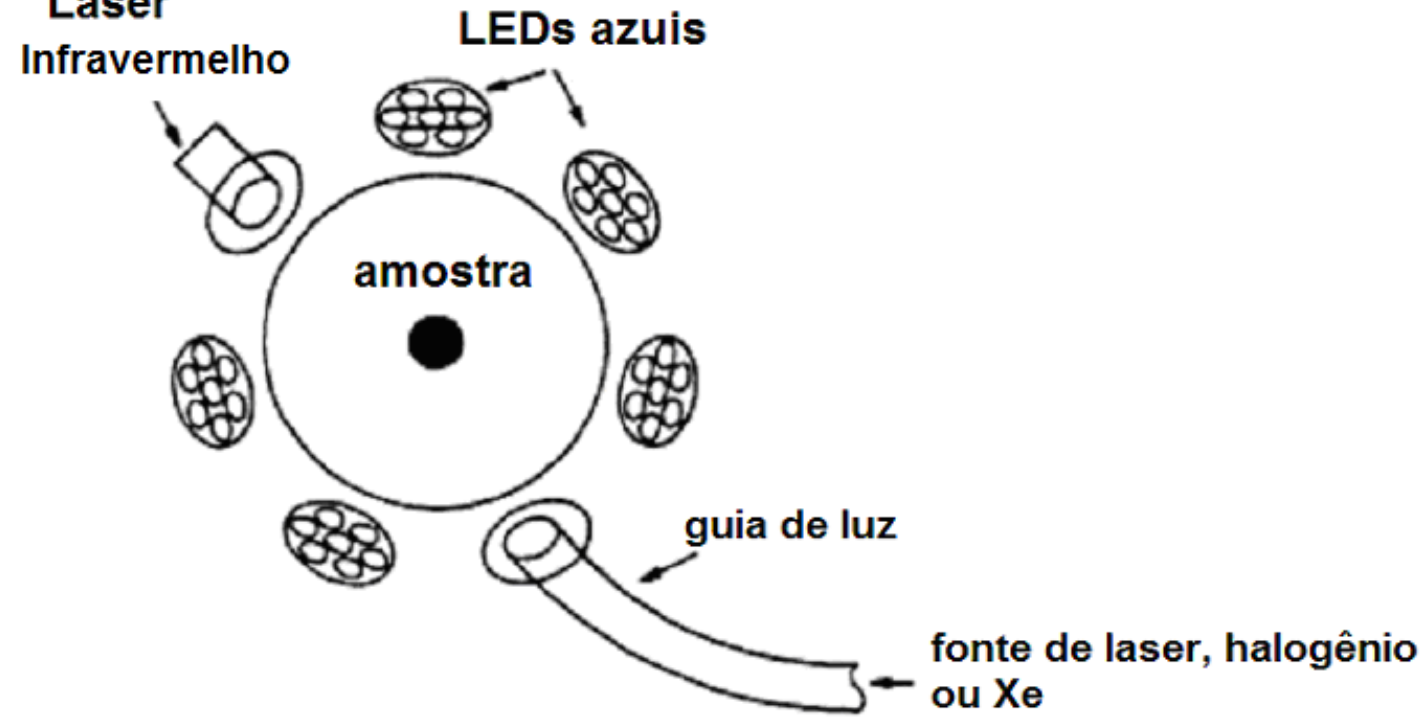

Figura 2.4. a) Diagrama esquemático do grupo combinado de LEDs azuis e o laser IR para medidas de OSL e b) esquema visto de cima do prato com amostra para mostrar disposição das fontes.

A fonte de infravermelho consiste em um arranjo de 30 a 40 diodos que ficam a $20 \mathrm{~mm}$ da amostra, um sensor de resposta (um fototransistor) estabiliza a potência que sai da fonte, lentes cilíndricas montadas em frente ao laser fornecem uma iluminação uniforme em $1 \mathrm{~cm}^{2}$ sob a posição da amostra e um filtro de corte do tipo passa alta Schott RG-115 reduz o sinal de fundo na fotomultiplicadora. A unidade com os LEDs consiste em sete aglomerados de sete LEDS montados em circulo em volta do prato em que fica a amostra. Todos os aglomerados são individualmente focados na amostra a $25 \mathrm{~mm}$ de distância. Um filtro de 
corte tipo passa alta GG-420 é colocado em frente de cada aglomerado de LEDs para minimizar a incidência de luz azul espalhada na fotomultiplicadora. Um filtro de 7,5 mm Hoya U-340 recebe o sinal emitido pela amostra (filtro de detecção) e estabiliza o sinal que chegará a fotomultiplicadora.

\subsection{Espectrômetros.}

Nesse trabalho foram usados dois tipos de espectrômetros: de ressonância paramagnética eletrônica (Electron Paramagnetic Resonance, EPR) e óptico. Esses espectrômetros são descritos a seguir.

\subsubsection{Espectrômetro de EPR (Bruker).}

Espectrômetros de EPR são usados para estudo de centros paramagnéticos. Com este pode-se detectar impurezas, determinar a simetria dos centros paramagnéticos e suas interações com os átomos vizinhos.

A técnica consiste em submeter uma amostra que possua centros paramagnéticos (ou seja, com spins desemparelhados) a dois campos magnéticos: um quase estático $\left(\hat{B}_{0}(t)\right)$, que separa seus níveis de energia; e um outro campo perpendicular ao primeiro $\left(\hat{B}_{1}(t)\right)$, normalmente da ordem de microondas, que provoca as transições enttre os estados. A energia absorvida é monitorada e convertida num espectro de EPR.

O exemplo clássico usado para ilustrar os princípios de EPR é o sistema de spin $\mathrm{s}=1 \frac{1}{2}$ formado por um elétron livre sujeito a um campo magnético $\hat{B}_{0}$ [16]. Os centros estudados 
por EPR possuem um momento de dipolo magnético $\mu_{\mathrm{e}}$ associado ao momento de spin através da equação abaixo:

$$
\hat{\mu}_{e}=-g \cdot \mu_{B} \cdot \hat{S} \quad \text { Equação }(2.2)
$$

Onde $\hat{S}$ é o operador do momento angular de spin do elétron, g é uma constante adimensional chamada constante $\mathrm{g}$ do elétron (que para o elétron livre, considerando correções relativísticas, é igual a 2,0023) e $\mu_{B}$ é o magneton eletrônico de Bohr, dado por $e \hbar / 2 \mathrm{mc}$ ("c" é a velocidade da luz, " $e$ " e "m" são respectivamente a carga e massa do elétron).

A energia do dipolo magnético em um campo magnético $\hat{B}_{0}(t)$ externo é dado por:

$$
\hat{\mathcal{H}}=-\hat{\mu}_{e} \cdot \hat{B}_{0} \quad \text { Equação }(2.3)
$$

Substituindo $\mu_{\mathrm{e}}$ pela expressão da Equação (2.2) temos:

$$
\hat{\mathcal{H}}=-\hat{\mu}_{e} \cdot \hat{B}_{0}=g \cdot \mu_{B} \cdot B \cdot S_{z} \quad \text { Equação }(2.4)
$$

A magnitude do momento de spin $\hat{S}$ é dada pela raiz quadrada dos autovalores de $S^{2}$, ou seja $[S(S+1)] 1 / 2$. Os autovalores para a projeção do momento de spin em alguma direção específica são os $\mathrm{M}_{\mathrm{S}}$ (no caso acima, na direção de $\mathrm{z}$ ), os valores permitidos variam em múltiplos inteiros de $-\mathrm{S}$ até $+\mathrm{S}$. Para um elétron livre, $\mathrm{S}=1 / 2$ e os valores de $\mathrm{M}_{\mathrm{S}}$ são $-1 / 2$ e $+1 / 2$. Existem, então, dois estados que são degenerados quando o campo $B_{0}$ for nulo, e cuja separação aumenta linearmente à medida que $\mathrm{B}_{0}$ aumenta, como mostrado na Figura 2.5. 


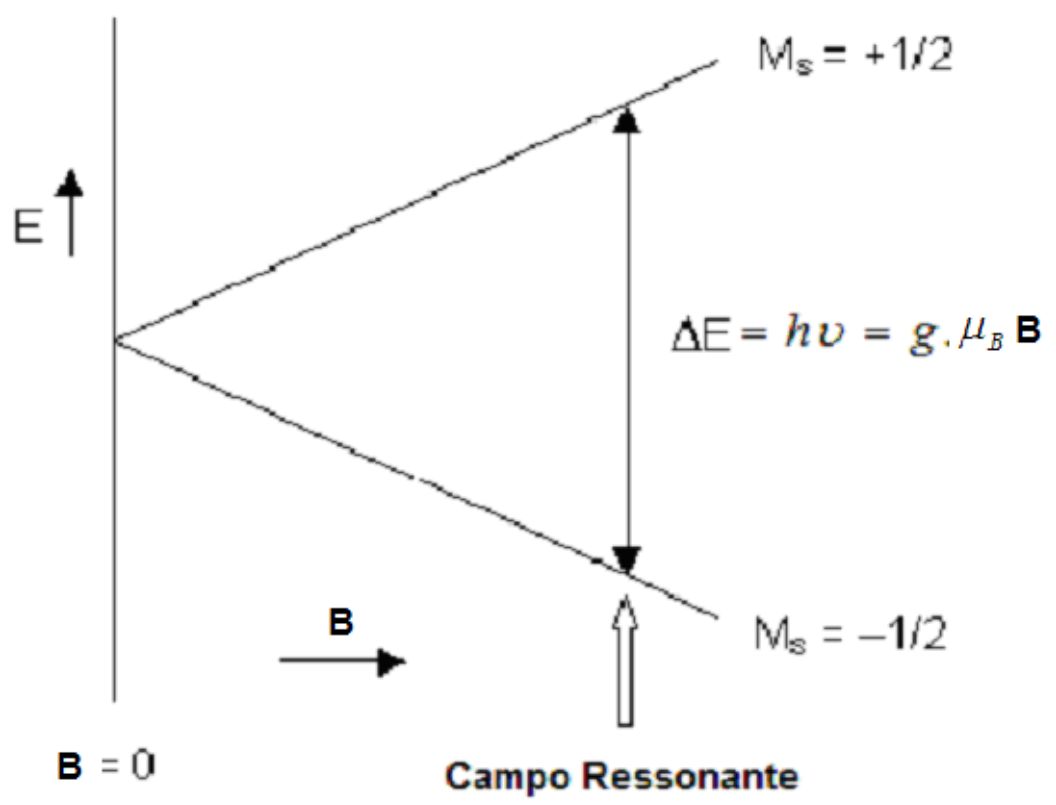

Figura 2.5. Diagrama de níveis de energia para o spin de um elétron livre em função de um campo magnético aplicado $B$.

Dessa forma o campo oscilante $\hat{B}_{1}(t)$ aplicado perpendicularmente a $\hat{B}_{0}(t)$, com frequiência que satisfaça a condição de ressonância, induz transições de maneira que passamos a ter absorção ou emissão de energia:

$$
\Delta E=h v=g \cdot \mu_{B} \cdot B \quad \text { Equação (2.5) }
$$

Para satisfazer a condição de ressonância existem diferentes bandas em que medidas de EPR são feitas. Como exemplo temos a banda $\mathrm{X}$ que opera na região de microondas do espectro eletromagnético, com freqüência em torno de 9,5 GHz; outro exemplo é a banda Q, que usa freqüência da ordem de $35 \mathrm{GHz}$.

O espectrômetro usado tanto nas medidas no Brasil quanto nos Estados Unidos foi um espectrômetro de EPR modelo Bruker ELEXSYS E580 FT/CW. Na Figura 2.6. temos o esquema geral de um espectrômetro de EPR Bruker e na Figura 2.7., mais detalhadamente, a ponte de microondas. 


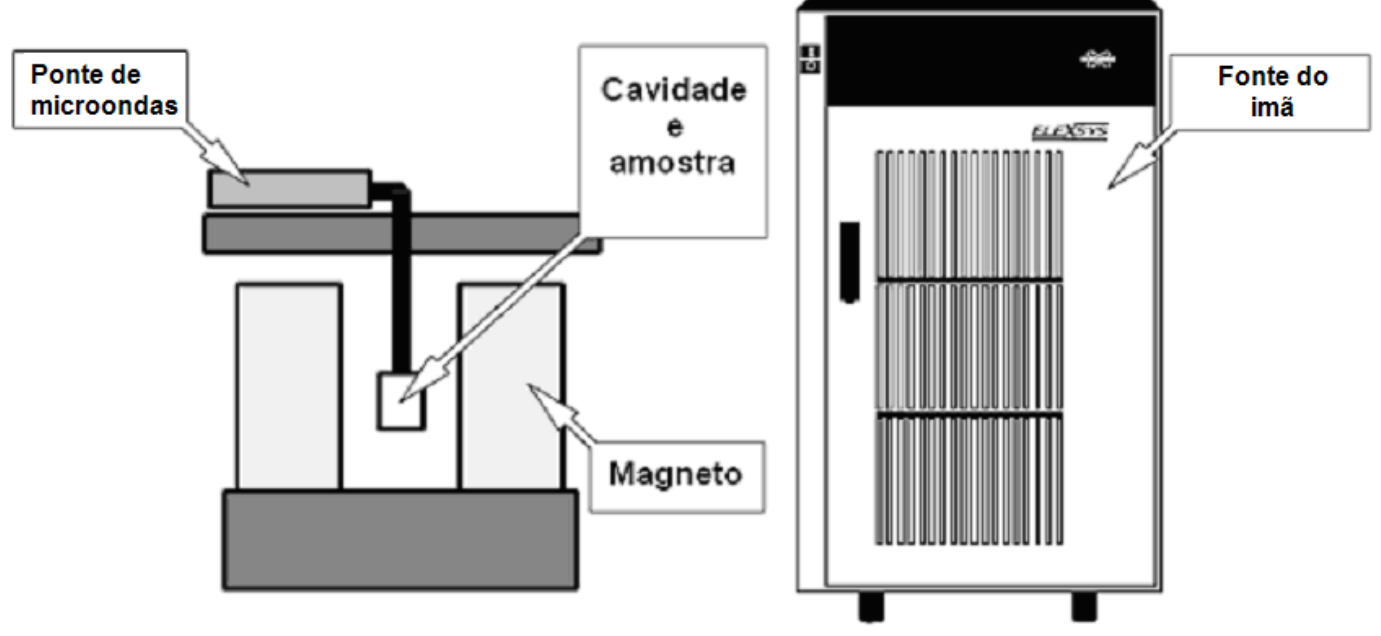

Figura 2.6. Esquema geral de um espectrômetro de EPR Bruker ELEXSYS E580 FT/CW.

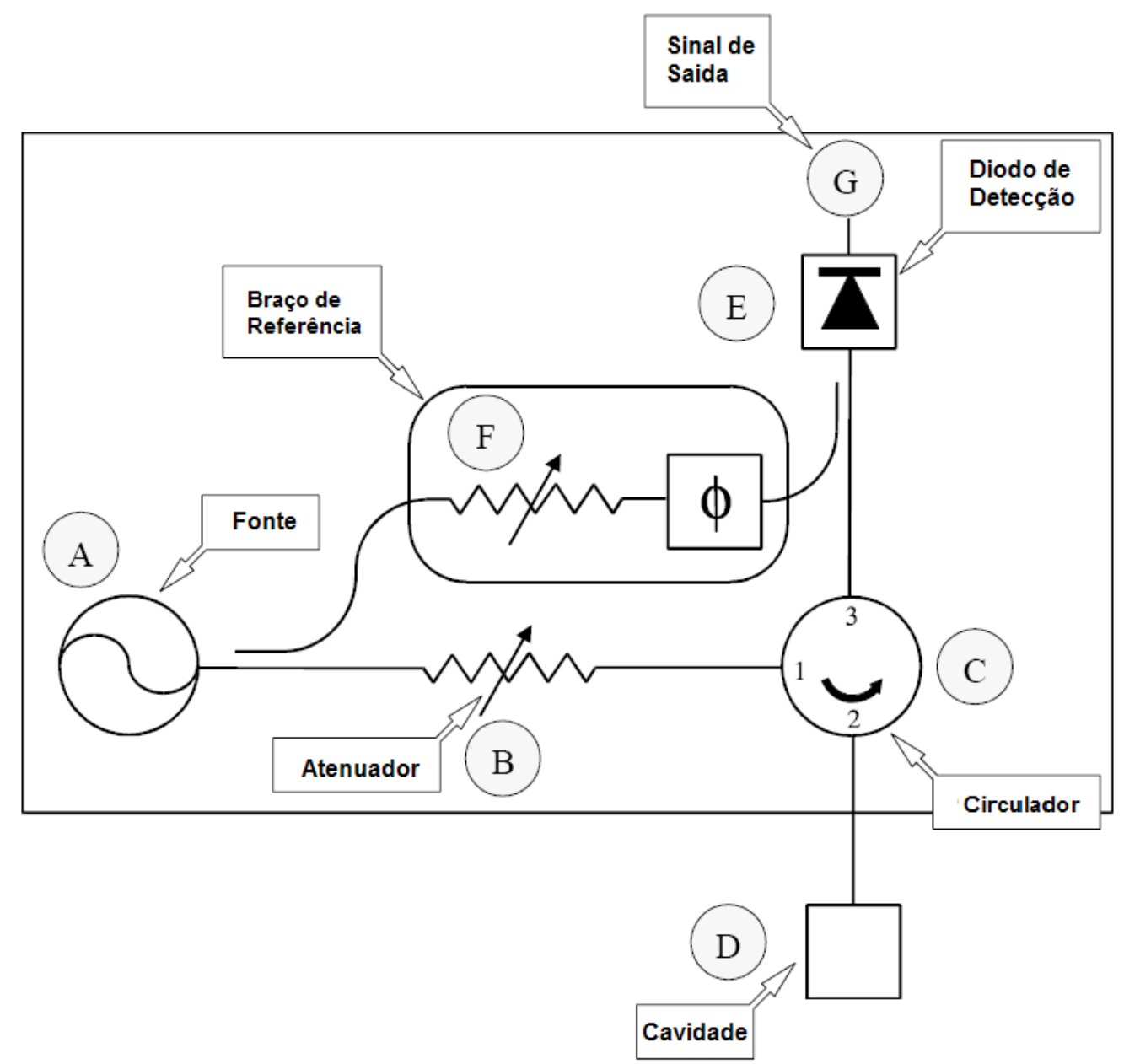

Figura 2.7. Diagrama da ponte de microondas. 
O campo magnético $\mathrm{B}$ é produzido pela corrente elétrica nas bobinas (no magneto). $\mathrm{O}$ controle da estabilidade do campo divide-se em duas partes: microprocessador encarregado em verificar a voltagem enviada em cada passo do campo (4096 passos, no máximo); e um controlador de efeito Hall entre as bobinas que envia informação ao microprocessador para controle da estabilidade.

A amostra é colocada em uma cavidade ressonante cujas dimensões casam com o comprimento de onda da radiação incidente de tal forma que esta entra em ressonância, gerando um padrão de ondas estacionárias. Ela pode ter uma forma retangular ou cilíndrica. A cavidade usada em nossas medidas (modelo ER 4102ST) é retangular e opera no modo $\mathrm{TE}_{102}$ com uma freqüência central de 9,8 GHz, com fator Q de qualidade de 6000.

A ponte de microondas abriga a fonte de microondas (um diodo Gumn) e o detector (Figura 2.7.). Seguindo o caminho que as microondas fazem da fonte até o detector começamos pelo ponto $\mathrm{A}$, a fonte de microondas. A potência de saída da fonte de microondas não pode ser variada facilmente, por isso, no ponto $\mathrm{B}$, temos um atenuador que controla precisamente a potência de microondas. Deseja-se que o detector (ponto G) receba apenas a radiação de microondas que volta da cavidade ressonante (ponto D) onde a amostra se encontra, para isso o circulador (ponto C) direciona as microondas incidentes (da fonte de microondas, que passa pelo braço de referência) na porta 1 apenas para a porta 2 (para a cavidade) e microondas vindo da cavidade apenas para a porta 3, ou seja, para o detector. Um diodo Schottky (ponto E) detecta a microonda que sai pela porta 3 do circulador e converte potência de microondas em corrente elétrica. Para medidas quantitativas da intensidade do sinal bem como otimização da sensibilidade, o diodo deve operar na região linear (potência acima de $1 \mathrm{~mW}$ ) que 
corresponde a uma corrente de $200 \mu \mathrm{A}$ (no detector). Para assegurar que o detector opere nessa faixa há um braço de referência (ponto F) que balanceia o sistema.

\subsubsection{Espectroscopia Óptica: FluoroLog-3.}

Espectroscopia de ultravioleta/visível (UV/VIS) usa luz no visível ou ultravioleta. Nessa região de energia moléculas passam por transições eletrônicas. Elétrons existem em diferentes níveis de energia dentro de um átomo. Esses níveis possuem, normalmente, energia bem definida e elétrons que se movem entre eles emitem ou absorvem fótons (luz). $\mathrm{O}$ comprimento de onda da luz é relacionado com sua energia, dessa forma adquirimos o espectro para a varredura no comprimento de onda.

Espectroscopia óptica pode ser de: absorção, excitação e emissão (ou fluorescência). Nesse trabalho foram feitas medidas de dois tipos: emissão e excitação.

Espectroscopia de absorção: luz atravessa uma amostra. Se o comprimento de luz incidente corresponder a diferença de energia entre dois níveis de energia dos átomos, então uma porção dos fótons será absorvida. A relação entre a concentração de átomos, o caminho óptico na amostra e a porção de luz que é absorvida são dados pela lei de Lambert-Beer [17].

Para se obter o espectro de emissão, em geral, costuma-se escolher como comprimento de onda para a excitação àquele coincidente com o máximo de absorção. Essa radiação irá levar a espécie a um certo estado eletrônico excitado. Posteriormente, a espécie vai dissipar parte desta energia até atingir o primeiro estado eletrônico excitado e a seguir a amostra poderá emitir em uma faixa de comprimentos de onda. O espectro de emissão se constitui em um 
registro das intensidades de emissão nos diversos comprimentos de onda da banda de emissão, em um comprimento de onda fixo de excitação.

Podemos registrar emissões que ocorram num comprimento de onda fixo, geralmente aquele que a amostra emitir com maior intensidade, enquanto varia-se o comprimento de onda de excitação sobre toda a faixa do seu espectro de absorção. Embora em ambos os casos o registro seja o de emissões por fluorescência, convenciona-se chamar espectro de fluorescência apenas ao primeiro, denominando-se espectro de excitação ao segundo. Este deve, portanto, apresentar picos nos mesmos comprimentos de onda do espectro de absorção e, além disto, ter forma semelhante a este último.

O aparelho usado nesse trabalho para medidas de espectroscopia UV/Vis foi o FluoroLog-3. Essas medidas foram feitas no LDR (Stillwater, EUA). Este mede a intensidade de luz que passa pela amostra (I) e compara com a intensidade de luz da fonte $\left(\mathrm{I}_{0}\right)$. A razão $\mathrm{I} / \mathrm{I}_{0}$ é chamada de transmitância.

A fonte de luz do equipamento consiste numa lâmpada de 450W de Xenônio num envelope de quartzo para comprimentos de onda no visível e ultravioleta.

Um esquema óptico do espectrômetro é mostrado na Figura 2.8. Luz emitida pela lâmpada de Xe é focada na entrada na fenda F1 após ser concentrada pelo espelho elipsoidal M1. Após passar pela fenda F1 a luz é refletida pelo espelho M2 até a rede de excitação G1 (monocromador automático de excitação de feixe simples) de onde é dispersa através da fenda de saída F2. A luz de excitação é focada, então, na amostra em A pelas lentes L1 e L2. Parte da luz de excitação é refletida por BS para uma fotomultiplicadora de referência (PM1). Sinal emitido da amostra é coletado pelas lentes L3 e L4, passando então pela fenda F3 para ser 
disperso pela rede em G2 (monocromador automático de emissão de feixe simples). A luz dispersa passa pela fenda F4 para chegar a fotomultiplicadora PM2.

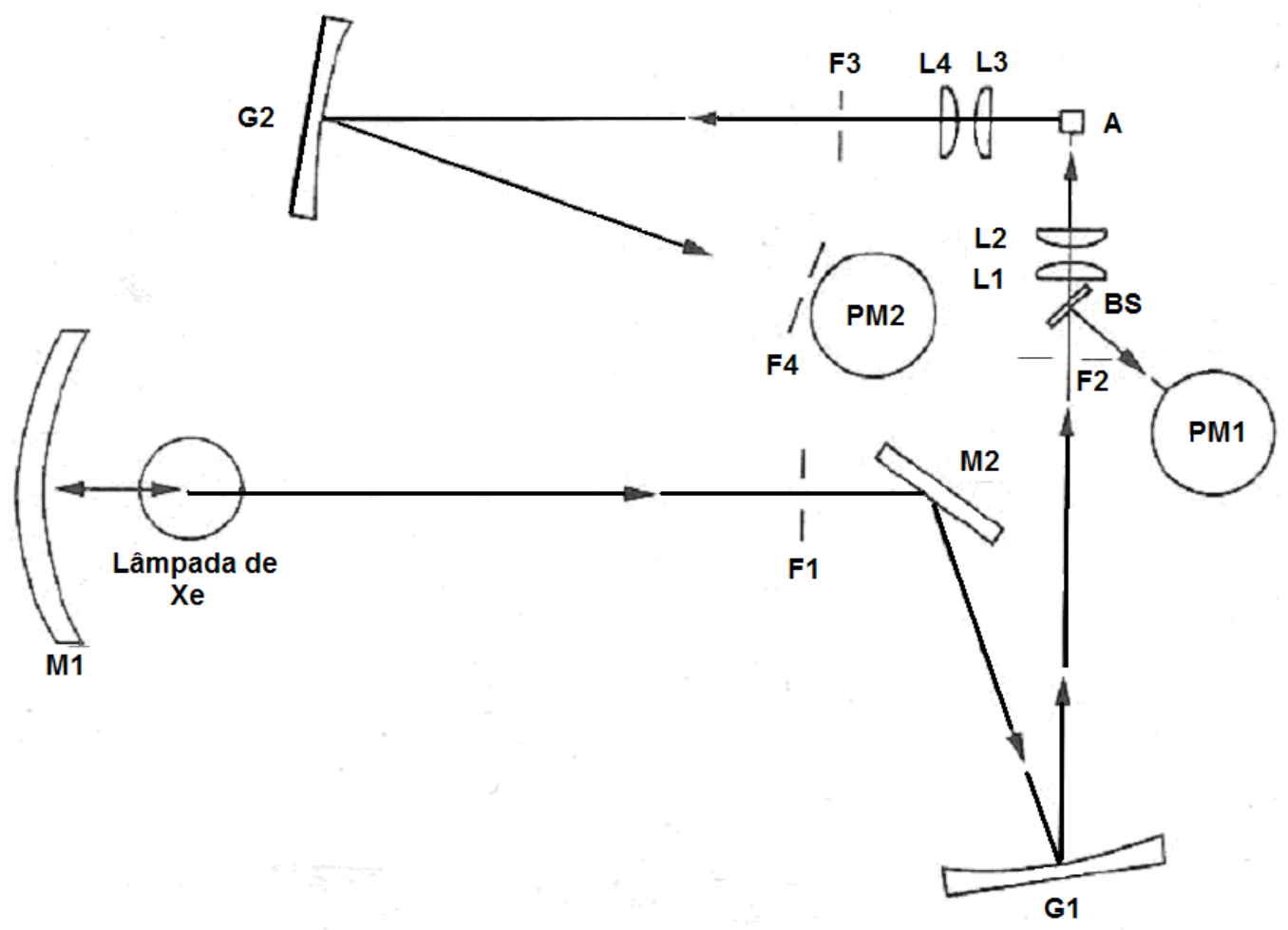

Figura 2.8. Esquema óptico do FluoroLog ${ }^{\circledR}-3$. 


\section{RESULTADOS I: MODELO DE CERTIFICAÇÃO DE DOSIMETRIA INDIVIDUAL EXTERNA NO BRASIL.}

Nos últimos anos a luminescência opticamente estimulada tornou-se extensivamente utilizada em dosimetria, devido aos bons resultados obtidos usando $\mathrm{Al}_{2} \mathrm{O}_{3}: \mathrm{C}$ como material dosimétrico.

No Brasil, a Comissão Nacional de Energia Nuclear - CNEN [18] - é responsável pelo processo de certificação dos serviços de dosimetria. O primeiro processo de certificação nessa área ocorreu em 1996 para os laboratórios de dosimetria e mais recentemente foi estendido para laboratórios de calibração. Os testes são baseados em uma extensa regulamentação que atinge aspectos de: 1) organização geral do laboratório, 2) recursos humanos, 3) instalações, 4) garantia de qualidade do processo, 5) tipo de suporte para o detector, 6) tipo de detector, 7) avaliação do dosímetros e 8) avaliação dos equipamentos de leitura.

Os itens 1 a 4 são de caráter organizacional e de estabelecimento de controles, e podem ser entendidos como independentes da tecnologia utilizada para a realização da dosimetria. Contudo os itens 5 a 8 foram especificados no regulamento técnico IRD- RT N. 002.01.05 [IRD RT No.002.01/95 - Critérios Gerais para Certificação de um Serviço de monitoração Individual Externa para Dosimetria Fotográfica e Termoluminescente.

Não há, no Brasil, um processo aprovado pela CNEN para certificação de laboratório de dosimetria individual externa que faça a dosimetria com tecnologia OSL. A parte formal da instituição pode e deve seguir os padrões ISO 17.025 de regulamentação, mas a parte técnica requer controles e padrões específicos.

Esse tipo de documentação segue os padrões internacionais, estabelecidos pela Agência Internacional de Energia Atômica [19] (IAEA) através de órgãos relacionados com proteção 
radiológica - ICRP [20] (Comissão Internacional de Proteção Radiológica) - e padronização de unidades e medidas - ICRU (Comissão Internacional de Unidades e Medidas em Radiação) [21].

Neste trabalho fazemos uma proposta de modelo de certificação de dosimetria OSL no Brasil apresentando uma matriz de correlação (apresentado no Apêndice A) entre certificação de dosimetria com filme, dosimetria termoluminescente e dosimetria fotoluminescente. Foram feitas algumas das medidas propostas para os testes de desempenho, apresentadas a seguir nos itens 3.2.1., 3.2.2. e 3.2.3.

\subsection{O Dosímetro, o Leitor e o Porta Dosímetro.}

Os testes são divididos em: testes do leitor, testes do dosímetro e testes do porta dosímetro.

O leitor usado para os testes foi o Manual Inlight ${ }^{\circledR}$ Reader (descrito no Capítulo 2, item 4.1.), desenvolvido para aquisição de sinal luminescente e para calcular doses para uso em dosimetria individual externa. O estimulo usado é o OSL pulsado e as doses calculadas são a Dose Profunda, Dose Rasa e Dose de Cristalino. Os testes de desempenho, apresentados nesse trabalho, possuem resultados usando apenas Dose Profunda, pois obtivemos resultados com igual qualidade para todos os tipos de dose calculada. Nossa proposta de uso de OSL em dosimetria individual externa no Brasil será encaminhada a CNEN com testes de desempenho para os três tipos de doses.

O porta dosímetro usado foi o Panasonic ${ }^{\circledR}$ (descrito no Capitulo 2 item 3.2) e o dosímetro usado foi o Inlight ${ }^{\circledR}$ (descrito no Capitulo 2, item 3.2). 
As irradiações foram feitas usando uma fonte de ${ }^{60} \mathrm{Co}$ e a limpeza do sinal luminescente foi feita expondo os detectores por 12 horas sob quatro lâmpadas fluorescentes de 40 W montadas paralelamente em uma única luminária, a uma distância de 10 centímetros dos detectores.

Os testes foram feitos usando estatística $t$ de Student, uma breve explicação da estatística e outros detalhes matemáticos usados para avaliação dos testes são dadas no Apêndice B.

\subsection{Resultados e Discussão}

\subsubsection{Testes de Desempenho do Leitor}

a) Reprodutibilidade da Luz de Referência.

O teste de Luz de Referência é feito pelo leitor a cada dez leituras (o número de leituras antes de cada teste de referência pode ser modificado, de acordo com configuração feita pelo usuário) e consiste na medida realizada pela fotomultiplicadora em resposta a uma amostra radioluminescente de Carbono 14 (padrão de referência). A amostra de Carbono 14 fica constantemente dentro do leitor e contém uma pequena quantidade de ${ }^{14} \mathrm{C}$ misturada com fósforo. A emissão dessa amostra independe de temperatura ou umidade, o que permite a medida da estabilidade da fotomultiplicadora.

Foram feitas vinte leituras consecutivas da Luz de Referência do leitor e então foi calculado seu coeficiente de variação V, dado pela Equação 3.1.

$$
V=\frac{s}{\bar{x}}=\frac{1}{\bar{x}} \sqrt{\frac{1}{n-1} \sum_{i=1}^{n}\left(x_{i}-\bar{x}\right)^{2}} \text { Equação (3.1) }
$$


Sendo $\bar{x}$ a média das vinte medidas e $\mathrm{S}$ o desvio padrão da média.

De acordo com os padrões de desempenho estabelecidos o coeficiente de variação deve ser da forma: $V \leq 0,01$.

A contagem da fotomultiplicadora por número de medida realizado pelo leitor é mostrada na Figura 3.1.

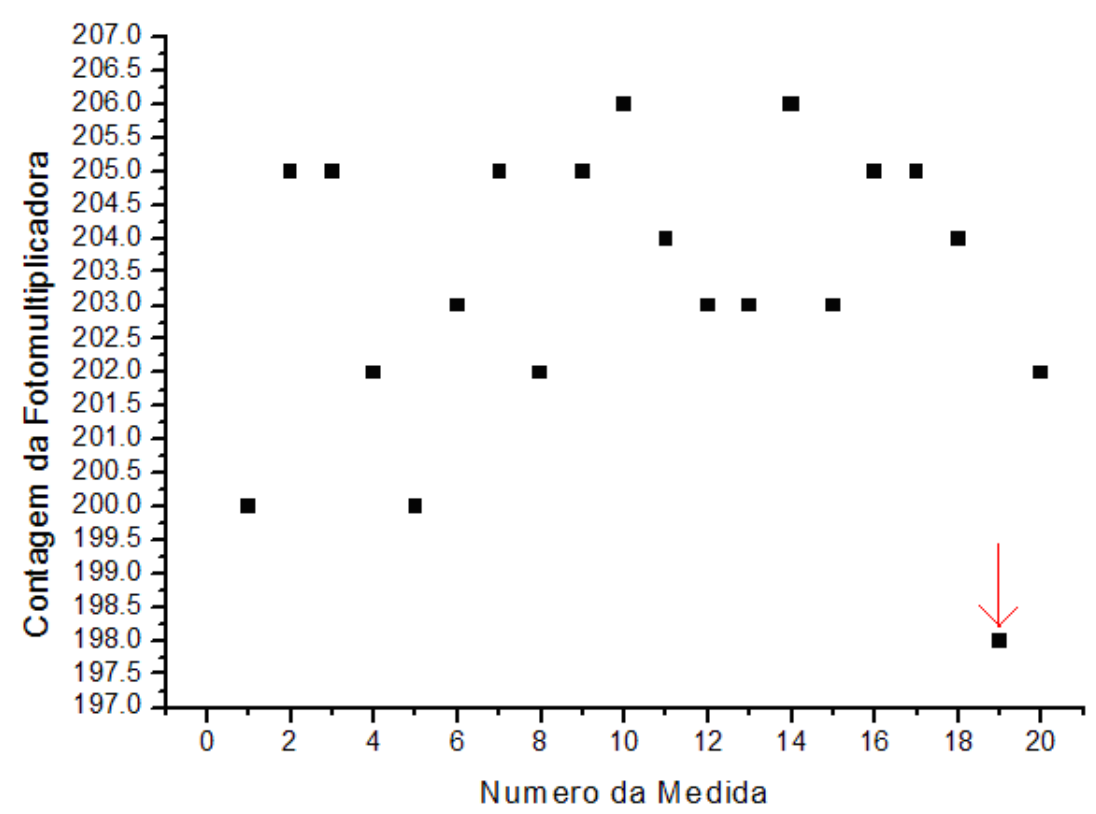

Figura 3.1. Contagem de fundo de fotomultiplicadora por leitura.

O valor médio e desvio padrão das vinte medidas é $203,3 \pm 2,1$, que resulta em um coeficiente de variação de $V=0,0106$, um valor um pouco acima do desejado ( $V \leq 0,01)$. Excluindo do gráfico o ponto de número 19 (mostrado pela seta em vermelho), temos média e desvio padrão de 203,6 \pm 1,8, com coeficiente de variação de $V=0,0086$.

Esse resultado demonstra que durante as 20 leituras o leitor se manteve estável em relação à Luz de Referência. 
b) Estabilidade do Leitor

Um grupo com doze dosímetros foi irradiado com 10 mGy, lido e limpo. As medidas foram feitas da seguinte forma:

- A primeira leitura foi feita após a primeira irradiação (denominado de Leitura 1);

- A segunda leitura foi feita após limpeza do sinal, irradiação e espera de $24 \mathrm{~h}$ após a irradiação (denominado de Leitura 2);

- A terceira leitura foi feita após limpeza do sinal, irradiação e espera de 168h após a irradiação (denominado de Leitura 3).

Para avaliar a estabilidade do leitor determina-se valor de leitura "A" para cada dosímetro, calculando em seguida a média $\bar{A}_{i}(\mathrm{i}=1,2$ e 3$)$, e os desvios padrão $\mathrm{S}_{\mathrm{i}}$ para cada média.

As médias para cada leitura devem estar de maneira que:

$$
\begin{aligned}
& 0,95 \leq \frac{\bar{A}_{2}}{\bar{A}_{1}} \pm I \leq 1,05 \text { Equação (3.2) } \\
& 0,90 \leq \frac{\overline{A_{3}}}{\bar{A}_{1}} \pm I \leq 1,10 \text { Equação (3.3) }
\end{aligned}
$$

Onde I é o intervalo de confiança da razão das médias e é calculado de acordo com o Apêndice B.

Na Figura 3.2. temos o gráfico com as medidas normalizadas de cada leitura pela Leitura 1, de maneira que podemos verificar se houve uma mudança nas medidas devido a instabilidade do leitor. No mesmo gráfico há a média, o desvio padrão e I de cada grupo. 


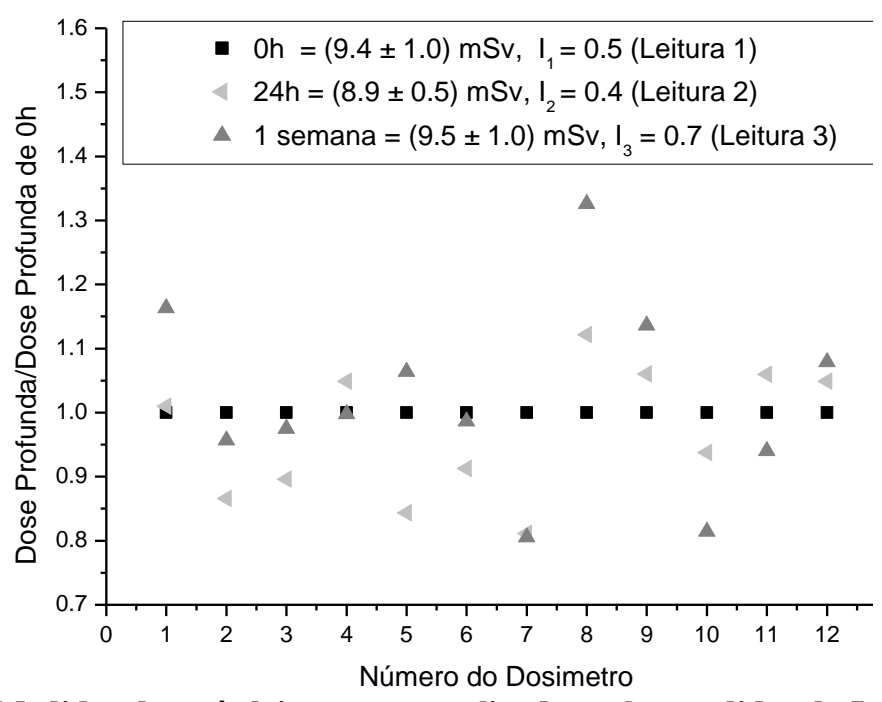

Figura 3.2. Medidas das três leituras, normalizadas pelas medidas da Leitura 1.

O cálculo de $\frac{\bar{A}_{i}}{\bar{A}_{1}} \pm I$ para os grupos 1 e 2 resultou em 1,02 para o limite superior e 0,95 para o limite inferior; e para os grupos 1 e 3 em 1,10 para o limite superior e 0,92 para o limite inferior. Dessa maneira mostramos que os resultados calculados estão dentro dos limites esperados para o teste de Estabilidade do Leitor.

c) Efeito das Condições Climáticas.

Três grupos com doze dosímetros OSL foram separados e irradiados com 10 mGy. Cada grupo foi lido da seguinte forma:

- Grupo 1: leitor sob condições normais de operação (denominado CN*);

- Grupo 2: leitor em um ambiente a $35^{\circ} \mathrm{C}$ (denominado “ $35^{\circ} \mathrm{C}$ ”);

- Grupo 3: leitor em um ambiente a $20^{\circ} \mathrm{C}$ (denominado “ $20^{\circ} \mathrm{C}$ ”).

O valor avaliado A para cada dosímetro foi calculado, junto da média $\bar{A}_{i}(\mathrm{i}=1,2$ e 3 ) e o desvio padrão para cada média. 
As médias para cada leitura devem estar de maneira que:

$$
0,90 \leq \frac{\overline{A_{i}}}{\bar{A}_{1}} \pm I \leq 1,10 \text { Equação (3.4) }
$$

Onde I é o intervalo de confiança da razão das médias e é calculado de acordo com o Apêndice B.

As doses medidas para cada dosímetro de cada grupo são apresentadas a seguir na Figura 3.3:

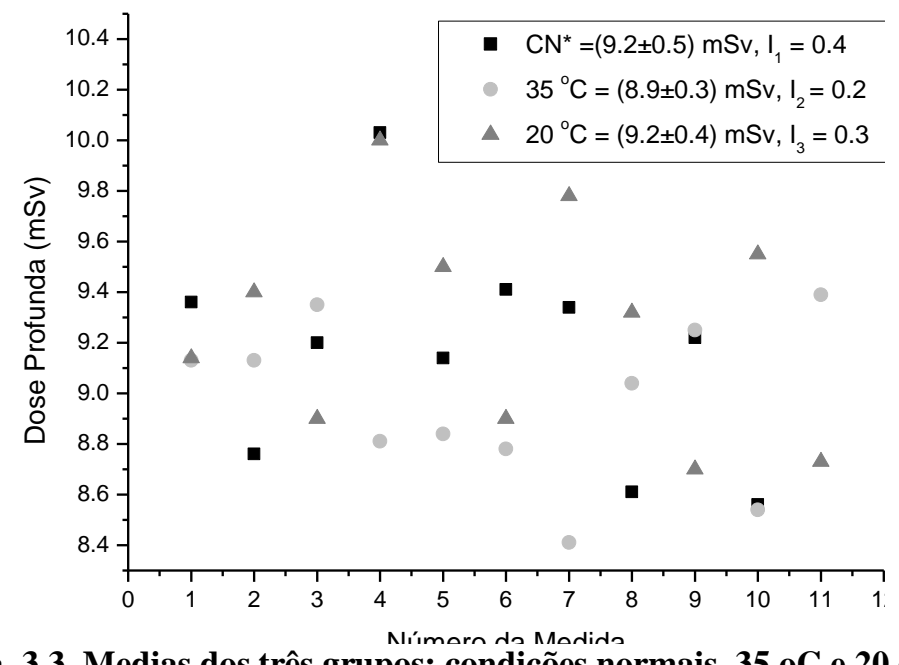

Figura 3.3. Medias dos três grupos: condições normais, 35 oC e 20 oC.

$* \mathrm{CN}=$ Condições Normais

O cálculo de $\frac{\bar{A}_{i}}{\bar{A}_{1}} \pm I$ para os grupos 1 e 2 resultou em 1,02 para o limite superior e 0,95 para o limite inferior; e para os grupos 1 e 3 em 1,10 para o limite superior e 0,92 para o limite inferior.

Dessa forma mostramos que nossas medidas estão dentro dos limites esperados para o teste de Condições Climáticas do Leitor. 


\subsubsection{Teste de Desempenho do Porta Dosímetro.}

a) Efeito de Exposição à Luz

Dois grupos com vinte dosímetros cada foram preparados. Metade de cada grupo (10 dosímetros) foi irradiada com 10 mGy e a outra metade foi limpa.

Um dos grupos, denominado de Grupo 1, foi exposto por 24 horas a quatro lâmpadas fluorescentes de $40 \mathrm{~W}$ montadas paralelamente em uma única luminária, a uma distância de 1 metro, durante (a temperatura dos dosímetros foram mantidas menores que $40^{\circ} \mathrm{C}$ ). $\mathrm{O}$ outro grupo, denominado de Grupo 2, foi deixado em um ambiente escuro, com as demais condições ambientais inalteradas (temperatura dos dosímetros do Grupo 1 não mudou mais de 5\% em relação ao Grupo 2). Após uma semana todos os dosímetros foram medidos. Calculamos o valor avaliado A para cada dosímetro OSL, a média $\bar{A}_{i}(\mathrm{i}=1,2)$ e o desvio padrão $S_{\mathrm{i}}$ das médias.

As médias para as leituras dos dosímetros irradiados com 10 mGy devem satisfazer a equação 3.5:

$$
0,90 \leq \frac{\bar{A}_{2}}{\bar{A}_{1}} \pm I \leq 1,10 \quad \text { Equação (3.5) }
$$

Onde I é o intervalo de confiança para a razão das médias e é calculado de acordo com o Apêndice B.

As médias para as leituras dos dosímetros não irradiados devem estar de maneira que:

$$
\left|\bar{A}_{1}-\bar{A}_{2}\right|+I \leq 0,20 m G y \quad \text { Equação (3.6) }
$$


Onde I é o intervalo de confiança para o módulo da diferença das médias e é calculado de acordo com o Apêndice B.

Para mostrar que não há variação de dose devido a exposição à luz foi feito um gráfico das doses dos dosímetros expostos à luz normalizada pelas doses dos dosímetros não expostos à luz, na Figura 3.4.

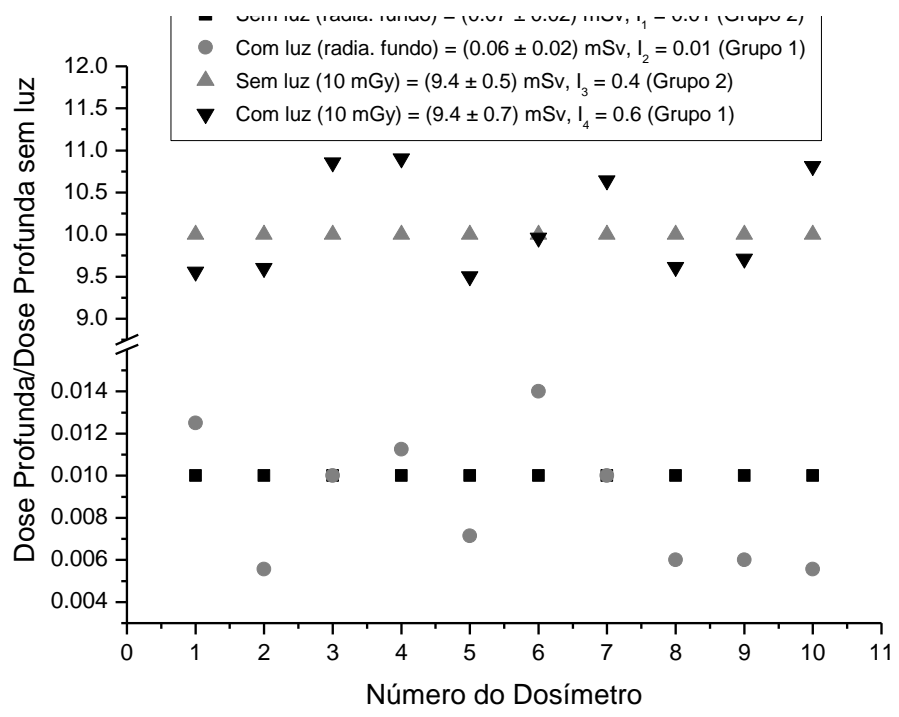

Figura 3.4. Distribuição de medidas normalizadas pelas medidas sem exposição à luz.

O cálculo de $\frac{\bar{A}_{2}}{\bar{A}_{1}} \pm I$ para os dosímetros irradiados resultou em 1,02 para o limite superior e 0,96 para o limite inferior; e o cálculo de $\left|\bar{A}_{1}-\bar{A}_{2}\right|+I$ para os dosímetros não irradiados resultou em 0,1 mGy. Dessa forma mostramos que nosso teste de desempenho para Efeitos de Exposição à Luz está dentro do esperado. 


\subsubsection{Teste de Desempenho do Dosímetro.}

a) Homogeneidade do Lote.

Dois grupos com 25 dosímetros cada foram irradiados com 2 (denominado "homo_2") e 10 mGy (denominado "homo_10") e medidos. Então foi calculada a média $\bar{A}_{i}(i=1,2)$, os desvios padrões $\mathrm{S}_{\mathrm{i}}$ para cada média e o desvio máximo relativo dos valores avaliados. $\mathrm{O}$ desvio máximo relativo é dado por:

$$
\frac{A_{\max }-A_{\min }}{A_{\min }} \leq 0,3 \text { Equação (3.7), }
$$

sendo $\mathrm{A}_{\max }$ a $\mathrm{A}_{\min }$ as doses de maior e menos valor medidas.

O valor avaliado A para qualquer dosímetro não pode diferir de outro valor avaliado em mais de $30 \%$, segundo as normas para teste de desempenho para homogeneidade do lote.

As medidas para cada dosímetro, os limites esperados, as médias e o desvio padrão de cada média de cada grupo são apresentados na Figura 3.5. abaixo.

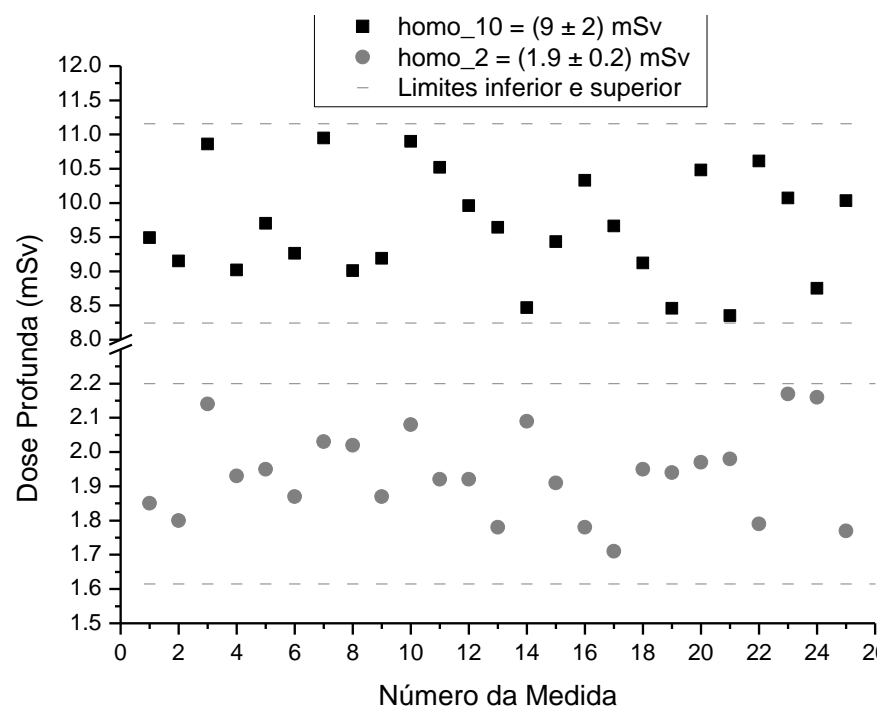

Figura 3.5. Distribuição de medidas e limites. 
Todas as medidas estão dentro dos limites esperados para teste de desempenho de homogeneidade para duas irradiações (2 e 10 mGy).

b) Reprodutibilidade.

Um grupo com 15 dosímetros foi irradiado com 10 mGy, medido e limpo dez vezes. Para cada dosímetro temos $\mathrm{A}_{\mathrm{ij}}$, em que i se refere a i-ésima irradiação e j ao j-ésimo dosímetro.

Para cada um dos dosímetros OSL (medidos 10 vezes), calculamos o valor médio $\bar{A}_{j}$ e o desvio padrão $S_{j}$.

Segundo as normas do teste de desempenho para reprodutibilidade, as avaliações devem se comportar de maneira que:

$$
\frac{S_{j}+I_{j}}{\bar{A}_{j}} \leq 0,075 \text { Equação (3.8) }
$$

Onde $\mathrm{I}_{\mathrm{j}}$ é o intervalo de confiança de $\mathrm{S}_{\mathrm{j}}$ e é calculado de acordo com o Apêndice B.

As medidas para cada teste de reprodutibilidade são mostradas na Tabela 3.1 abaixo: 


\begin{tabular}{|c|c|c|c|c|c|c|c|c|c|c|}
\hline \multicolumn{11}{|c|}{ Dose Profunda (mSv) } \\
\hline dosímetro & repro & $\underline{\text { repor1 }}$ & repro2 & repro3 & repro4 & $\underline{\text { repro5 }}$ & repro6 & $\underline{\text { repro7 }}$ & $\underline{\text { repro8 }}$ & repro9 \\
\hline 1 & 10,09 & 9,51 & 9,92 & 9,11 & 9,54 & 9,14 & 9,48 & 8,23 & 9,51 & 9,51 \\
\hline 2 & 9,35 & 9,75 & 9,44 & 9,86 & 9,56 & 9,57 & 9,97 & 9,27 & 9,66 & 8,92 \\
\hline 3 & 9,65 & 9,51 & 9,81 & 9,56 & 9,59 & 9,35 & 9,03 & 9,77 & 8,65 & 8,92 \\
\hline 4 & 9,52 & 9,44 & 10,06 & 9,87 & 9,99 & 9,46 & 9,59 & 9,36 & 9,29 & 8,77 \\
\hline 5 & 10,05 & 9,75 & 9,09 & 9,28 & 9,84 & 9,69 & 9,17 & 9,90 & 9,79 & 9,85 \\
\hline 6 & 10,09 & 9,89 & 9,60 & 9,22 & 9,52 & 9,55 & 9,83 & 9,82 & 8,52 & 8,09 \\
\hline 7 & 9,27 & 9,59 & 9,38 & 9,45 & 9,04 & 9,13 & 9,91 & 9,02 & 8,44 & 9,51 \\
\hline 8 & 9,92 & 9,38 & 9,94 & 9,71 & 9,91 & 9,45 & 9,19 & 9,37 & 9,93 & 9,21 \\
\hline 9 & 10,00 & 9,26 & 9,48 & 9,67 & 9,37 & 9,11 & 9,72 & 9,65 & 8,72 & 9,03 \\
\hline 10 & 10,07 & 9,97 & 9,84 & 8,44 & 9,03 & 8,71 & 9,24 & 9,44 & 9,56 & 8,50 \\
\hline 11 & 9,80 & 9,17 & 10,00 & 9,23 & 9,02 & 9,20 & 9,77 & 9,35 & 9,04 & 9,46 \\
\hline 12 & 9,91 & 9,17 & 9,72 & 9,31 & 9,30 & 8,21 & 9,21 & 9,15 & 9,13 & 8,13 \\
\hline 13 & 9,89 & 8,64 & 9,73 & 9,93 & 9,29 & 8,60 & 9,95 & 8,91 & 9,20 & 9,26 \\
\hline 14 & 9,76 & 9,38 & 9,87 & 8,87 & 9,48 & 9,25 & 9,79 & 9,99 & 8,59 & 9,79 \\
\hline 15 & 9,91 & 9,69 & 10,05 & 10,11 & 8,03 & 9,00 & 8,57 & 9,17 & 8,68 & 9,02 \\
\hline
\end{tabular}

Tabela 3.1. Doses medidas para teste de Reprodutibilidade.

Os cálculos da média, do desvio padrão da média, do I do desvio e de $\frac{S_{j}+I_{j}}{\bar{A}_{j}}$ (denominado de

"Resultado") são mostrados na Tabela 3.2. abaixo para cada rotina de reprodutibilidade:

\begin{tabular}{|ccccccccccc|}
\hline repro & repor1 & $\underline{\text { repro2 }}$ & $\underline{\text { repro3 }}$ & $\underline{\text { repro4 }}$ & $\underline{\text { repro5 }}$ & $\underline{\text { repro6 }}$ & $\underline{\text { repro7 }}$ & $\underline{\text { Repro8 }}$ & $\underline{\text { Repro9 }}$ \\
\hline Media & Media & Media & Media & Media & Media & Media & Media & Media & Media \\
\hline 9,8 & 9,5 & 9,7 & 9,4 & 9,4 & 9,2 & 9,5 & 9,4 & 9,1 & 9,1 \\
\hline Desvio & Desvio & Desvio & Desvio & Desvio & Desvio & Desvio & Desvio & Desvio & Desvio \\
\hline 0,3 & 0,3 & 0,3 & 0,4 & 0,5 & 0,4 & 0,4 & 0,4 & 0,5 & 0,5 \\
\hline I desvio & I desvio & I desvio & I desvio & I desvio & I desvio & I desvio & I desvio & I desvio & I desvio \\
\hline 0,15 & 0,19 & 0,17 & 0,15 & 0,16 & 0,12 & 0,12 & 0,15 & 0,17 & 0,12 \\
\hline Resultado & Resultado & Resultado & Resultado & Resultado & Resultado & Resultado & Resultado & Resultado & Resultado \\
\hline 0,069 & 0,075 & 0,069 & 0,071 & 0,066 & 0,072 & 0,057 & 0,061 & 0,071 & 0,072 \\
\hline
\end{tabular}

Tabela 3.2. Cálculo das médias, dos desvios padrões das médias, de I dos desvios e Resultado para as medidas para teste de Reprodutibilidade.

Um histograma com a distribuição dos pontos foi feito para melhor observação da distribuição dos valores medidos, mostrado na Figura 3.6. 


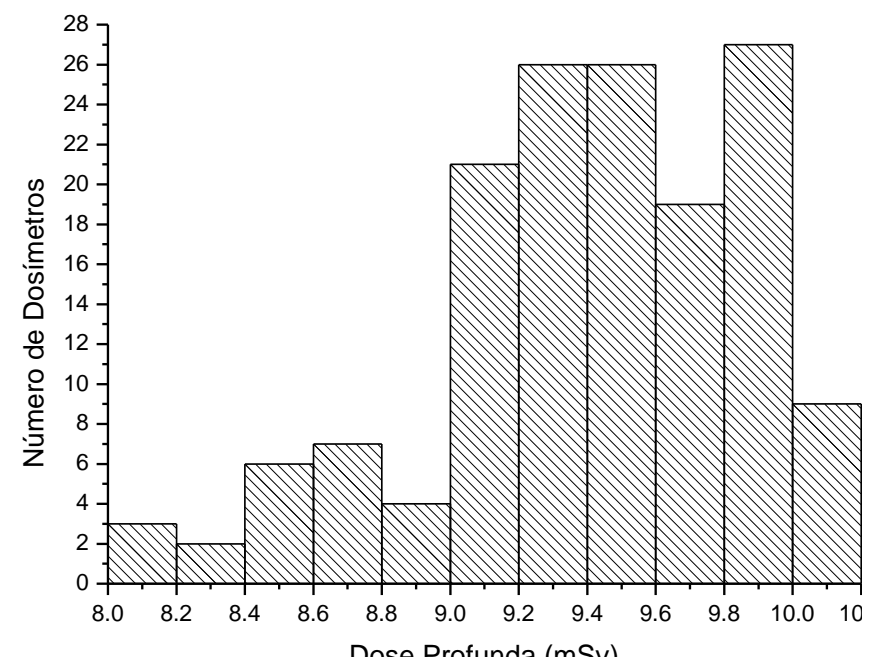

Figura 3.6. Histograma com distribuição de medidas para teste de Reprodutibilidade.

Em todas as medidas de reprodutibilidade vemos que o Resultado está abaixo ou igual ao limite superior desejado, de 0,075. Dessa forma mostramos que nossos testes estão de acordo com as normas para teste de desempenho de reprodutibilidade.

c) Releitura.

No teste de releitura um grupo com oito dosímetros foi irradiado com 10 mGy e lido dez vezes (sem limpeza, ou irradiação entre as leituras). Para cada dosímetro temos $\mathrm{A}_{\mathrm{ij}}$, em que $\mathrm{i}$ se refere a i-ésima irradiação e j ao j-ésimo dosímetro. Para cada uma das dez irradiações foi calculada a média $\bar{A}_{i}$ e o desvio padrão $\mathrm{S}_{\mathrm{i}}$.

Não existe norma para teste de desempenho para releitura em dosimetria usando filme fotográfico ou dosimetria termoluminescente. Contudo podemos aplicar as normas de teste de desempenho, já que para releitura esperamos observar um comportamento equivalente.

Dessa forma, segundo as normas do teste de desempenho para reprodutibilidade, as avaliações devem se comportar de maneira que: 


$$
\frac{S_{i}+I_{i}}{\bar{A}_{i}} \leq 0,075 \text { Equação (3.9) }
$$

Onde $\mathrm{I}_{\mathrm{i}}$ é o intervalo de confiança de $\mathrm{S}_{\mathrm{i}}$ e é calculado de acordo com o Apêndice B.

As medidas para cada teste de releitura (separados por dosímetro) são mostradas na tabela abaixo, bem como os cálculos da média, do desvio padrão da média, do I do desvio e de $\frac{S_{i}+I_{i}}{\bar{A}_{i}}$ (denominado de "Resultado") são mostrados na Tabela 3.3. abaixo para cada releitura:

\begin{tabular}{|c|c|c|c|c|c|c|c|c|}
\hline \multicolumn{9}{|c|}{ Dose Profunda (mSv) } \\
\hline Leitura & Dosímetro1 & Dosímetro2 & Dosímetro3 & Dosímetro4 & Dosímetro5 & Dosímetro6 & Dosímentro7 & Dosímentro8 \\
\hline 1 & 8,50 & 9,25 & 9,37 & 9,05 & 9,35 & 9,91 & 9,00 & 9,52 \\
\hline 2 & 8,10 & 9,77 & 9,71 & 9,00 & 10,09 & 9,37 & 9,38 & 9,58 \\
\hline 3 & 8,47 & 9,23 & 9,12 & 9,32 & 9,81 & 9,43 & 9,41 & 9,69 \\
\hline 4 & 8,95 & 9,46 & 9,78 & 9,71 & 9,75 & 9,08 & 9,91 & 9,56 \\
\hline 5 & 8,47 & 9,31 & 9,08 & 9,84 & 9,69 & 9,10 & 9,79 & 9,40 \\
\hline 6 & 8,76 & 9,28 & 9,35 & 9,48 & 9,25 & 9,79 & 9,02 & 9,06 \\
\hline 7 & 8,74 & 9,18 & 9,99 & 9,62 & 9,34 & 9,16 & 9,63 & 9,38 \\
\hline 8 & 8,78 & 9,16 & 9,86 & 9,83 & 9,75 & 9,93 & 9,12 & 9,34 \\
\hline 9 & 8,20 & 9,00 & 9,78 & 9,56 & 10,08 & 9,74 & 9,61 & 9,08 \\
\hline \multirow[t]{10}{*}{10} & 8,54 & 9,74 & 9,55 & 9,49 & 9,17 & 9,78 & 9,78 & 9,27 \\
\hline & Dosímetro1 & Dosímetro2 & Dosímetro3 & Dosímetro4 & Dosímetro5 & Dosímetro6 & Dosímentro7 & Dosímentro8 \\
\hline & Media & Media & Media & Media & Media & Media & Media & Media \\
\hline & 8,5 & 9,3 & 9,5 & 9,5 & 9,6 & 9,5 & 9,5 & 9,4 \\
\hline & Desvio & Desvio & Desvio & Desvio & Desvio & Desvio & Desvio & Desvio \\
\hline & 0,3 & 0,2 & 0,3 & 0,3 & 0,3 & 0,3 & 0,3 & 0,2 \\
\hline & I desvio & I desvio & I desvio & I desvio & I desvio & I desvio & I desvio & I desvio \\
\hline & 0,28 & 0,26 & 0,33 & 0,31 & 0,35 & 0,36 & 0,35 & 0,22 \\
\hline & Resultado & Resultado & Resultado & Resultado & Resultado & Resultado & Resultado & Resultado \\
\hline & 0,064 & 0,055 & 0,068 & 0,063 & 0,071 & 0,073 & 0,072 & 0,046 \\
\hline
\end{tabular}

Tabela 3.3. Doses medidas, cálculo das médias, dos desvios padrões das médias, de I dos desvios e Resultado para as medidas para teste de Releitura.

Para mostrar a variação da dose em função da releitura, um gráfico foi feito usando a média das leituras. Dessa forma se houvesse diminuição progressiva das doses por leitura, devido à 
perda de sinal, as médias apresentariam um decaimento também progressivo. No gráfico da Figura 3.7 podemos ver o comportamento das médias em função da Leitura.

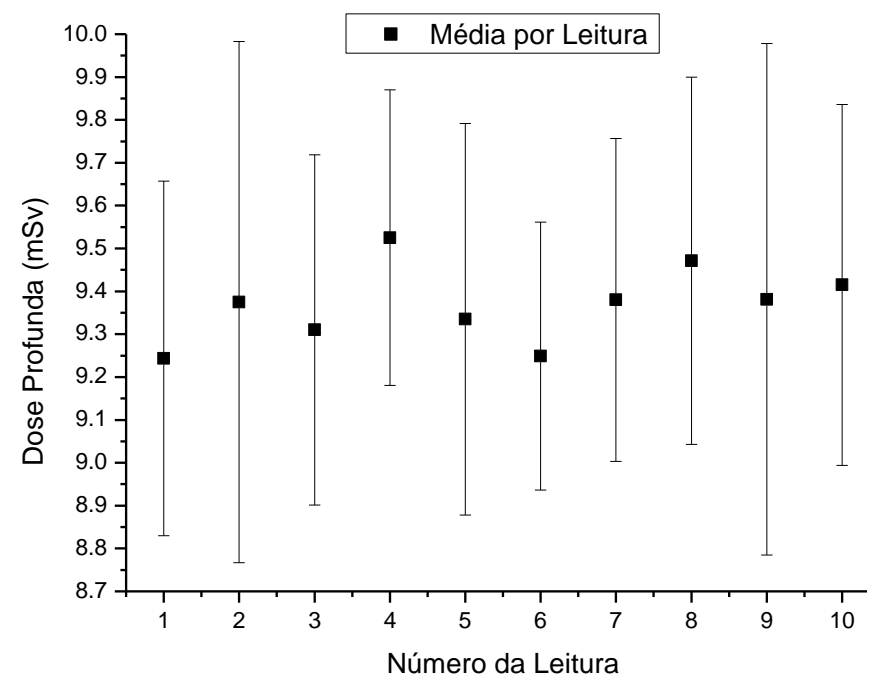

Figura 3.7. Média por medida para teste de Releitura.

Para as releituras por dosímetro vemos que o Resultado está abaixo ao limite superior desejado, de 0,075. E também vemos, pelo gráfico da Figura 3.7. que as médias não apresentam um decaimento progressivo, ou seja, não mostram perda de sinal por releitura. Dessa forma mostramos que nossos testes estão de acordo com as normas para teste de desempenho de Reprodutibilidade e que podemos aplicar esse teste para avaliação do teste de Releitura. 


\section{RESULTADOS II: ESPECTROSCOPIA DE EPR}

Na literatura [22, 23] o Óxido de Alumínio crescido em uma baixa pressão na presença de uma atmosfera de Carbono é dito um ótimo material para dosimetria opticamente estimulada por possuir uma grande quantidade de defeitos no cristal que aumentam o número de armadilhas de elétrons e buracos. Essas armadilhas recebem o nome de centros F (vacâncias de Oxigênio, com estado de carga $2^{-}$como mostrado no Capítulo 1, item 1.1.). Quando um elétron cai nessa armadilha temos então estado de carga $1^{-}$e a esse tipo de armadilha damos o nome de centros $\mathrm{F}^{+}$. Por possuírem um elétron desemparelhado os centros $\mathrm{F}^{+}$são paramagnéticos. Uma das propostas desse trabalho é a de correlacionar centros de luminescência (importante em dosimetria) e medidas de espectroscopia EPR.

O mesmo principio (defeitos cristalinos e centros luminescentes) observa-se em MgO:Tb, $\mathrm{MgO}: \mathrm{Tb}, \mathrm{Co}, \mathrm{CaO}: \mathrm{Tb}$ e $\mathrm{Li}_{2} \mathrm{O}: \mathrm{Tb}$, de maneira que também foram obtidos espectros de EPR para tentar observar os centros paramagnéticos criados devido a exposição dos materiais a radiação ionizante.

\subsection{Resultados e Discussão.}

Tanto monocristais quanto pós de $\mathrm{Al}_{2} \mathrm{O}_{3}: \mathrm{C}$ foram usados para aquisição de espectros de EPR em banda Q (35 GHz) e X (9,8 GHz), onda contínua e pulsada, temperatura ambiente e Hélio líquido, mas nem todas as medidas revelaram presença de centros paramagnéticos. Assim nesse trabalho apresentamos apenas resultados com alguma relevância física.

No caso dos óxidos dopados com Tb, só dispúnhamos de pó, e o aparelho usado no Instituto de Física da Universidade Estadual de Oklahoma (Stillwater, EUA) não possuía 
instrumentação para medidas a baixa temperatura. Então foram feitas medidas em banda $\mathrm{X}$ $(9.8 \mathrm{GHz})$ em temperatura ambiente, de onda continua. $\mathrm{O}$ mesmo aparelho foi usado para medidas em pó virgem de $\mathrm{Al}_{2} \mathrm{O}_{3}: \mathrm{C}$ (cedidas durante visita aos EUA) e conseqüentemente nossos espectros foram medidos nas mesmas condições.

\subsubsection{Monocristal de $\mathrm{Al}_{2} \mathrm{O}_{3}: \mathrm{C}$ Temperatura Ambiente.}

Os parâmetros usados para aquisição dos espectros de EPR foram: varredura de 8000 G, centrado em $4300 \mathrm{G}$, com $13 \mathrm{~dB}$, ganho de $10^{3}$ e tempo total de varredura de $5400 \mathrm{~s}$.

Os monocristais de $\mathrm{Al}_{2} \mathrm{O}_{3}: \mathrm{C}$ não sofreram tratamento químico ou térmico antes da aquisição dos espectros de EPR. Os cristais foram orientados e cortados no Grupo de Crescimento de Cristais do Instituto de Física de São Carlos (Universidade de São Paulo) de maneira que o eixo de simetria $C_{3}$ fosse perpendicular ao plano de corte $\vec{a} \vec{b}$ do cristal. As amostras dos cristais (descritas no Capítulo 2, item 1) foram medidas no espectrômetro de EPR do Grupo de Biofísica Molecular Sérgio Mascarenhas do Instituto de Física de São Carlos (Universidade de São Paulo), cujo modelo é descrito no Capitulo 2, item 6.1.

Os espectros dos cristais foram medidos perpendicularmente a três planos cristalinos diferentes, fazendo-se para cada plano variação angular de 5 graus por espectro medido (vide esquema do cristal na Figura 4.1.). Depois de medidos os cristais foram irradiados com tempos diferentes em Raios-X com energia de $70 \mathrm{kV}$ usando doses de 10, 20, 30, 40, 50, 60, 70, 80, 90 e 100 Gy, e medidos em espectroscopia de EPR para os mesmos planos. Nenhuma mudança foi observada entre cristais irradiados e não irradiados. 
Em todos os casos foram vistos sinais devido a $\mathrm{Cr}^{3+}$, esses sinais possuem grande variação angular, para todas as orientações. Na Figura 4.2 temos um espectro de EPR para um monocristal na orientação $\vec{b} \| \hat{B}$, e nas Figuras 4.3 e 4.4 variação angular desse cristal por orientação.

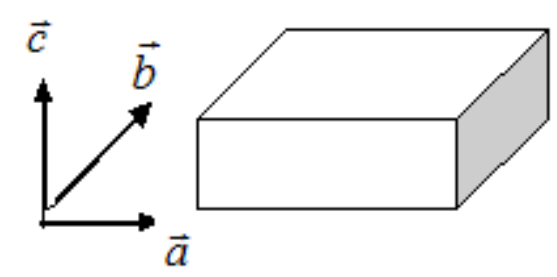

Figura 4.1. Orientações do cristal de $\mathrm{Al}_{2} \mathrm{O}_{3}$ :C.

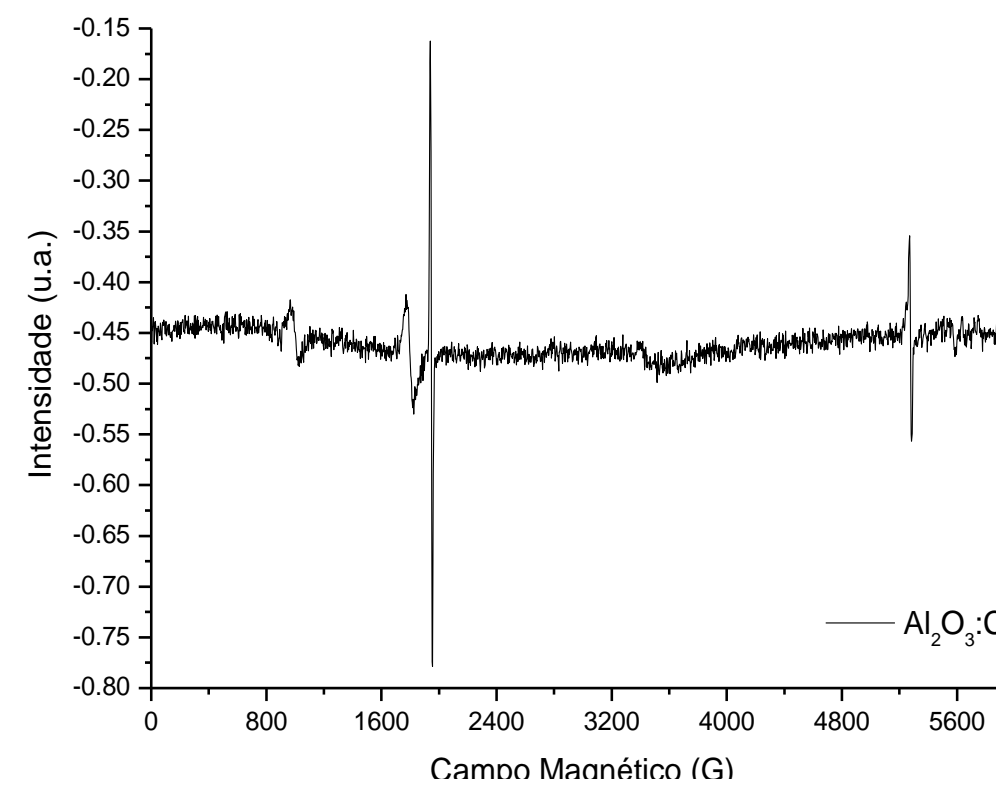

Figura 4.2. Espectro de EPR para monocristal de $\mathrm{Al}_{2} \mathrm{O}_{3}: \mathrm{C}$ no plano $\perp$ a $\vec{b}$. 


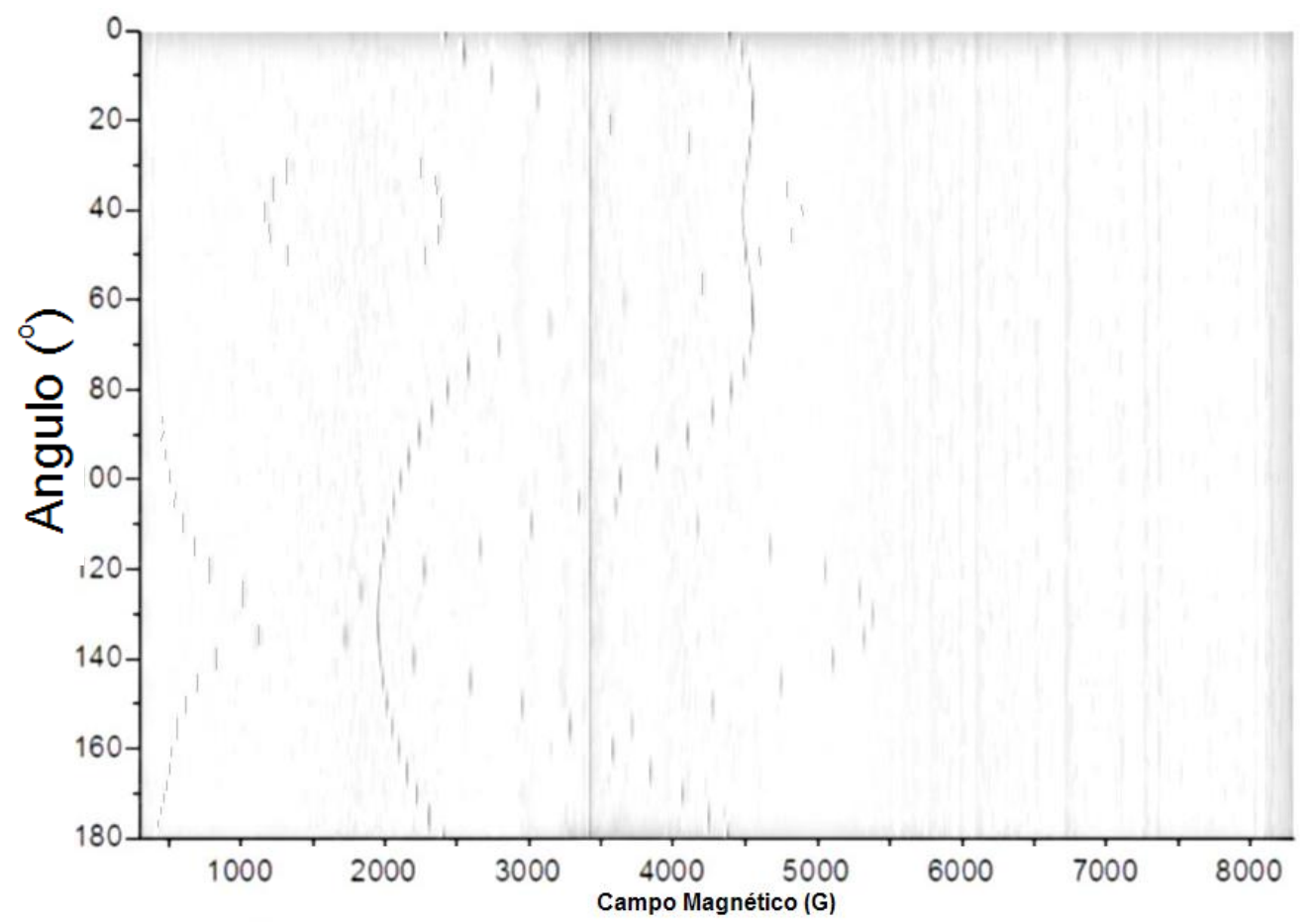

Figura 4.3. Variação angular dos sinais de $\mathrm{Cr}^{3+}$ para uma varredura de $8000 \mathrm{G}$ no plano $\perp$ a $\vec{c}$.

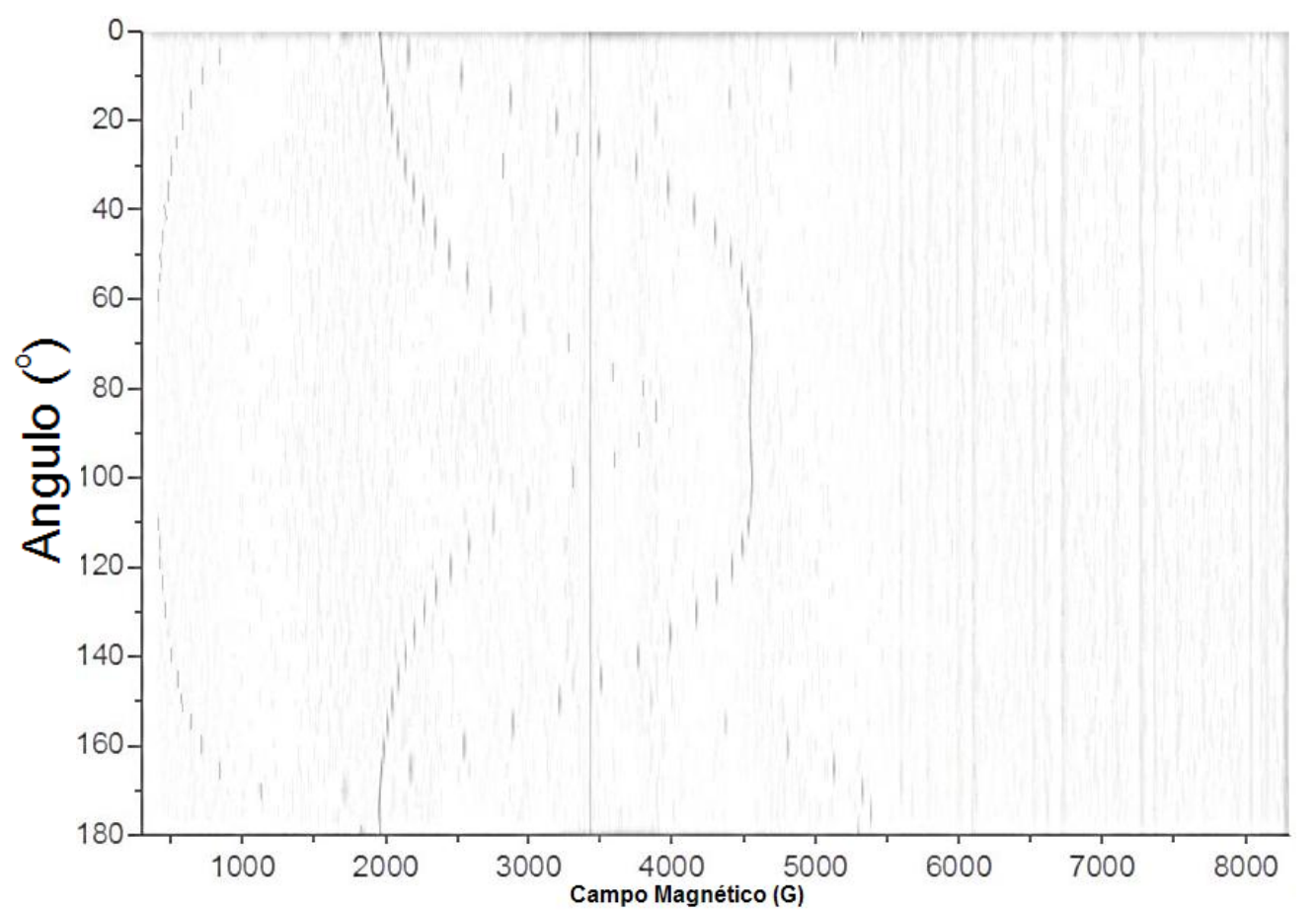

Figura 4.4. Variação angular dos sinais de $\mathrm{Cr}^{3+}$ para uma varredura de $8000 \mathrm{G}$ no plano $\perp$ a $\vec{b}$. 
Os átomos de $\mathrm{Cr}^{3+}$ substituem átomos de $\mathrm{Al}^{3+}$ num sitio de simetria octaédrica destorcida como no do rubi, que possui resultados bastante conhecidos na literatura. [24, 25, 26, 27]. As linhas do $\mathrm{Cr}^{3+}$ pode ser interpretado usando o Hamiltoniano abaixo: [25, 26].

$$
\hat{\mathcal{H}}=g_{l l} \cdot \mu_{B} \cdot B_{z} \cdot S_{z}+g_{\perp} \cdot \mu_{B} \cdot\left(B_{x} \cdot S_{x}+B_{y} \cdot S_{y}\right)+D \cdot\left(S_{z}^{2}-5 / 4\right) \text { Equação (4.1) }
$$

Sendo $\mathrm{g}_{\|}$e $\mathrm{g}_{\perp}$ o fator g paralelo e perpendicular, respectivamente, ao eixo $\vec{c}$ do cristal; $\mu_{B}$ é magnéton de Bohr, $B_{x}, B_{y}$ e $B_{z}$ as componentes do campo magnético aplicado; $S_{x}, S_{y}$ e $S_{z}$ os componentes do operador de spin eletrônico; D é o parâmetro de campo cristalino e a direção z está ao longo do eixo $\vec{c}$ do cristal. A temperatura ambiente (como nosso caso) $g_{\|}$e $g_{\perp}$ e D são, respectivamente, $1,9817,1,9819$ e $-0,19110 \mathrm{~cm}^{-1}$. [28]

No Rubi os átomos de $\mathrm{Cr}^{3+}$ são encontrados em sitio de simetria $\mathrm{C}_{3}$, porém em nossos espectros eles são encontrados em sítios diferentes. Embora seja um resultado muito interessante não aprofundamos nossos estudos no entendimento desse comportamento das linhas do $\mathrm{Cr}^{3+}$, uma vez que nossa intenção era tentar encontrar sinais criados após exposição dos cristais à radiação ionizante. Mas certamente é uma pergunta que pode e deve ser respondida por algum trabalho futuro.

\subsubsection{Pó de $\mathrm{Al}_{2} \mathrm{O}_{3}: \mathrm{C}$ Temperatura Ambiente.}

Nesse item apresentamos os resultados encontrados para o pó de $\mathrm{Al}_{2} \mathrm{O}_{3}: \mathrm{C}$ em espectroscopia de EPR feitas em onda contínua (CW), banda X (9,8 Ghz) e temperatura ambiente.

Os parâmetros usados para aquisição dos espectros de EPR foram: varredura de 8000 G, centrado em $4300 \mathrm{G}$, com $13 \mathrm{~dB}$, ganho de $10^{3}$, tempo de varredura de $5400 \mathrm{~s}$. 
Para as medidas do pó recuperado foram usadas duas amostras (denominadas "Amostra 1" e “Amostra 2"), recuperadas em dias diferentes, mas usando o mesmo processo explicado no item 2.2.2. Fizemos medidas com as duas amostras irradiadas e não irradiadas usando os mesmos parâmetros e condições.

O espectro das duas amostras não irradiadas é mostrado abaixo na Figura 4.5:

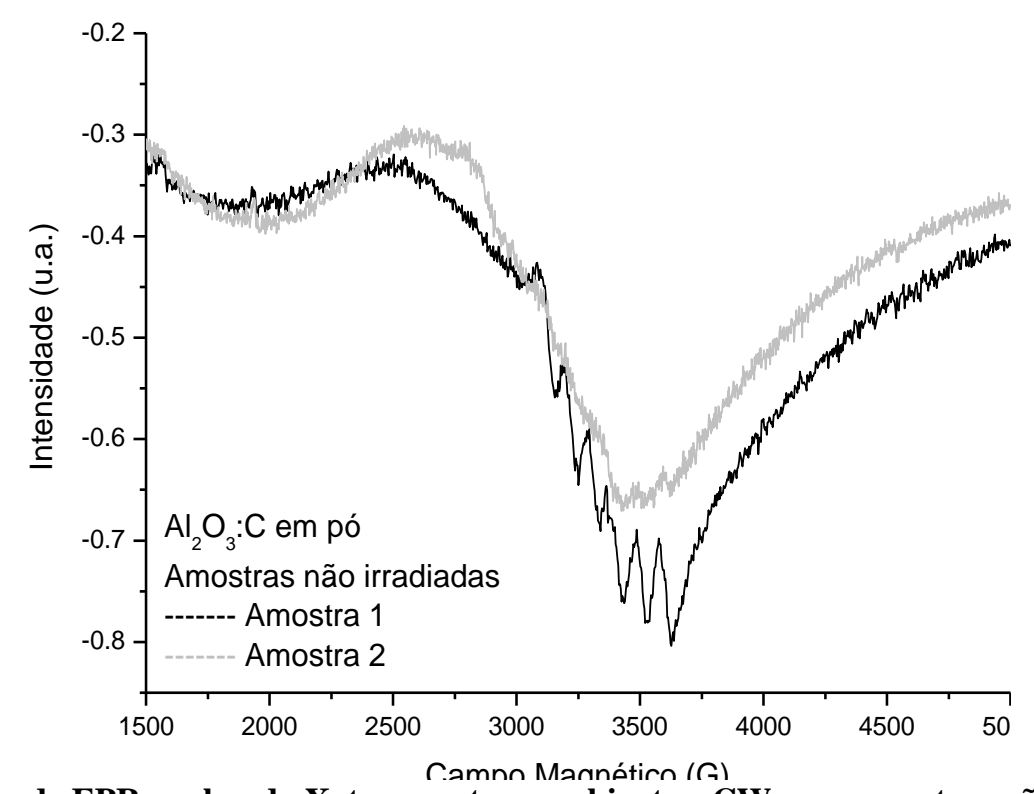

Figura 4.5. Espectro de EPR em banda $X$, temperatura ambiente e CW para amostras não irradiadas de pó recuperado da $\mathrm{Al}_{2} \mathrm{O}_{3}: \mathrm{C}$.

As seis linhas que aparecem mais evidenciadas no espectro da Amostra 1 são devidos a Manganês $\left(\mathrm{Mn}^{4+}\right)$ [29], as linhas ficam entre 3000 e $3750 \mathrm{G}$, possuem $\mathrm{g}=1,993 \pm 0,002$ e hiperfina de $78 \pm 2 \mathrm{G}$. Os íons $\mathrm{Mn}^{4+}$ ocupam os sítios octaédricos dos $\mathrm{Al}^{3+}$ distorcem o sítio de simetria do $\mathrm{Al}_{2} \mathrm{O}_{3}: \mathrm{C}$ por compensação de carga.

$\mathrm{O}$ íon $\mathrm{Mn}^{4+}$ é isoeletrônico ao $\mathrm{Cr}^{3+}$ (com configuração $3 \mathrm{~d}^{3}$ ) e comporta-se de maneira equivalente ao rubi. Entretanto devido ao aumento de carga do $\mathrm{Mn}^{4+}$ em relação ao $\mathrm{Cr}^{3+} \mathrm{O}$ parâmetro de campo cristalino e a colavência são maiores em $\mathrm{Mn}^{4+}$ do que em $\mathrm{Cr}^{3+}$. 
Podemos ver que a Amostra 1 possui uma quantidade de Manganês (impureza, $\mathrm{Mn}^{4+}$ ) maior que a Amostra 2. Essa diferença é fruto de condições de crescimento e recuperação do material. Como as medidas foram feitas com pós de amostras diferentes e como foram recuperadas em dias diferentes explica-se a diferença na concentração de impurezas.

Essas amostras foram irradiadas com 10 Gy com Raios-X (energia de $70 \mathrm{kV}$ ) e medidas no EPR usando os mesmos parâmetros. O espectro das duas amostras irradiadas comparadas com as duas não irradiadas é mostrado na Figura 4.6, para Amostra 1 e Figura 4.7, para Amostra 2:

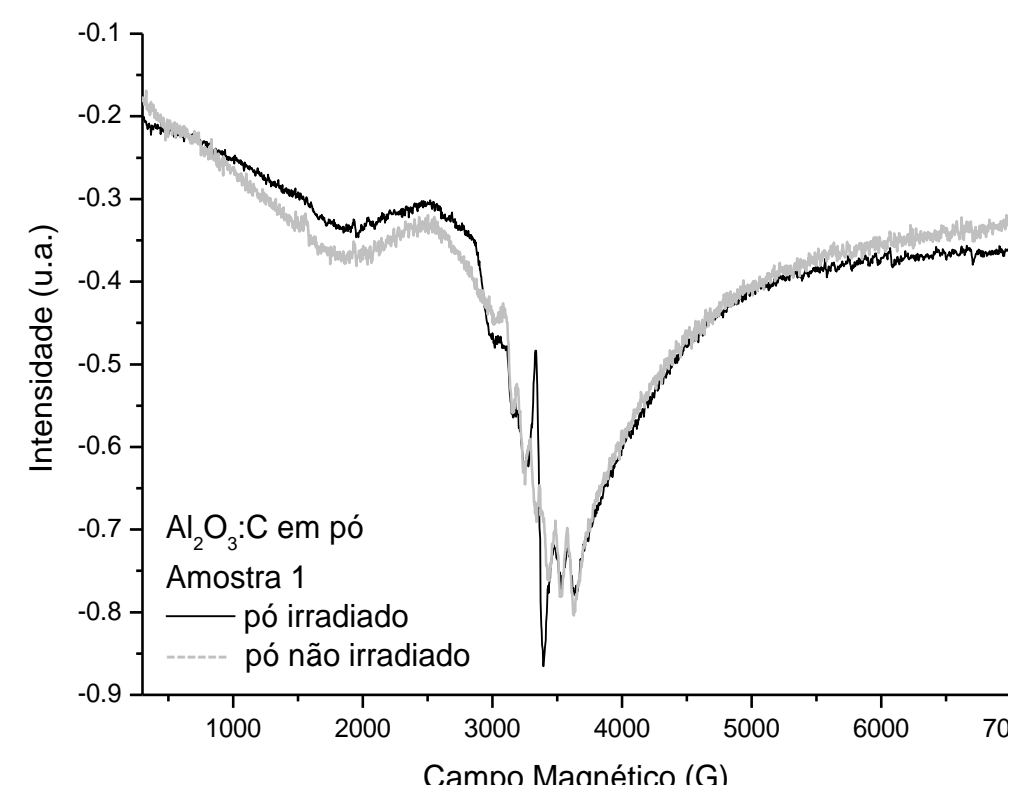

Figura 4.6. Espectro de EPR em banda X, temperatura ambiente e CW para Amostra 1 irradiada e não irradiadas de pó recuperado. 


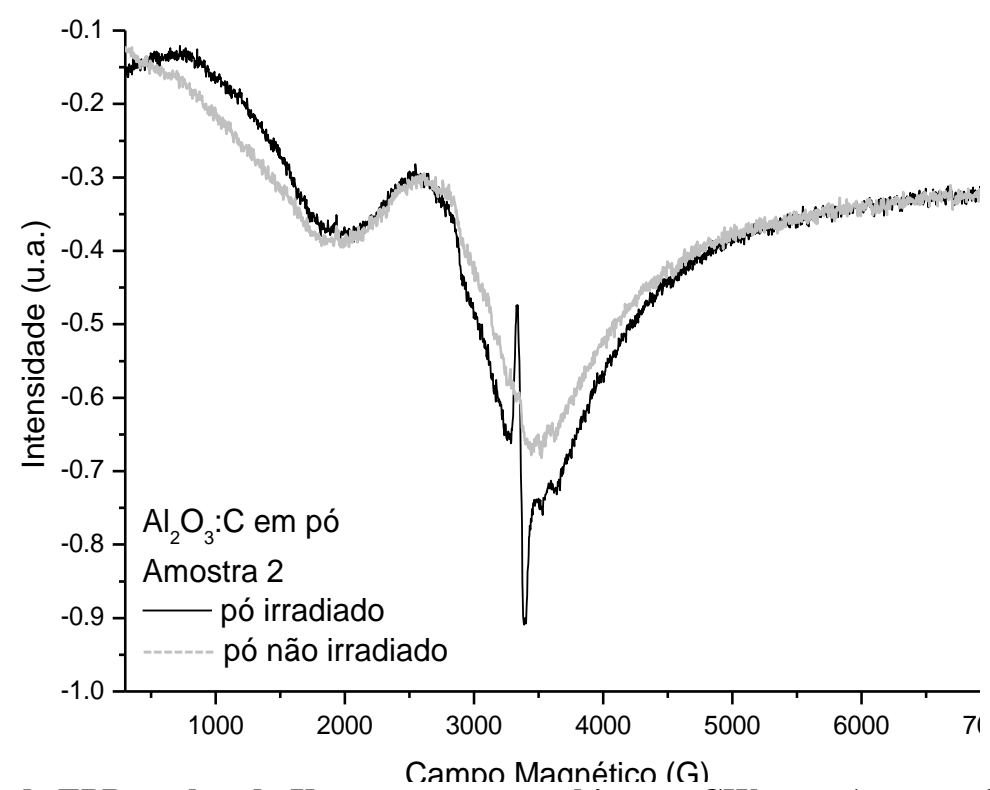

Figura 4.7. Espectro de EPR em banda X, temperatura ambiente e CW para Amostra 2 irradiada e não irradiadas de pó recuperado.

Podemos observar um sinal largo, não assimétrico na região de 2750 a 3750 G. Esse sinal é visto no espectro de todas as amostras, irradiadas e não irradiadas. Não nos foi possível identificar o centro, ou centros, responsáveis pelo sinal. Não conseguimos observar mudanças desse sinal entre amostras irradiadas e não irradiadas. Obtemos espectros de pó de $\mathrm{Al}_{2} \mathrm{O}_{3}: \mathrm{C}$ em banda $\mathrm{X}$ a baixa temperatura $(\mathrm{He})$ e em banda $\mathrm{Q}$ a temperatura ambiente, contudo não obtivemos resultado conclusivo que ajudasse a classificar qualquer componente deste sinal.

Acreditamos que ele seja um aglomerado de sinais de centros paramagnéticos com g $\sim 2$ A esses temos como candidatos: centros com spin $1 \frac{1}{2}$, centros $\mathrm{F}^{+}$, centros de buraco.

Em ambas as amostrar irradiadas podemos ver um sinal fino em $3350 \mathrm{G}$, em $\mathrm{g}=$ $2.0018 \pm 0.0002$ com largura de $60 \pm 2$ G. Esse sinal é um candidato em potencial para ser relacionado com os centros de luminescência no $\mathrm{Al}_{2} \mathrm{O}_{3}: \mathrm{C}$, pois foi criado após exposição do material à radiação ionizante. 
Para verificar essa hipótese primeiramente colocamos as amostras expostas a quatro lâmpadas fluorescentes de $40 \mathrm{~W}$, do tipo "luz do dia" por 24h para tentar limpar o sinal. Se o sinal fosse devido a um centro luminescente do tipo centro $\mathrm{F}^{+}$desapareceria ou diminuiria consideravelmente de intensidade após ser exposto à luz (principio de OSL). Depois de adquirido novamente o espectro de EPR, usando os mesmos parâmetros, vimos que o sinal fino em $3350 \mathrm{G}$ não desapareceu, nem apresentou mudanças na sua intensidade.

O próximo teste foi irradiar um pouco de amostra não irradiada com o dobro da dose usada anteriormente e medir no EPR. Novamente obtivemos o sinal fino em $3350 \mathrm{G}$ com g = 2,0018 $\pm 0,0002$, mas com a mesma intensidade.

Em seguida tentamos irradiar com metade da dose inicial uma amostra não irradiada (pois talvez as doses anteriores tivessem saturado o sinal) e submeter uma amostra irradiada a tratamento com luz por 36h; novamente não observamos mudança no sinal.

Nessa fase do projeto entramos em contato direto com o pesquisador responsável pelo crescimento dos cristais, o Dr. Mark Akselrod, responsável chefe pela Divisão de Crescimento de Cristais da Landauer (Landauer Crystal Group Division, Stillwater, EUA). Seguindo sua sugestão passamos a fazer o mesmo teste em amostras do pó virgem, pois essas supostamente teriam menos contaminantes e seria mais fácil observar qualquer sinal correspondente aos centros luminescentes.

Essa nova fase do projeto foi feita durante minha permanência no grupo de Dosimetria das Radiações do Departamento de Física da Universidade Estadual de Oklahoma (Stillwater, EUA) com parceria com a Divisão de Crescimento de Cristais da Landauer (Stillwater, EUA). De posse do pó virgem foi feito o seguinte procedimento: nove amostras foram preparadas do mesmo lote. Todas foram pesadas com $300 \mathrm{mg}$ e deixadas por 10 minutos em forno a $900{ }^{\circ} \mathrm{C}$ 
para limpeza de qualquer sinal luminescente. A Amostra 1 não foi irradiada, a Amostra 2 foi irradiada com 5 Gy, a Amostra 3 foi irradiada com 10 Gy, a Amostra 4 foi irradiada com 20 Gy, a Amostra 5 foi irradiada com 30 Gy, a Amostra 6 foi irradiada com 40 Gy, a Amostra 7 foi irradiada com 50 Gy, a Amostra 8 foi irradiada com 80 Gy e a Amostra 9 foi irradiada com $100 \mathrm{~Gy}$. Todas as irradiações foram feitas numa fonte de ${ }^{90} \mathrm{Sr} /{ }^{90} \mathrm{Y} \operatorname{com} \beta$.

As nove amostras foram medidas no espectrometro de EPR da Universidade Estadual de Oklahoma (modelo descrito no Capítulo 2, item 6.1.).

Os parâmetros usados para aquisição dos espectros foram: varredura de 3000 G, centrado em $3500 \mathrm{G}, 13 \mathrm{~dB}$, ganho de $10^{4}$.

Um sinal em $3350 \mathrm{G}$, com largura média de $62 \pm 3 \mathrm{G}$, foi visto em todas as amostras de pó virgem (como mostra a Figura 4.8). Esse sinal é o mesmo sinal fino com $\mathrm{g}=2,0018$ encontrado nas amostras de pó recuperado nas medidas no Brasil.

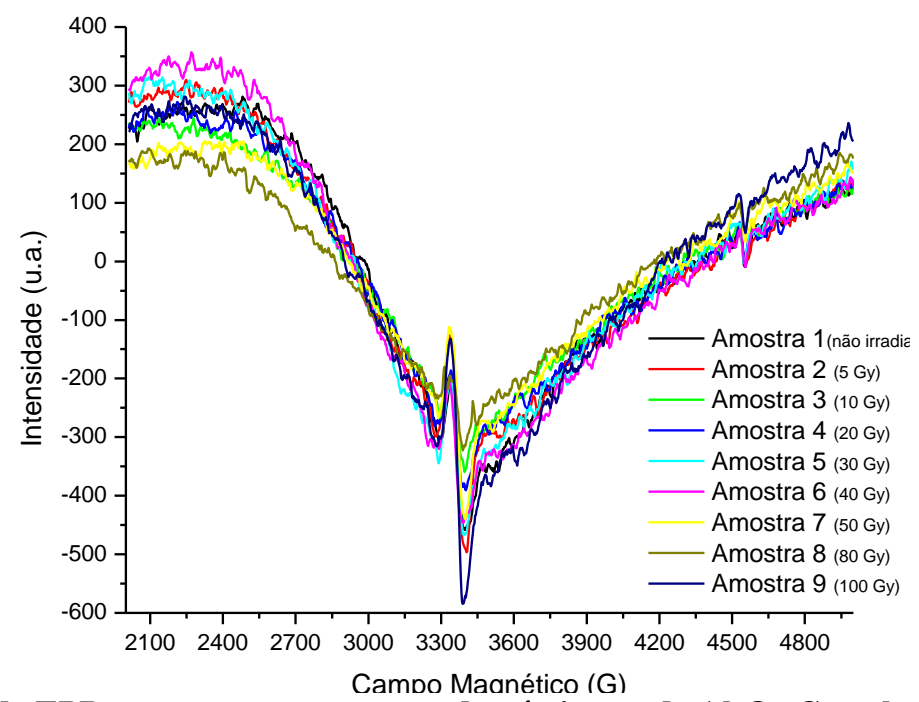

Figura 4.8. Espectro de EPR para as nove amostras de pó virgem de $\mathrm{Al}_{2} \mathrm{O}_{3}$ : $\mathrm{C}$ em banda $\mathrm{X}$, temperatura ambiente e CW.

Esse resultado foi reproduzido usando outro lote de pó virgem de maneira que confirmamos que o sinal fino em $3350 \mathrm{G}$ era o mesmo encontrado para amostras de pó recuperado medidos 
no Brasil. Embora esse sinal seja criado pela exposição do material à radiação ionizante ele não é limpo quando exposto à luz (como era de se esperar para centros paramagnéticos do tipo $\mathrm{F}^{+}$).

Fazendo uma busca bibliográfica observamos resultado que nos leva a acreditar que esse sinal seja um centro de buraco $\left(\mathrm{V}_{-\mathrm{OH}}\right)[30]$

Nesse trabalho, baseado em estudos da estabilidade térmica e resposta da oxidação em $\mathrm{Al}_{2} \mathrm{O}_{3}: \mathrm{C}$ a $1360{ }^{\circ} \mathrm{C}$, foi concluído que o único sinal, assimétrico e anisotrópico, encontrado para amostras irradiadas com $\gamma\left(\operatorname{com} g_{\|}=2,0018 \pm 0,0002, g_{\perp}=2,0011 \pm 0,0002\right.$ e largura da ordem de $50 \mathrm{G}$ ) é devido a um centro $\mathrm{V}_{-\mathrm{OH}}$. Esse sinal só foi removido quando o cristal foi exposto a $1360{ }^{\circ} \mathrm{C}$ por $70 \mathrm{~h}$, o que explica porque não conseguimos remover o sinal encontrado em nossos espectros em exposições com luz ou em forno de $900{ }^{\circ} \mathrm{C}$.

Em ambos os espectros do monocristal e pó do $\mathrm{Al}_{2} \mathrm{O}_{3}: \mathrm{C}$ não conseguimos observar sinais devido aos centros $\mathrm{F}^{+}$, importantes no processo OSL.

A resposta do $\mathrm{Al}_{2} \mathrm{O}_{3}: \mathrm{C}$ à radiação ionizante vai até exposições com 100 Gy [31] (referente à exposição da Amostra 9 para o pó virgem), dessa forma não acreditamos que exposições com doses maiores nos trariam melhores resultados. Mesmo com o aumento significativo de defeitos pontuais devido ao método de crescimento do material (explicado no Capítulo 1) e, conseguentemente, com o aumento de centros $\mathrm{F}^{+}$(que são paramagnéticos) quando o material é exposto à radiação ionizante não houve correspondência detectável usando espectroscopia de EPR. 


\subsection{3. Óxidos Dopados com Térbio: Resultados Preliminares.}

Os espectros de EPR, para as amostras em pó dos óxidos dopados com Tb, medidos durante minha permanência no Laboratório de Dosimetria das Radiações do Instituto de Física da Universidade Estadual de Oklahoma (Stillwater, EUA), são resultados preliminares de um estudo mais cuidadoso que será feito no laboratório a partir do segundo semestre de 2007.

Essas medidas preliminares foram feitas para tentar observar correlação entre sinais de EPR e centros de luminescência. Aqui apresentamos alguns dos espectros e a tentativa de reconhecer e classificar a maior quantidade que nos foi possível de linhas paramagnéticas.

Os espectros para todas as amostras foram adquiridos em onda contínua $(\mathrm{CW})$, banda $\mathrm{X}$ e temperatura ambiente, usando os seguintes parâmetros: varreduras de 8000, de 5000 e de $3000 \mathrm{G}$, campo central de $4300 \mathrm{G}$, potência de $11 \mathrm{~mW}$, ganho de $10^{4}$, constante de tempo de 1310 ms e tempo total de $335 \mathrm{~s}$.

As amostras em pó dos óxidos dopados com Térbio não sofreram tratamento químico, mas foram deixados por 20 minutos em forno de $200{ }^{\circ} \mathrm{C}$ para limpeza de eventuais sinais devido a exposição à luz (especialmente UV), depois $300 \mathrm{mg}$ de cada amostra foi pesada em uma balança analítica e então os espectros de EPR desses pós "limpos” foram adquiridos.

As mesmas amostras, então, foram irradiadas com 50 Gy de $\beta$ em uma fonte de ${ }^{90} \mathrm{Sr} /{ }^{90} \mathrm{Y}$ e em seguida adquiridos seus espectros de EPR sob as mesmas condições (tomadas as devidas precauções em manter a sala escura, para que não houvesse perda de sinal sob exposição a luz). Depois disso as amostras foram levadas a tratamento térmico (20 minutos em forno a $200^{\circ} \mathrm{C}$ ) para nova limpeza dos sinais, irradiadas com 200 Gy de $\beta$ numa fonte de ${ }^{90} \mathrm{Sr} /{ }^{90} \mathrm{Y}$ e adquiridos novamente os espectros de EPR. 
O campo foi calibrado usando uma amostra de DPPH (diphenil-pycril hydrazil, fator $\mathrm{g}=$ 2.0036) e a freqüência de microondas medida foi de banda $X$.

O resultado comparativo para cada amostra (amostras rotuladas segundo a Tabela 2.1, no Capítulo 2) é apresentado a seguir.

\subsubsection{Grupo $1-\mathrm{Li}_{2} \mathrm{O}: \mathrm{Tb}$.}

O Óxido de Lítio possui estrutura tetragonal (Figura 4.9), massa molar de 29,881 g/mol, densidade de $2013 \mathrm{~kg} / \mathrm{m}^{3}$ e ponto de fusão de $1570{ }^{\circ} \mathrm{C}$.

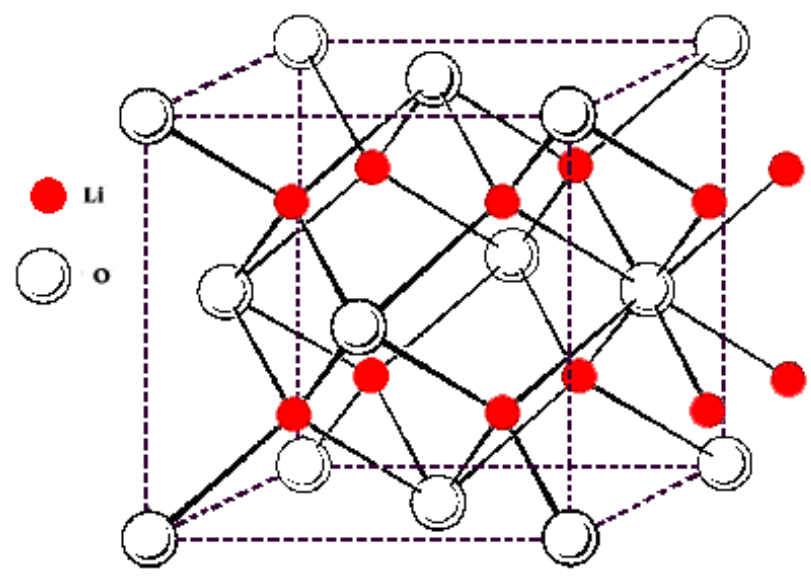

Figura 4.9. Estrutura do Óxido de Lítio.

Os três espectros apresentados a seguir foram adquiridos de amostras de Óxido de Lítio dopados com Térbio, crescidos nas mesmas condições, mas não pertencentes ao mesmo lote. 


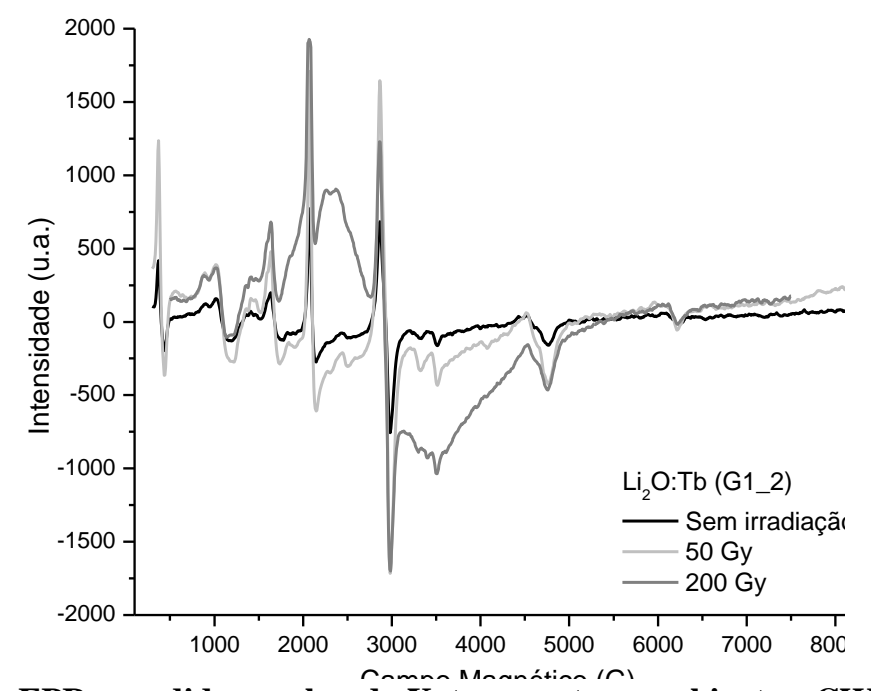

Figura 4.10. Espectro de EPR e medidos em banda $X$, temperatura ambiente e $\mathrm{CW}$ para $\mathrm{Li}_{2} \mathrm{O}$ :Tb (G1_2) não irradiado, irradiado com 50 Gy e $200 \mathrm{~Gy}$.

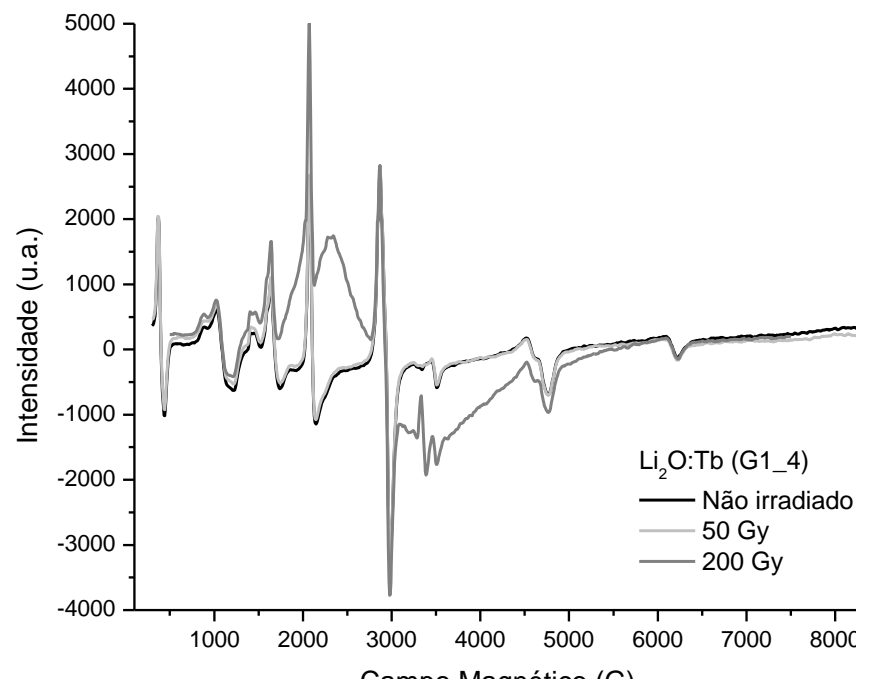

Figura 4.11. Espectro de EPR e medidos em banda X, temperatura ambiente e $\mathrm{CW}$ para $\mathrm{Li}_{2} \mathrm{O}$ :Tb (G1_4) não irradiado, irradiado com 50 Gy e 200 Gy. 


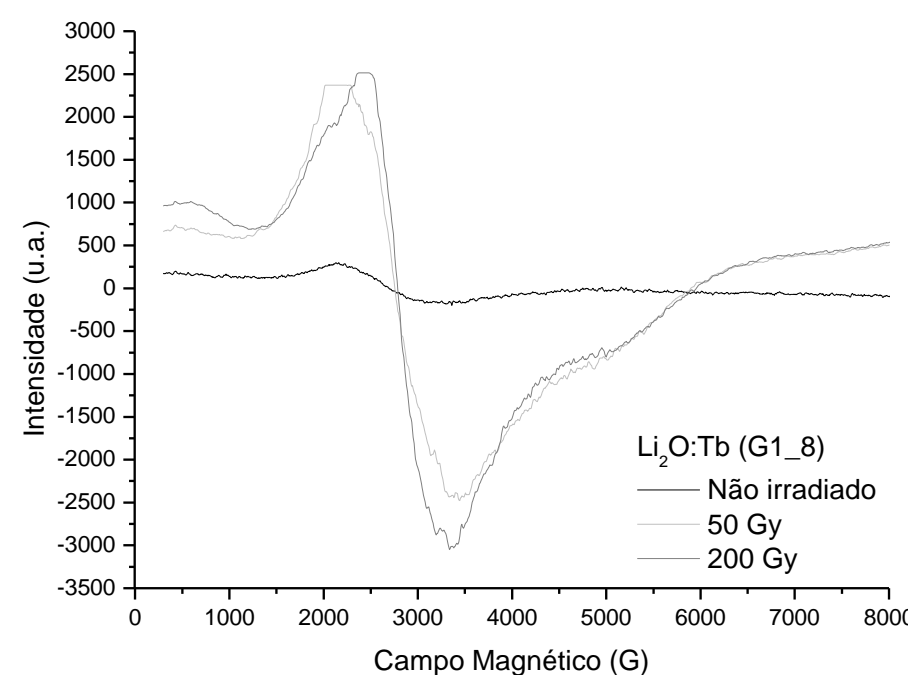

Figura 4.12. Espectro de EPR e medidos em banda X, temperatura ambiente e CW para Li2O:Tb (G1_8) não irradiado, irradiado com 50 Gy e 200 Gy.

O primeiro aspecto que tentamos observar foi a existência de algum sinal paramagnético devido a algum centro luminescente criado por exposição do material a radiação ionizante.

As amostras G1_2 (Figura 4.11) e G1_4 (Figura 4.12) apresentam espectros bastante semelhantes. Ambas possuem mesmas linhas (superposição dos espectros para irradiação com 200 Gy mostrado na Figura 4.13) e podemos observar um sinal largo ( $800 \mathrm{G}$ de largura) centrado em $2750 \mathrm{G}$ que fica evidente apenas para irradiação de $200 \mathrm{~Gy}$ (linha desenhada em vermelho na Figura 4.13). Esse sinal, evidente apenas após irradiação com 200 Gy, é um forte candidato a centro luminescente. É nesse sinal que faremos nossa primeira análise. 


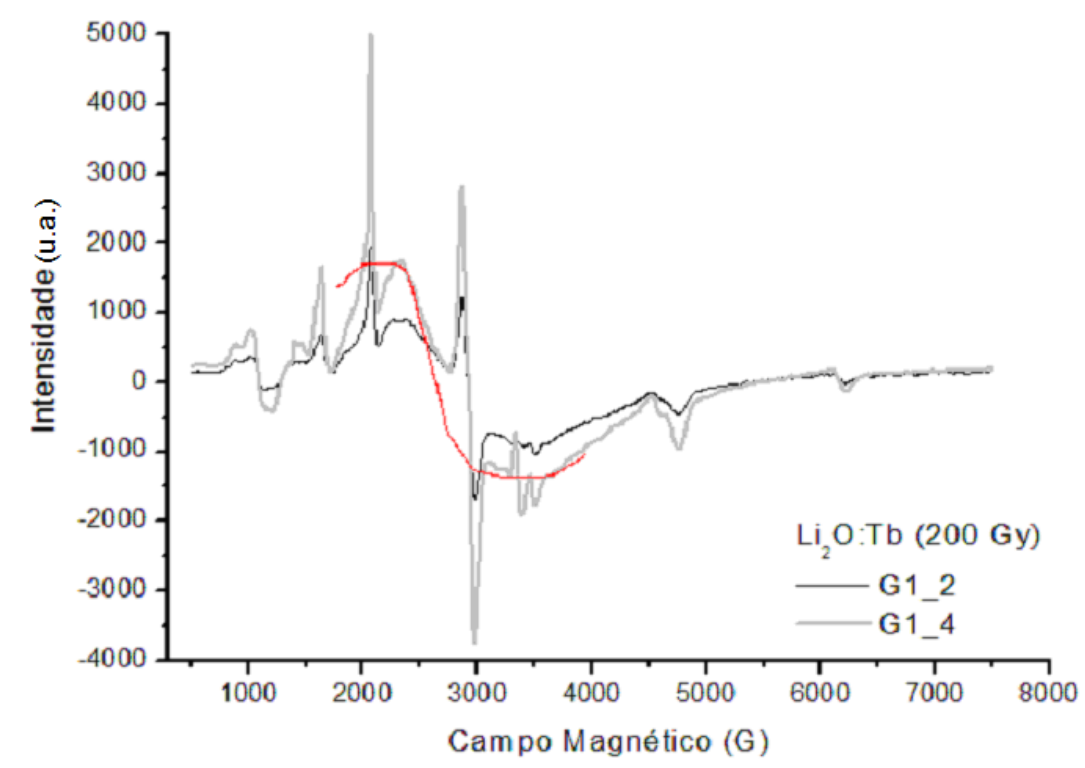

Figura 4.13. Espectro para G1_2 e G1_4 irradiados com 200 Gy com linha desenhada em vermelho para sinal largo.

O sinal evidente para irradiação com 200 Gy nas amostras G1_2 e G1_4 seja o mesmo sinal observado na amostra G1_8 (Figura 4.12.), que por não possuir outros sinais sobrepostos apresenta mais claramente o comportamento do sinal em relação à dose recebida. Entretanto não fica, a princípio, claro, porque no espectro de G1_8 o sinal para irradiação com 200 Gy é parecido com o espectro da amostra irradiada com 50 Gy, já que nos espectros das outras duas amostras esse sinal não é visível para a irradiação com 50 Gy. Tampouco porque o espectro da amostra G1_8 apresenta espectro tão diferente aos apresentados pelas outras duas amostras (G1_2 e G1_4) uma vez as amostras, embora de lotes diferentes, foram feitos da mesma forma. Uma superposição dos espectros das três amostras, irradiadas com 200 Gy, é mostrada na Figura 4.14. abaixo. 


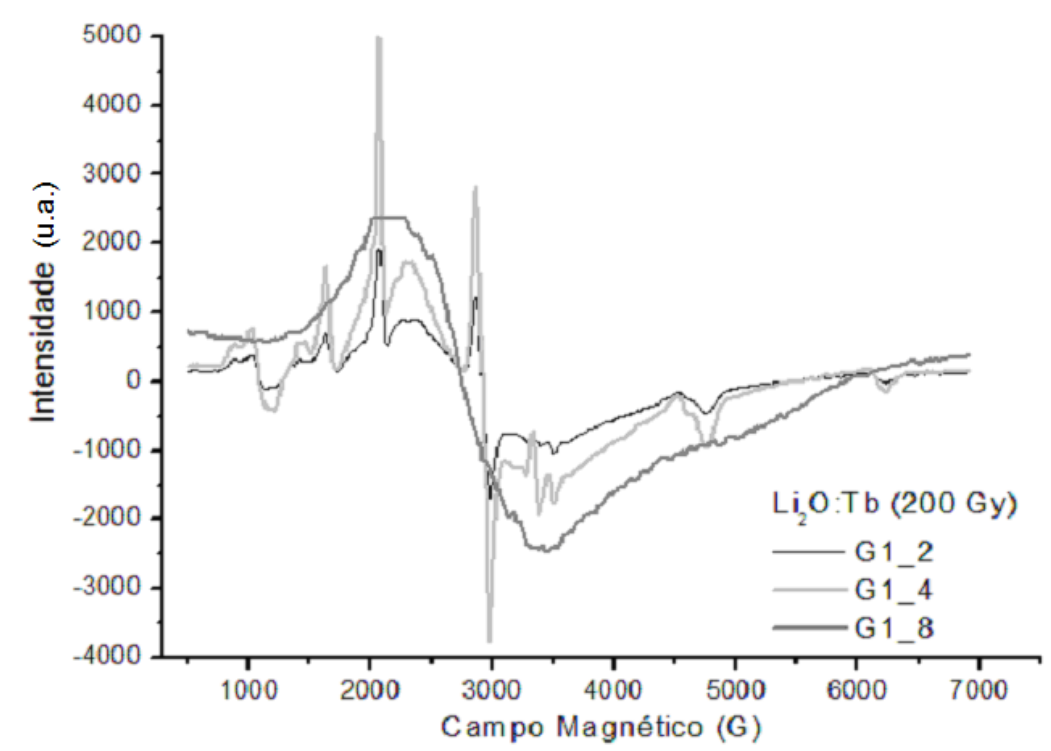

Figura 4.14. Espectro para G1_2, G1_4 e G1_8 irradiados com 200 Gy e medidos em banda X, temperatura ambiente e CW.

O Óxido de Lítio possui centros paramagnéticos diretamente relacionados com irradiação. Resultados em EPR mostram correlação entre centros F e irradiação com nêutron (exemplo na Figura 4.15.) [32]. Entretanto esses sinais, dos centros F, não são observados para amostras não irradiadas ou para amostras irradiadas com $\gamma$ em uma fonte de ${ }^{60} \mathrm{Co}$ com menos de $10^{6}$ Gy. [32, 33].

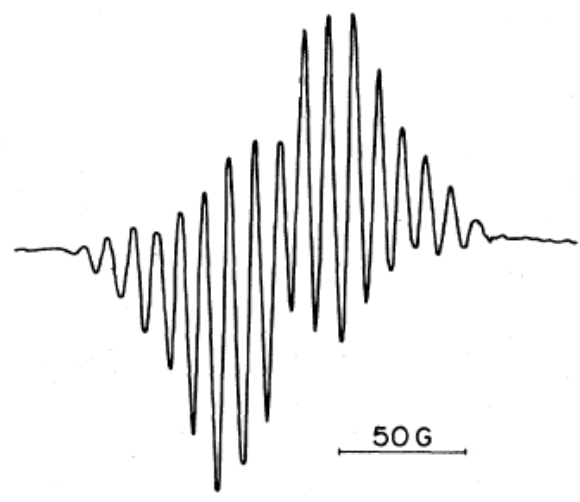

Figura 4.15. Espectro de EPR de centro $\mathrm{F}$ em monocristal de $\mathrm{Li}_{2} \mathrm{O}$ irradiado com 4.5 x 1021 nêutrons térmicos por $\mathbf{m}^{2}$.[32]

Nossas irradiações foram somente ate 200 Gy e mesmo com a dopagem com Térbio (que aumenta o número de defeitos pontuais e conseqüentemente centros luminescentes, como 
centros $\mathrm{F}$ e $\mathrm{F}^{+}$) não observamos em nossos espectros nenhum sinal correspondente ao sinal de centro F encontrado na literatura (Figura 4.15). Dessa forma, descartamos relação entre os sinais largos, encontrados em todos os espectros irradiados com $200 \mathrm{~Gy}$, com centros luminescentes do tipo centro $\mathrm{F}^{+}$.

Nosso passo seguinte é tentar encontrar e classificar a maior parte possível dos sinais vistos nos espectros para o Óxido de Lítio dopado com Térbio. Sabemos que $\mathrm{Li}_{2} \mathrm{O}$ puro não possui centros paramagnético, dessa forma, certamente os sinais vistos são devidos a impurezas no cristal (e nelas incluímos o próprio dopante, o Tb).

Impurezas comumente encontradas em $\mathrm{Li}_{2} \mathrm{O}$ são: $\mathrm{H}, \mathrm{Fe}, \mathrm{Al}, \mathrm{Na}, \mathrm{Si}, \mathrm{Cu}, \mathrm{K}, \mathrm{Mn}$ e Cr. [34]. A essa lista adicionamos, como impureza encontrada na amostra, o $\mathrm{Tb}^{3+} \mathrm{e} \mathrm{Tb}^{4+}$.

Terras raras não mostram, comumente, sinal de EPR a temperatura ambiente devido ao seu tempo de relaxação [35], contudo a situação é diferente para íons de terras raras com a camada f preenchida pela metade, como $\mathrm{Gd}^{3+}, \mathrm{Eu}^{2+} \mathrm{e} \mathrm{Tb}^{4+}$ devido ao estado fundamental ${ }^{8} \mathrm{~S}_{7 / 2}$. Dessa forma, se o Térbio é tetravalente pode-se observar suas linhas características em espectroscopia de EPR a temperatura ambiente. As linhas características do $\mathrm{Tb}^{4+}$ estão na região de $\mathrm{g}=2,0012$ [36], e como temos muitas transições possíveis (níveis de energia para $\mathrm{Tb}^{4+}$ gerado pelo programa EasySpin, na Figura 4.16) é possível que o sinal largo, visto no espectro de todas as amostras, seja um conjunto das linhas do $\mathrm{Tb}^{4+}$ (como se trata de um pó todas as orientações são possíveis), que na estrutura do material substituiria átomos de $\mathrm{L}_{\mathrm{i}}$. 


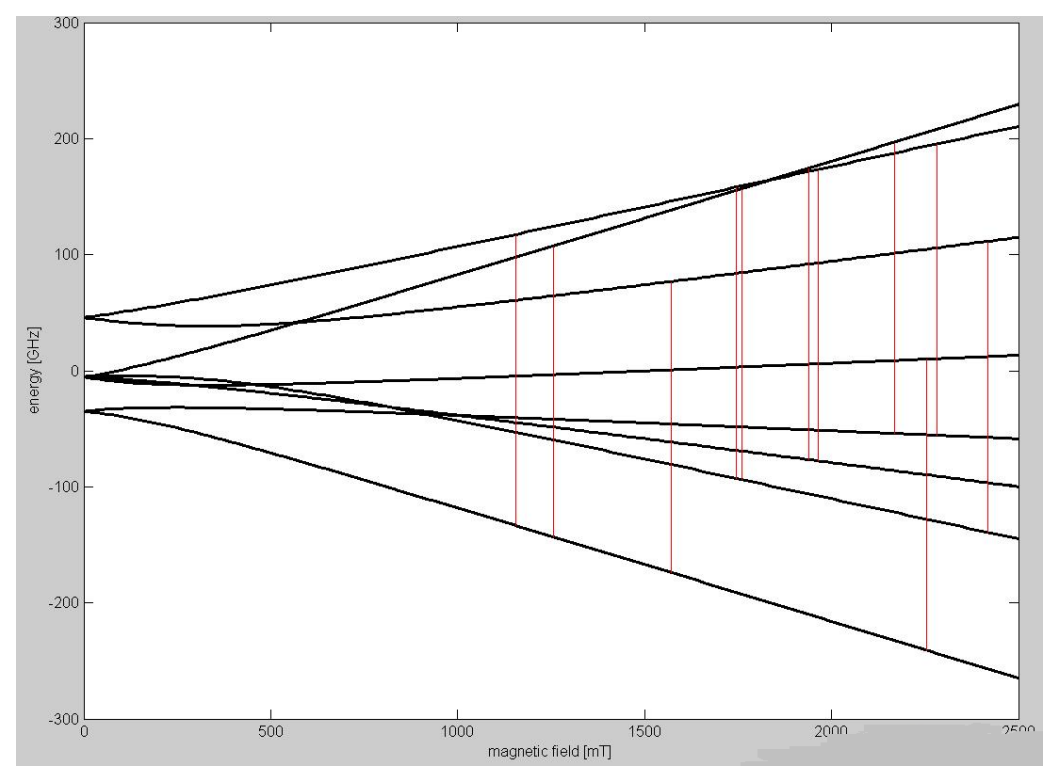

Figura 4.16. Transições possíveis para $\mathrm{Tb}^{4+}$.

Continuando nossa análise por sinais de impurezas temos que nas amostras G1_2 e G1_4 (Figuras 4.10. e 4.11.) a linha fina em $1630 \mathrm{G}$, com $\mathrm{g}=4,130 \pm 0,002$, é possivelmente devido a $\mathrm{Fe}^{+}$. Não observamos linhas devido a $\mathrm{Fe}^{2+}$, que no caso de simetria do $\mathrm{Li}_{2} \mathrm{O}$ só poderia ser vista em um dos estados do tripleto com $\mathrm{g}=1(6733 \mathrm{G}$ para $v=9,43 \mathrm{GHz})$ [37]. Linhas devidas a $\mathrm{Fe}^{3+}$ já são conhecidas pela literatura [38], essas linhas são detectadas no sitio tetragonal com duas vacâncias de $\mathrm{Li}^{+}$e possuem $\mathrm{g}=2,008$, com 5 linhas finas $(\mathrm{S}=5 / 2)$. Novamente, como se trata de um pó, temos uma superposição dessas linhas do $\mathrm{Fe}^{3+}$. As linhas para $\mathrm{Fe}^{+}$e $\mathrm{Fe}^{3+}$ são destacadas na Figura 4.17. 


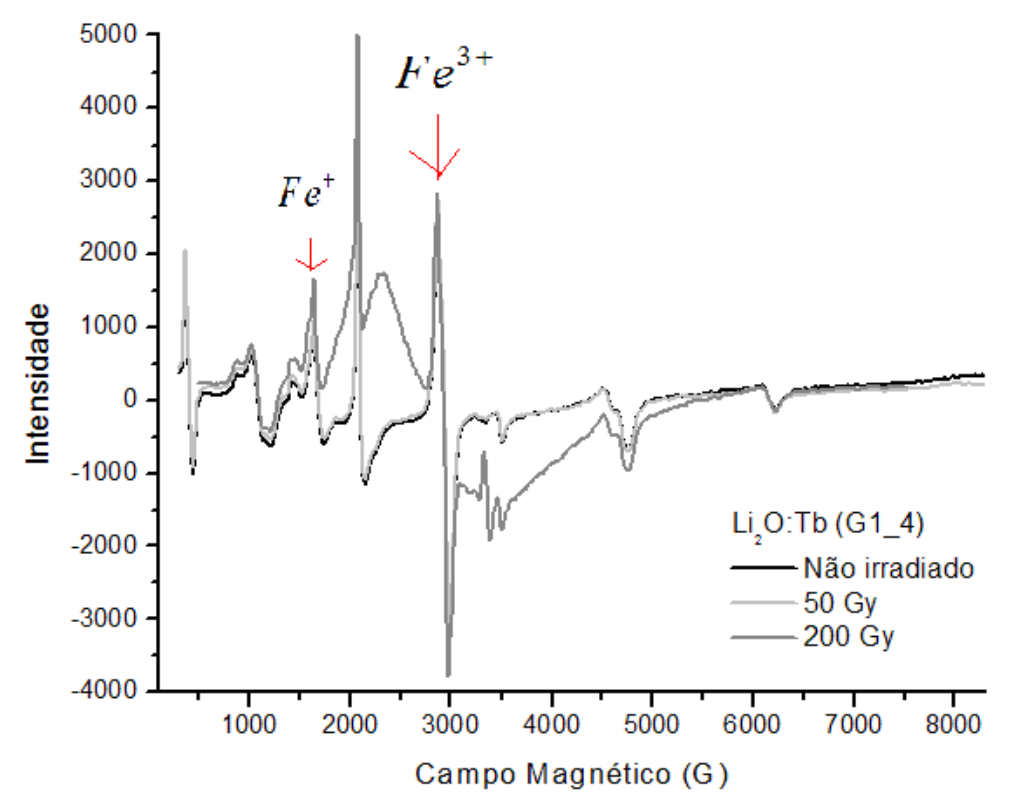

Figura 4.17. Impurezas classificadas nas amostras G1_2 e G1_4 .

Não nós foi possível classificar as demais linhas presentes nos espectros das amostras de $\mathrm{Li}_{2} \mathrm{O}: \mathrm{Tb}$. O que fica claro, nessas medidas preliminares, é que o aparecimento de sinais, devido a centros luminescentes do tipo $\mathrm{F}^{+}$, não foram observados.

Existem dois possíveis motivos que explicam porque não observamos os sinais devidos ao centro $\mathrm{F}^{+}$. A primeira é de que precisaríamos de amostras expostas a doses da ordem de $10^{4}$ Gy (como as encontradas na literatura). A segunda é de que a constante de tempo de $1310 \mathrm{ms,}$ usada para varreduras de $8000 \mathrm{G}$, cortou sinais finos, de maneira que os sinais devido a centros F (com largura de $50 \mathrm{G}$ ) não foram vistos. Certamente com mais tempo esses aspectos teriam sido refinados e teríamos melhores resultados. 


\subsubsection{Grupo 2 - MgO:Tb,Co e MgO:Tb.}

O Óxido de Magnésio possui estrutura cúbica de face centrada (Figura 4.18.). Possui massa molar de 40,3044 g/mol, densidade de $3580 \mathrm{~kg} / \mathrm{m}^{3}$, ponto de fusão de $2800{ }^{\circ} \mathrm{C}$, ponto de ebulição de $3600{ }^{\circ} \mathrm{C}$ e solubilidade de $0,00062 \mathrm{~g}$ em $100 \mathrm{~g}$ de água.

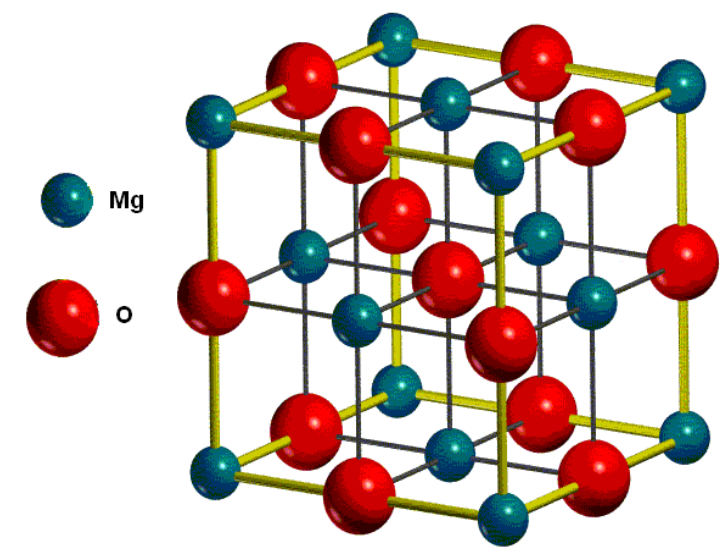

Figura 4.18. Estrutura do Óxido de Magnésio.

Os quatro espectros apresentados a seguir foram adquiridos de amostras de Óxido de Magnésio dopados com Térbio e, em duas das amostras, também dopados com Cobalto. As amostras dopadas somente com $\mathrm{Tb}$ foram crescidas nas mesmas condições, mas não pertencentes ao mesmo lote, e o mesmo para as amostras dopadas com Tb e Co. 


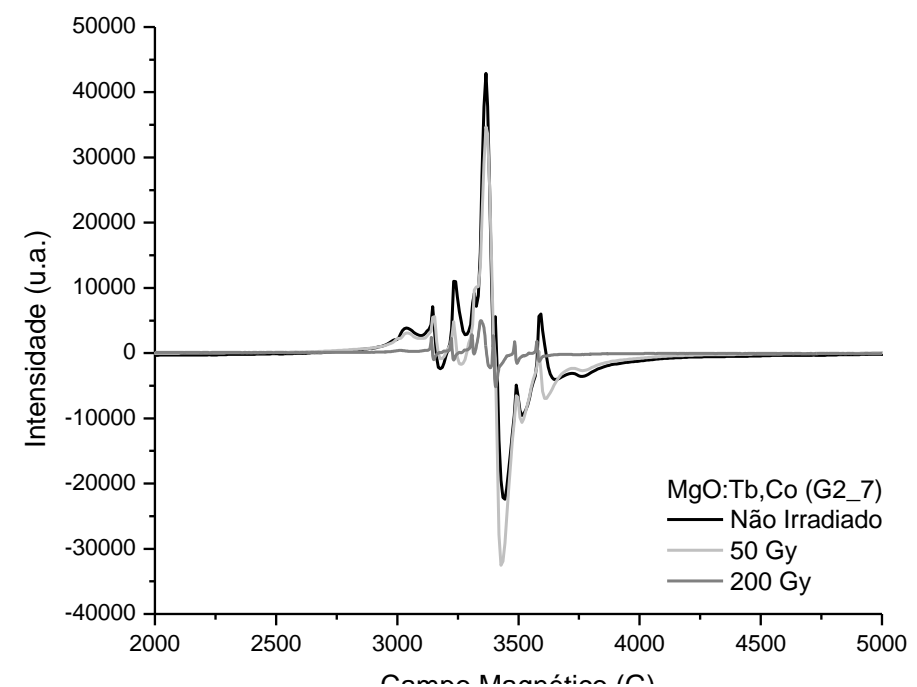

Figura 4.19. Espectro de EPR medidos em banda $\mathrm{X}$, temperatura ambiente e $\mathrm{CW}$ para $\mathrm{MgO}$ :Tb,Co (G2_12) não irradiado, irradiado com 50 Gy e 200 Gy.

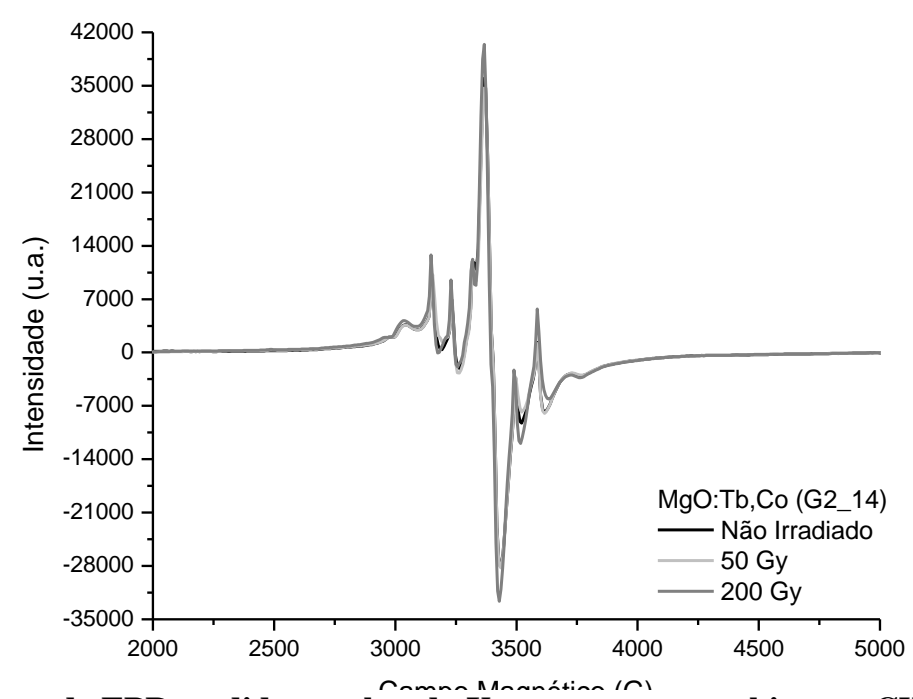

Figura 4.20. Espectro de EPR medidos em banda X, temperatura ambiente e $\mathrm{CW}$ para $\mathrm{MgO}$ :Tb,Co (G2_12) não irradiado, irradiado com 50 Gy e 200 Gy. 


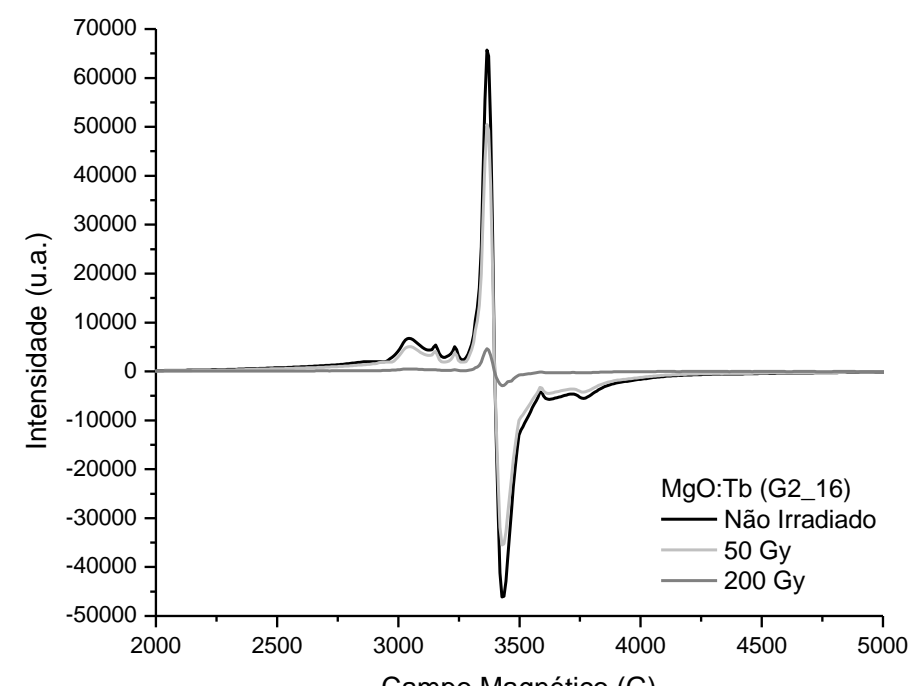

Figura 4.21. Espectro de EPR medidos em banda X, temperatura ambiente e CW para MgO:Tb (G2_16) não irradiado, irradiado com 50 Gy e 200 Gy.

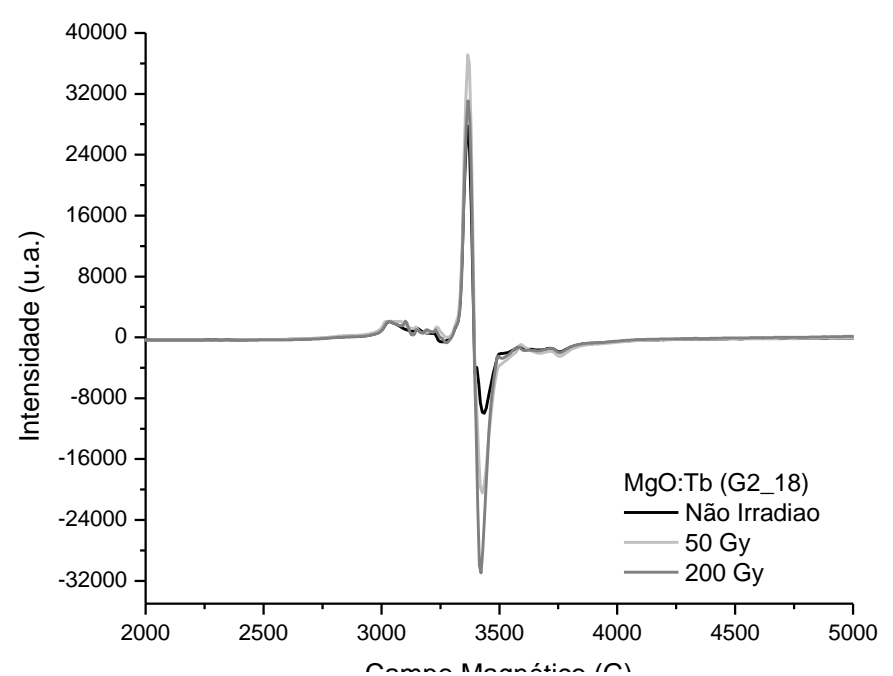

Figura 4.22. Espectro de EPR medidos em banda X, temperatura ambiente e CW para MgO:Tb (G2_18) não irradiado, irradiado com 50 Gy e $200 \mathrm{~Gy}$.

Novamente, o primeiro aspecto que tentamos observar foi a existência de algum sinal paramagnético devido a algum centro luminescente (criado por exposição do material a radiação ionizante).

A literatura possui trabalhos de EPR em que são encontrados sinais devidos a centros F [39. 40, 41], esses sinais aparecem após exposição do material a nêutron, $\gamma$ e UV (nossas 
irradiações foram feitas com $\beta$ ). O sinal característico para centro $\mathrm{F}$ em $\mathrm{MgO}$ é mostrado na Figura 4.23. abaixo.

O sinal devido ao centro F possui $\mathrm{g}=2,0023 \pm 0,0001$ e a largura entre as linhas nos extremos é de 24,7 G. As linhas obtidas em nossos espectros possuem larguras muito maiores do que as do sinal característico de centro $\mathrm{F}$ em $\mathrm{MgO}$ e estão na mesma região (com g próximo de 2).

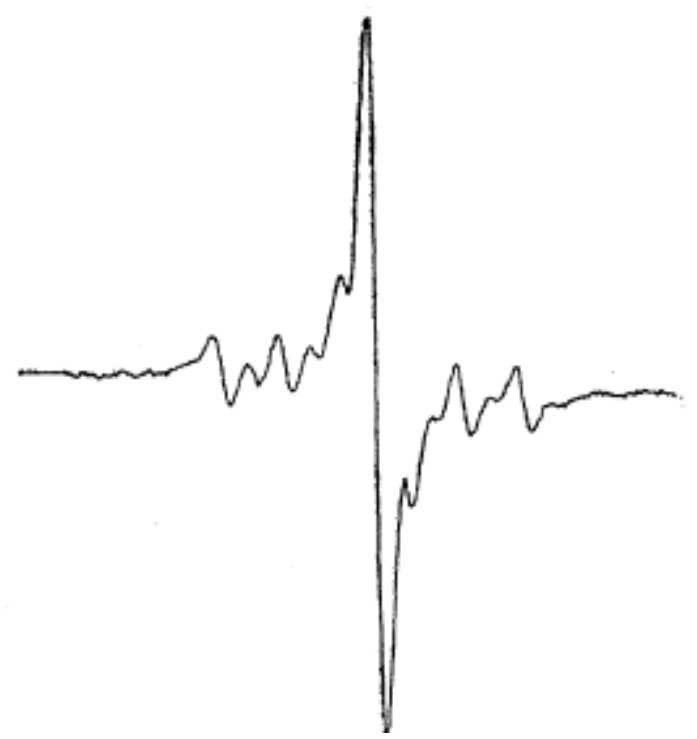

Figura 4.23. Espectro de EPR medidos em banda X, temperatura ambiente e CW de centro F em MgO. [39]

Como $\mathrm{MgO}$ não possui centros paramagnéticos nossa próxima tentativa é verificar a qual impureza - ou impurezas - consiste o espectro obtido para as quatro amostras.

Os espectros do Grupo 2 são bastante parecidos. Todos apresentam sinal em 3400 G com g = $1,980 \pm 0,002$.

Descartamos sinais devidos ao Co e ao Tb. Sinais de EPR de Co são vistos apenas a baixa temperatura, devido ao seu tempo de relaxação, e o mesmo para o $\mathrm{Tb}^{3+}$. Sinal paramagnético do $\mathrm{Tb}^{4+}$ pode ser visto a temperatura ambiente, mas sua linha característica não foi observada em nossas amostras. 
Contudo um estudo das linhas do $\mathrm{Cr}^{3+}$ em $\mathrm{MgO}$ nos trás maiores evidências de nossas linhas nas amostras dopadas com $\mathrm{Tb}$ e $\mathrm{Co}$ [42]. O espectro mostrado na Figura 4.24. mostra o espectro do $\mathrm{Cr}^{3+}$ para um mono cristal de $\mathrm{MgO}$ [42]. A linha mais intensa é devida ao eixo de simetria cúbica pura. As linhas $\mathrm{A}_{0}, \mathrm{~B}_{0}$ e $\mathrm{C}_{0}$ aparecem do eixo de simetria do campo elétrico ao longo do campo aplicado $\mathrm{H}_{0}$, enquanto que $\mathrm{B}_{90}, \mathrm{C}_{90}$ e $\mathrm{A}_{90}$ são cada dupla de linhas coincidentes de íons com eixo de simetria perpendicular a $\mathrm{H}_{0}$. A única linha reproduzida nos pós (nosso caso) é a linha intensa (destacada na Figura 4.25. a) e é a linha que se assemelha com as linhas de nossas medidas (em $3400 \mathrm{G})$.

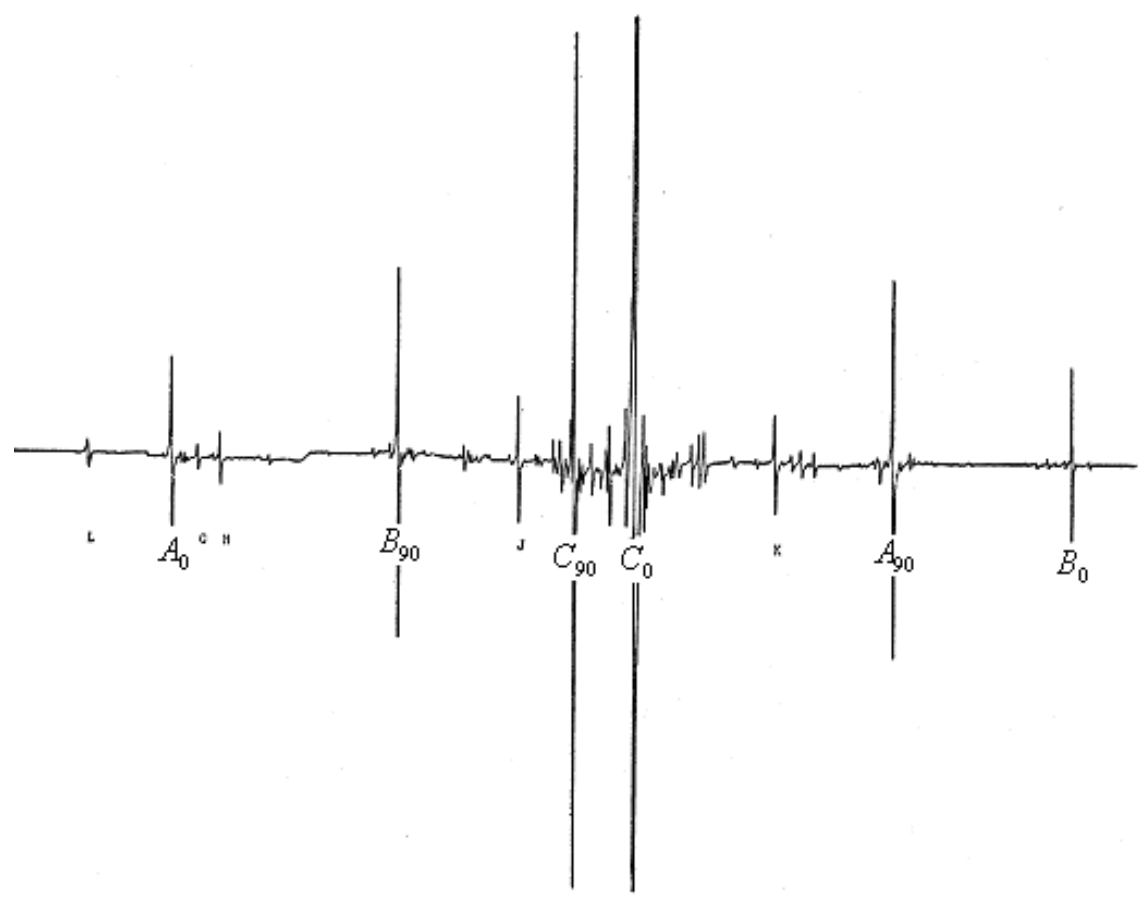

Figura 4.24. Linhas do $\mathrm{Cr}^{3+}$ em monocristal de MgO. [40] 

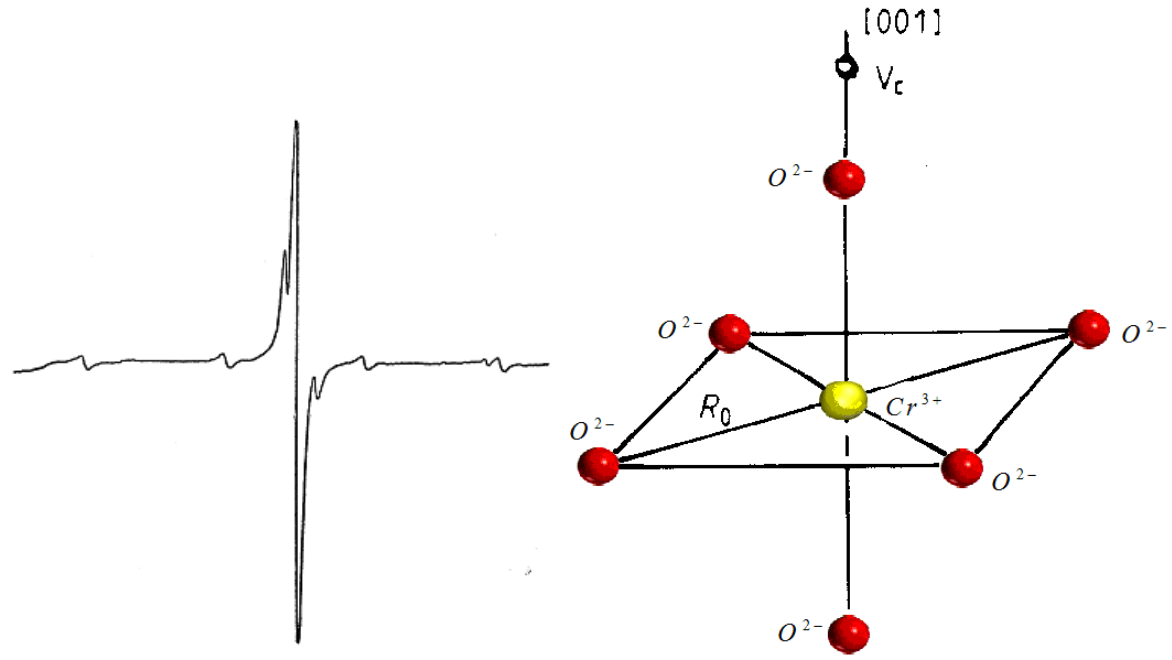

Figura 4.25. a) Linhas do $\mathrm{Cr}^{3+}$ em pó de $\mathrm{MgO}$. [42]. b) Estrutura do $\mathrm{Cr}^{3+}$ em simetria cúbica no MgO.

Átomos de Cromo substituem íons de Magnésio $\left(\mathrm{Mg}^{2+}\right)$. O espectro do $\mathrm{Cr}^{3+}$ depende de onde a compensação da carga extra ocorre. O sinal da Figura 4.25. a. possui $g=1,979$ e é devido a íons na simetria octaédrica (Figura 4.25. b). Exposições à radiação podem tornar o $\mathrm{Cr}^{3+}$ para $\mathrm{Cr}^{2+}$, segundo resultado observado para exposições a raios-X [43] e pode explicar a diminuição na intensidade do sinal para irradiações com 200 Gy em todas as amostras.

Dessa forma identificamos o sinal existente em todos os espectros como devido a $\mathrm{Cr}^{3+}$, ou seja, uma impureza. Como o sinal característico de centro F para $\mathrm{MgO}$ está na mesma região e possui largura bastante fina é preciso que novas amostras, sem $\mathrm{Cr}^{3+}$, sejam medidas para que as linhas, devido a centros luminescentes, sejam observadas. 


\subsubsection{Grupo 3 - CaO:Tb.}

O Óxido de Cálcio possui estrutura cúbica de face centrada (Figura 4.26.). Possui massa molar de $56,1 \mathrm{~g} / \mathrm{mol}$, densidade de $3358 \mathrm{~kg} / \mathrm{m}^{3}$, ponto de fusão de $2572{ }^{\circ} \mathrm{C}$, ponto de ebulição de $2850{ }^{\circ} \mathrm{C}$ e solubilidade de $0,00062 \mathrm{~g}$ em $100 \mathrm{~g}$ de água.

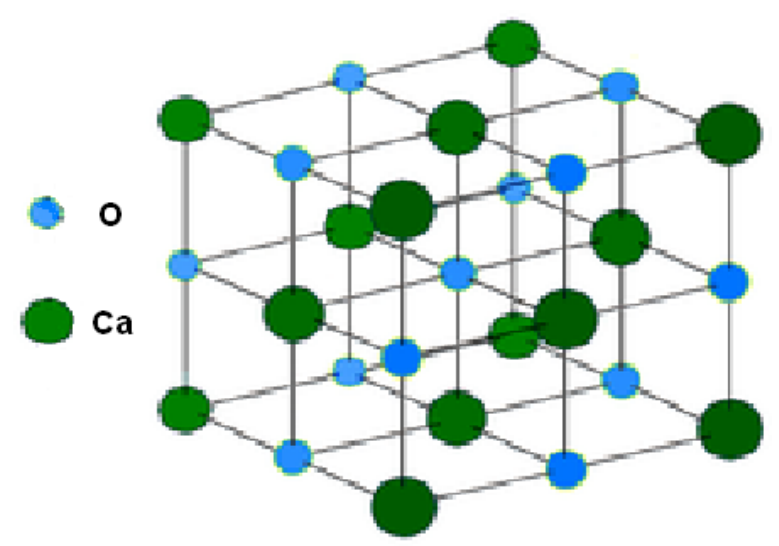

Figura 4.26. Estrutura do Óxido de Cálcio.

Os dois espectros apresentados a seguir foram adquiridos de amostras de Óxido de Cálcio dopados com Térbio. As amostras foram crescidas nas mesmas condições, mas não pertencentes ao mesmo lote. 


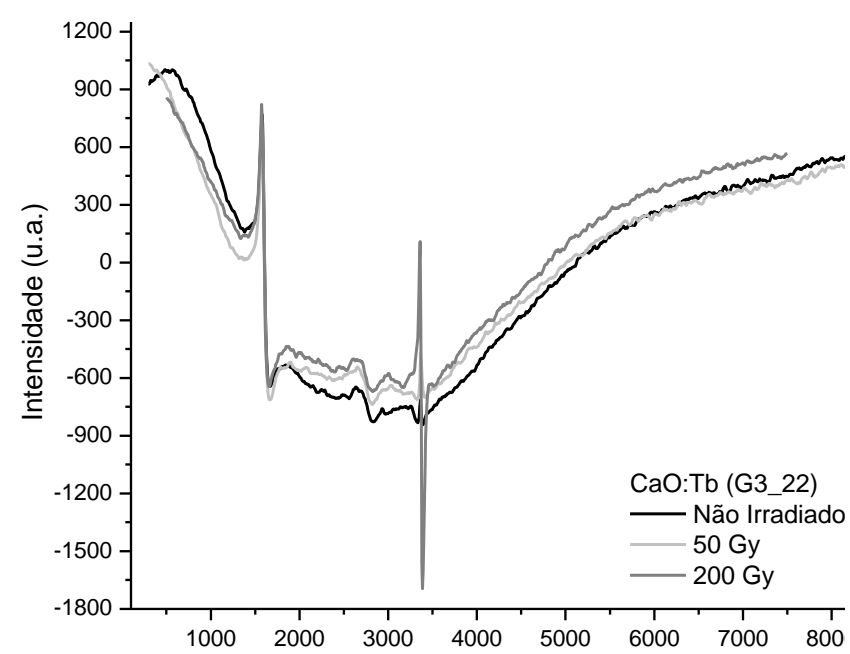

Figura 4.27. Espectro de EPR medidos em banda X, temperatura ambiente e CW para CaO:Tb (G3_22) não irradiado, irradiado com 50 Gy e 200 Gy.

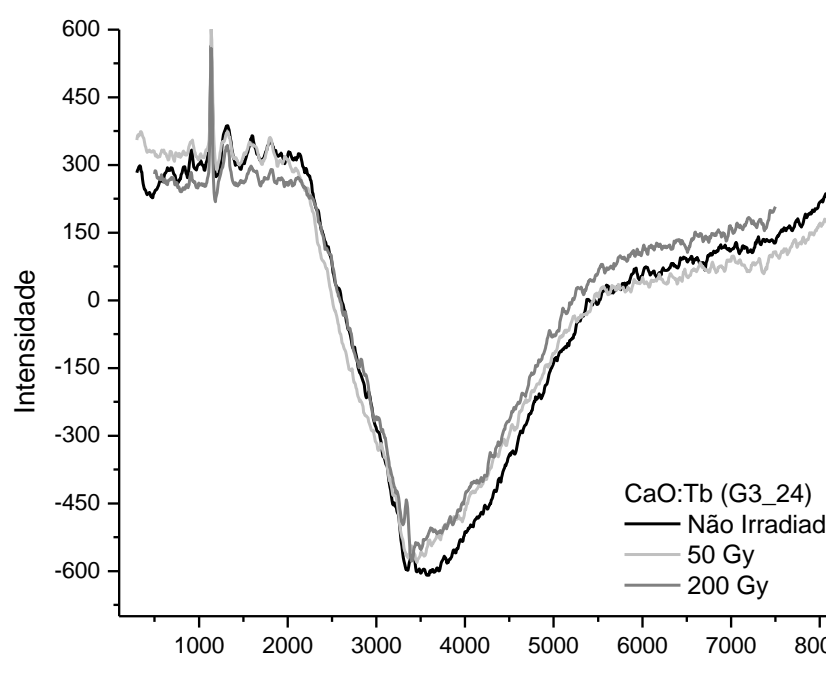

Figura 4.28. Espectro de EPR medidos em banda X, temperatura ambiente e CW para CaO:Tb (G3_24) não irradiado, irradiado com 50 Gy e 200 Gy.

Novamente, o primeiro aspecto que tentamos observar foi a existência de algum sinal paramagnético devido a algum centro luminescente (criado pela exposição do material a radiação ionizante).

Nos espectros de EPR para o óxido de cálcio dopado com Térbio não vemos aparecimento ou desaparecimento de sinais devido à exposição à radiação. Também não observamos mudança na intensidade das linhas. Os centros luminescentes (centros F) possuem linhas conhecidas de 
EPR para $\mathrm{CaO}$ e não foram vistas em nossas amostras [44]. O sinal característico do centro $\mathrm{F}$ em $\mathrm{CaO}$ é similar ao do encontrado no $\mathrm{MgO}$ (mostrado na Figura 4.23.), uma vez que possuem mesma simetria.

Óxido de Cálcio puro não possui centros paramagnéticos, então nossa busca é por sinais de EPR devido impurezas, normalmente observados em cristais de $\mathrm{CaO}$, que são: $\mathrm{Gd}^{2+}, \mathrm{Mn}^{2+}$, $\mathrm{Fe}^{3+}, \mathrm{Cr}^{3+}, \mathrm{V}^{3+}$ e $\mathrm{Ti}^{+}$[45]. Não observamos as linhas características do $\mathrm{Gd}^{2+}, \mathrm{Cr}^{3+}$ [46]. Também não observamos as linhas características do $\mathrm{Mn}^{2+}$ [47].

$\mathrm{Na}$ amostra G3_22 a linha característica do $\mathrm{Fe}^{3+}$ [48] casa com a linha em $3365 \mathrm{G}$ e $\mathrm{g}=$

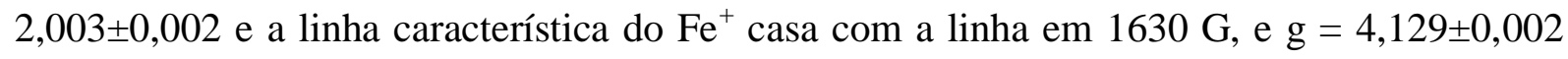
(mostrados na Figura 4.28).

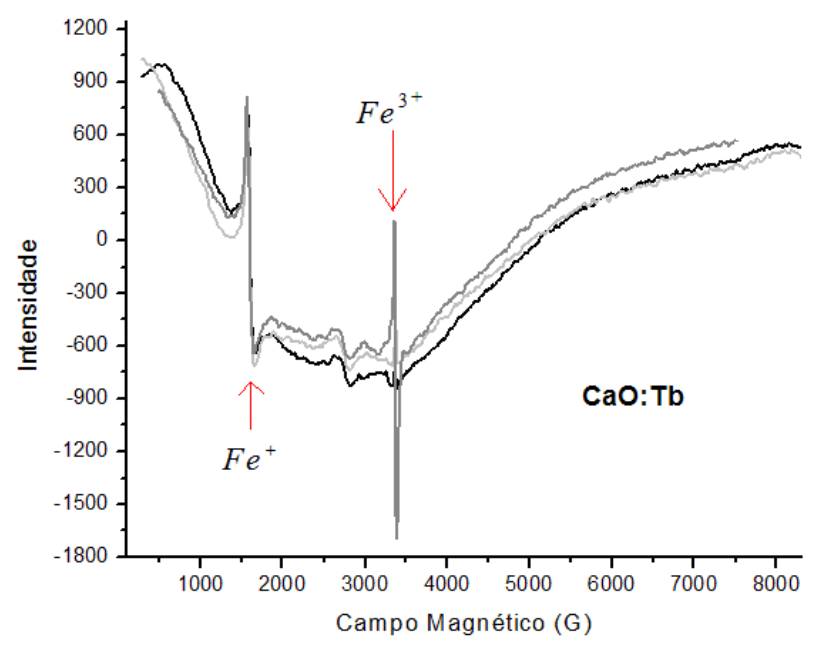

Figura 4.29. Sinais do $\mathrm{Fe}^{+} \mathrm{e} \mathrm{Fe}^{3+} \mathrm{em} \mathrm{CaO}$ (G2_22).

Tantos no espectro da amostra G3_22 quanto G3_24 podemos observar um sinal largo em torno de $\mathrm{g}=2,0023$ ( $\mathrm{g}$ do elétron livre). Pouco se pode dizer sobre esses sinais, pois provavelmente deve-se a um aglomerado de sinais diferentes. Nessa região temos, por exemplo, centros de buraco, e centros com spin $1 / 2$. 
Novamente, para que possam ser observados os sinais devido ao centro F amostras mais puras são necessárias, bem como medidas com constante de tempo maior e varreduras menores, para que sinais finos, como os do centro F, possam ser observados. 


\section{RESULTADOS III: SENSIBILIDADE DO $\mathrm{Al}_{2} \mathrm{O}_{3}: \mathrm{C}$ A UV}

Entender os efeitos da radiação UV em humanos é essencial para podermos avaliar as conseqüências de exposição em diferentes tecidos sob diferentes intensidades, especialmente com a descoberta do processo de rarefação da camada de ozônio, que filtra raios UV do Sol, pela constante emissão de monóxido de carbono.

Por ser um material bastante sensível a radiação ionizante $\mathrm{Al}_{2} \mathrm{O}_{3}: \mathrm{C}$ é um bom candidato como material para dosimetria UV. Mas é preciso estudar se existem mudanças na sensibilidade do material quando exposto a diferentes comprimentos de onda de UV, ou seja verificar a reprodutibilidade, padrão do sinal OSL e se exposições a UV alteram a resposta do material quando exposto a outros tipos de radiação (como $\beta, \gamma$ e raios-X, com resposta bastante conhecida para $\left.\mathrm{Al}_{2} \mathrm{O}_{3}: \mathrm{C}\right)$.

\subsection{As Amostras e Detalhes Experimentais.}

Em nosso estudo uma fita de $\mathrm{Al}_{2} \mathrm{O}_{3}: \mathrm{C}$ (usada em dosímetros Luxel, Figura 2.2. a) foi cortada em 8 pequenas circunferências de $1 \mathrm{~cm}$ de diâmetro. Cada amostra recebeu um número correspondente (de 1 a 8 ).

A exposição das amostras a UV foi feita usando a lâmpada de Xe do FluoroLog®-3 (descrito no Capítulo 2, item 6.2):

- A amostra de número 1 foi usada para exposição de comprimento de onda de $350 \mathrm{~nm}$.

- A amostra de número 2 foi usada para exposição de comprimento de onda de $325 \mathrm{~nm}$.

- A amostra de número 3 foi usada para exposição de comprimento de onda de $300 \mathrm{~nm}$.

- A amostra de número 4 foi usada para exposição de comprimento de onda de $275 \mathrm{~nm}$. 
- A amostra de número 5 foi usada para exposição de comprimento de onda de $250 \mathrm{~nm}$.

- A amostra de número 6 foi usada para exposição de comprimento de onda de $225 \mathrm{~nm}$.

- A amostra de número 7 foi usada para exposição de comprimento de onda de $210 \mathrm{~nm}$.

A amostra de número 8 não foi exposta a UV para servir de referência, ou seja, para assegurar que eventuais mudanças no sinal OSL seriam devido a UV e não a algum outro fator externo (que também seria percebido pela amostra de referência).

No total foram feitas seis exposições com UV, mudando o tempo de exposição: 10, 20, 50, 100, 200 e 500 segundos. Para cada exposição era lido o sinal OSL no aparelho Risø (descrito no Capítulo 2, item 5.2), usando LED azul com 120 segundos de tempo de leitura.

O esquema com a sequiência das irradiações com UV, $\beta$ e medidas do sinal OSL é apresentado na Tabela 5.1: 


\begin{tabular}{|c|c|c|c|c|c|c|c|c|}
\hline \multirow{3}{*}{$\begin{array}{c}\begin{array}{c}\text { Exposição } \\
\text { e medida } \\
\text { OSL }\end{array} \\
\beta_{1}\end{array}$} & \multicolumn{8}{|c|}{ Esquema com Seqüência das Exposições e Medidas do Sinal OSL por Amostra } \\
\hline & \multirow{2}{*}{$\begin{array}{c}\text { Amsotra 1 } \\
3\end{array}$} & \multirow{2}{*}{$\begin{array}{c}\text { Amostra } 2 \\
3\end{array}$} & \multirow{2}{*}{$\begin{array}{c}\text { Amostra } 3 \\
\text { oo de Exposiç } \\
3\end{array}$} & \multirow{2}{*}{$\begin{array}{c}\text { Amostra 4 } \\
\text { (para } \beta \text { ou U } \\
3\end{array}$} & \multirow{2}{*}{$\begin{array}{c}\text { Amostra } 5 \\
\text { e de Medida } \\
3\end{array}$} & \multirow{2}{*}{$\begin{array}{c}\text { Amsotra } 6 \\
\text { SL) em segu } \\
3\end{array}$} & \multirow{2}{*}{$\begin{array}{c}\text { Amsotra 7 } \\
\text { dos } \\
3\end{array}$} & \multirow{2}{*}{$\begin{array}{c}\text { Amsotra } 8 \\
3\end{array}$} \\
\hline & & & & & & & & \\
\hline OSL & 120 & 120 & 120 & 120 & 120 & 120 & 120 & 120 \\
\hline UV & 10 & 10 & 10 & 10 & 10 & 10 & 10 & - \\
\hline OSL & 120 & 120 & 120 & 120 & 120 & 120 & 120 & - \\
\hline$\beta_{2}$ & 3 & 3 & 3 & 3 & 3 & 3 & 3 & 3 \\
\hline OSL & 120 & 120 & 120 & 120 & 120 & 120 & 120 & 120 \\
\hline UV & 20 & 20 & 20 & 20 & 20 & 20 & 20 & - \\
\hline OSL & 120 & 120 & 120 & 120 & 120 & 120 & 120 & - \\
\hline$\beta_{3}$ & 3 & 3 & 3 & 3 & 3 & 3 & 3 & 3 \\
\hline OSL & 120 & 120 & 120 & 120 & 120 & 120 & 120 & 120 \\
\hline UV & 50 & 50 & 50 & 50 & 50 & 50 & 50 & - \\
\hline OSL & 120 & 120 & 120 & 120 & 120 & 120 & 120 & - \\
\hline$\beta_{4}$ & 3 & 3 & 3 & 3 & 3 & 3 & 3 & 3 \\
\hline OSL & 120 & 120 & 120 & 120 & 120 & 120 & 120 & 120 \\
\hline UV & 100 & 100 & 100 & 100 & 100 & 100 & 100 & - \\
\hline OSL & 120 & 120 & 120 & 120 & 120 & 120 & 120 & - \\
\hline$\beta_{5}$ & 3 & 3 & 3 & 3 & 3 & 3 & 3 & 3 \\
\hline OSL & 120 & 120 & 120 & 120 & 120 & 120 & 120 & 120 \\
\hline $\mathbf{U V}$ & 200 & 200 & 200 & 200 & 200 & 200 & 200 & - \\
\hline OSL & 120 & 120 & 120 & 120 & 120 & 120 & 120 & - \\
\hline$\beta_{6}$ & 3 & 3 & 3 & 3 & 3 & 3 & 3 & 3 \\
\hline OSL & 120 & 120 & 120 & 120 & 120 & 120 & 120 & 120 \\
\hline $\mathbf{U V}$ & 500 & 500 & 500 & 500 & 500 & 500 & 500 & - \\
\hline OSL & 120 & 120 & 120 & 120 & 120 & 120 & 120 & - \\
\hline$\beta_{7}$ & 3 & 3 & 3 & 3 & 3 & 3 & 3 & 3 \\
\hline OSL & 120 & 120 & 120 & 120 & 120 & 120 & 120 & 120 \\
\hline
\end{tabular}

Tabela 5.1. Esquema com a seqüência das irradiações com UV, $\beta$ e medidas do sinal OSL.

Todas as amostras foram expostas por três segundos de radiação $\beta$ de uma fonte de ${ }^{90} \mathrm{Sr} /{ }^{90} \mathrm{Y}$ para comparação de sinal OSL entre cada exposição a UV. Essa comparação é necessária para averiguar se houve mudança na sensibilidade do material, pois o sinal OSL para exposição a $\beta$ deve se comportar de mesma forma para cada uma das amostras, ou seja, se UV altera a sensibilidade do $\mathrm{Al}_{2} \mathrm{O}_{3}: \mathrm{C}$ então isso se refletirá nas medidas OSL para exposição a $\beta$. 
a)
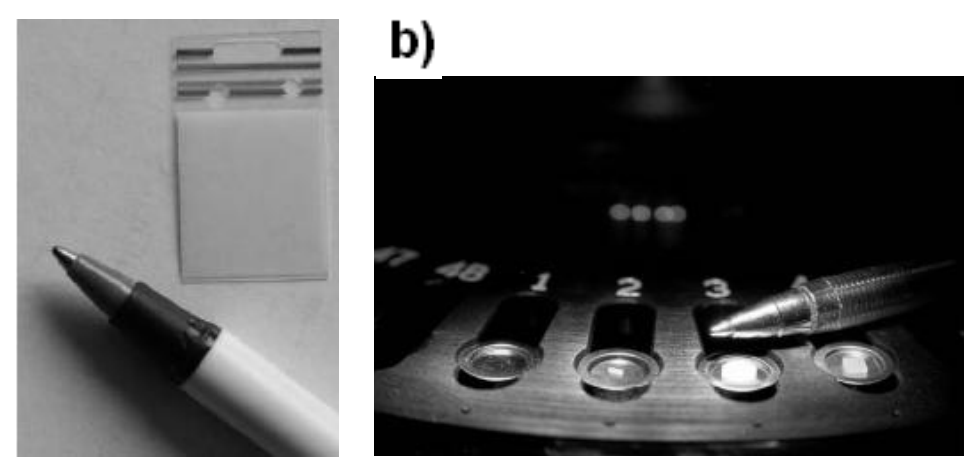

Figura 5.1. a) Fita Luxel de Al203:C e b) amostra no Risø para medida.

\subsection{Resultados e Discussão.}

Apresentamos os decaimentos exponenciais medidos pelo Risø para as exposições a UV e $\beta$ de cada amostra.

Contudo para compararmos corretamente os resultados entre comprimentos de onda de UV diferentes é preciso calcular a área do sinal OSL e correlacionar com a intensidade da fonte de Xe, ou seja, com o número de fótons por unidade de tempo e de área (fótons $/ \mathrm{cm}^{2} . \mathrm{s}$ ) para cada comprimento de onda.

A intensidade da lâmpada para cada comprimento de onda foi medida e é dada na Tabela 5.2. abaixo e pelo gráfico da Figura 5.2:

\begin{tabular}{cc|}
$\begin{array}{c}\text { Comprimento } \\
\text { de Onda }(\mathbf{n m})\end{array}$ & $\begin{array}{c}\text { Intensidade } \\
\left(\mathbf{m W} / \mathbf{c m}^{2}\right)\end{array}$ \\
210 & 0.00042 \\
225 & 0.0049 \\
250 & 0.087 \\
275 & 0.300 \\
300 & 0.398 \\
325 & 0.545 \\
350 & 0.705 \\
\hline
\end{tabular}

Tabela 5.2. Comprimento de onda e intensidade da lâmpada de Xe. 


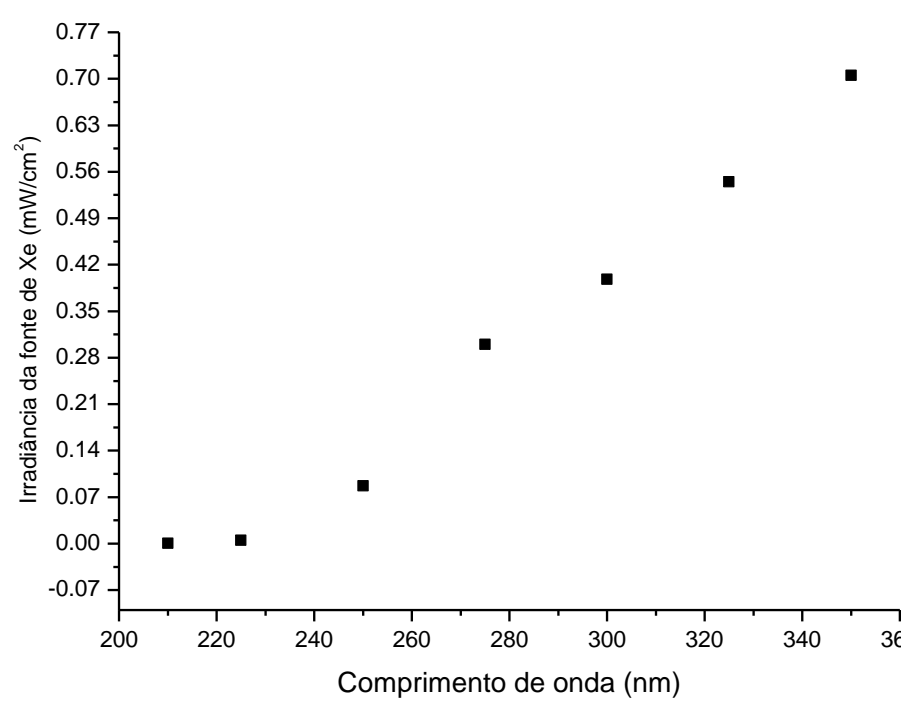

Figura 5.2. Intensidade da lâmpada de Xe por comprimento de onda.

Para calcular o sinal integrado total OSL (denominado I) de cada linha OSL somamos a intensidade dos 120 pontos (cada ponto descrito por $n_{i}$, com $i=1,2,3 \ldots 120$ ) e subtraímos a média dos últimos vinte pontos multiplicados por 120, como descrito na equação 5.1, abaixo:

$$
I=\sum_{i=1}^{120} n_{i}-120 *\left(\sum_{i=100}^{120} n i / 20\right) \text { Equação (5.1) }
$$

Dessa forma temos a área de cada decaimento exponencial, que é a soma das intensidades dos 120 pontos menos o sinal de fundo. Como já explicado na introdução, item 2.1. a dose é proporcional à área total da curva OSL menos o sinal de fundo.

Dessa forma temos então gráficos, de I para cada intensidade da lâmpada.

Apresentamos, em sequiência, os resultados para decaimento exponencial para cada amsotra irradiada com $\beta$ e UV, e o gráfico de I por número de fótons por unidade de área e tempo.

\section{a) Amostra 1 .}

Para a Amostra 1 (Figura 5.3 b.), exposta a $350 \mathrm{~nm}$ de UV, nota-se que a resposta do material a $\beta$ decai da mesma maneira até aproximadamente 10 segundos para todas as medidas e começa a se separar de maneira que ao final dos 120 segundos vemos que cada irradiação 
termina com uma intensidade diferente, sendo que a maior diferença entre as intensidades está entre a sétima irradiação (linha amarela), com 375 u.a., e quarta irradiação (linha azul anil), com 600 u.a.
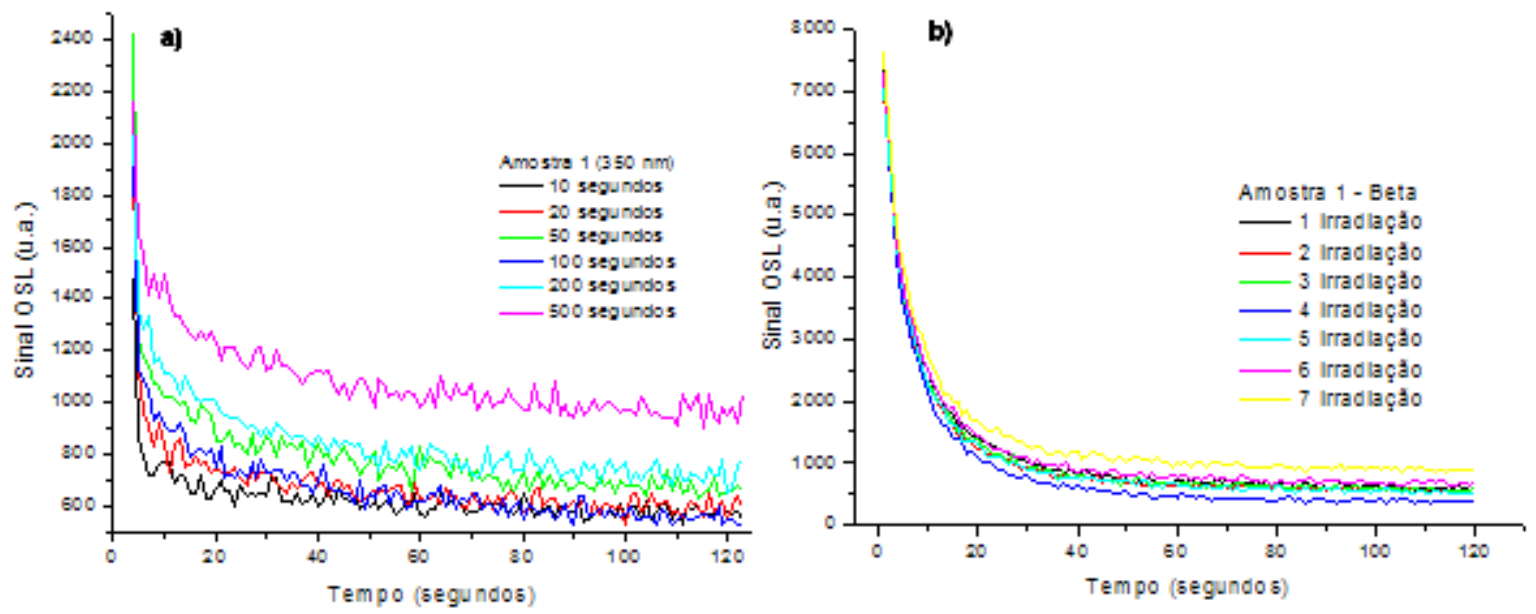

Figura 5.3. a) sinal OSL da Amostra 2 exposta a $325 \mathrm{~nm}$ de UV para diferentes tempos e b) sinal OSL da amostra 2 irradiada $\operatorname{com} \beta$ por três segundos.

Analisando o gráfico da Figura 5.4 vemos um crescimento linear até o terceiro ponto (correspondente ao ponto para exposição com 50 segundos) e então intensidades praticamente constantes até a sexta exposição (500 segundos). Isso nos leva a acreditar que a intensidade está saturada (o ultimo ponto está em 7 x $10^{7}$ fótons por tempo e área). 


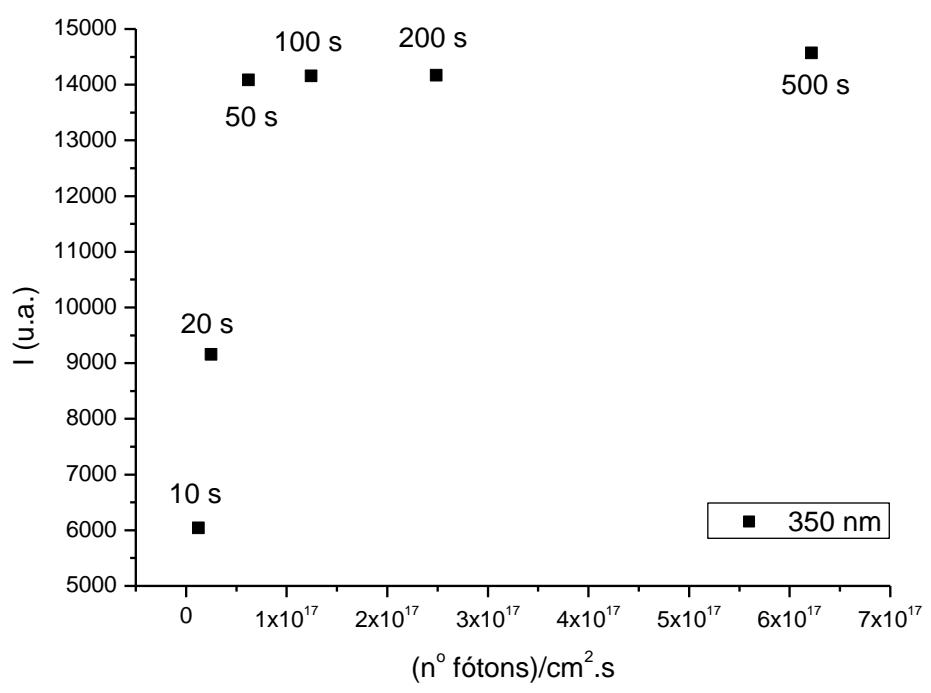

Figura 5.4. Sinal integrado OSL por numero de fótons, para exposição de $350 \mathrm{~nm}$.

b) Amostra 2 .

Para a Amostra 2 (Figura 5.5), exposta a $325 \mathrm{~nm}$ de UV, nota-se que a resposta do material a $\beta$ já começa com decaimentos separados para todas as irradiações. Nenhum dos decaimentos se cruza até o final da leitura (a quinta e a sétima irradiação são quase coincidentes desde o começo da leitura e seguem esse padrão até o final) e a maior diferença entre as intensidades iniciais é vista entre primeira irradiação (em preto) em 800 u.a. e a sexta irradiação (em rosa) em 1400 u.a. Essas separações não seguem um padrão aparente, ou seja, a primeira irradiação e a ultima não são os extremos de diferença de intensidade OSL ao final da medida. 

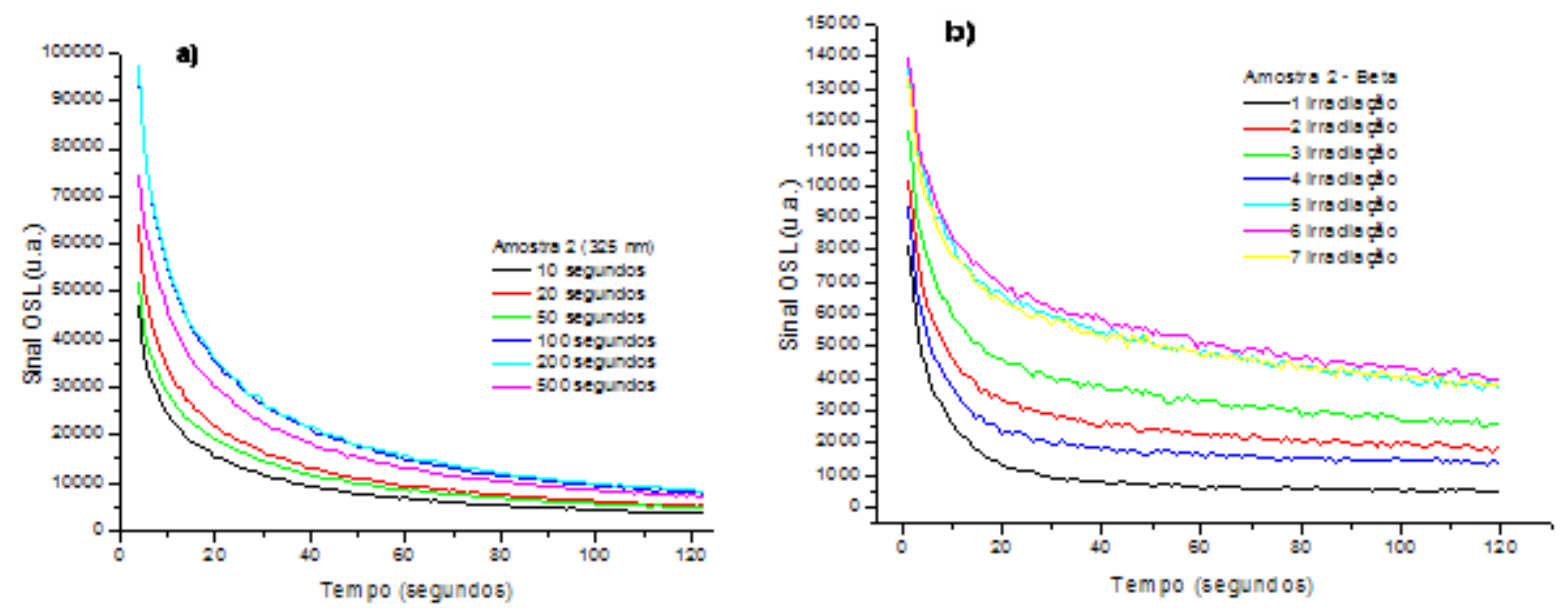

Figura 5.5. a) sinal OSL da Amostra 2 exposta a $325 \mathrm{~nm}$ de UV para diferentes tempos e b) sinal OSL da amostra 2 irradiada com $\beta$ por três segundos.

Pelo gráfico da Figura 5.6 vemos que a intensidade não cresce de acordo com o tempo de exposição. Esse comportamento repete o observado no gráfico 5.5. a. em que a terceira exposição (50 segundos) possui intensidade menor do que a exposição por 20 segundos e a sexta exposição (500 segundos) possui intensidade menor que a de 200 e 100 segundos.

$\mathrm{O} \mathrm{Al}{ }_{2} \mathrm{O}_{3}$ possui luminescência característica em $3.8 \mathrm{eV}(325 \mathrm{~nm})$ devido a excitação em 5.4 eV (230 nm) [49]. Essa banda é devido ao centro $\mathrm{F}^{+}$.

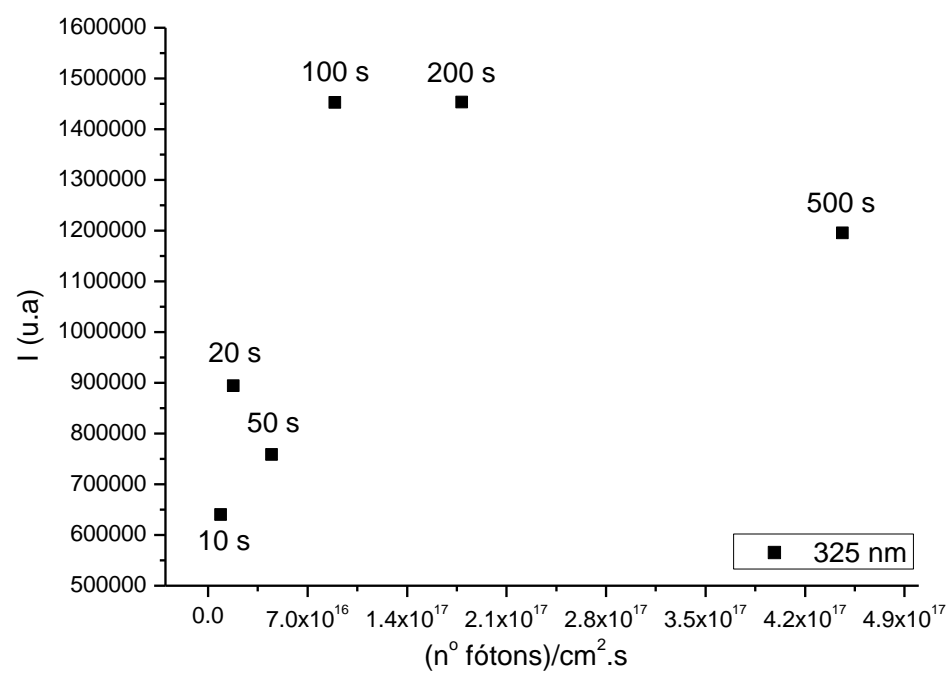

Figura 5.6. Sinal integrado OSL por numero de fótons, para exposição de $325 \mathrm{~nm}$. 


\section{c) Amostra 3 .}

Para a Amostra 3 (Figura 5.7. b.), exposta a $300 \mathrm{~nm}$ de UV, nota-se que a resposta do material a $\beta$ começa com decaimentos bem separados para todas as irradiações. Nenhum decaimento se cruza até o final da leitura e a maior diferença nas intensidades iniciais é vista entre primeira irradiação (em preto) em 7500 u.a. e a sétima irradiação (em amarelo) em 12000 u.a. Embora a primeira irradiação a última sejam os extremos em intensidade não vemos um aumento crescente das intensidades com a irradiação.
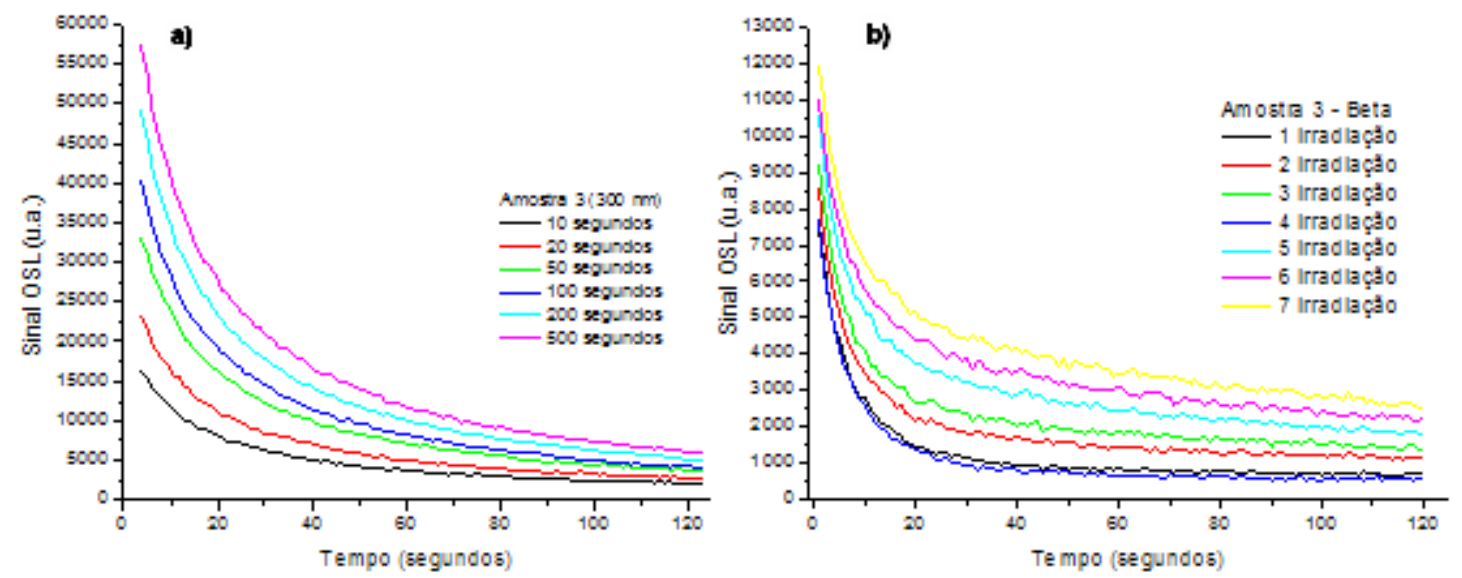

Figura 5.7. a) sinal OSL da Amostra 3 exposta a $300 \mathrm{~nm}$ de UV para diferentes tempos e b) sinal OSL da amostra 3 irradiada $\operatorname{com} \beta$ por três segundos.

O comportamento de I por número de fótons no gráfico da Figura 5.8. apresenta um crescimento exponencial dos pontos que segue o mesmo comportamento observado para o decaimento das curvas no gráfico da Figura 5.7. a. 


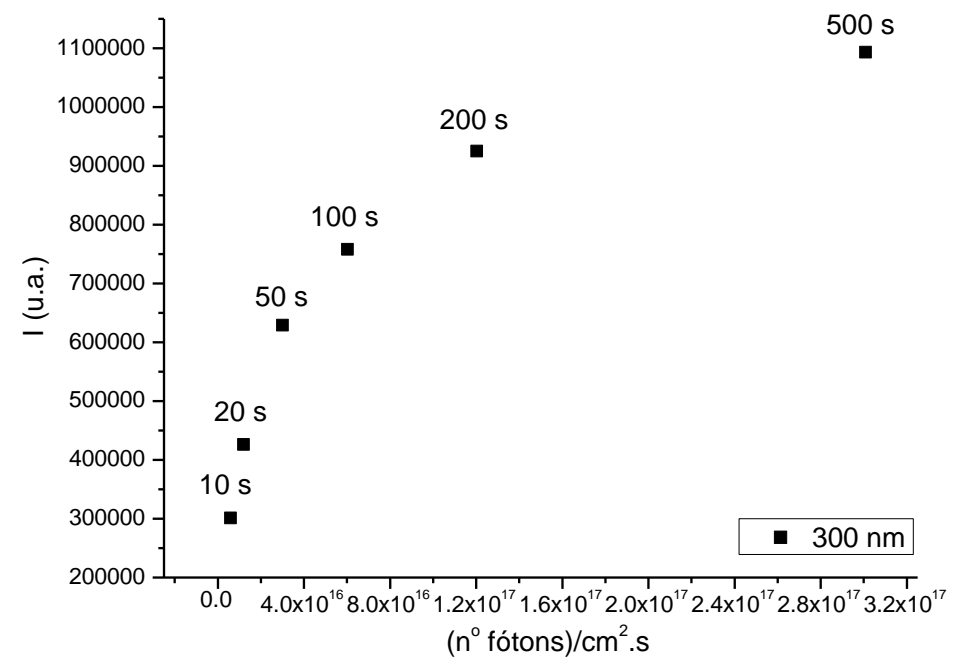

Figura 5.8. Sinal integrado OSL por numero de fótons, para exposição de $300 \mathrm{~nm}$.

d) Amostra 4 .

Para a Amostra 4 (Figura 5.9. b.), exposta a $275 \mathrm{~nm}$ de UV, nota-se que a resposta do material a $\beta$ começa com decaimentos coincidentes em 9000 u.a. e segue decaindo com pouca separação entre as exposições. A maior diferença em intensidade ao final da medida esta entre a sétima exposição (em amarelo) com 950 u.a. e a quarta exposição (em azul anil) com 350 u.a.
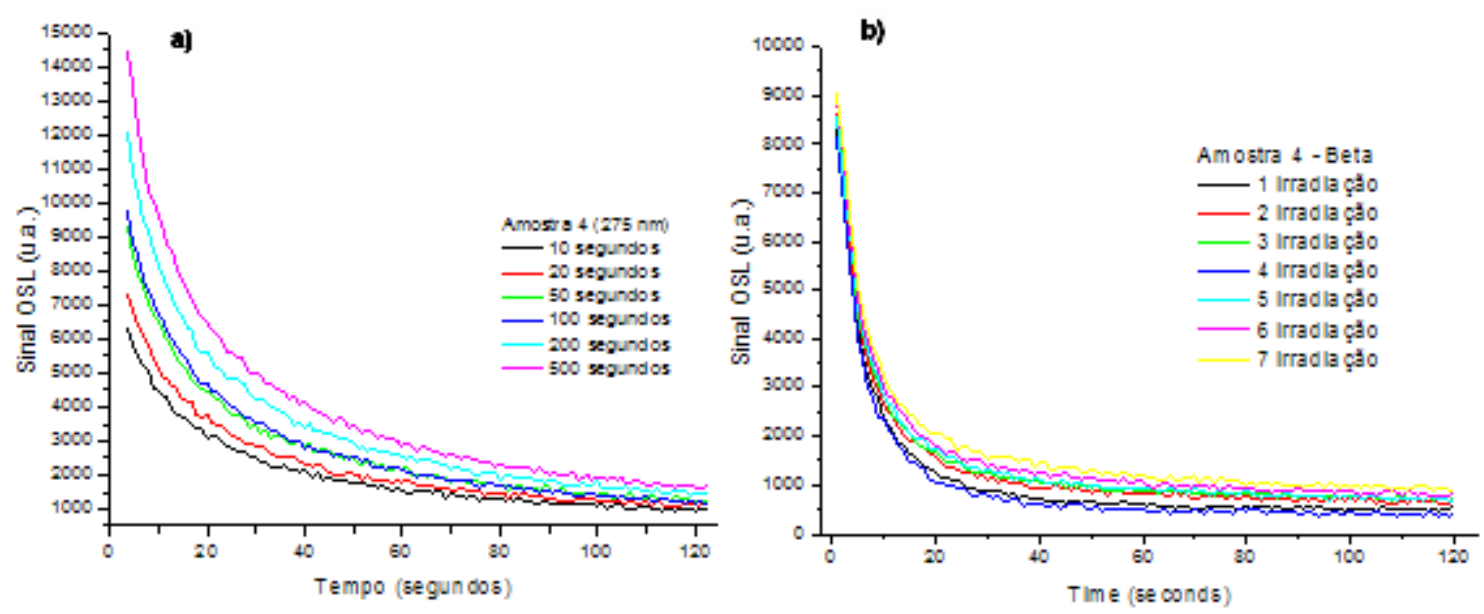

Figura 5.9. a) sinal OSL da Amostra 4 exposta a $275 \mathrm{~nm}$ de UV para diferentes tempos e b) sinal OSL da amostra 4 irradiada com $\beta$ por três segundos. 
No gráfico de I por número de fótons da Figura 5.10. vemos um crescimento exponencial dos pontos, seguindo um padrão esperado (com intensidade do sinal crescendo com o aumento do tempo de exposição) mesmo comportamento observado no gráfico da Figura 5.9. a.

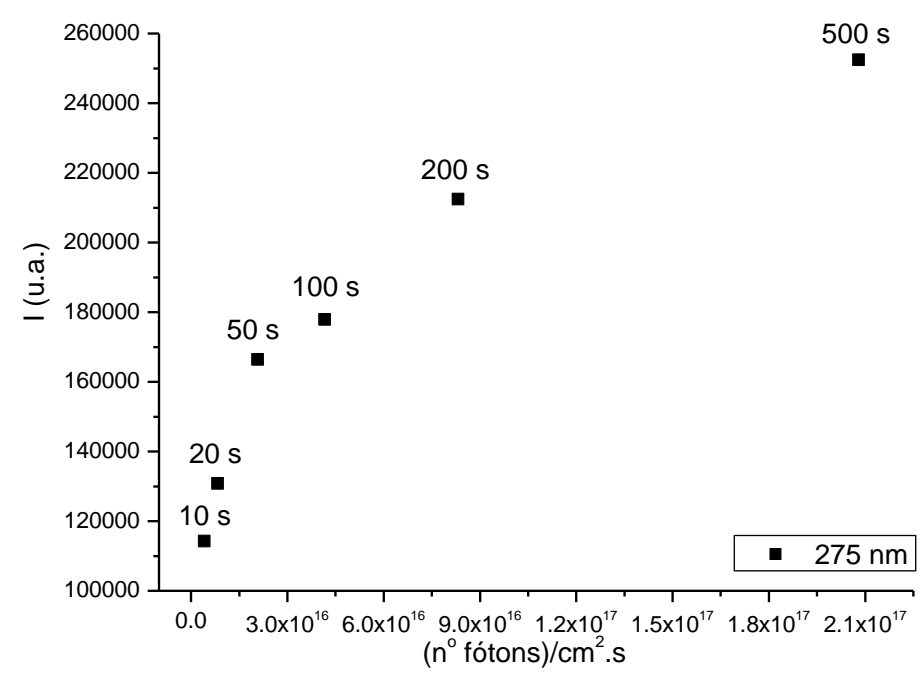

Figura 5.10. Sinal integrado OSL por número de fótons, para exposição de 275 nm.

e) Amostra 5 .

Para a Amostra 5 (Figura 5.11. b), exposta a $250 \mathrm{~nm}$ de UV, nota-se que a resposta do material a $\beta$ começa com os decaimentos coincidentes em 7750 u.a. e segue decaindo sem separação entre as exposições. As intensidades ao final da medida estão na faixa encontrada para as medidas da amostra de referência (amostra 8), em 500 u.a. 

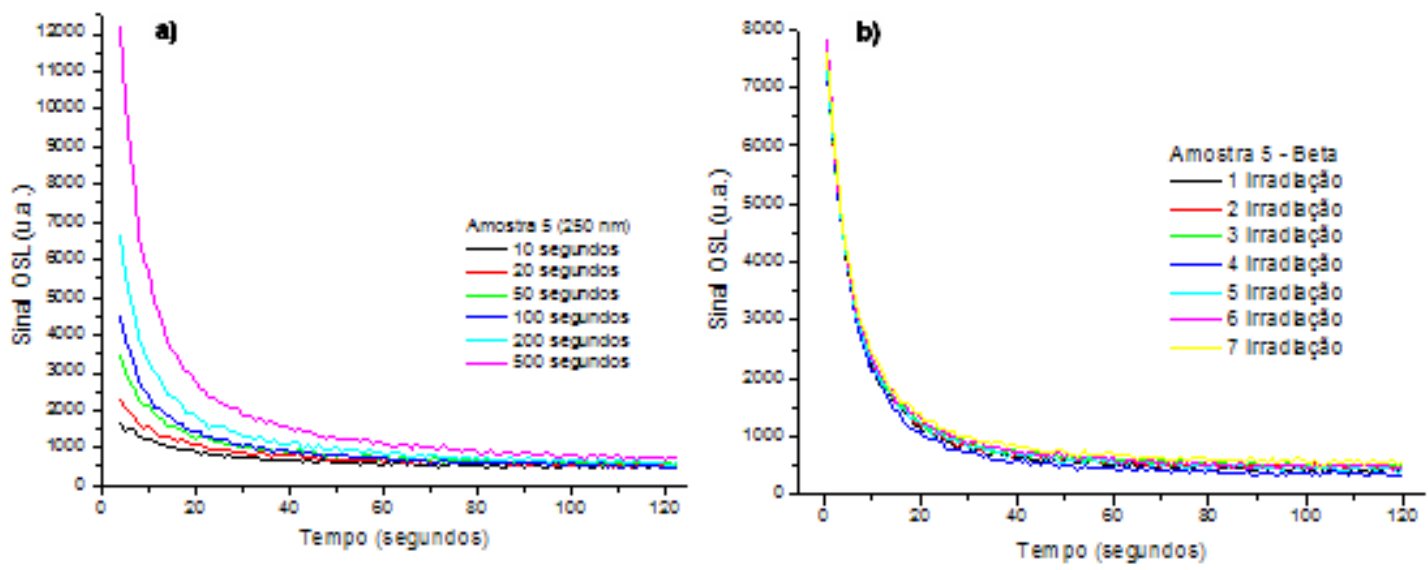

Figura 5.11. a) sinal OSL da Amostra 5 exposta a $250 \mathrm{~nm}$ de UV para diferentes tempos e b) sinal OSL da amostra 5 irradiada com $\beta$ por três segundos.

Para a exposição com $250 \mathrm{~nm}$ (Figura 5.12.) vemos um crescimento exponencial até a quarta exposição (100 segundos), mas o comportamento dos dois últimos decaimentos não segue a tendência dos primeiros, sugerindo um comportamento que pode ser descrito pela soma de exponenciais.

$\mathrm{O} \mathrm{Al}_{2} \mathrm{O}_{3}: \mathrm{C}$ apresenta uma banda de absorção em $4.8 \mathrm{eV}(256 \mathrm{~nm})$ devido ao centro $\mathrm{F}^{+}$.[49] $\mathrm{O}$ comportamento para exposição com $\beta$ mostra que não houve mudança no material e que a emissão é devido a centros $\mathrm{F}^{+}$.

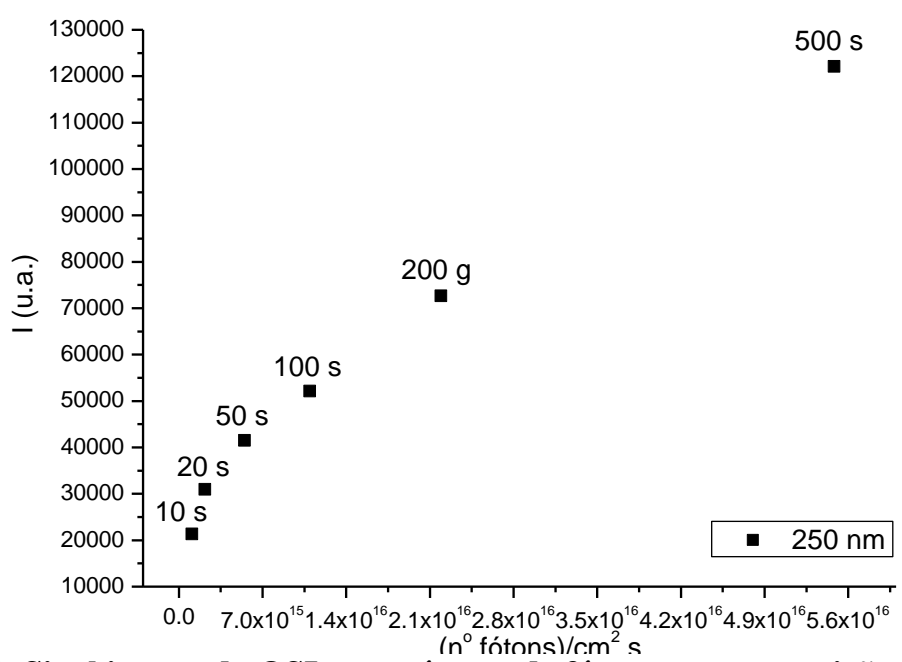

Figura 5.12. Sinal integrado OSL por número de fótons, para exposição de $250 \mathrm{~nm}$. 


\section{f) Amostra 6 .}

Para a Amostra 6 (Figura 5.13. b), exposta a $225 \mathrm{~nm}$ de UV, nota-se que a resposta do material a $\beta$ começa com decaimentos coincidentes em 7500 u.a. com exceção da sétima irradiação (em amarelo) que começa ligeiramente acima, com 8500 u.a. A intensidade ao final da medida esta na faixa encontrada para as medidas da amsotra de referência (Amostra 8), em 500 u.a., com exceção da sétima irradiação que mantém decaimento com intensidade acima das demais, terminando com 1000 u.a.
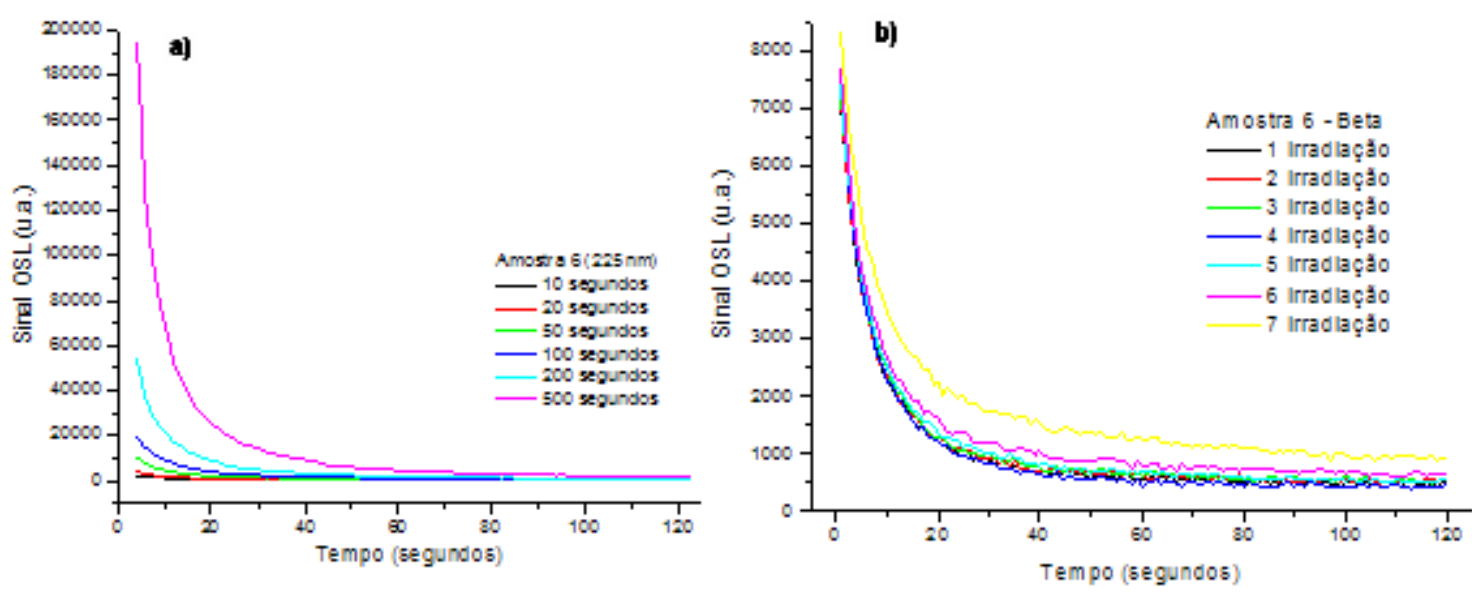

Figura 5.13. a) sinal OSL da Amostra 6 exposta a $225 \mathrm{~nm}$ de UV para diferentes tempos e b) sinal OSL da amostra 6 irradiada com $\beta$ por três segundos.

O comportamento do gráfico da Figura 5.14. apresenta a mesma grande diferença de intensidade entre os extremos observado para o gráfico da Figura 5.13. a.

O comportamento da exposição com $225 \mathrm{~nm}$ (Figura 5.13) nos leva a acreditar que a resposta linear deve-se a baixa potencia da lâmpada para os tempos usados nessa exposição. Provavelmente tempos maiores (com número de fótons da ordem das exposições para 300 $\mathrm{nm}$, por exemplo) apresentariam maiores informações sobre o comportamento da intensidade do sinal OSL para exposição com UV de $225 \mathrm{~nm}$. 
$\mathrm{O} \mathrm{Al}_{2} \mathrm{O}_{3}: \mathrm{C}$ apresenta uma banda de absorção em 6 eV ( 206 nm) devido ao centro F.[49] O comportamento para exposição com $\beta$ mostra que não houve mudança no material e que a emissão é devido a centros F.

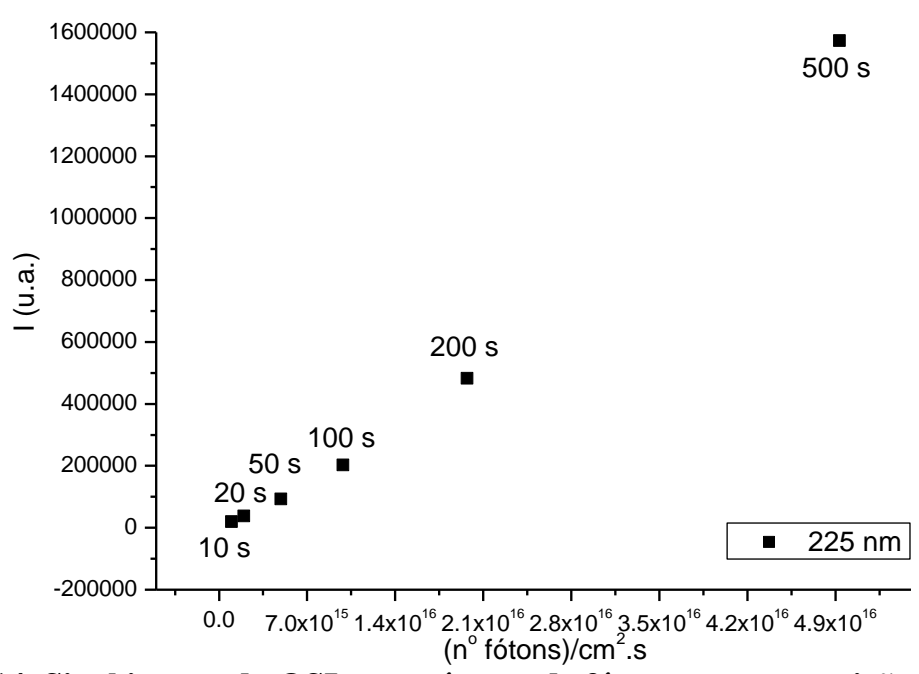

Figura 5.14. Sinal integrado OSL por número de fótons, para exposição de $225 \mathrm{~nm}$.

g) Amostra 7.

Para a Amostra 7 (Figura 5.15. b), exposta a $210 \mathrm{~nm}$ de UV, nota-se que a resposta do material a $\beta$ começa com decaimentos coincidentes em 8000 u.a. e segue sem separação até o final da medida. A intensidade ao final da medida esta na faixa encontrada para as medidas da amostra de referência (amostra 8), em 500 u.a.
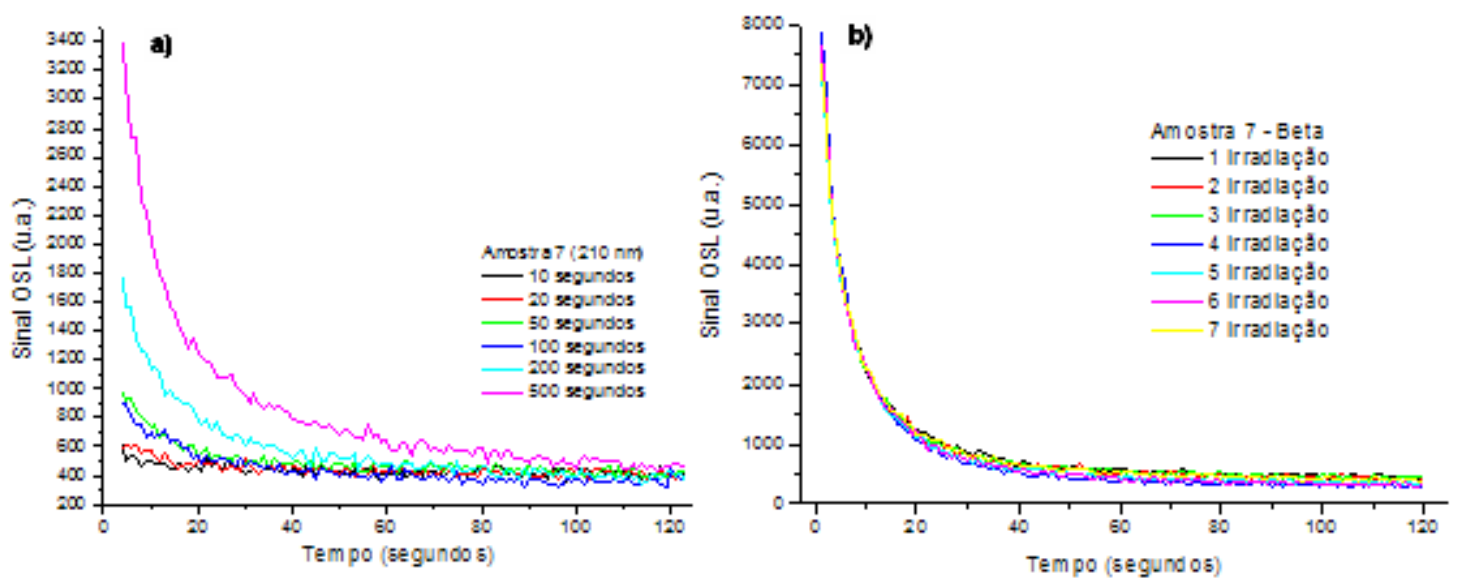

Figura 5.15. a) sinal OSL da Amostra 7 exposta a $210 \mathrm{~nm}$ de UV para diferentes tempos e b) sinal OSL da amostra 7 irradiada com $\beta$ por três segundos. 
O comportamento do gráfico da Figura 5.16 apresenta comportamento semelhante ao gráfico da exposição com 225 nm (Figura 5.14) o que nos leva a acreditar que a resposta linear devese, novamente, a baixa potencia da lâmpada para os tempos usados nessa exposição. Provavelmente tempos maiores (com número de fótons da ordem das exposições para 300 $\mathrm{nm}$, por exemplo) apresentariam maiores informações sobre o comportamento da intensidade do sinal OSL para exposição com UV de $210 \mathrm{~nm}$.

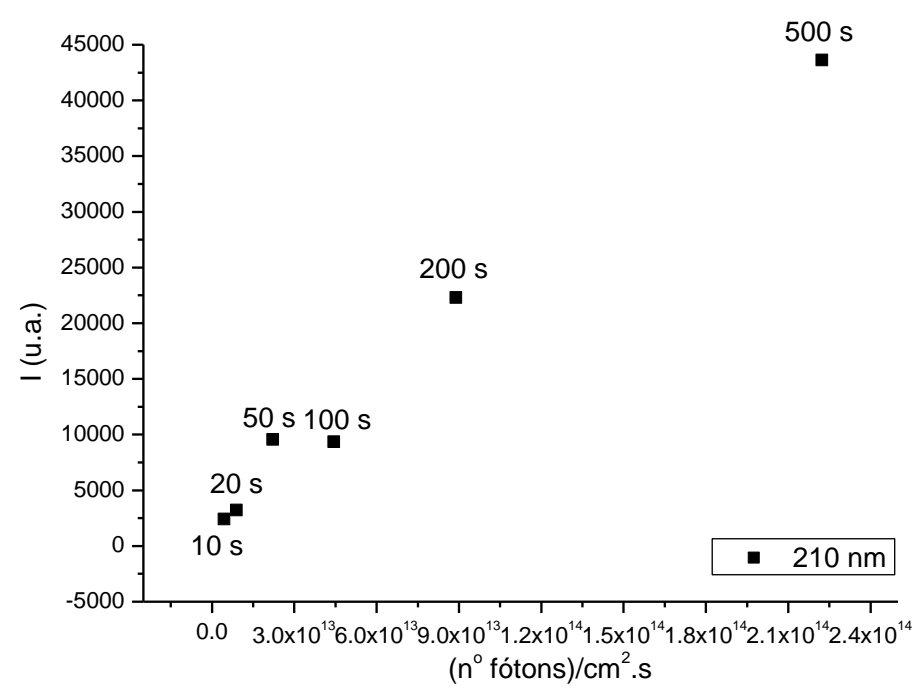

Figura 5.16. Sinal integrado OSL por número de fótons, para exposição de $210 \mathrm{~nm}$.

h) Amostra 8 .

Para a amostra 8 (Figura 5.17), sem exposição a UV, nota-se que a resposta do material a $\beta$ começa com decaimentos coincidentes em 9000 u.a. e segue sem separação até o final da medida (em 500 u.a.), com exceção da quarta irradiação (em azul anil) que começa a se separar em 20 segundos e termina com intensidade ligeiramente maior que as demais, em 750 u.a. 


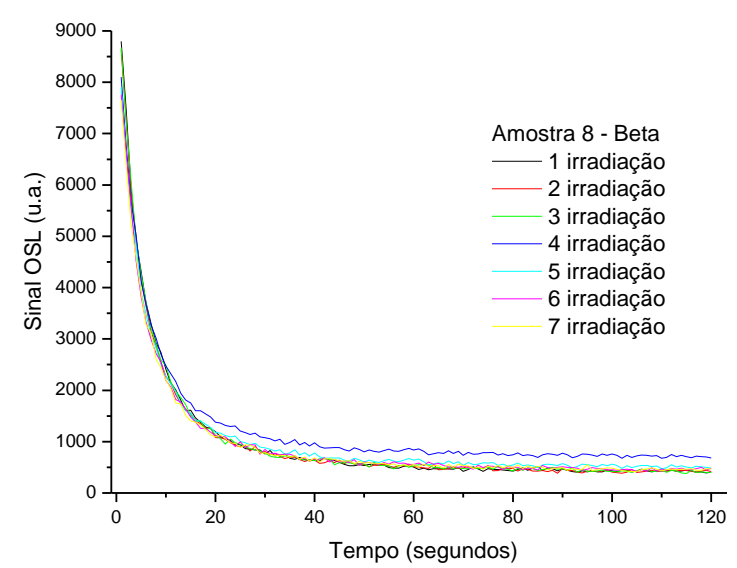

Figura 5.17. Sinal OSL da Amostra 8 irradiada com $\square$ por três segundos.

Esses resultados são os primeiros de uma serie de outras análises que serão feitas, relacionando $\mathrm{Al}_{2} \mathrm{O}_{3}: \mathrm{C}$, OSL e dosimetria com ultravioleta.

Podemos dizer que a resposta do material depende do comprimento de onda de UV utilizado e que o algoritmo para cálculo de dose usando resultado de exposição à UV deverá levar em conta essa informação.

Ainda faz-se necessário estudar com maiores detalhes o comportamento da resposta OSL para diferentes tempos de exposição, quais tempos de exposições saturam o material e principalmente se o comportamento observado em nossas medidas se repete. Já existe estudo relacionando exposições a UV e resposta termoluminescente [50] o que agrega mais informações sobre o problema e ajudará no desenvolvimento de um modelo usando $\mathrm{Al}_{2} \mathrm{O}_{3}: \mathrm{C}$ como material sensível em dosimetria de UV. 


\section{RESULTADOS IV: ESPECTRO DE EMISSÃO E EXCITAÇÃO EM ÓXIDOS DOPADOS COM TÉRBIO.}

A radiação ionizante, ao criar centros de elétrons e buracos ou alterar estados de valência de íons presentes no cristal, introduz novos estados de energia que possibilitam a excitação do espectro eletromagnético em regiões antes transparentes. $\mathrm{O}$ estudo das bandas de excitação óptica possibilita assim obter informações sobre como esses defeitos participam do processo em uma técnica como a luminescência opticamente estimulada.

\subsection{As Amostras e Detalhes Experimentais.}

Embora o uso de luminescência opticamente estimulada (OSL) em dosimetria tenha sido sugerido há muito tempo [2] não existem muitos trabalhos relacionados a esse assunto, especialmente devido à falta de materiais que possuam alta sensibilidade à radiação ionizante e que também apresentem alta eficiência a estimulo óptico. Atualmente as aplicações usando dosimetria OSL são dominadas pelo Óxido de Alumínio dopado com Carbono, que pode ser considerado como material padrão nessa área [1].

$\mathrm{Na}$ busca de novos materiais para uso em dosimetria usando OSL vários estudos têm sido feitos no Laboratório de Dosimetria das Radiações da Universidade Estadual de Oklahoma (Stillwater, EUA). Parte desses trabalhos são feitos em parceria com o Instituto de Ciências Nucleares em Vinca (Belgrado, Sérvia), que forneceu amostras em pó de três óxidos dopados com Térbio, $\mathrm{MgO}: \mathrm{Tb}, \mathrm{Li}_{2} \mathrm{O}: \mathrm{Tb}, \mathrm{CaO}: \mathrm{Tb}$, para análises em dosimetria OSL.

O interesse nesses óxidos está principalmente no desenvolvimento de um modelo para dosimetria em UV e dosimetria de nêutrons, e análises preliminares já mostram resultados promissores nessa área [51]. 
Um estudo bastante importante consiste em adquirir o espectro de emissão e o de excitação para esses óxidos, para então refinar os resultados e determinar com qual comprimento de onda os materiais devem ser expostos para a leitura do sinal OSL.

Em minha estada científica no Laboratório de Dosimetria das Radiações fiz as medidas iniciais de emissão e excitação, usando para essas medidas o Fluorolog-3, descrito no Capitulo 2, item 5.2.

As amostras forma preparadas da seguinte maneira: $10 \mathrm{mg}$ de cada amostra foi pesado usando uma balança analítica com precisão de $0.1 \mathrm{mg}$ (Figura 6.1. a), então o material foi depositado homogeneamente em copinhos de alumínio, mostrado na Figura 6.1. b, de $1 \mathrm{~cm}$ de diâmetro e $0.5 \mathrm{~cm}$ de profundidade, e coberto com spray de silicone (para impedir que o pó caísse dos copinhos), em seguida os copinhos foram colocados por 20 minutos em um forno a $200{ }^{\circ} \mathrm{C}$ para que o silicone secasse e para limpar qualquer sinal no material criado por exposição à luz.

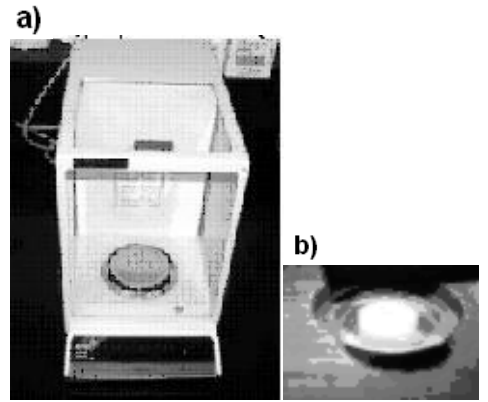

Figura 6.1. a) balança analítica e b) amostra em pó disposta em copo de alumínio.

Os copinhos com as amostras então foram dispostas num pedaço de madeira contendo numeração como mostrado na Figura 6.2. b e depois lidas no FluoroLog ${ }^{\circledR}$ (Figura 6.2. a). Cada amostra recebeu um número e foi classificado em um grupo, como mostrado na Tabela 2.1 no Capítulo 2. 
a)

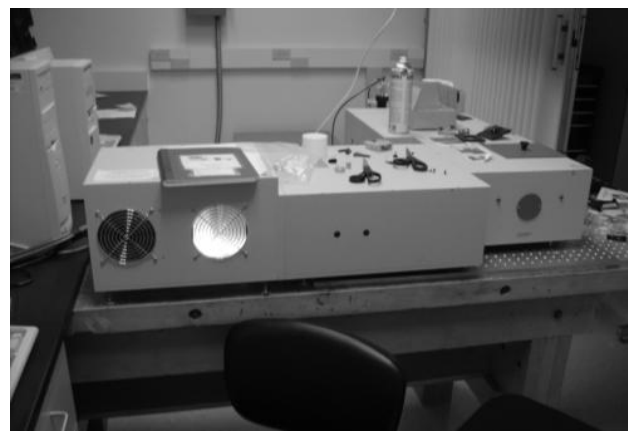

b)

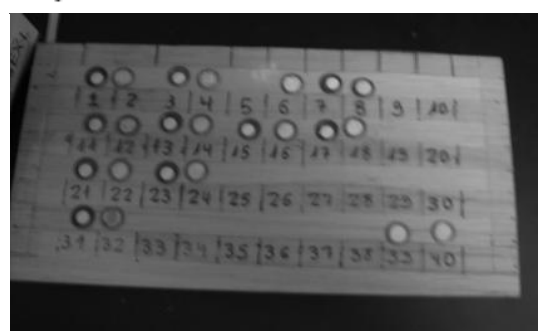

Figura 6.2. a) FluoroLog ${ }^{\circledR}$ em funcionamento b) amostra em pó disposta em copo de alumínio em pedaço de madeira com referência numérica.

Para medidas de excitação foi usado um filtro para UV passa alta de $455 \mathrm{~nm}$ (transmitância por comprimento de onda na Figura 6.3) de 2" x 2" 3mm em frente a fonte.

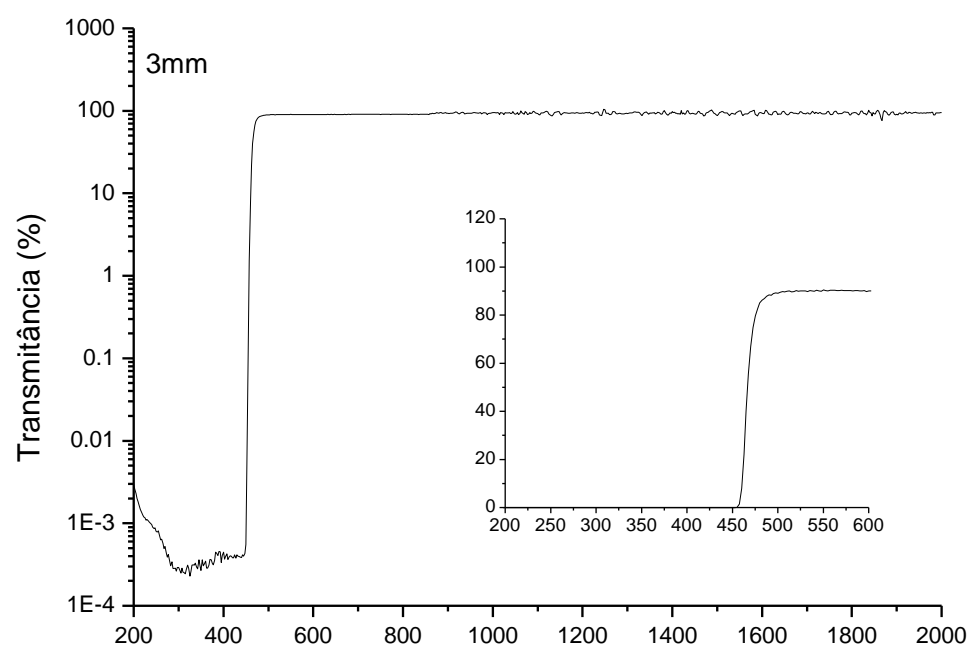

Figura 6.3. Transmitância por comprimento de onda para filtro passa alta de $455 \mathrm{~nm}$.

Para os espectros de emissão foi usado um filtro para UV passa alta de $515 \mathrm{~nm}$ (transmitância por comprimento de onda na Figura 6.4.) de 2" x 2" $2 \mathrm{~mm}$ em frente a fonte. 


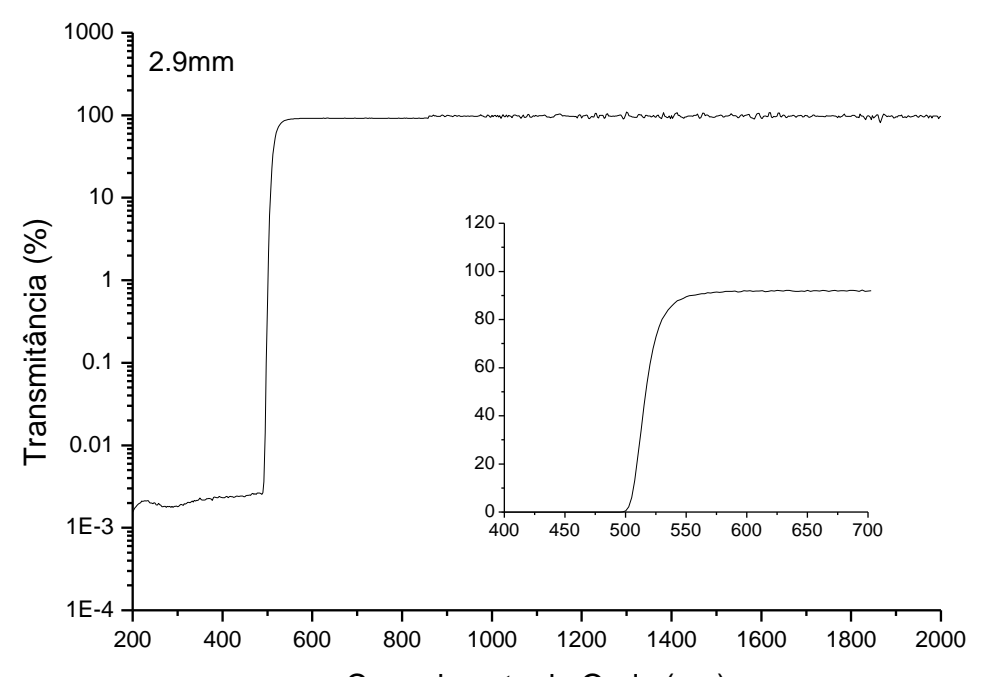

Figura 6.4. Transmitância por comprimento de onda para filtro passa alta de $515 \mathrm{~nm}$.

\subsection{Resultados e Discussão.}

\subsubsection{Espectro de Emissão.}

Os espectros de emissão foram adquiridos para amostras irradiadas. Os óxidos em pó foram irradiados com 200 Gy de radiação $\beta$ numa fonte de ${ }^{90} \mathrm{Sr} /{ }^{90} \mathrm{Y}$. Dessa forma temos os gráficos para as amostras irradiadas.

Para aquisição dos espectros de emissão usamos um intervalo de 200 a 470 nm; excitação de $525 \mathrm{~nm}$; tempo integrado de 0.5 segundos, e tempo de incremento de 0.5 . O aparelho foi usado na função S/R, ou seja, intensidade da amostra dividido pela intensidade da lâmpada. O espectro de emissão para cada amostra é mostrado a seguir.

a) Grupo 1- $\mathrm{Li}_{2} \mathrm{O}: \mathrm{Tb}$. 


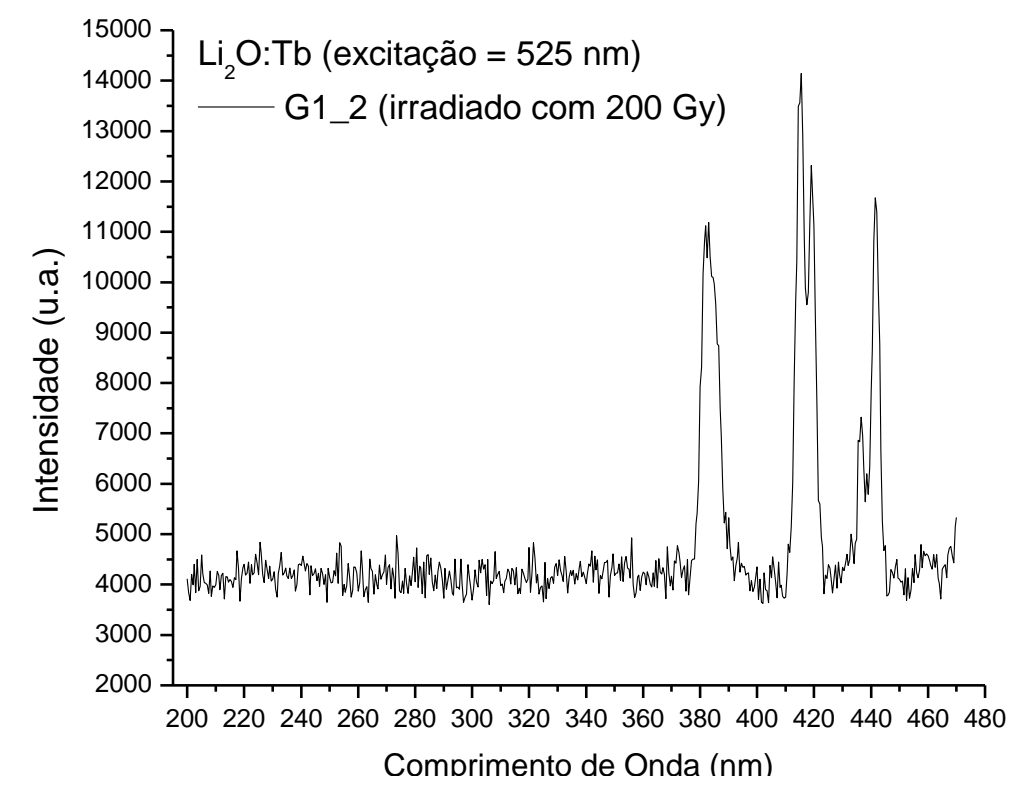

Figura 6.5. Espectro de emissão para $\mathrm{Li}_{2} \mathrm{O}$ :Tb (G1_2) irradiado, com excitação de 525 nm.

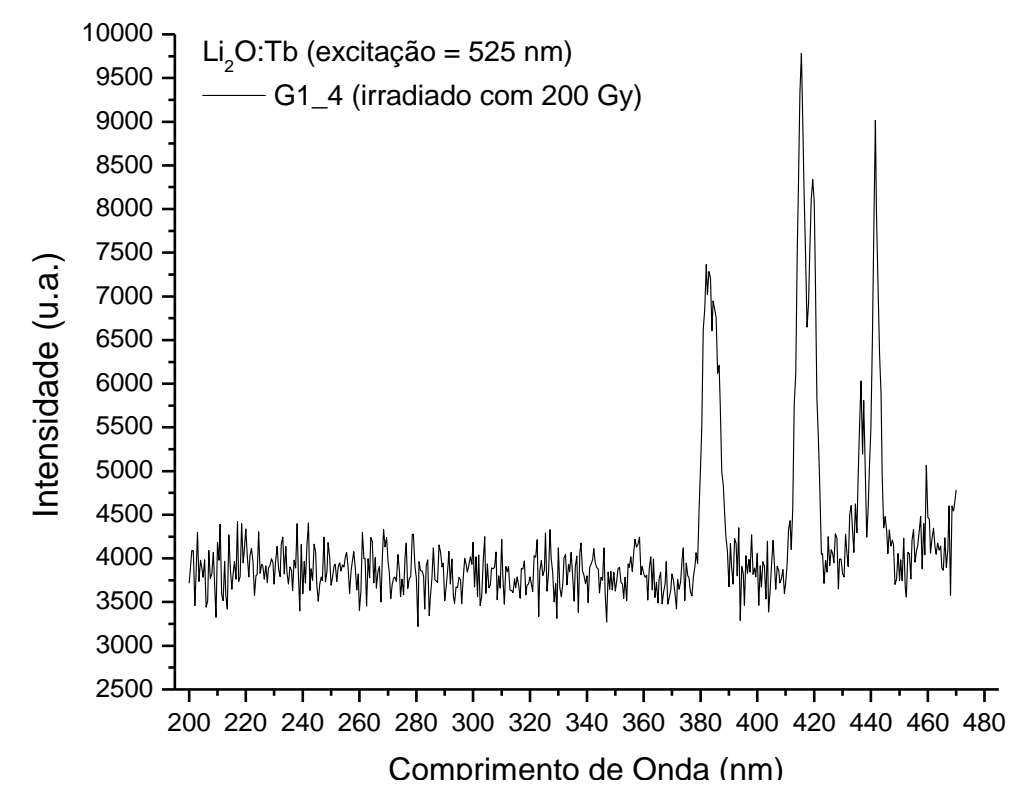

Figura 6.6. Espectro de emissão para $\mathrm{Li}_{2} \mathrm{O}$ :Tb (G1_4) irradiado, com excitação de 525 nm. 


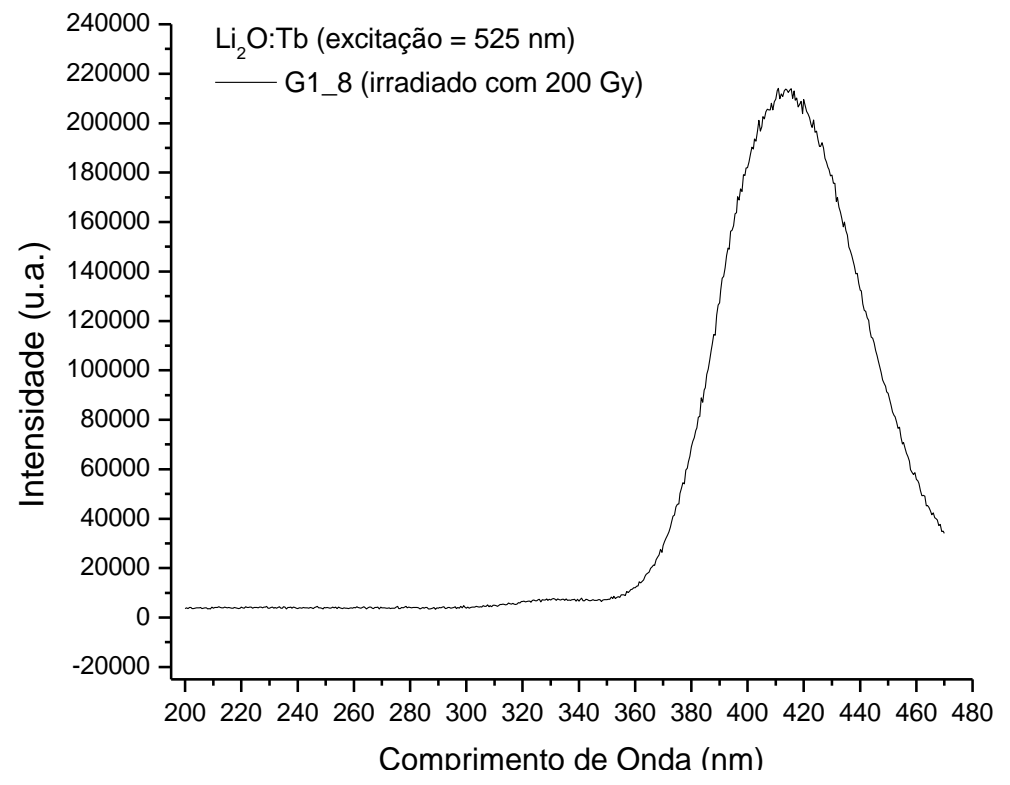

Figura 6.7. Espectro de emissão para $\mathrm{Li}_{2} \mathrm{O}$ :Tb (G1_8) irradiado, com excitação de 525 nm.

b) Grupo 2 - MgO:Tb.

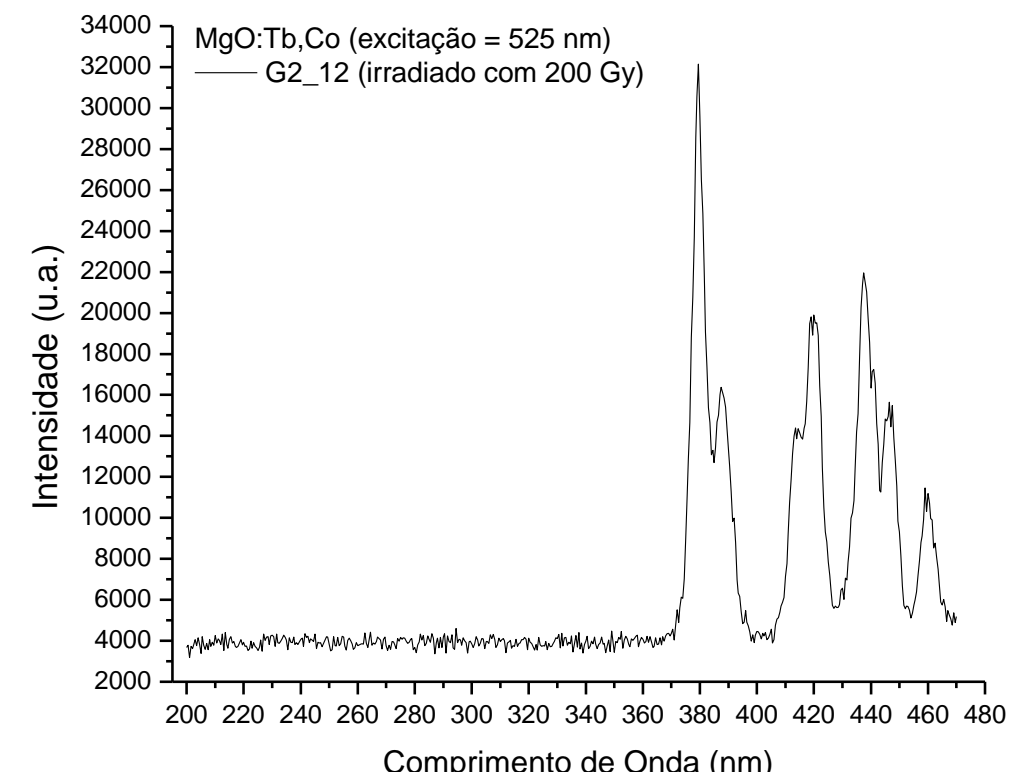

Figura 6.8. Espectro de emissão para MgO:Tb (G2_12) irradiado, com excitação de 525 nm. 


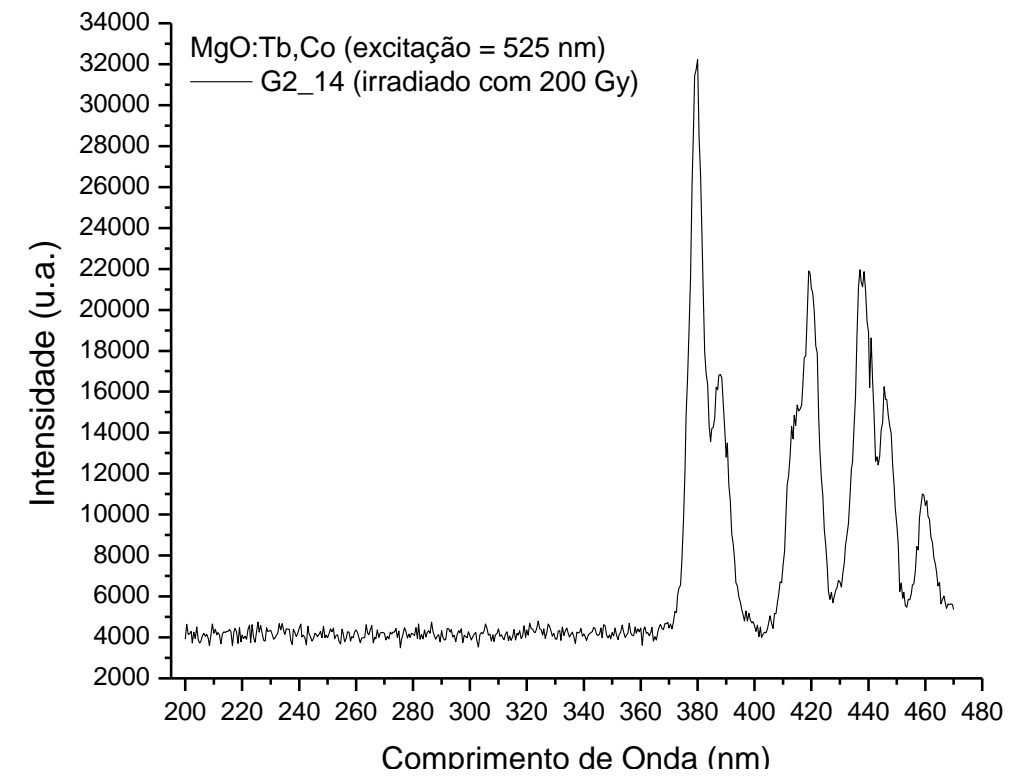

Figura 6.9. Espectro de emissão para MgO:Tb (G2_14) irradiado, com excitação de 525 nm.

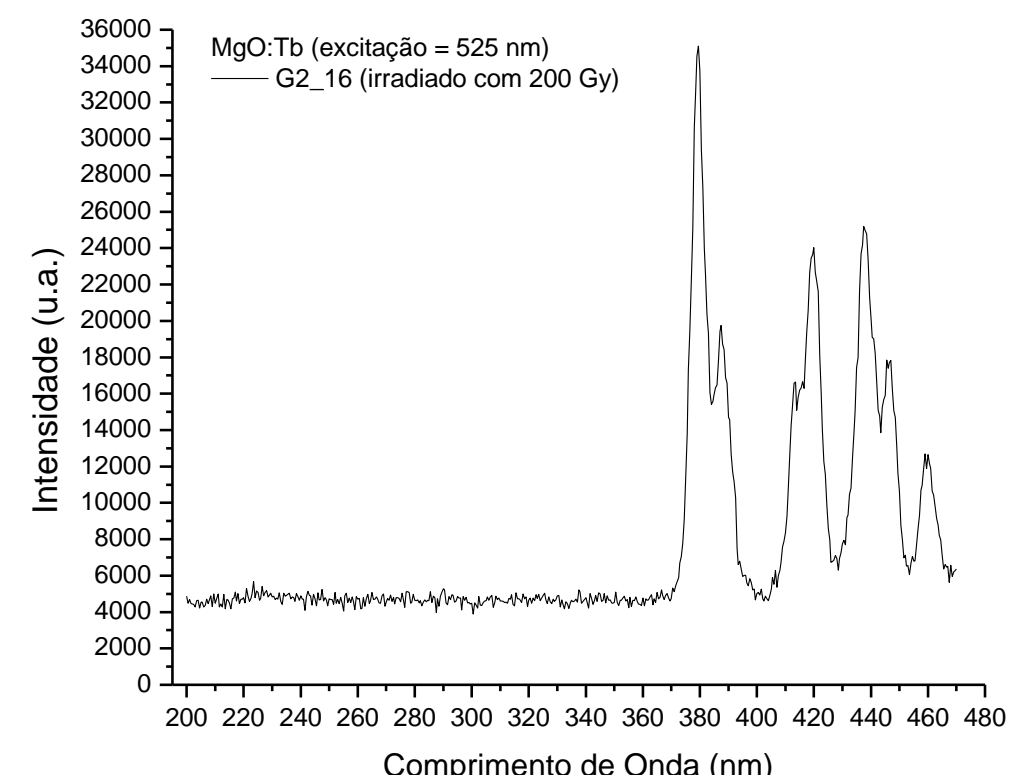

Figura 6.10. Espectro de emissão para MgO:Tb (G2_16) irradiado, com excitação de 525 nm. 


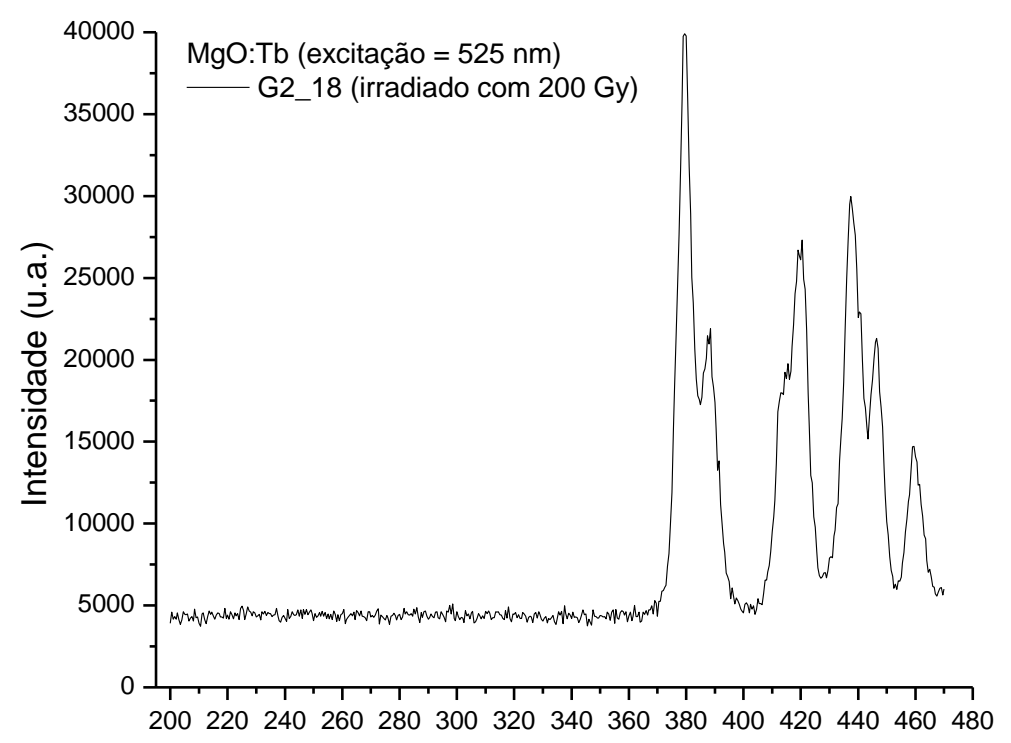

Combrimento de Onda $(\mathrm{nm})$

Figura 6.11. Espectro de emissão para MgO:Tb (G2_18) irradiado, com excitação de 525 nm.

c) Grupo 3 - $\mathrm{CaO}: \mathrm{Tb}$.

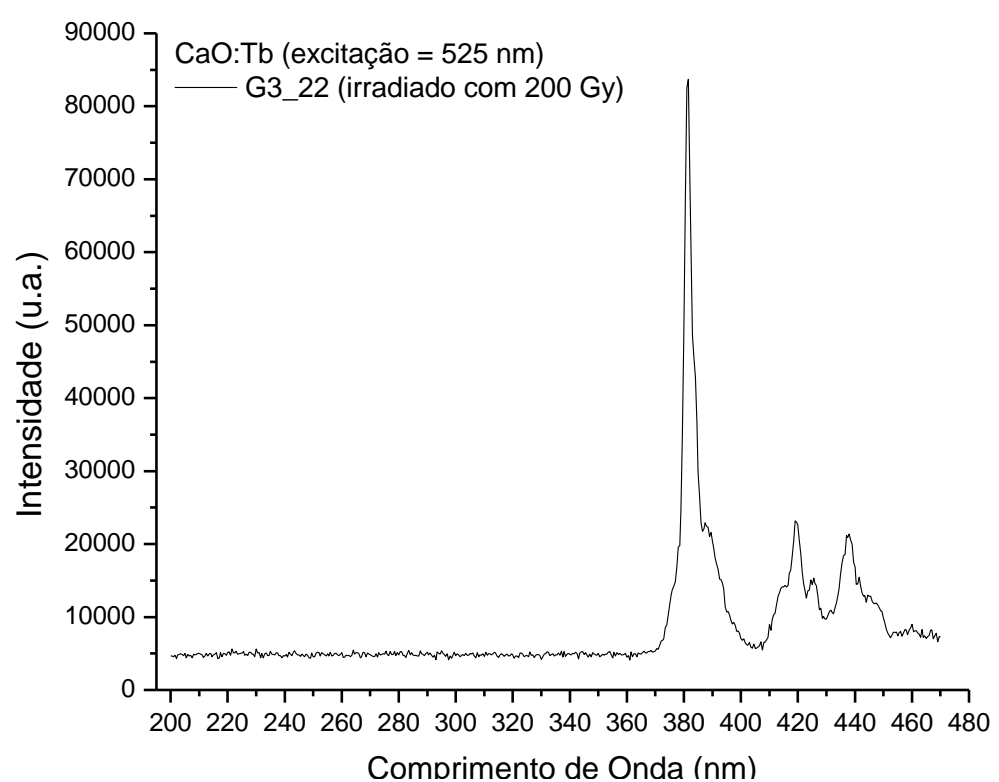

Figura 6.12. Espectro de emissão para CaO:Tb (G3_22) irradiado, com excitação de 525 nm. 


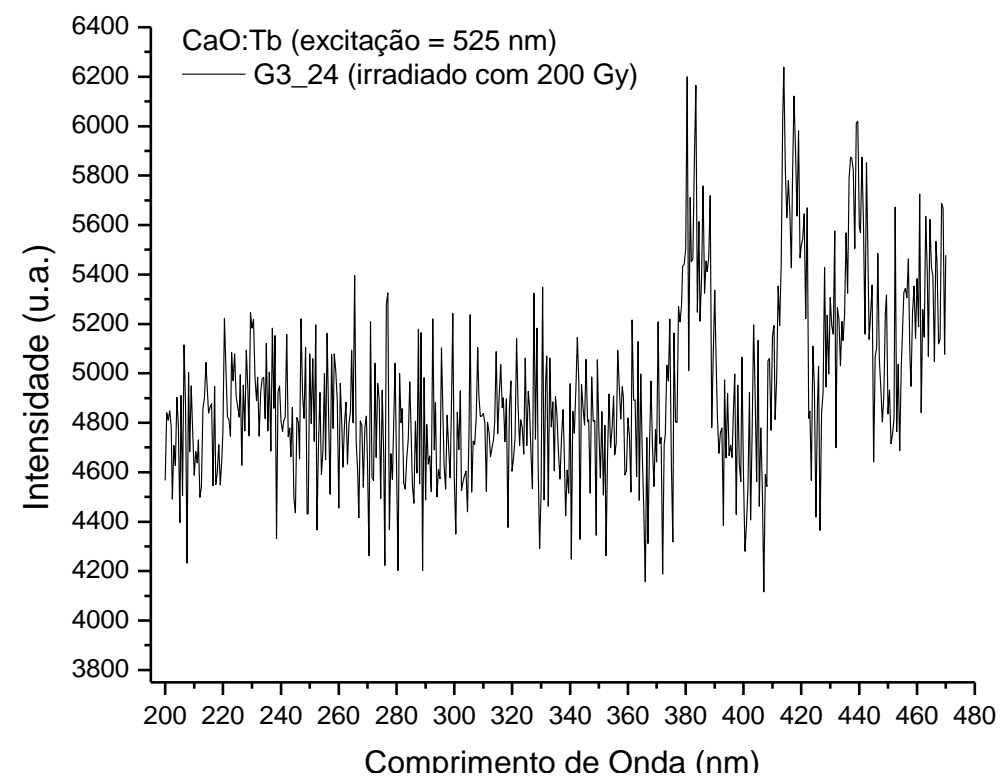

Figura 6.13. Espectro de emissão para CaO:Tb (G3_24) irradiado, com excitação de 525 nm.

Todos os espectros, com exceção de $\mathrm{Li}_{2} \mathrm{O}: \mathrm{Tb}$ na amostra G1_8 (Figura 6.7), apresentam as mesmas linhas, com intensidades diferentes. Alguns dos picos podem ser atribuídos a transições entre níveis de energia do Tb, de acordo com o esquema mostrado na Figura 6.14 a. com as linhas identificadas na Figura 6.14. b. a seguir (usamos o espectro de G2_14, $\mathrm{MgO}: \mathrm{Tb})$.

Nenhuma das linhas do Tb foram vistas em amostras não irradiadas. Esse comportamente era esperado de acordo com os niveis de energia para $\mathrm{Tb}$ [52]. O que indica que o processo de emissão visto para as amostras deve-se a novos estados de energia, provavelmente envolvidos com centros luminescentes. 

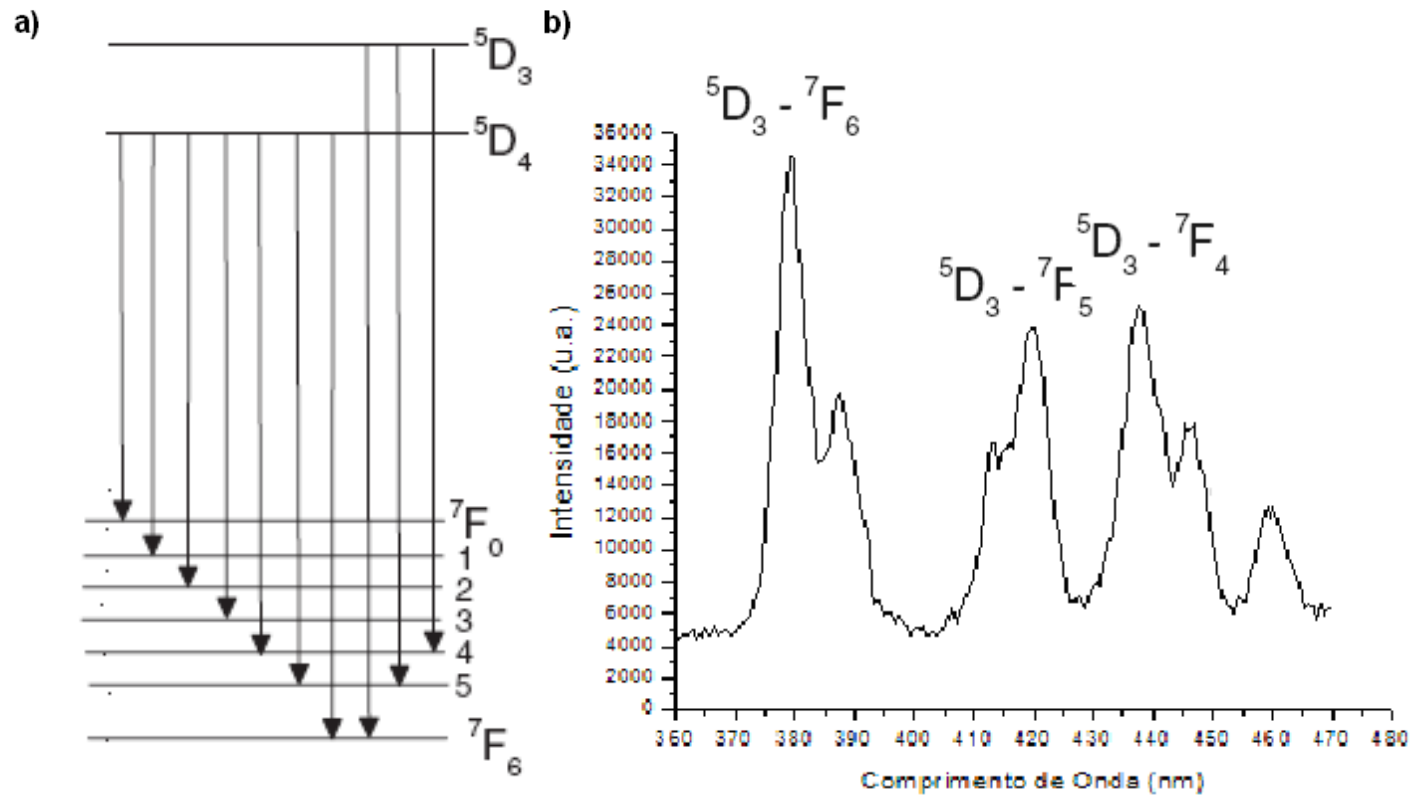

Figura 6.14. a) Transições entre níveis de energia do Tb (diferença entre linhas não esta corretamente representada) e b) picos identificados no espectro de emissão da amostra MgO:Tb (G2_14), mas que se observa em todas as outras amostras, com exceção de $\mathrm{Li}_{2} \mathrm{O}$ :Tb na amostra G1_8.

O comportamento não esperado da amostra G1_8 ( $\left.\operatorname{Li}_{2} \mathrm{O}: \mathrm{Tb}\right)$ também foi observado para os espectros de EPR do Capítulo 4, cujos sinais são diferentes dos encontrados para as duas outras amostras de $\mathrm{Li}_{2} \mathrm{O}: \mathrm{Tb}$.

Para o Óxido de Lítio o pico com maior intensidade é o com a transição ${ }^{5} D_{3}-{ }^{7} F_{5}$, ao contrário das amostras de $\mathrm{MgO}: \mathrm{Tb}$ e $\mathrm{CaO}: \mathrm{Tb}$ que possuem pico com maior intensidade para a transição ${ }^{5} D_{3}-{ }^{7} F_{6}$.

\subsubsection{Espectro de Excitação.}

Os espectros de excitação foram adquiridos para amostras "limpas" e amostras irradiadas. Os óxidos em pó "limpos" foram submetidos a 20 minutos em forno de $200{ }^{\circ} \mathrm{C}$ e os irradiados 
foram expostos a 200 Gy de radiação $\beta$ numa fonte de ${ }^{90} \mathrm{Sr} /{ }^{90} \mathrm{Y}$. Dessa forma temos os gráficos comparativos para amostras irradiadas e não irradiadas.

Para aquisição dos espectros de excitação usamos um intervalo de 700 a $500 \mathrm{~nm}$; duas emissões (380 e 415 nm, usando a denominação "a" para os espectros com emissão de 380 nm e "b" para os espectros de emissão $415 \mathrm{~nm}$ ), referentes aos picos observados para o espectro de emissão das amostras no item anterior; tempo integrado de 0.5 segundos, e tempo de incremento de 0.5. As leituras foram feitas usando a função $S / R$, ou seja, intensidade da amostra dividido pela intensidade da lâmpada.

a) Grupo $1-\mathrm{Li}_{2} \mathrm{O}: \mathrm{Tb}$.

a)

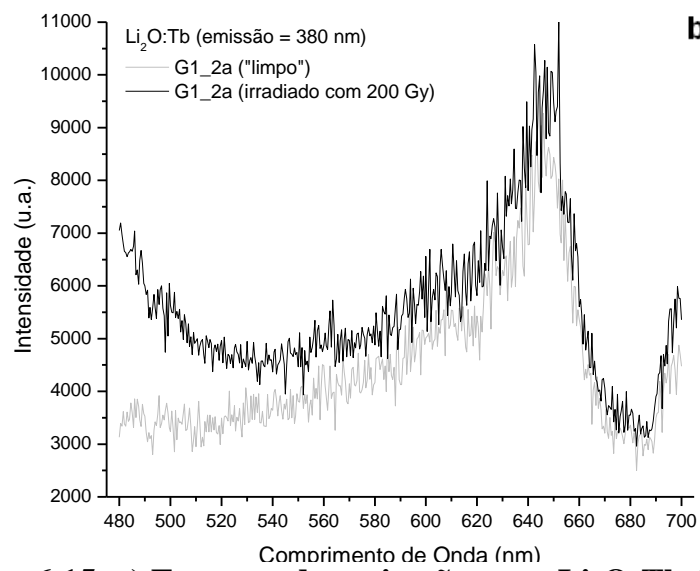

b) 14000$] \quad \mathrm{Li}_{2} \mathrm{O}: \mathrm{Tb} 1($ emissão $=415 \mathrm{~nm})$

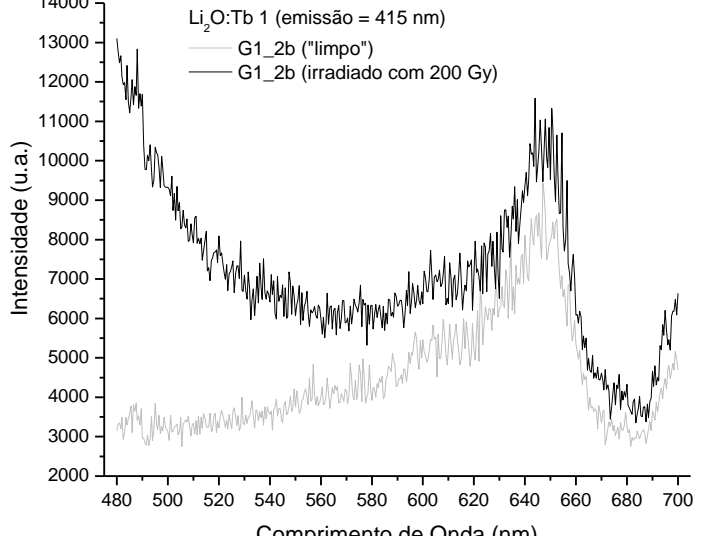

Figura 6.15. a) Espectro de excitação para $\mathrm{Li}_{2} \mathrm{O}$ :Tb (G1_2) irradiado e não irradiado com emissão de 380 nm e b) $415 \mathrm{~nm}$. 
a)

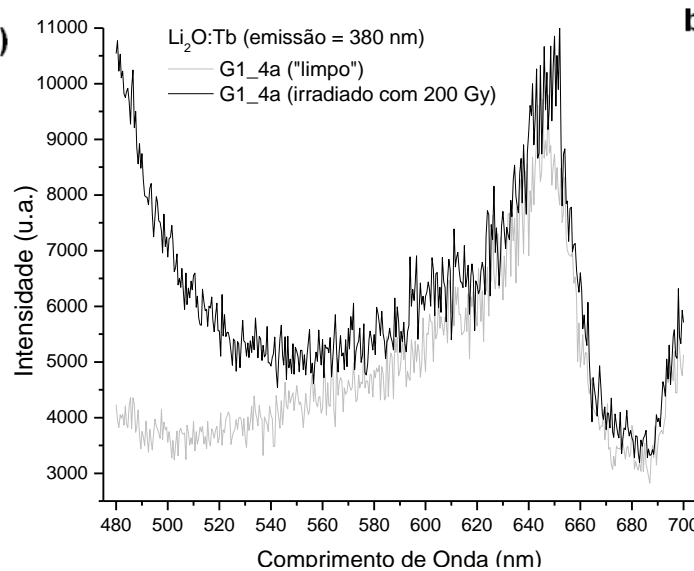

b)

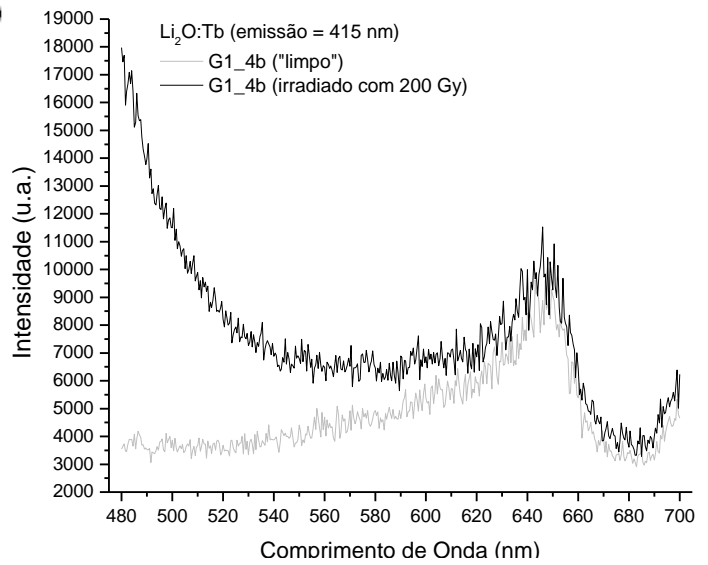

Figura 6.16. a) Espectro de excitação para $\mathrm{Li}_{2} \mathrm{O}$ :Tb (G1_4) irradiado e não irradiado com emissão de 380 nm e b) $415 \mathrm{~nm}$.

a)

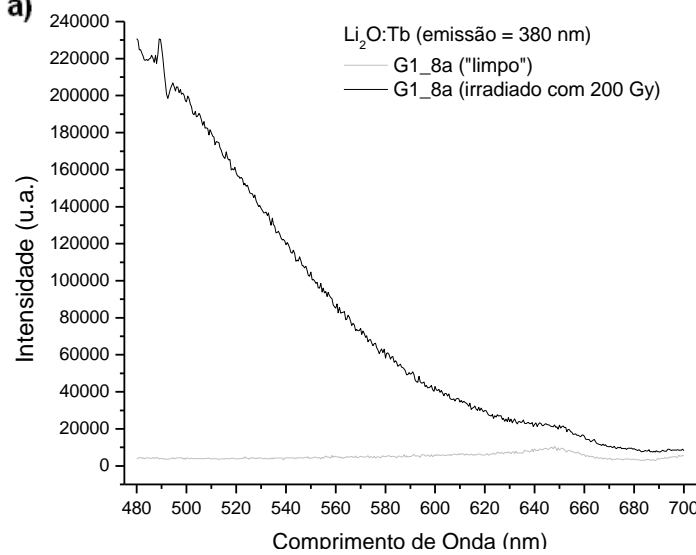

b)

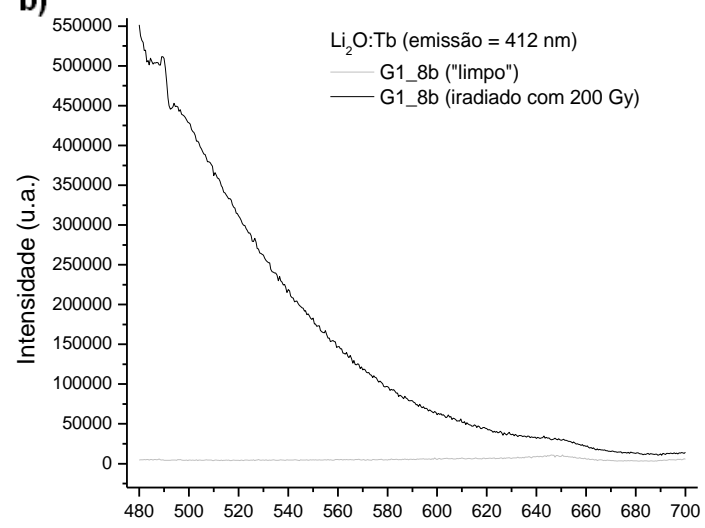

Figura 6.17. a) Espectro de excitação para $\mathrm{Li}_{2} \mathrm{O}$ :Tb (G1_8) irradiado e ênão nirradiandiado com emissão de 380 nm e b) $415 \mathrm{~nm}$.

b) Grupo 2 - MgO:Tb.
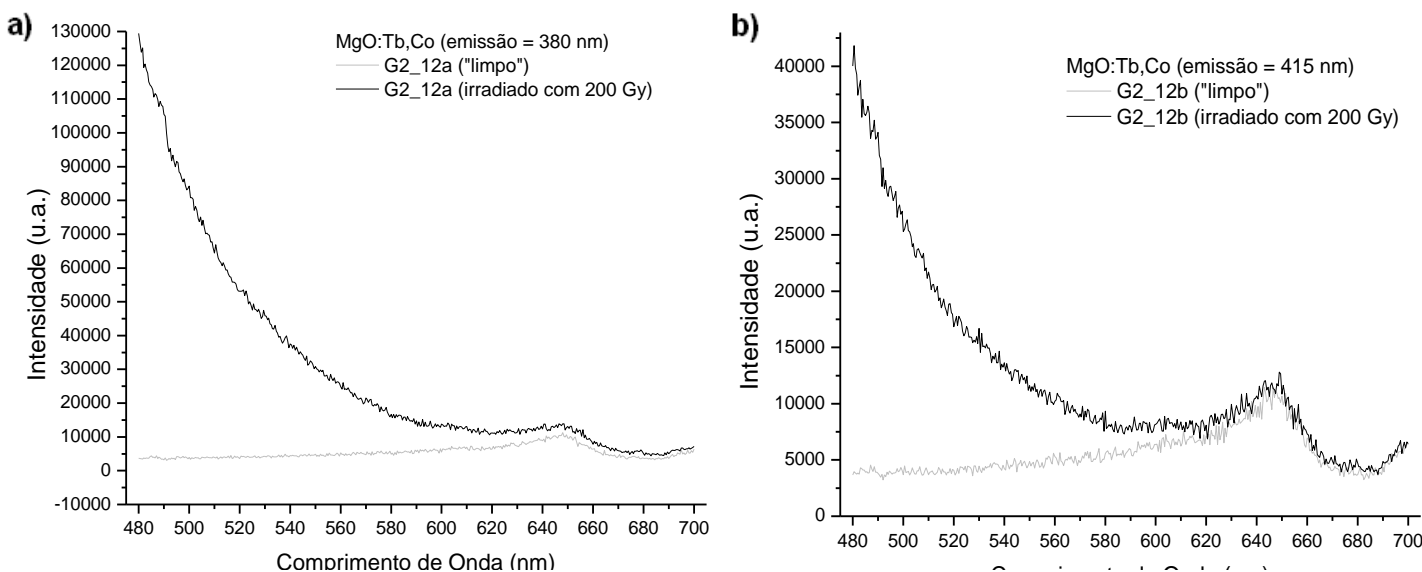

Figura 6.18. a) Espectro de excitação para MgO:Tb (G2_12) irradiadô e não irradiado com emissão de $380 \mathrm{~nm}$ e b) $415 \mathrm{~nm}$. 

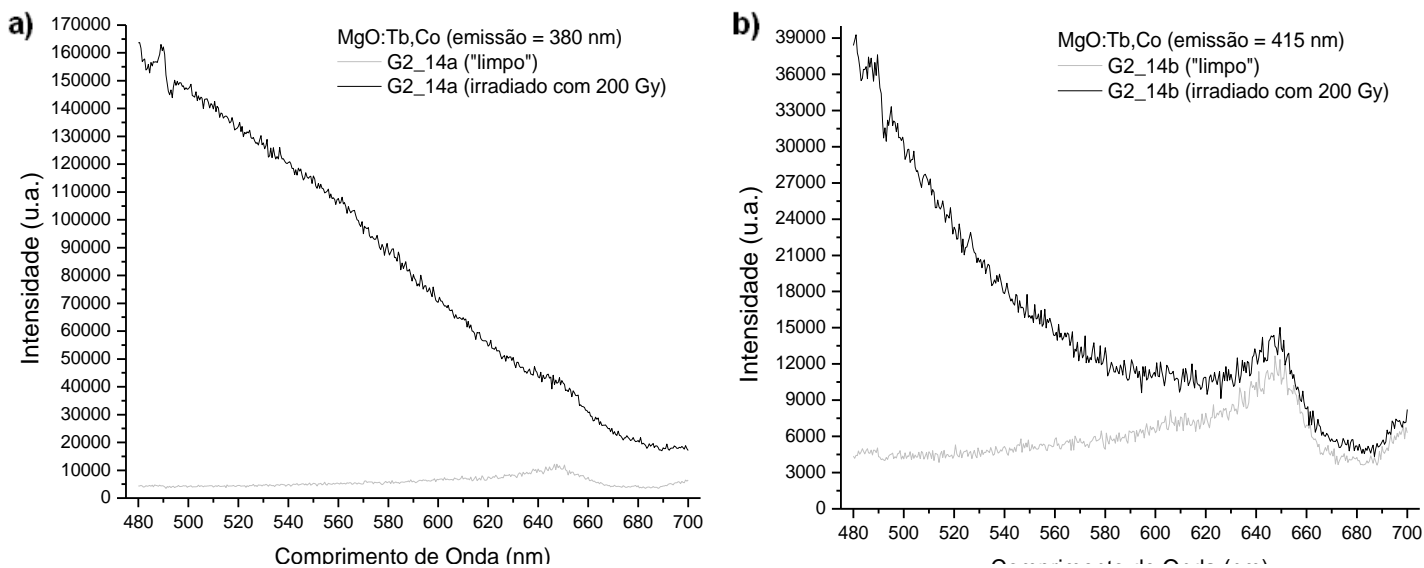

Figura 6.19. a) Espectro de excitação para $\mathrm{MgO}$ :Tb (G2_14) irradiadô e não irradiado com emissão de $380 \mathrm{~nm}$ e b) $415 \mathrm{~nm}$.
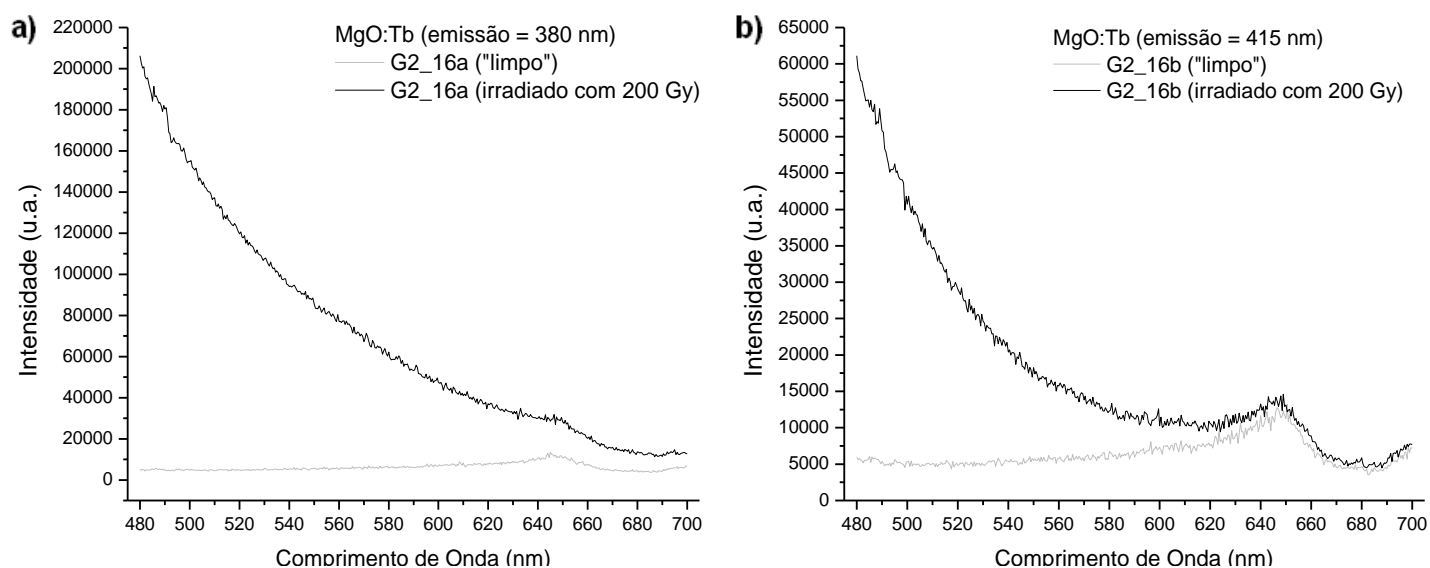

Figura 6.20. a) Espectro de excitação para MgO:Tb (G2_16) irradiado e não irradiado com emissão de $380 \mathrm{~nm}$ e b) $415 \mathrm{~nm}$.
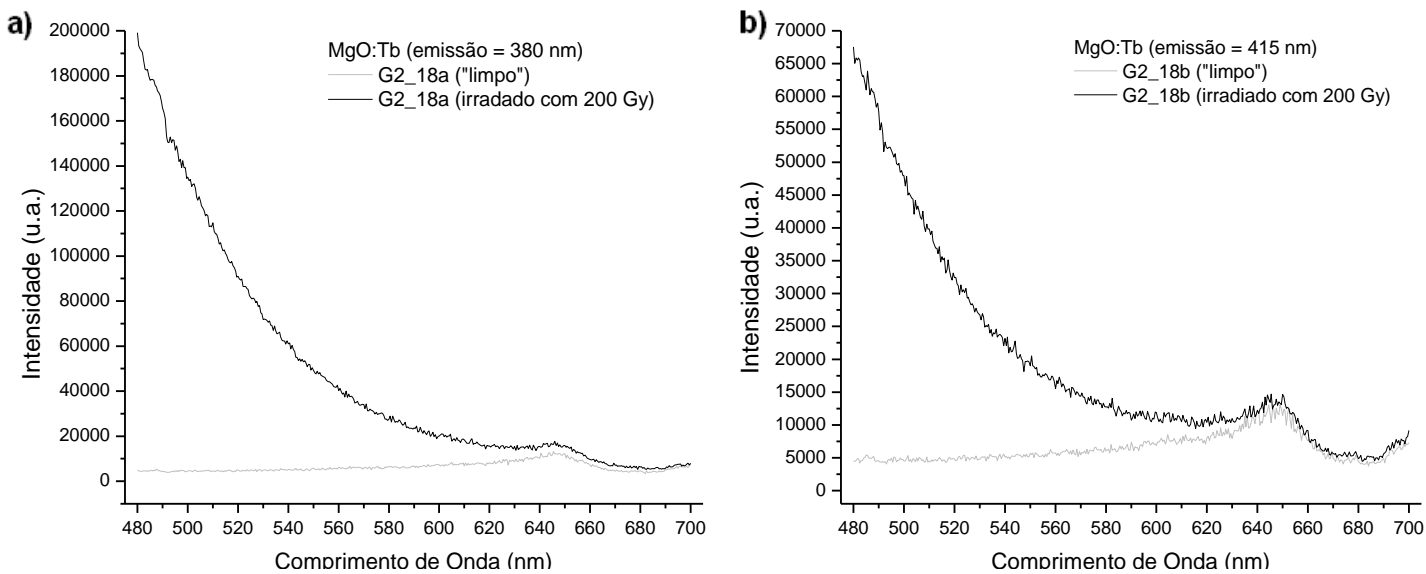

Figura 6.21. a) Espectro de excitação para MgO:Tb (G2_18) irradiado e não irradiado com emissão de $380 \mathrm{~nm}$ e b) $41 \overline{5} \mathrm{~nm}$.

c) Grupo 3 - $\mathrm{CaO}: \mathrm{Tb}$. 

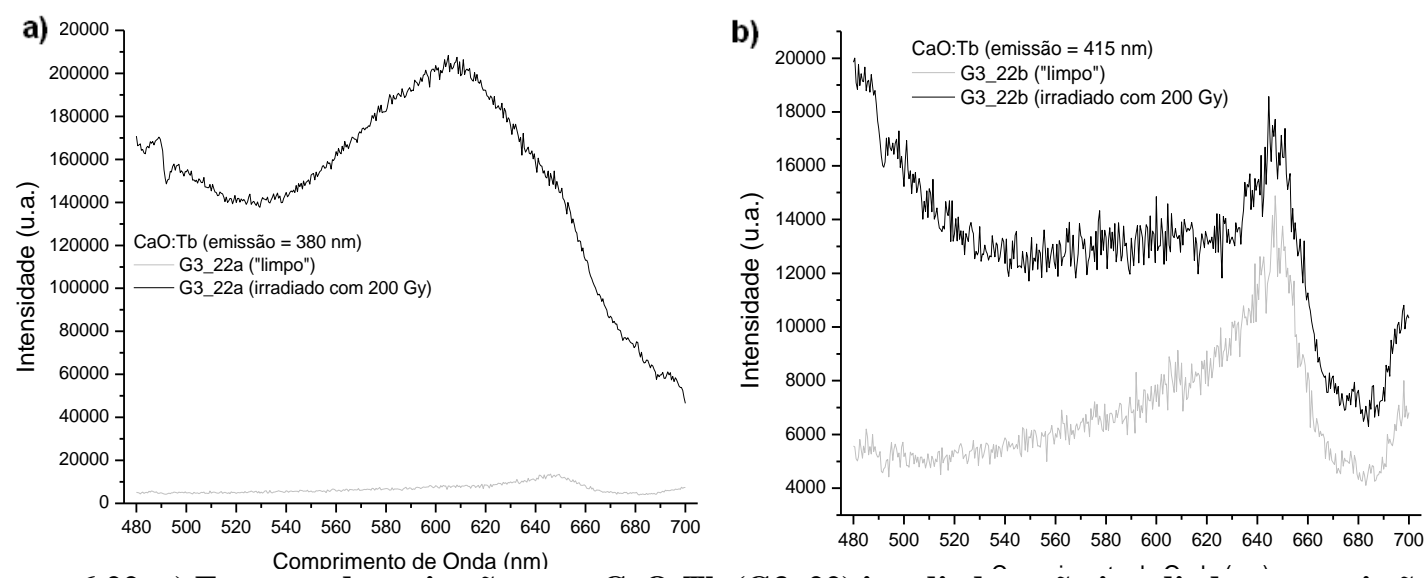

Figura 6.22. a) Espectro de excitação para CaO:Tb (G3_22) irradiadô e não irradiado com emissão de $380 \mathrm{~nm}$ e b) $415 \mathrm{~nm}$.
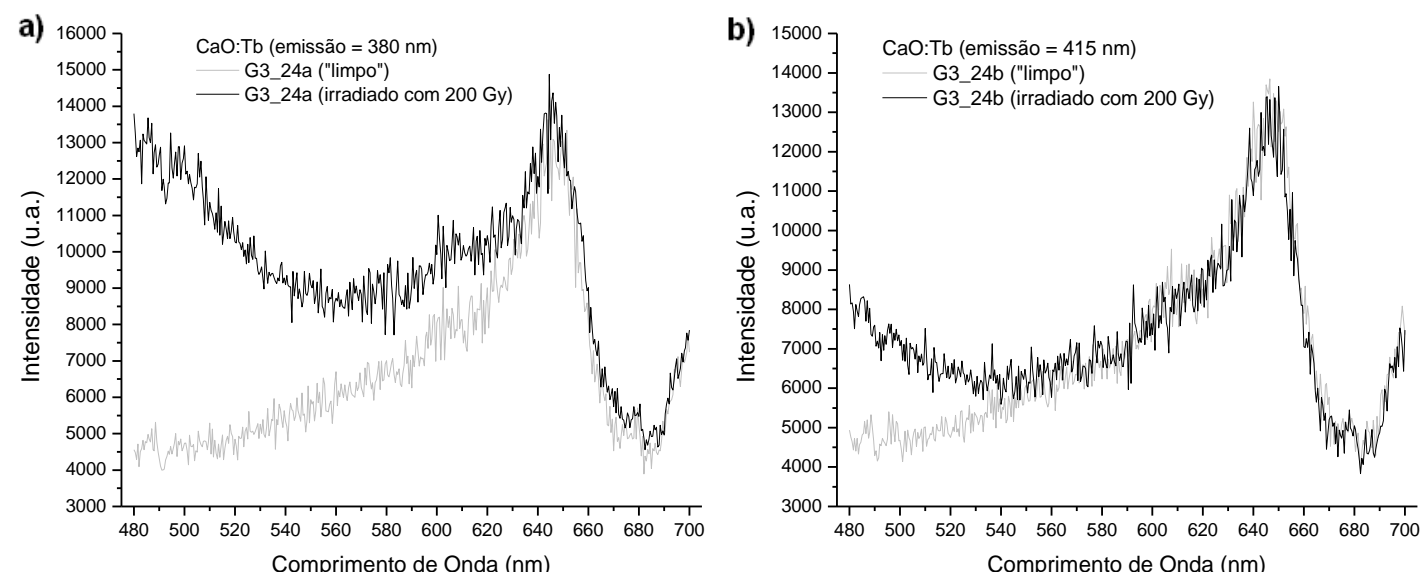

Figura 6.23. a) Espectro de excitação para CaO:Tb (G3_24) irradiado e não irradiado com emissão de $380 \mathrm{~nm}$ e b) $415 \mathrm{~nm}$.

Dos espectros de excitação vemos que as amostras de Óxido de Magnésio apresentam melhores resultados, em especial para os espectros com emissão em $380 \mathrm{~nm}$.

Isso indica que, a princípio, o material é um bom candidato a material OSL para ser usado em dosimetria quando comparado com os outros óxidos.

Na região estudada os espectros para $\mathrm{Li}_{2} \mathrm{O}: \mathrm{Tb}$ são caracterizados por: a) presença de banda de excitação em $1.92 \mathrm{eV}$ ( 645 nm) em todas as amostras irradiadas e não irradiadas; b) presença de banda de excitação em $2.53 \mathrm{eV}(\sim 490 \mathrm{~nm})$ em todas as amostras irradiadas e não irradiadas e; c) excitação maior na região entre 480 e $560 \mathrm{~nm}$, em que o espectro apresenta crescimento 
contínuo em direção a $480 \mathrm{~nm}$. Novamente podemos observar a diferença do comportamento da amostra G1_8 de $\mathrm{Li}_{2} \mathrm{O}: \mathrm{Tb}$ em comparação com as duas outras amostras do mesmo óxido. O espectro apresenta intensidade alta, em especial para o espectro com emissão em $415 \mathrm{~nm}$, cujo comprimento de onda de emissão encontra-se mais próximo ao pico em $420 \mathrm{~nm}$ do espectro de emissão.

Na região estudada os espectros para $\mathrm{MgO}: \mathrm{Tb}$ são caracterizados por: a) presença de banda de excitação em $1.92 \mathrm{eV}(\sim 645 \mathrm{~nm})$ em todas as amostras irradiadas e não irradiadas; b) presença de banda de excitação em $2.53 \mathrm{eV}(\sim 490 \mathrm{~nm})$ em todas as amostras irradiadas e não irradiadas e; c) excitação maior na região entre 480 e 560 nm, em que o espectro apresenta crescimento contínuo em direção a $480 \mathrm{~nm}$. Ambos apresentam uma estrutura relativamente comum na região de $2.58 \mathrm{eV}$.

Na região estudada os espectros para $\mathrm{CaO}$ :Tb são caracterizados por: a) presença de banda de excitação em 1.92 eV ( 645 nm) em todas as amostras irradiadas e não irradiadas; b) presença de banda de excitação em $2.53 \mathrm{eV}(\sim 490 \mathrm{~nm})$ em todas as amostras irradiadas e não irradiadas; c) excitação maior na região entre 480 e 560 nm e; d) no espectro com emissão de $380 \mathrm{~nm}$ da amostra G3_22 (Figura 6.22. a.) ainda existe um pico na amostra irradiada em 2.06 $\mathrm{eV}(\sim 600 \mathrm{~nm})$.

Com o espectro de emissão para cada óxido o próximo passo é fazer testes com doses diferentes e observar saturação e comportamento do sinal de excitação. Em seguida, testes com diferentes tipos de exposição, como por exemplo, usar UV, $\gamma$, ou nêutrons. 


\section{CONCLUSÕES}

O Óxido de Alumínio, crescido numa baixa pressão na presença de uma atmosfera de Carbono, é o material que atualmente apresenta melhores resultados em dosimetria usando luminescência opticamente estimulada. A união do material à técnica também trouxe vantagens no uso de dosimetria OSL em áreas como dosimetria individual externa, datação, dosimetria médica e dosimetria espacial.

Em rotinas de laboratórios de dosimetria individual externa usa-se, atualmente no Brasil, dosimetria usando filmes fotográficos ou termoluminescência. Contudo, em países como Estados Unidos, Japão e França as rotinas tem sido substituídas por dosimetria opticamente estimulada. Isso devido ao baixo custo dos equipamentos de medida, dos dosímetros e, também, pela diminuição do tempo de leitura em comparação com as outras duas técnicas conhecidas.

Para que um laboratório possa prestar serviços de proteção radiológica é necessário passar por uma seqüência de testes certificados pela CNEN (Comissão Nacional de Energia Nuclear). Esses testes seguem padrões internacionais, estabelecidos pela Agência Internacional de Energia Atômica [19] (IAEA) através de órgãos relacionados com proteção radiológica ICRP [20] (Comissão Internacional de Proteção Radiológica) - e padronização de unidades e medidas - ICRU (Comissão Internacional de Unidades e Medidas em Radiação) [21].

Nesse trabalho apresentamos uma proposta de certificação de dosimetria individual externa usando OSL pulsado. Nossa proposta faz uma correspondência entre os testes já credenciados pela CNEN às características de dosimetria usando estimulo óptico pulsado. Também apresentamos alguns testes de desempenho usando dosimetria OSL e mostramos que todos os testes respondem satisfatoriamente ao esperado. 
Nossa proposta, junto aos testes de desempenho, será apresentada a CNEN para que seja elaborado um documento oficial que permita o uso de dosimetria individual externa usando luminescência opticamente estimulada no Brasil.

A literatura apresenta muitos estudos usando espectroscopia de EPR em Óxido de Alumínio, contudo nada com o material dopado com Carbono. De posse de monocristal e pó de $\mathrm{Al}_{2} \mathrm{O}_{3}: \mathrm{C}$ adquirimos espectros de EPR e tentamos identificar sinais criados pela exposição de nossas amostras a radiação ionizante. Exposições desse tipo de radiação cria estados metaestáveis (pares elétron-buraco) e aumenta o número de centros paramagnéticos do tipo centro $\mathrm{F}^{+}$, mas não conseguimos identificar a criação desses estados em nossos espectros. Contudo, apresentamos nesse trabalho a identificação de sinais devidos a impurezas no material. Impurezas, essas, que existem em pouca quantidade e que não afetam a sensibilidade do material em dosimetria OSL. Dessa forma mostramos a eficácia da técnica de espectroscopia de EPR em detectar impurezas, mesmo quando se encontram em poucas partes por milhão.

Em minha estada no Laboratório de Dosimetria das Radiações do Instituto de Física da Universidade Estadual de Oklahoma (Stillwater, EUA), de Fevereiro e Abril de 2007, tive a oportunidade de trabalhar em dois projetos diferentes.

No primeiro tive contato com medidas de luminescência opticamente estimulada usando onda contínua (CW OSL) fazendo medidas em $\mathrm{Al}_{2} \mathrm{O}_{3}: \mathrm{C}$ para observar mudança na sensibilidade do material quando expostos à UV. Essas medidas apresentam resultados interessantes quanto ao comportamento do sinal OSL quando exposto a diferentes comprimentos de onda na região do UV. O uso do $\mathrm{Al}_{2} \mathrm{O}_{3}: \mathrm{C}$ para dosimetria UV é viável, mas um modelo válido para dosimetria deverá levar em consideração o comprimento de onda a que o material foi exposto. 
Observamos que para algumas exposições $(275,300,325$ e $350 \mathrm{~nm})$ houve mudança no material, pois a resposta a exposições com mesma dose de $\beta$ mostrou decaiemntos diferentes. Esse resultado sugere a diferença de caminhos de recombinação para cada exposição com UV.

No segundo participei de pesquisas preliminares que fazem parte da busca por novos materiais sensíveis a radiação ionizante e com boa resposta para estimulo óptico. De posse de amostras em pó de três óxidos dopados com Térbio ( $\mathrm{Li}_{2} \mathrm{O}: \mathrm{Tb}$, MgO:Tb e $\left.\mathrm{CaO}: \mathrm{Tb}\right)$ fiz medidas de espectroscopia de EPR, de emissão e de excitação.

Em espectroscopia de EPR esperava, novamente, poder observar aparecimento de sinais no espectro por exposição dos materiais a radiação ionizante pela criação de centros metaestáveis. Algumas linhas em nosos espectros foram identificadas e são devidas a impurezas nas amostras, contudo não obtivemos resultados conclusivos sobre centros criados após irraidação das amostras.

Nos espectros de emissão observamos picos devidos às transições do Tb. Esses picos não são observados para amostras não irradiadas, uma vez que o comprimento de energia de excitação usado não é suficiente para que sejam vistas as linhas de emissão. Esse resultado indica que o processo de emissão visto para as amostras deve-se a novos estados de energia, provavelmente envolvidos com centros luminescentes. O pico com maior intensidade para $\mathrm{Li}_{2} \mathrm{O}: \mathrm{Tb}$ está em $415 \mathrm{~nm}$ com transição ${ }^{5} D_{3}-{ }^{7} F_{5}$ e para CaO:Tb e MgO:Tb está em $380 \mathrm{~nm}$ com transição ${ }^{5} D_{3}-{ }^{7} F_{6}$.

Os espectros de excitação foram adquiridos usando os comprimentos de onda dos picos dos espectros de emissão. Nestes foi observado que $\mathrm{MgO}: \mathrm{Tb}$ apresenta melhores resultados para 
ser usado em dosimetria, uma vez que seus espectros possuem intensidades bem mais altas, quando comparados com os dos outros óxidos.

O foco central desse trabalho foi estudar dosimetria usando luminescência opticamente estimulada. Nele tive a oportunidade de aprender e trabalhar diretamente com dois tipos de estímulos diferentes, o OSL pulsado e o de onda contínua (CW OSL). Ao meu conhecimento agrego as técnicas de espectroscopia de EPR, de emissão e de excitação. E ainda a experiência com o ambiente de um laboratório que presta serviços de proteção radiológica, e uma experiência internacional em um laboratório de dosimetria. 


\section{REFERÊNCIAS}

[1] BOTTER-JENSEN, L., MCKEEVER, S. W. S., AND WINTLE, A. G. Optically Stimulated Luminescence Dosimetry. Elsevier (2003).

[2] ANTONOV-ROMANOVSKII, V. V., KEIRUM-MARCUS, I. F., POROSHINA, M. S., AND TRAPEZNIKOVA, Z. A. Conference of the Academy of Sciences Session of the Division of Physical and Mathematical Sciences, USAEC Report AEC-tr-2435(Pt. 1), pp. 239-250 (1956).

[3] BRANDLE, C. D. Czocharalski Growth of Oxides. Journal of Crystal Growth, 264, 593-604, (2004).

[4] SUMMERS, G. P. Themoluminescence in Single Crystal $\alpha$-Al203. Radiation Dosimetry Protection. Vol 8, 69-80 (1984).

[5] BotTer-Jensen, L., DUller, G. A. T., POOlton N. R. J. Excitation and Emission spectroscopy of stimulated luminescence from Quartz and feldspars. Radiat. Meas. 23. 613-616 (1994).

[6] MCKEEVER, S. W. S. Optically Stimulated Luminescence Dosimetry. Nuclear Instruments and Methods in Physics Research B. 184 (2001).

[7] SOLOMON, F. AND MARSTON, R. Q. The Medical Implications of Nuclear War. National Academies Press, p. 235-236 (1986).

[8] Whitley, V. H., MCKEEVER, S. W. S. Photoionisation of Deep Centers in $\mathbf{A l}_{2} \mathbf{O}_{3}$. J. Appl. Phys. 87 (2000).

[9] WHITLEY, V. H., MCKEEVER, S. W. S. Linearly Modulated Photoconductivity and Linearly Modulated Optically Stimulated Luminescence Measurements $\mathrm{Al}_{2} \mathrm{O}_{3}: \mathrm{C}$. J. Appl. Phys. 90 (2001).

[10] EVAns, B. D. And StapelbroeK, M. Optical Properties of $\mathbf{F}^{+}$Properties in Crystalline $\mathbf{A l}_{\mathbf{2}} \mathbf{O}_{\mathbf{3}}$. Phys. Rev. B18 7089-7098 (1978).

[11] ARNOLD, G. W. AND COMPTON, W. D. Luminescence from Electron-Irradiated Sapphire Phys. Rev. Lett. 4, 66 (1980).

[12] POGAtShnik, G. J. CHEN, Y., EVAns, B. D. A Model of Lattice Defects in Saphire. IEEE Trans Nucl. Sci. NC-34, 1709-1712 (1987).

[13] SANCHES, E. A. Caracterização pelo Método de Rietveld do Óxido de Alumínio Recuperado de Sensores Dosimetricos e Estudo de Parâmetros Envolvidos no Processo de Recuperação. Dissertação de Mestrado Instituto de Física de São Carlos, Universidade de São Paulo (2006).

[14] BAILIF, I. K. Characteristics of Time-resolved luminescence in Quartz. Rdiat. Meas. 32 (2000). 
[15] BOTTER-JENSEN, L. MURRAY, A. S. Developments in Optically Luminescence Dosimetry Techniques for Dating and Retrospective Dosimetry. Radiat. Prot. Dosim. 84 (1999).

[16] KNOWLES, P.F., D. MARSH AND H.W.E. RATTLE. Magnetic Resonance of Biomolecules. J. Wiley, New York, (1976).

[17] PAVIA, D. L., LAMPMAN, G. M., AND KRIZ, G. S. Introduction to Spectroscopy. Saunders (2000).

[18] http://www.cnen.gov.br/

[19] http://www.iaea.org/

[20] http://www.icrp.org/

[21] http://www.icru.org/

[22] AKSElROD, M. S., KORTOV, V. S., KRAVESKY, D. J., GOTLIB, V. I. Higly Sensitivity Thermoluminescent Anion-Defect $\alpha-\mathrm{Al}_{2} \mathrm{O}_{3}: \mathrm{C}$ Single Crystal Detectors. Radiat. Dosim. 33 (1990).

[23] MARKEY, B. G., COLYOT, L. E., MCKEEVER, S. W. S. Time-Resolved Optically Stimulated Luminesence from $\boldsymbol{\alpha}-\mathbf{A l}_{2} \mathbf{O}_{3}$ :C. Radiat. Meas. 24 (1995).

[24] MANENKOV, A. A. AND PROKHOROV, A. M. The Fine Structure of the Paramagnetic Resonance of the Ion Cr3+ in Chromium Corundum. Sov. Phys. -JETE 1 (1955).

[25] ZARIPOV, M. M. AND SHAMONIN, I. I. Paramagnetic Resonance in Synthetic Ruby. Sov. Phys.-JETP 3 (1956).

[26] GEUSIC, J. R. Paramagnetic Fine Structure Suectrum of Cr+++ in a Single Ruby Crystal. Phys. 'Rev., 102 (1956).

[27] MANENKOV, A. A. AND PROKHOROV, A. M. Hyperfine Structure of the Paramagnetic Resonance Spectrum of $\mathbf{C r}^{\mathbf{3 +}}$ in $\mathbf{A 1}_{2} \mathbf{0}_{3}$. Sov. Phys. -JETP, 4 [2] 288-89 (1957).

[28] MANENKOV, A. A. AND FEDOROV, V. B. Investigation of the Line Width and Shape in the Paramagnetic Resonance Spectrum of the $\mathrm{Cr}+++$ Ion in Corundum Single Crystals. Sov. Phys.-JETP, 11 (1960).

[29] GERSCHWIND, S., KISLIUK, P., KLEIN, M. P., REMEIKA, J. P., WOOD, D. L. Sharp-Line Fluorescence, Electron Paramagnetic Resonance, and Thermoluminescence of $\mathbf{M n}^{4+} \mathfrak{i v} \boldsymbol{\alpha}-\mathbf{A l}_{2} \mathbf{O}_{3}$. Phys. Rev. 126 (1962).

[30] LEE, K. H, HOLMBERG, G. E, CRAWFORD, D. J. H. Optical and ESR Studies of Hole Centers in $\boldsymbol{\gamma}$-Irradiated $\mathbf{A l}_{\mathbf{2}} \mathbf{O}_{\mathbf{3}}$. phys. stat. sol. (a) 39, 669 (1977).

[31] AKSELROD, M. S., MCKEEVER, S. W. S. A Radiation Dosimetry Method Using Pulsed Optically Stimulated Luminescence. Radiat. Prot. Dosim. 81 (1999). 
[32] NODA, K. UCHIDA, K., TANIFUJI, T., NASU, S. Study of Irradiation Damage in $\mathbf{L i}_{2} \mathbf{O}$ by Means of Electron Spin Ressonance, Phys. Rev. B 24 (1981).

[33] VAJDA, P. AND BEUNEU, F. Electron radiation damage and Li-colloid creation in Li2 O. Phys. Rev. B Vol 53 (1996).

[34] BEUNEU, F AND VAJDA, P. Spectroscopic Evidence for Large (>>1 mm) LithiumColloid Creation in Electron-Irradiated $\mathbf{L i}_{2} \mathrm{O}$ Single Crystals. Phys. Rev. Ltts 76, 4544 (1996).

[35] ABRAGAM, A., BLEANEY, B. Electron Paramagnetic Resonance of Transition Ions. Oxford Univ. Press, London (1970).

[36] HINATSU. Y. Manetic Susceptibility and Electron Paramagnetic Resonance Studies of Tetravalent Terbium Íons in BaTbO3 and SrTbO3. Journal of Solid State Chemistry 100 (1992).

[37] SLACK G A, HAM F S AND CHRENKO R M. Optical Absorption of Tetrahedral Fe 2 (3d 6) in Cubic ZnS, CdTe, and MgAl 20 4. Phys. Rev. 152376 (1966).

[38] J M Baker, A A Jenkins and R C C Ward. Electron Magnetic Resonance in Lithium Oxide from a Centre Containing $\mathrm{Fe}^{3+}$. J. Phys. Cond. Mat. Vol 3 (1991).

[39] MURPHY. D. M, GIAMENLO, E., PAGANINI, C., FERRARI, A. M., PACCHIONI, G. A Combined EPR and Quantum Chemical Approach to the Structure of Surface Fs+ $(\mathrm{H})$ Centers on MgO. J. Phys. Chem. B 101 (1997).

[40] WERTS, J. E., AUZINS, P. Electron Spin Resonance of F Centers in Magnesium. Confirmation of the Spin on Magnesium 25. Phys. Rev. 107 (1957).

[41] KAPPERS, L. A., KROES, R. L., HENSLEY, E. B. F and F' Centers in Magnesium Oxide. Phys. Rev. B 1 (1970).

[42] WERTS, J. E., AUZINS, P. Crystal Vacancy Evidence from Electron Spin Resonance. Phys. Rev. 106 (1957).

[43] DU MAO-LU AND ZHAO MIN-GUANG. A study of the structure of the Cr3+vacancy centre in MgO using EPR and optical spectra. J. Phys. C: Solid State Phys. 19 (1986).

[44] HENDRENSON, B., STOKOWSKI, S. E., ENSIGN, T. C. Luminescence from F Centers in CaO. Phs. Rev. 183 (1969).

[45] TOMLINSON, A. C, HENDRENSON, B. SOME STUDIES OF DEFECTS IN CALCIUM OXIDE-I. IMPURITY EFFECTS. J. Phys. Chem. Solids. Vol. 30 (1969).

[46] MARSHALL, S. A., HODGES, J. A., SERWAY, R. A. Isotopic Shift in the ElectronSpin-Resonance Absorption Spectrum of $\mathbf{C r}^{3+}$ in Magnesium Oxide. Phys. Rev. 136 (1964).

[47] BIASI, R. S., GRILLO, M. L. N. Influence of manganese concentration on the ESR spectrum of Mn in CaO. Journal of Alloys and Compounds, 282 (1999). 
[48] MARSHALL, S. A., HODGES, J. A., SERWAY, R. A. Evidence for na Isotopic Shift in the Electron-Spin-Resonance Absorpion Spectrum of Fe3+ in Calcite. Phys. Rev. 133 (1964).

[49] EVAnS, B. D., POGATSHNIK, G. J., AND CHEN, Y. Optical Properties of Lattce Defects in $\boldsymbol{\alpha}-\mathbf{A l}_{\mathbf{2}} \mathbf{O}_{3}$. Nucl. Inst. and Met. in Phys. Res. B 91 (1994).

[50] PRADHAN, A. S., DASH SHARMA, P. K., SHIRVA, V. K. Thermoluminescence Response of al2O3:C to UV and Ionizing Radiation. Radiation Protection Dosimetry vol 64 (1996).

[51] MITANI, J. C., PROKIAE, M., AND YUKIHARA, E.G. Optically Stimulated Luminescence and Thermoluminescence Of Terbium-Activated Silicates and Aluminates. (In preparation, 2007).

[52] LANGE, K. L., LITTLE, R. J. A., AND TAYLOR, J. M. G. Robust Statistical Modeling Using the $\mathbf{t}$ Distribution. Journal of the American Statistical Association 84, 881 896 (1989).

[53] DIEKE, G. H. Spectra and Energy Levels of Rare Earth Ions in Crystals. Crosswhite and Crosswhite (1968).

[54] GELMAN, A., CARLIN, J. B., STERN, H. S. AND RUBIN, D. B. Bayesian Data Analysis (Second Edition), CRC/Chapman \& Hall (2004). 


\section{APÊNDICE A - MATRIZ DE CORRESPONDÊNCIA}

A seguir temos uma tabela com os testes de tipo e de desempenho para dosimetria pessoal externa usando termoluminescência (coluna TLD), filme fotográfico (coluna Filme) e o teste correspondente para dosimetria pessoal externa usando luminescência opticamente estimulada (coluna OSL).

\section{Processo de Certificação - Padrão de desempenho, características físicas e dosimétricas.}

IRD RT No. 002 - deve ter uma seção especifica para OSL, apresentamos abaixo um resumo em forma de tabela para os testes a serem realizados.

I - Leitor;

Para dosimetria OSL realizada com um dosímetro modelo InLight $^{\circledR}$ temos a presença de 4 componentes.

II - Porta Monitor;

III - Porta Leitor que contém os filtros e é um invólucro resistente à luz; IV - Dosímetro com quatro janelas de $\mathrm{Al}_{2} \mathrm{O}_{3}: \mathrm{C}$.

NA = Não se Aplica

\begin{tabular}{|c|c|c|c|}
\hline Nome & Filme & TLD & OSL \\
\hline Definições & $\begin{array}{l}\text { 3.1.1 - Dosímetro Fotográfico; } \\
\text { 3.1.2 - Sistema de Dosimetria } \\
\text { Fotográfica; } \\
\text { 3.1.3 - Densidade Ótica de } \\
\text { Transmissão; } \\
\text { 3.1.4 - Curva Característica; } \\
\text { 3.1.5 - Imagem Latente; }\end{array}$ & $\begin{array}{l}\text { 4.1.1 - Termoluminescência (TL); } \\
\text { 4.1.2 - Material Termoluminescente; } \\
\text { 4.1.3 - Detector Termoluminescente (TLD); } \\
\text { 4.1.4 - Dosímetros Termoluminescentes; } \\
\text { 4.1.5 - Leitor de Detectores Termoluminescentes; } \\
\text { 4.1.6 - Sistema de Dosimetria Termoluminescente; }\end{array}$ & $\begin{array}{l}\text { 5.1.1 - Luminescência Opticamente } \\
\text { Estimulada (OSL); } \\
\text { 5.1.2 - Material OSL; } \\
\text { 5.1.3 - Detector Opticamente Estimulado; } \\
\text { 5.1.4 - Dosímetros OSL; } \\
\text { 5.1.5 - Leitor de Detectores OSL; } \\
\text { 5.1.6 - Sistema de Dosimetria OSL; }\end{array}$ \\
\hline
\end{tabular}




\begin{tabular}{|c|c|c|c|}
\hline & 3.1.6 - Solarização. & $\begin{array}{l}\text { 4.1.7 - Lote (detectores ou dosímetros TL); } \\
\text { 4.1.8 - Recozimento; } \\
\text { 4.1.9 - Preparação; } \\
\text { 4.1.10 - Leitura; } \\
\text { 4.1.11 - Auto-irradiação; } \\
\text { 4.1.12 - Leitura zero; } \\
\text { 4.1.13 - Ruído de fundo do Leitor. }\end{array}$ & $\begin{array}{l}\text { 5.1.7 - Lote (detectores ou dosímetros OSL); } \\
\text { 5.1.8 - Preparação; } \\
\text { 5.1.9 - Leitura; } \\
\text { 5.1.10 - Leitura zero; } \\
\text { 5.1.11 - Ruído de fundo do Leitor. }\end{array}$ \\
\hline $\begin{array}{l}\text { Responsabilidade } \\
\text { Pelos Testes }\end{array}$ & 3.2 - Responsabilidade pelos testes & 4.2 - Responsabilidade pelos testes & $\begin{array}{l}5.2 \text { - Responsabilidade pelos testes (igual ao } \\
4.2 \text { ) }\end{array}$ \\
\hline $\begin{array}{l}\text { Procedimento de } \\
\text { Teste }\end{array}$ & 3.3 - Procedimento de Teste & 4.3 - Procedimento de teste & 5.3 - Procedimento de teste (igual ao 4.3) \\
\hline $\begin{array}{ll}\text { Teste } & \text { de } \\
\text { Desempenho } & \text { do } \\
\text { Leitor } & \end{array}$ & $\begin{array}{l}3.4 \text { - 1) Densitômetro deve medir } \\
\text { densidades óticas entre } 0,01 \text { e } 5 ; 2 \text { ) A } \\
\text { reprodutibilidade das medidas deve } \\
\text { ser } \pm 0.01 \text { entre } 0,01 \text { e } 0,1 \text {; e } \pm 0.02 \\
\text { entre } 0,1 \text { e } 5 \text {. }\end{array}$ & $\begin{array}{l}\text { 4.3.1 - Reprodutibilidade da luz de referência. Para } \\
\text { 10 leituras a variância deve ser < } 0,01 \text {; } \\
\text { 4.3.2 - Estabilidade do leitor - a estabilidade deve ser } \\
\text { verificada no período de } 168 \mathrm{~h} \text {; } \\
\text { 4.3.3 - Efeito das condições climáticas (temperatura) } \\
\text { - para } 3 \text { temperaturas faz-se a comparação no sinal } \\
\text { de fundo e no sinal do dosímetro; } \\
\text { 4.3.4 - Efeito de luz dobre o leitor (sem a presença de } \\
\text { dosímetro). }\end{array}$ & $\begin{array}{l}\text { 5.4.1 - Reprodutibilidade da luz de referência } \\
\text { (4.3.1) } \\
\text { 5.4.2 - Estabilidade do leitor (4.3.2) } \\
\text { 5.4.3 - Efeito das condições climáticas (4.3.3) } \\
\text { 5.4.4 - Efeito de luz sobre o leitor (4.3.4) }\end{array}$ \\
\hline $\begin{array}{l}\text { Teste } \\
\text { desempenho } \\
\text { detector }\end{array}$ & 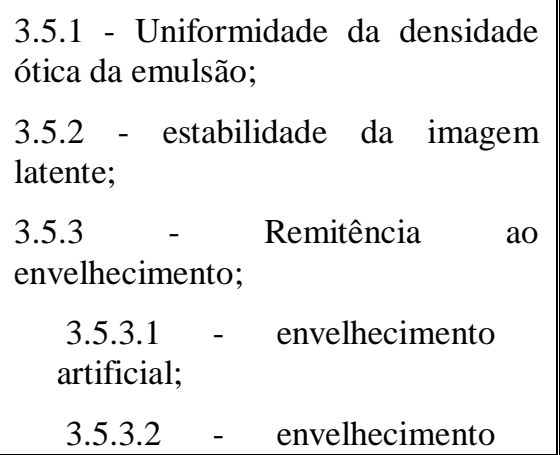 & $\begin{array}{l}\text { 4.4.1 - Homogeneidade do lote }- \text { prepara-se e } \\
\text { irradia-se os detectores do lote, com o mesmo valor } \\
\text { verdadeiro convencional C igual a } 2 \mathrm{mGy} \text {. } \\
\text { Determina-se o valor avaliado A para cada detector. } \\
\text { Encontre } \mathrm{A}_{\max }, \mathrm{A}_{\min } \text { e calcule } \mathrm{A}_{\text {médio }} \\
\text { 4.4.2 - Linearidade - A resposta não deve variar em } \\
\text { mais de } 10 \% \text { no intervalo } 0,2 \mathrm{mGy}-1 \mathrm{~Gy} \text {; } \\
\text { 4.4.3 - Dependência energética - quatro grupos são } \\
\text { irradiados com } 10 \mathrm{mGy} \text {, nos intervalos: } 20-25 \mathrm{keV} \text {, }\end{array}$ & $\begin{array}{l}\text { Para OSL - InLight }{ }^{\circledR} \text { o valor da sensibilidade de cada } \\
\text { detector é estabelecido pelo fabricante. O teste pode ser } \\
\text { realizado exatamente como em TL para um lote de } \\
\text { mesma sensibilidade. } \\
\text { No modelo InLight }{ }^{\circledR} \text { o par detector/porta-monitor esta } \\
\text { sempre associado. O dosímetro só é vendido dentro do } \\
\text { porta dosímetro, e o teste de detector isolado do porta } \\
\text { dosímetro não se aplica. } \\
\text { A análise cabível é a influência do porta monitor. } \\
\text { Os testes - equivalentes aos testes } 4.4 \text { para TL devem ser } \\
\text { feitos sem a presença da porta monitor. } \\
\text { Testes a serem realizados: }\end{array}$ \\
\hline
\end{tabular}




\begin{tabular}{|c|c|c|c|}
\hline & $\begin{array}{l}\text { natural; } \\
\text { 3.5.4 - Opacidade dos envelopes; } \\
\text { 3.5.5 - Resistência do invólucro ao } \\
\text { vapor de } \mathrm{H}_{2} \mathrm{O} \text {. }\end{array}$ & $\begin{array}{l}30-40 \mathrm{keV}, 80-100 \mathrm{keV} \mathrm{e}{ }^{137} \mathrm{Cs} \mathrm{ou}{ }^{50} \mathrm{Co} . \\
4.4 .4 \text { - efeito de exposição à luz do detector } \\
\text { (equivalente ao 3.5.4). }\end{array}$ & $\begin{array}{l}\text { 5.5.1 - Homogeneidade do lote (4.4.1) } \\
\text { 5.5.2 - Linearidade (4.4.2) } \\
\text { 5.5.3 - Dependência energética (4.4.3) } \\
\text { 5.5.4 - Efeito de exposição à luz (4.4.4) } \\
\text { 5.5.5 - Opacidade dos detectores (3.5.4) } \\
\text { 5.5.6 - Resistência do detector ao vapor de } \\
\mathrm{H}_{2} \mathrm{O}(3.5 .5)\end{array}$ \\
\hline $\begin{array}{l}\text { Requisitos de } \\
\text { desempenho do } \\
\text { porta dosímetro }\end{array}$ & $\begin{array}{l}\text { 3.6.1 - Homogeneidade dos filtros; } \\
\text { 3.6.2 - Auto irradiação; } \\
\text { 3.6.3 - Resistência a impactos. }\end{array}$ & $\begin{array}{l}\text { NA } \\
\text { NA } \\
\text { NA }\end{array}$ & $\begin{array}{c}\text { NA } \\
\text { NA } \\
\text { 5.6.1- Resistência a impactos }(3.6 .3)\end{array}$ \\
\hline $\begin{array}{l}\text { Requisitos } \\
\text { desempenho } \\
\text { sistema. }\end{array}$ & $\begin{array}{l}\text { 3.7.1 - limite inferior de detecção; } \\
\text { 3.7.2 - Reprodutibilidade; } \\
\text { 3.7.3 - Linearidade; } \\
\text { 3.7.4 - Dependência Energética; } \\
\text { 3.7.5 - Dependência Angular; } \\
\text { 3.7.6 - Influência da presença de um } \\
\text { fantoma; } \\
\text { 3.7.7 - Influência da Irradiação } \\
\text { Póstero-Anterior. }\end{array}$ & $\begin{array}{l}\text { 4.5.1 - Homogeneidade do Lote; } \\
\text { 4.5.2 - Reprodutibilidade; } \\
\text { 4.5.3 - Linearidade; } \\
\text { 4.5.4 - Limite Inferior de Detecção; } \\
\text { 4.5.5 - Auto Irradiação; } \\
\text { 4.5.6 - Estabilidade dos dosímetros sob diferentes } \\
\text { condições climáticas. (a) Tempo CNPT } 30 \text { dias; (b) } \\
\text { Tempo CNTP } 90 \text { dias; (c) Tempo por sete dias em } \\
\text { T=50 } \pm 2^{\circ} \mathrm{C} ;(\mathrm{d}) \text { Tempo por } 30 \text { dias com T=25 }{ }^{\circ} \mathrm{C} \\
\text { e umidade = 90\%. } \\
\text { 4.5.7 - Sinal residual (devido à reutilização do } \\
\text { dosímetro); } \\
\text { 4.5.8 - Efeito de Luz sobre o Dosímetro; } \\
\text { 4.5.9 - Dependência Energética; } \\
\text { 4.5.10 - Dependência Angular; } \\
\text { 4.5.11 - Influência na Presença de um Fantoma; } \\
\text { 4.5.12 - Influência da Irradiação Póstero-Anterior; }\end{array}$ & $\begin{array}{l}\text { 5.7.1 - Homogeneidade do Lote (4.5.1) } \\
\text { 5.7.2 - Reprodutibilidade (4.5.2) } \\
\text { 5.7.3 - Linearidade (4.5.3) } \\
\text { 5.7.4 - Limite inferior de Detecção (4.5.4) } \\
\text { 5.7.5 - Estabilidade dos dosímetros (4.5.6) } \\
\text { 5.7.6 - Sinal Residual (4.5.7) } \\
\text { 5.7.7 - Efeito de luz sobre dosímetro (4.5.8) } \\
\text { 5.7.8 - Dependência Energética (4.5.9) } \\
\text { 5.7.9 - Dependência Angular (4.5.10) } \\
\text { 5.7.10 - Influência na presença de um } \\
\text { Fantoma (4.5.11) } \\
\text { 5.7.11 - Influência da Irradiação Póstero- } \\
\text { Anterior (4.5.12) } \\
\text { 5.7.12 - Resistência a Impactos (4.5.13) }\end{array}$ \\
\hline
\end{tabular}




\begin{tabular}{|c|c|c|c|}
\hline & & 4.5.13 - Resistência a Impactos. & \\
\hline $\begin{array}{ll}\begin{array}{l}\text { Releitura } \\
\text { dosímetros }\end{array} & \text { dos }\end{array}$ & NA & NA & $\begin{array}{l}\text { Os monitores tipo OSL InLight }{ }^{\circledR} \text { são } \\
\text { analisados com um feixe de luz de baixa } \\
\text { intensidade (não com laser como o modelo } \\
\text { Luxel }^{\circledR} \text { ), dessa forma podem ser re-analisados } \\
\text { por mais de } 10 \text { vezes sem que o sinal seja } \\
\text { reduzido. Caso o laboratório venha a fazer uso } \\
\text { dessa propriedade um teste de desempenho } \\
\text { deve ser feito. }\end{array}$ \\
\hline
\end{tabular}

\section{Processo de Certificacão - Critérios Gerais.}

IRD RT No. 001 - Deve ter um item sobre o detector OSL.

\begin{tabular}{|l||c|c|c|}
\hline \multicolumn{1}{|c|}{ Nome } & \multicolumn{1}{|c|}{ Filme } & TLD & \multicolumn{1}{c|}{ OSL } \\
\hline \multirow{2}{*}{ O detector } & 6.2-O Filme & O Detector Termoluminescente (TL) & $\begin{array}{l}\text { 6.4 - O Detector Opticamente Estimulado } \\
\text { (OSL) - essa seção é muito similar ao 6.3 para } \\
\text { dosimetria TL, toda a parte relativa a } \\
\text { tratamento térmico deve ser substituída por } \\
\text { tratamento óptico. }\end{array}$ \\
\hline
\end{tabular}

\section{Processo de Certificação - LNMRI, auditoria e registro de doses.}

IRD RT No. 003 a 005 - não necessitam de alteração (desempenho de sistemas de monitoração individual externa - testes no LNMRI; processo de auditoria para certificação de um sistema de monitoração individual externa; sistema de registro de doses - procedimentos de cadastro). 


\section{APÊNDICE B - MODELO ESTATÍSTICO PARA AVALIAÇÃO DOS TESTES PARA OSL.}

O modelo estatístico usado para avaliar os resultados dos testes de tipo e de desempenho para dosimetria pessoal externa termoluminescente e de filme fotográfico é o $t$-student. Esse modelo também é usado para nossa proposta de testes para dosimetria pessoal externa usando luminescência opticamente estimulada.

Nesse Apêndice daremos uma breve explicação do modelo estatístico e de termos usados no capítulo 3 para validação de nossos dados.

Em probabilidade e estatística a distribuição $t$, ou distribuição $t$-student é uma distribuição probabilística que surge do problema de se trabalhar com a média de uma população normalmente distribuída quando o tamanho da população é pequeno [52]. É bastante usado em analise estatística entre médias de populações e entre intervalos de confiança dessas médias. [54]

A seguir apresentamos as equações para cálculo do intervalo de confiança para a média, desvio padrão e grandezas compostas de uma amostra usando distribuição t.

\section{a) Intervalo de Confiança para o Desvio Padrão.}

O intervalo de confiança para o desvio padrão S é:

$$
\left(S-l_{S}, S+l_{S}\right) \text { Equação (10.1) }
$$

Sendo $1_{S}$ a meia largura do intervalo de confiança de $S$. Se $S$ for calculado de $n_{s}$ medidas, o limite superior de $1_{\mathrm{S}}$ com um nível de confiança de $95 \%$ será dado por: 


$$
l_{s}\left(n_{s}\right)=t_{n s} \cdot \sqrt{\frac{0.5}{n_{s}-1}} \cdot S \text { Equação (10.2) }
$$

Sendo $\mathrm{t}_{\mathrm{ns}} \mathrm{o}$ fator $t$ de student para $\mathrm{n}_{\mathrm{s}}$ medidas presente na Tabela 10.1 .

\section{b) Intervalo de Confiança para a Média $\bar{x}$.}

Intervalo de confiança para a média $\bar{x}$ é:

$$
\left(\bar{x}-l_{i}, \bar{x}+l_{i}\right) \text { Equação (10.3) }
$$

Sendo $l_{i}$ a meia largura do intervalo de confiança relativa ao i-ésimo conjunto de medidas com um nível de confiança de $95 \%$. Ao calcular $\bar{x}$ de $n_{\mathrm{i}}$ medidas, a meia largura do intervalo de confiança é dada por:

$$
l_{i}\left(n_{i}\right)=\frac{t_{n i} \cdot S_{i}}{\sqrt{n_{i}}} \text { Equação (10.4) }
$$

Onde $S_{\mathrm{i}}$ é o desvio padrão do i-ésimo grupo de medidas e $t_{n i}$ o fato $t$ de student para $n_{i}$ medidas presente na Tabela 10.1.

\section{c) Intervalo de Confiança para uma Grandeza Composta.}

Se os limites de variação são estabelecidos para uma grandeza $\bar{x}$ calculada com $\mathrm{k}$ médias independentes $\bar{x}_{1}, \bar{x}_{2}, \bar{x}_{3}, \ldots, \bar{x}_{k}$ :

$$
\bar{x}=f\left(\bar{x}_{1}, \bar{x}_{2}, \bar{x}_{3}, \ldots, \bar{x}_{k}\right) \text { Equação (10.5) }
$$

E a meia largura do intervalo de confiança da i-ésima média é $\mathrm{I}_{\mathrm{i}}$, a meia largura do intervalo de confiança para $\bar{x}$ é dado por:

$$
l=\sqrt{\sum_{i=1}^{k}\left|\frac{\partial f\left(\bar{x}_{1}, \bar{x}_{2}, \bar{x}_{3}, \ldots, \bar{x}_{k}\right)}{\partial \bar{x}}\right|^{2} \cdot l_{i}^{2}} \text { Equação (10.6) }
$$


Por exemplo, se a relação das médias é dada por:

$$
\bar{x}=\bar{x}_{1}+\bar{x}_{2} \quad \text { Equação (10.7) }
$$

Então a meia largura do intervalo de confiança é escrito de maneira que:

$$
l=\sqrt{l_{1}^{2}+l_{2}^{2}} \text { Equação (10.8) }
$$

Abaixo apresentamos a tabela com fator $\mathrm{t}$ de Student para quantidades $\mathrm{n}_{\mathrm{i}}$ de medidas.

$\begin{array}{cc}\mathbf{n}_{\mathbf{i}} & \mathbf{t}_{\mathbf{n i}} \\ 2 & 12.71 \\ 3 & 4.3 \\ 4 & 3.18 \\ 5 & 2.78 \\ 6 & 2.57 \\ 7 & 2.45 \\ 8 & 2.37 \\ 9 & 2.31 \\ 10 & 2.26 \\ 15 & 2.15 \\ 20 & 2.09 \\ 25 & 2.06 \\ 30 & 2.05 \\ 40 & 2.02 \\ 60 & 2.00 \\ 120 & 1.98 \\ \infty & 1.96\end{array}$

Tabela 10.1 Fator $t$-student $\left(t_{n i}\right)$ por numero de medidas $\left(n_{i}\right)$ 